FERNANDO PEDRO HENRIQUES DE MIRANDA

\title{
ESTUDO E PROJETO DE CIRCUITOS DUAL-MODULUS PRESCALERS EM TECNOLOGIA CMOS
}

\author{
Dissertação apresentada à Escola Politécnica da \\ Universidade de São Paulo para obtenção do \\ Título de Mestre em Engenharia Elétrica
}

São Paulo 
FERNANDO PEDRO HENRIQUES DE MIRANDA

\title{
ESTUDO E PROJETO DE CIRCUITOS DUAL-MODULUS PRESCALERS EM TECNOLOGIA CMOS
}

\author{
Dissertação apresentada à Escola Politécnica da \\ Universidade de São Paulo para obtenção do \\ Título de Mestre em Engenharia Elétrica \\ Área de Concentração: \\ Microeletrônica \\ Orientador: \\ Dr. João Navarro Soares Júnior
}

São Paulo

2006 
Este exemplar foi revisado e alterado em relação à versão original, sob responsabilidade única do autor e com a anuência de seu orientador.

São Paulo, 17 de novembro de 2006.

Assinatura do autor

Assinatura do orientador

FICHA CATALOGRÁFICA

Miranda, Fernando Pedro Henriques de

Estudo e projeto de circuitos dual-modulus prescalers em tecnologia CMOS/ F. P. H. de Miranda. -- São Paulo, 2006.

$102 \mathrm{p}$.

Dissertação (Mestrado) - Escola Politécnica da Universidade de São Paulo. Departamento de Engenharia de Sistemas Eletrônicos.

1.Microeletrônica 2.Circuitos Integrados MOS 3.Circuito Digitais I.Universidade de São Paulo. Escola Politécnica. Departamento de Engenharia de Sistemas Eletrônicos Il.t. 
À minha mãe

À meu pai

À minha namorada À meus amigos 


\section{AGRADECIMENTOS}

Ao Doutor João Navarro Soares Júnior, pela orientação dada no desenvolvimento deste trabalho na Universidade de São Paulo.

Ao Professor Edgar Charry Rodriguez pela ajuda no desenvolvimento do trabalho.

Ao Conselho Nacional de Desenvolvimento Cientifico e Tecnológico (CNPq), pelo suporte financeiro dado através da bolsa de mestrado.

À Fundação de Amparo à Pesquisa do Estado de São Paulo (FAPESP), pelo financiamento da fabricação dos circuitos integrados.

Ao Laboratório de Sistemas Integráveis (LSI) e ao Laboratório de Microeletrônica (LME), pela disposição de sua infra-estrutura física para o desenvolvimento deste trabalho.

Ao Centro de Pesquisas Renato Archer (CENPRA) pela realização da micro-soldagem no circuito integrado.

Aos colegas da Divisão de Metodologias e Projetos VLSI (DMPSV) pelo apoio e amizade.

Aos meus amigos que me acompanharam nos momentos alegres e tristes.

Aos meus pais, Diva Elisabeth Henriques de Miranda e Lúcio Henriques de Miranda, pelo apoio moral e até mesmo financeiro.

À minha namorada Fabiola Carolina da Silva, pela companhia e pelo apoio moral, que me fortaleceu ao longo do mestrado. 


\section{RESUMO}

Este trabalho consiste no estudo e projeto de circuitos Dual-Modulus Prescaler utilizados em sistemas de comunicação $R F$ (radio frequency). Sistemas de comunicação $R F$ trabalham em bandas de freqüência pré-definidas e dentro destas há, normalmente, vários canais para transmissão. Neste caso, decidido o canal onde se vai trabalhar, o receptor e o transmissor geram, através de um circuito chamado Sintetizador de Freqüências, sinais que têm a freqüência igual a freqüência central do canal utilizado. Esses sinais ou tons são empregados na modulação e demodulação das informações transmitidas ou recebidas. $\mathrm{O}$ Sintetizador de Freqüências possui como componentes um oscilador controlável, contadores programáveis, comparadores de fase e um divisor de freqüências chamado Dual-Modulus Prescaler. O funcionamento do Sintetizador é descrito a seguir: o Prescaler recebe um sinal

proveniente da saída do oscilador controlável e gera um sinal que tem a freqüência igual a aquela do sinal de entrada dividida por $N$ ou $N+1$, dependendo do valor lógico de um sinal de controle. O sinal gerado por esse circuito divisor será ainda dividido por contadores e comparado a um sinal de referência externo no comparador de fase. O comparador, por sua vez, gera o sinal de controle do oscilador controlável, aumentando ou reduzindo sua velocidade. Pelo ajuste do número de vezes que o circuito Prescaler divide por $N$ ou $N+1$, se controla a freqüência da saída do Sintetizador.

De todos os circuitos que compõe o Sintetizador de Freqüência, apenas o oscilador controlável e o Prescaler trabalham em altas freqüências (freqüência máxima do sistema) e por conseqüência, a velocidade máxima de trabalho e o consumo de potência do Sintetizador dependerão da performance destes. Neste trabalho se utilizou a técnica Extended True Single Clock Phase para se projetar o Prescaler.

O projeto do circuito Prescaler foi realizado na tecnologia CMOS (Complementary Metal Oxide Silicon) 0,35 $\mu \mathrm{m}$ da AMS [Au03a], que satisfaz as necessidades visadas (banda de trabalho centrada em 2,4 GHz) e tem um custo para prototipagem satisfatório. Vários circuitos foram implementados nesta tecnologia e testados, se obtendo um Prescaler que atinge velocidade de 3,6 GHz, consumo de 1,6 $\mathrm{mW}$ para tensão de alimentação de 3,3 V. 


\begin{abstract}
This work consists of the study and project of circuits Dual-Modulus Prescaler used in communication systems RF (radio frequency). RF Communication Systems work in predefined frequency bands and inside of them, there are several transmission channels. In this case, once decided the channel where we will work, the receiver and the transmitter generate, through a circuit called Frequency Synthesizer, signs that have the same frequency of the central frequency of the used channel. Those signs or tones are used in the modulation and demodulation of the transmitted or received information. The Frequency Synthesizer possesses as components a controllable oscillator, programmable counters, phase comparator and a frequency divider called Dual-Modulus Prescaler. The Synthesizer operation is described: the Prescaler receives a sign from the oscillator and generates an output signal with frequency equal to the frequency of the input signal divided by $\mathrm{N}$ or $\mathrm{N}+1$, depending on the logical value of a control sign. The output of the Prescaler will be divided by other counters and compared with an external reference sign in the phase comparator. That comparator, for its turn, generates a control signal for the oscillator, increasing or reducing its speed. By the adjustment of the number of times that the circuit Prescaler divides for $\mathrm{N}$ or $\mathrm{N}+1$, the frequency of Synthesizer output is controlled.

From all the blocks that compose the Frequency Synthesizer, only the controllable oscillator and the Prescaler work in high frequencies (the maximum frequency of the system), and, in consequence, the maximum speed and the power consumption of the full Synthesizer will depend on the performance of these two blocks. In this work we applied the technique called Extended True Single Clock Phase to design the Prescaler.

The project of the circuit Prescaler used the technology CMOS (Complementary Metal Oxide Silicon) $0.35 \mu \mathrm{m}$ of AMS [Au03a]. This technology was used because it satisfies the sought needs (work band centered in $2.4 \mathrm{GHz}$ ) and has a satisfactory cost. Several circuits were implemented in this technology and tested and it was obtained a Prescaler which reaches $3.6 \mathrm{GHz}, 1.6 \mathrm{~mW}$ power consumption with power supply of $3.3 \mathrm{~V}$.
\end{abstract}




\section{ÍNDICE}

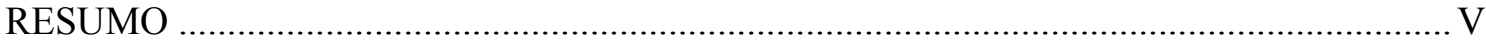

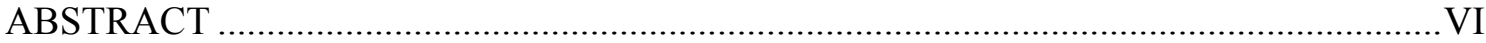

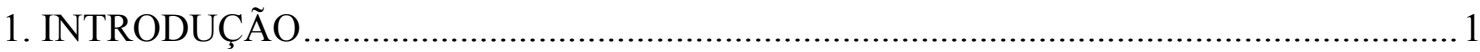

1.1 MoTIVAÇÃ 0 ............................................................................................................................1

1.2 OBJETIVO ....................................................................................................................... 2

1.3 ORGANIZAÇÃO DA DISSERTAÇ̃̃̃O .......................................................................................2

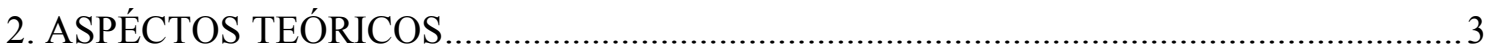

2.1 REGISTER TRANSFER SYSTEM (RTS) ................................................................................

2.2 LóGICA COMBINATÓRIA ................................................................................................4

2.2.1 Porta Estática Complementar CMOS ................................................................. 4

2.2.2 Porta Estática Pseudo NMOS ....................................................................... 5

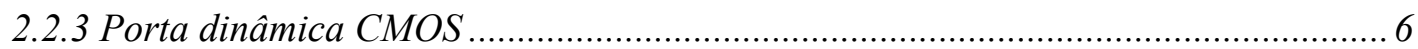

2.2.4 Porta Dinâmica Clocked CMOS $\left(C^{2} M O S\right)$........................................................... 8

2.3 REGISTRADORES ............................................................................................................ 10

2.3.1 Registradores Estáticos ……………………............................................ 10

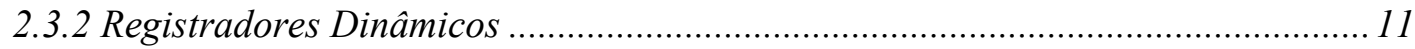

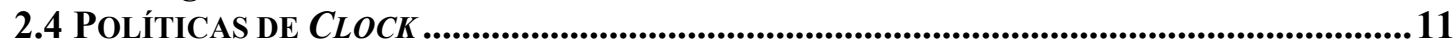

2.5 TÉCNICA NORA …….................................................................................................... 12

2.6 TÉCNICA TSPC ……................................................................................................. 13

2.6.1 Regras de Composição ............................................................................14

2.7 E-TSPC ...................................................................................................................... 16

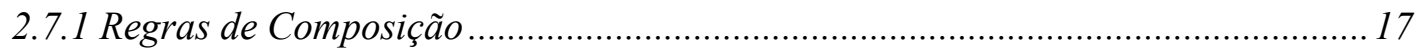

2.7.2 Novas estruturas para a E-TSPC ...................................................................... 19

3. DESCRIÇÃO DOS CIRCUITOS DUAL-MODULUS PRESCALERS ................................20

3.1 DESCRIÇÃO DE UM PLL.................................................................................................20

3.2 SINTETIZADOR DE FREQÜÊNCIAS.....................................................................21

3.3 ARQUITETURAS PARA SINTETIZADORES DE FREQÜÊNCIAS.............................................21

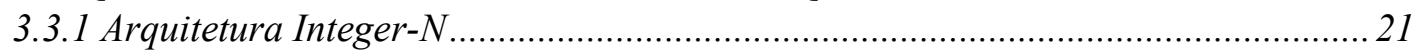

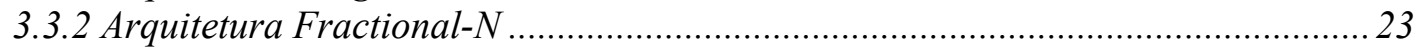

3.4 DUAL-MODULUS PRESCALER 32/33 ...............................................................................24

3.5 IMPLEMENTAÇÕES DO CIRCUITO DUAL-MODULUS PRESCALER 32/33 ...........................25

3.5.1 Dual-Modulus Prescaler 32/33 (versão com 3 D-FFs) .......................................26

3.5.2 Dual-Modulus Prescaler 32/33 (versão com 2 D-FFs) ...................................... 30

3.5.3 Dual-Modulus Prescaler 32/33 (versão com 3 D-FFs e clock dividido por 2)........31

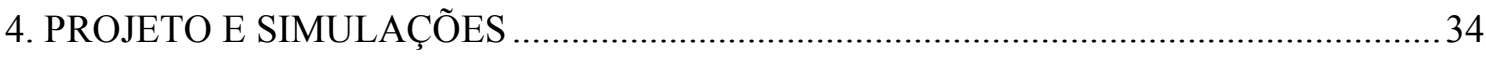

4.1. Projeto dos Circuitos DUAL-Modulus PRESCALER .................................................34

4.2. PROJETO DOS BUFFERS ............................................................................................... 35

4.3. LAYOUT DO C.I. COMPLETO PARA TESTE …………….....................................................40

4.4 SiMULAÇÕES ElÉTRICAS E RESULTADOS............................................................................. 41

5. TESTE DO CIRCITO INTEGRADO E RESULTADOS................................................... 48

5.1 MONTAGEM PARA A REALIZAÇÃo DAS MEDIDAS NO CIRCUITO INTEGRADO ...................48

5.2 RESULTADOS DAS MEDIDAS REALIZADAS NO CIRCUITO INTEGRADO..............................52

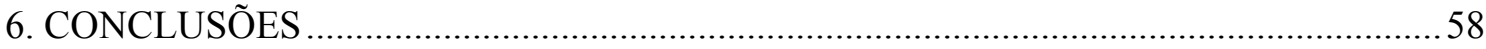




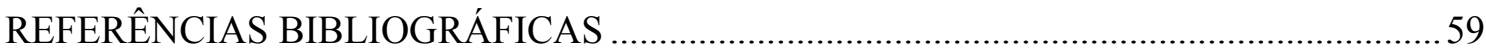

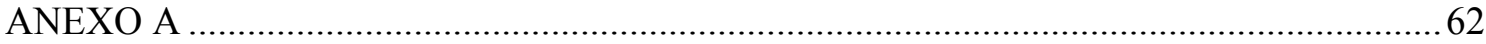

TABELAS COM RESULTADOS DE SIMULAÇÃO E DE MEDIDAS ELÉTRICAS. .............................62

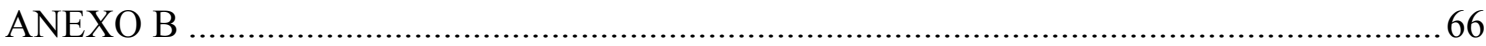

ARQuivo EXTRAído PARA SIMULAÇÃo No HSPICE dOS TRÊS PRESCALERS: ...................66 


\section{ÍNDICE DE FIGURAS}

FigURA 1. REPRESENTAÇ̃̃o GENÉRICA DE UM REGISTER TRANSFER SYSTEM (RTS) . ....................................... 4

Figura 2. Porta lógica estática COMPLEMENTAR CMOS: A), REPRESENTAÇ̃̃o COM TRANSISTORES E B), SUA

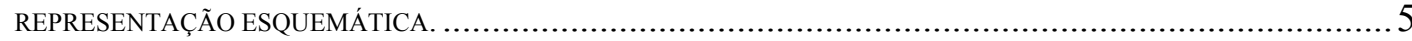

Figura 3. Porta Lógica estática PSEUdo NMOS: A), REPRESENTAÇÃo COM TRANSISTORES E B), SUA

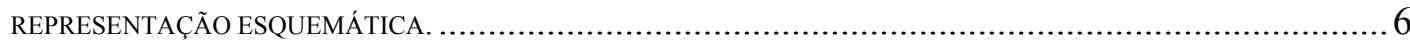

FigURA 4. PORTAS LÓGICAS DINÂMICAS: A), REPRESENTAÇ̃̃o COM TRANSISTORES DA PORTA N-DINÂMICA E B), SUA REPRESENTAÇÃO ESQUEMÁTICA; C), REPRESENTAÇ̃̃O COM TRANSISTORES DA PORTA LÓGICA PDINÂMICA E D), SUA REPRESENTAÇÃO ESQUEMÁTICA.................................................................... 7

Figura 5. LIGAÇÃO DE PORTAS LÓGICAS N-DINÂMICAS; A), LIGAÇÃo SUJEITA A DESCARGA INDESEJÁDA, B),

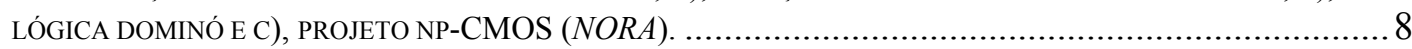

Figura 6. PORTA DinÂMICA C ${ }^{2}$ MOS: A), REPRESENTAÇÃO COM TRANSISTORES E B), SUA REPRESENTAÇÃO

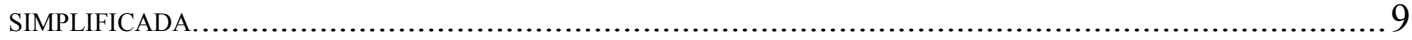

FigURA 7. REGISTRADOR ESTÁTICO: LATCH PSEUDO-ESTÁTICO COM TRANSISTORES DE PASSAGEM................... 10

FigURA 8. REGISTRADOR LATCH DINÂMICO COM TRANSISTOR DE PASSAGEM: A), PORTA DE PASSAGEM COM UM TRANSISTOR N E B), COM TRANSISTORES N E P (DOUBLE TRANSMISSION GATES). .................................. 11

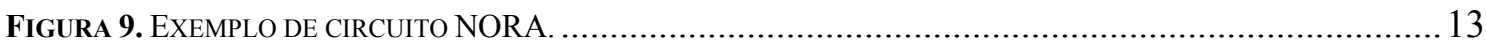

FiguRA 10. CIRCUITOS N-LATCH E P-LATCH: A), REPRESENTAÇ̃̃o COM TRANSISTORES E B), REPRESENTAÇÃO ESQUEMÁTICA DO N-LATCH; C), REPRESENTAÇ̃̃O COM TRANSISTORES E D), REPRESENTAÇ̃̃O ESQUEMÁTICA

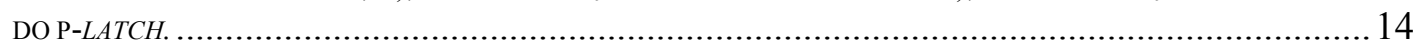

FigURA 11. GRÁFICO DE CONEXÕES PARA O TSPC. AS PORTAS E CIRCUITOS SÃO REPRESENTADOS PELOS QUADRADOS. O FLUXO DE DADOS PERMITIDO É INDICADO PELO SENTIDO DAS SETAS. \# INDICA LIGAÇÕES ONDE ATRASOS DIFERENCIADOS DO CLOCK NOS BLOCOS NÃO CAUSAM PROBLEMAS (SKEW SAFE COMMUNICATION); * INDICA PONTOS DE LATCH DEPOIS DOS QUAIS PORTAS ESTÁTICAS COMPLEMENTAR CMOS PODEM SER INSERIDAS; $\diamond$ INDICA LIGAÇÕES ONDE HÁ PROBLEMAS POTENCIAIS DE VIOLAÇÃO DE

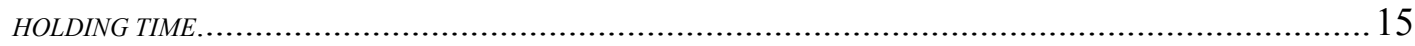

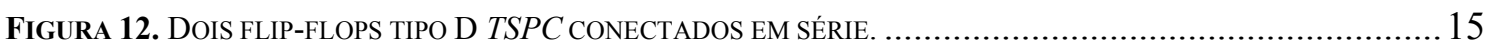

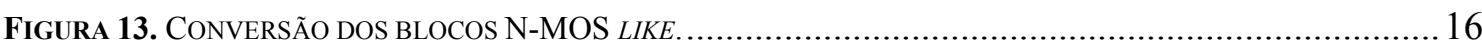

FigURA 14. EXEMPLOS DE N-DATA CHAINS. OS BLOCOS MENCIONADOS NO TEXTO SÃO NOMEADOS E INDICADOS NA

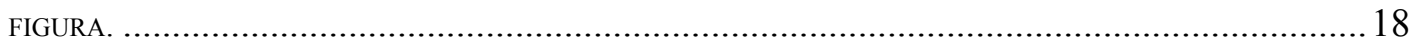

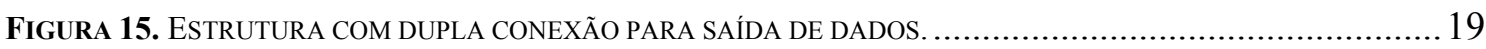

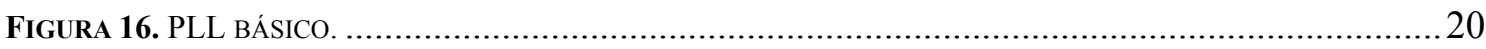

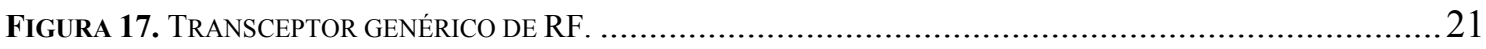

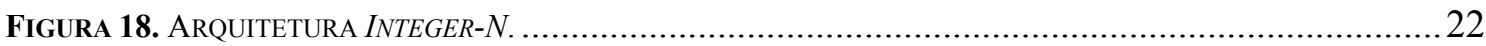

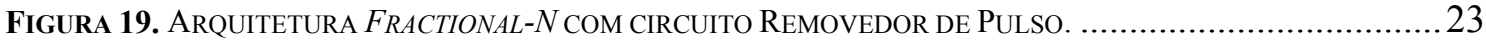

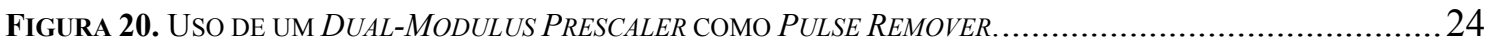

FigURA 21. ESQUEMÁTICO DE UM DUAL-MODULUS PRESCALER 32/33 ................................................25

FigURA 22. DiAGRAMA ESQUEMÁTICO DOS TRANSISTORES DA IMPLEMENTAÇÃO COM TRÊS $D-F F$ S NO CONTADOR SÍNCRONO. AS DIMENSÕES DE W EM $\mu$ M DOS TRANSISTORES ESTÃO INDICADAS NA FIGURA. A DIMENSÃO L É A MÍNIMA DA TECNOLOGIA PARA TODOS OS TRANSISTORES, L= 0,8 MM [NA99] ..............................26

Figura 23. DIAGRAMA ESQUEMÁTICO DOS TRANSISTORES DA IMPLEMENTAÇÃO COM TRÊS $D$-FFS E $C L O C K$ DIVIDIDO POR DOIS NO CONTADOR SÍNCRONO. AS DIMENSÕES DE W EM $\mu$ M DOS TRANSISTORES ESTÃO INDICADAS NA FIGURA. A DIMENSÃO L É A MÍNIMA DA TECNOLOGIA PARA TODOS OS TRANSISTORES, L $=0,8$

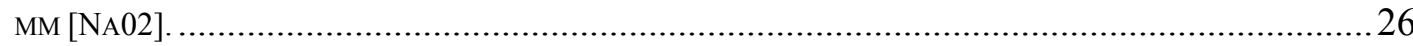

Figura 24. MÁquina DE ESTADOS PARA O CONTADOR SíNCRONO: A), DIAGRAMA DE ESTADOS E B), SinAiS NO

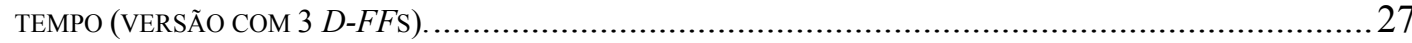

Figura 25. $D$ - $F F S$ SENSÍVEIS A BORDA DE DESCIDA: A), $D-F F$ DA TÉCNICA TSPC E B), $D-F F$ MODIFICADO. AS DIMENSÕES DE $\mathrm{W}$ EM $\mu$ M DOS TRANSISTORES DO CIRCUITO MODIFICADO ESTÃO INDICADAS NA FIGURA. A DIMENSÃO L É A MÍNIMA DA TECNOLOGIA PARA TODOS OS TRANSISTORES, L=0,35 MM, EXCEÇ̃̃O NOS

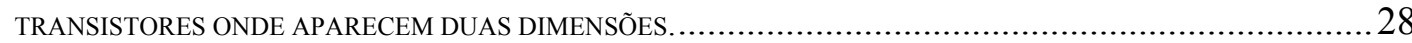

FiguRA 26. DIAGRAMA ESQUEMÁTICO DOS TRANSISTORES DA IMPLEMENTAÇ̃̃O COM TRÊS $D$-FFS NO CONTADOR SÍNCRONO. AS DIMENSÕES DE W EM $\mu$ M DOS TRANSISTORES ESTÃO INDICADAS NA FIGURA. A DIMENSÃO L É 
A MÍNIMA DA TECNOLOGIA PARA TODOS OS TRANSISTORES, L=0,35 MM, EXCEÇÃO NOS TRANSISTORES ONDE APARECEM DUAS DIMENSÕES.

FigURA 27. CONFIGURAÇÃO DOS $D-F F S$ TSPC SENSÍVEIS À BORDA SUBIDA DO CLOCK. AS DIMENSÕES DE W EM $\mu \mathrm{M}$ DOS TRANSISTORES ESTÃO INDICADAS NA FIGURA. A DIMENSÃO L É A MÍNIMA DA TECNOLOGIA PARA TODOS OS TRANSISTORES ( $\mathrm{L}=0,35 \mathrm{MM})$.

FigURA 28. DIAGRAMA ESQUEMÁTICO DE TRANSISTORES DA IMPLEMENTAÇÃO COM DOIS $D$ - $F F$ S DO CONTADOR SÍNCRONO. AS DIMENSÕES DE W DOS TRANSISTORES ESTÃO INDICADAS NA FIGURA. A DIMENSÃO L É A

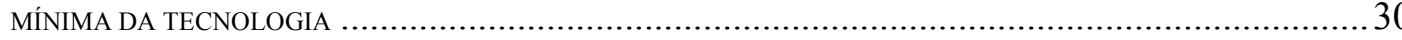

FigURA 29. MÁQUINA DE ESTADOS PARA O CONTADOR SÍNCRONO: A), DIAGRAMA DE ESTADOS E B), SINAIS NO TEMPO (VERSÃO COM 2D-FFS). URA 30. CONFIGURAÇÃO DOS $D$-FFS TSPC SENSÍVEIS À DESCIDA DE CLOCK PARA O CIRCUITO ASSÍNCRONO. AS DIMENSÕES DE W EM $\mu$ M DOS TRANSISTORES ESTÃO INDICADAS NA FIGURA. A DIMENSÃO L É A MÍNIMA

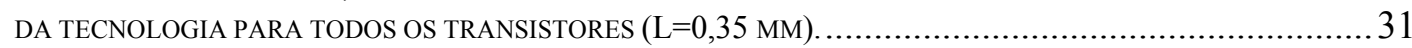

Figura 31. MÁQUINA DE ESTADOS PARA O CONTADOR SÍNCRONO: A), DIAGRAMA DE ESTADOS E B), SINAIS NO TEMPO (VERSÃO COM 3 D-FFS E CLOCK DIVIDIDO POR 2).

FIGURA 32. DIAGRAMA ESQUEMÁTICO DOS TRANSISTORES DA IMPLEMENTAÇÃO COM TRÊS $D$-FFS E $C L O C K$ DIVIDIDO POR DOIS NO CONTADOR SÍNCRONO. AS DIMENSÕES DE W EM $\mu$ M DOS TRANSISTORES ESTÃO INDICADAS NA FIGURA. A DIMENSÃO L É A MÍNIMA DA TECNOLOGIA PARA TODOS OS TRANSISTORES, L= 0,35 MM, EXCEÇÃO NOS TRANSISTORES ONDE APARECEM DUAS DIMENSÕES.

Figura 33. DiAgRAMA ESQUEMÁtico COMPLETO do DUAL-MODULUS PRESCALER 32/33 (VERSÃo COM 3 D-FFs).

Figura 34. Diagrama ESQUEMÁtico COMPLETO do DUAL-MODULUS PRESCALER 32/33 (VERSÃo COM 2 D-FFs).

Figura 35. DiAgRAMA ESQUEMÁtico COMPLETO DO DUAL-MODULUS PRESCALER 32/33 (VERSÃO COM 3 D-FFs).

FigURA 36. LA YOUT DOS CIRCUITOS DUAL-MODULUS PRESCALER 32/33: A) VERSÃO COM 3 D-FFS (DIMENSÕES DE 82 MM X 35 MM); B) VERSÃO COM 2 D-FFS (DIMENSÕES DE 47 MM X 36 MM.); C) VERSÃO COM $3 D$-FFS E

CLOCK DIVIDIDO POR 2 (DIMENSÕES DE 65 MM X 38 MM).

FigURA 37. SiMULAÇÕES ELÉTRICAS DO BUFFER DE ENTRADA COM VALORES DISTINTOS DE CAPACITÂNCIAS DE SAÍDA. . O BUFFER TEM N $=4$ E $\mathrm{X}=1,7$ E O SINAL DE ENTRADA ESTA NA FREQÜÊNCIA DE $3 \mathrm{GHz} . . . . . . . . .38$

FIGURA 38. SIMULAÇÃO ELÉTRICA DO BUFFER DE SAÍDA COM VALORES DISTINTOS DE CAPACITÂNCIAS DE SAÍDA. $\mathrm{O}$ BUFFER TEM N $=4$ E $\mathrm{X}=2,23$ E O SINAL DE ENTRADA ESTA NA FREQÜÊNCIA DE $125 \mathrm{MHZ} \ldots \ldots \ldots \ldots \ldots . . . . . .39$

FigurA 39. LA YOUT DOS BUFFERS: A), PARA O BUFFER DE ENTRADA E B), PARA O BUFFER DE SAÍDA...............39

FigurA 40. LA YOUT DO C.I. COMPLETO E SEUS RESPECTIVOS PADS COM DIMENSÕES DE 1420 MM X 769 MM. ... 40

Figura 41. SinAl de SAÍdA do CIRCUITO DUAL-MODULUS PRESCALER 32/33 SIMULAdO NO ELDO (VERSÃo COM

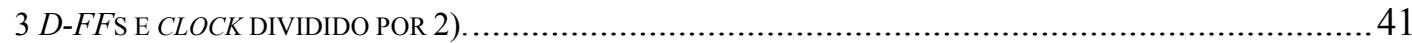

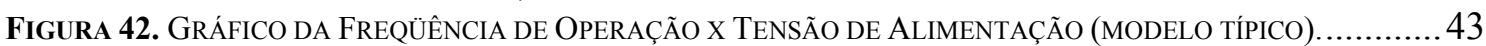

Figura 43. GRÁFICO dA PotÊNCIA X FREQÜÊNCIA DE OPERAÇÃo (PARA DIFERENTES VALORES DE TENSÃO DE

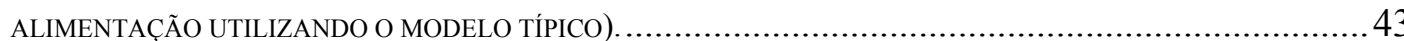

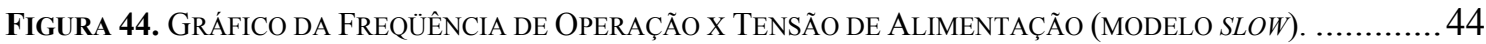

Figura 45. GRÁFICO dA POTÊNCIA X FREQÜÊNCIA DE OPERAÇÃo (PARA DIFERENTES VALORES DE TENSÃO DE

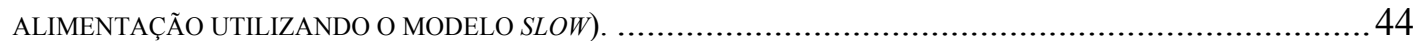

Figura 46. GRÁfico dA FREQÜÊNCIA dE OPERAÇÃo X TENSÃo DE ALIMENTAÇ̃̃o (MODELO FAST). .............45

Figura 47. GRÁfico dA POTÊNCIA X FREQÜÊNCIA DE OPERAÇÃo (PARA DifERENTES VALORES dE TENSÃO DE

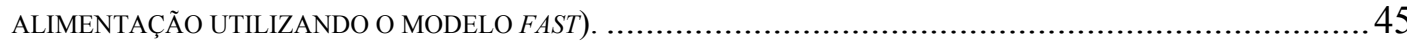

FIGURA 48. GRÁFICO DA POTÊNCIA X FREQÜÊNCIA DE OPERAÇÃO PARA UMA TENSÃO DE ALIMENTAÇÃO FIXA DE $3,3 \mathrm{~V}$.

FIGURA 49. LAYOUT PARA PLACA DE ALUMINA: A) LAYOUT COMPLETO COM OS SINAIS EXTERNOS, B) DETALHE DA REGIÃO ONDE FICA O C.I. E INDICAÇÕES DAS MICRO-SOLDAS.

Figura 50. FotOS DA MICRO-SOLDAGEM DOS C.IS.: A) MICRO-SOLDAGEM REALIZADA NO LME, B) MICROSOLDAGEM REALIZADA NO CENPRA.

Figura 51. PlaCA DE ALUMINA MONTADA COM O C.I. E OS DIVERSOS COMPONENTES PARA A REALIZAÇÃO DE TESTES.

FIGURA 52. FOTO DA BANCADA MONTADA PARA A REALIZAÇÃO DAS MEDIDAS. ....................................51

FigurA 53. FOTO DAS MICRO-PONTAS EM CONTATO COM OS PADS DO C.I..........................................51 
Figura 54. GrÁfico da FreqüÊnCia de OperaÇão X TENSÃo de AlimentaÇÃo do Prescaler 3. RESULTADOS OBTIDOS ATRAVÉS DAS SIMULAÇÕES ELÉTRICAS NOS MODELOS TÍPICO, SLOW, FAST E DAS

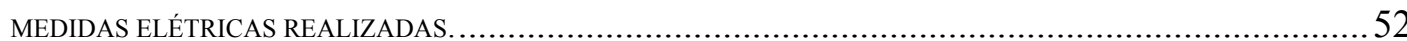

Figura 55. GRÁFICO DA FREQÜÊNCIA DE OPERAÇÃO X TENSÃO DE ALIMENTAÇÃO OBTIDO À PARTIR DAS MEDIDAS ELÉTRICAS REALIZADAS.

Figura 56. GRÁFICO DA POTÊNCIA X FREQÜÊNCIA DE OPERAÇÃO OBTIDA A PARTIR DAS MEDIDAS ELÉTRICAS

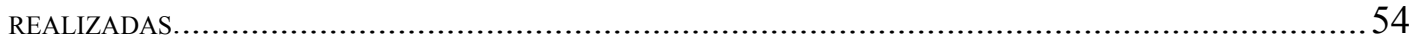

FigURA 57. FormAS DE ONDA DO SINAL DE SAÍDA DO PRESCALER 3: A) CLOCK NA FREQÜÊNCIA DE 3,58 GHZ E B), NA FREQÜÊNCIA DE 100 MHz. 


\section{ÍNDICE DE TABELAS}

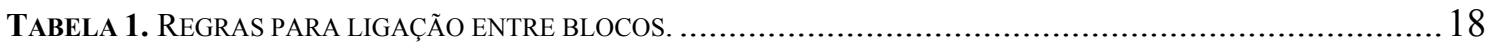

TABELA 2. VALOR DO NÚMERO DE ESTÁGIOS E DO FATOR DE AUMENTO PARA O BUFFER. .............................. 37

TABELA 3. CARACTERÍSTICAS DE VÁRIAS IMPLEMENTAÇ̃̃ES DE CIRCUITOS DUAL-MODULUS PRESCALERS........55

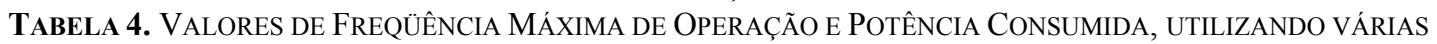

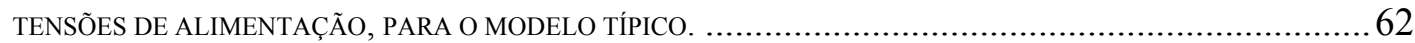

Tabela 5. Valores de FreqüÊnCia Máxima de Operação e Consumo de PotênCias, utilizando váRias

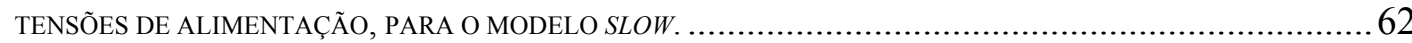

TABela 6. VALORES de FreqüÊnCIA MÁXIMA OPERAÇÃo e PotÊnCIA CONSUMIDA, UTILIZANDO VÁRIAS

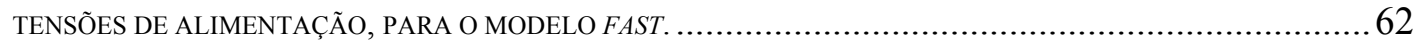

Tabela 7. Valores de FreQüÊnCia de OperaÇão e PotênCia Consumida, Para uma tensão de

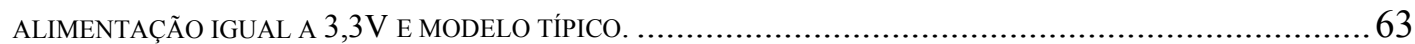

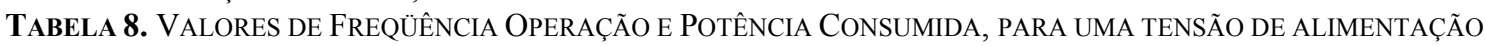

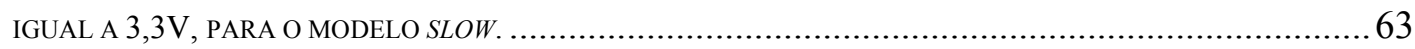

Tabela 9. Valores de FreQüÊnCIA de OperaÇão e PotênCia Consumida, PARA uma tensão de ALIMENTAÇÃO IGUAL A 3,3V, PARA O MODELO FAST.

Tabela 10. Valores de FreqüÊnCIA de Operação e PotênCIa Consumida, MEdidas Realizadas no C.I. PARA UMA TENSÃO DE ALIMENTAÇÃO IGUAL A 2,0V.

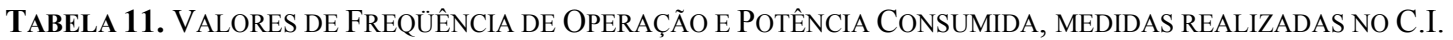
PARA UMA TENSÃO DE ALIMENTAÇÃO IGUAL A 3,3V.

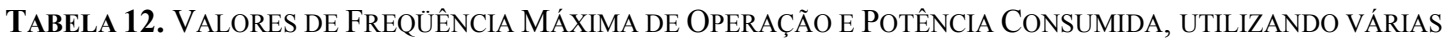
TENSÕES DE ALIMENTAÇÃO, MEDIDAS REALIZADAS NO C.I 


\section{LISTA DE SIMBOLOS, ABREVIATURAS e SIGLAS}

\begin{tabular}{|c|c|}
\hline $\mathrm{V}_{\mathrm{DD}}$ & Tensão de alimentação \\
\hline $\mathrm{V}_{\mathrm{SS}}$ & Tensão de referência (zero Volts) \\
\hline CMOS & Complementary Metal Oxide Silicon \\
\hline NMOS & Transistor Mosfet canal N \\
\hline PMOS & Transistor Mosfet canal P \\
\hline $\mathrm{V}_{\mathrm{T}}$ & Tensão de threshold \\
\hline$\phi$ & Fase de clock \\
\hline OUT & Saída de circuito \\
\hline IN & Entrada do circuito \\
\hline PLL & Phase Locked Loop \\
\hline $\mathrm{VCO}$ & Oscilador controlado por voltagem \\
\hline$\Delta_{\varnothing}$ & Diferença de fase entre os sinais $x(t)$ e $y(t)$ no PLL \\
\hline LPF & Low Pass Filter \\
\hline PD & Phase Detector \\
\hline RF & Rádio Freqüência \\
\hline$f_{\mathrm{OSC}}$ & Freqüência do Oscilador \\
\hline$f_{\text {REF }}$ & Freqüência de Referência \\
\hline $\mathrm{S}$ & Valor de divisão do Swallow Counter \\
\hline $\mathrm{P}$ & Valor de divisão do contador Principal \\
\hline M & Valor de divisão do Pulse Swallow \\
\hline $\mathrm{N}$ & Divisão por 32 do Prescaler \\
\hline $\mathrm{N}+1$ & Divisão por 33 do Prescaler \\
\hline $\mathrm{T}_{\mathrm{P}}$ & Período de remoção do pulso \\
\hline SM & Signal Modulus \\
\hline $\mathrm{D}-\mathrm{FF}$ & Flip-flop tipo D \\
\hline $\mathrm{L}$ & Largura do canal \\
\hline $\mathrm{W}$ & Comprimento do canal \\
\hline CLK & Clock \\
\hline $\operatorname{div} 8$ & Sinal do divisor por 8 \\
\hline $\mathrm{MC}$ & Modulus Control \\
\hline AMS & AustriaMicrosystems \\
\hline$f_{\text {clock }}$ & Freqüência de clock \\
\hline CLK/2 & Clock dividido por 2 \\
\hline CLK8 & Clock do divisor por 8 \\
\hline $\mathrm{C}_{\mathrm{OX}}$ & Capacitância do óxido \\
\hline $\mathrm{W}_{\mathrm{P}}$ & Comprimento de canal do transistor PMOS \\
\hline $\mathrm{W}_{\mathrm{N}}$ & Comprimento de canal do transistor NMOS \\
\hline $\mathrm{L}_{\mathrm{EF}}$ & Comprimento efetivo do canal dos transistores MOS \\
\hline $\mathrm{C}_{\mathrm{L}}$ & Capacitância da entrada \\
\hline $\mathrm{X}$ & Fator de aumento dos inversores no buffer \\
\hline $\mathrm{n}$ & Número de inversores utilizados no buffer \\
\hline $\mathrm{V}$ & Volts \\
\hline $\mathrm{fF}$ & FentoFaraday $\left(10^{-15} \mathrm{~F}\right)$ \\
\hline $\mathrm{pF}$ & PicoFaraday $\left(10^{-12} \mathrm{~F}\right)$ \\
\hline $\mathrm{V}_{\mathrm{DD} 1}$ & Tensão de alimentação do Prescaler 1 \\
\hline $\mathrm{V}_{\mathrm{DD} 2}$ & Tensão de alimentação do Prescaler 2 \\
\hline $\mathrm{V}_{\mathrm{DD} 3}$ & Tensão de alimentação do Prescaler 3 \\
\hline $\mathrm{V}_{\mathrm{DDB}}$ & Tensão de alimentação dos Buffers \\
\hline
\end{tabular}


OUT $_{1} \quad$ Saída do Prescaler 1

$\mathrm{OUT}_{2} \quad$ Saída do Prescaler 2

$\mathrm{OUT}_{3} \quad$ Saída do Prescaler 3

$\Omega \quad$ Resistência em Ohms

$\Omega / \square$ sqr $\quad$ Resistência em Ohms por quadrado

$\mu \mathrm{m} \quad$ micrômetros

Ty Parâmetros de simulação típico

S1 Parâmetros de simulação slow

Fa Parâmetros de simulação fast

$\mathrm{P}_{\mathrm{D}} \quad$ Potência dissipada

$\mathrm{MHz} \quad$ MegaHertz

$\mathrm{GHz} \quad$ GigaHertz

$\mathrm{mW} \quad$ miliWatts

$\mathrm{mW} / \mathrm{GHz}$ miliWatts por GigaHertz 


\section{INTRODUÇÃO}

\subsection{Motivação}

A tecnologia CMOS (Complementary Metal Oxide Silicon) é hoje usada em larga escala na fabricação de circuitos semicondutores $(75 \%$ dos circuitos semicondutores de silício), o que mostra a importância dela na indústria de microeletrônica [Se97][Br98]. A predominância do CMOS deve-se as suas inúmeras vantagens, indo de menor custo a maior nível de integração. Tecnologias como Bipolar e Arseneto de Gálio (GaAs) são utilizadas em algumas aplicações específicas pois podem apresentar melhores resultados em termos de velocidade.

Alguns desafios para aplicação da tecnologia CMOS estão constantemente sendo enfrentados, dentre eles podemos citar o aumento da velocidade e a diminuição do consumo de potência. Em ambos aspectos, melhoras consideráveis são obtidas graças a redução das dimensões mínimas das tecnologias, que chega hoje a nanômetros. Outro fator importante para o aumento da velocidade e diminuição do consumo é a implementação de novas técnicas de projetos, que propõem modificações nas implementações já existentes e nas ligações das portas lógicas, latches e flip-flops [Na98].

Nesse trabalho discutiremos uma dessas novas técnicas, a técnica E-TSPC (Extended True Single Phase Clock), explicando suas vantagens, desvantagens e sua evolução. Feito isso, descreveremos sua aplicação em implementações de um circuito Dual-Modulus Prescaler e faremos a comparação dos resultados obtidos.

Os circuitos construídos neste trabalho foram realizados com a tecnologia $C M O S$ de 0,35 $\mu \mathrm{m}$ da empresa AustriaMicrosystems (AMS), com quatro níveis de metal e dois de silício policristalino. Esta tecnologia visa aplicações com tensão de alimentação de 3,3V. 


\subsection{Objetivo}

Neste trabalho será realizado o estudo e o projeto de circuitos Dual-Modulus Prescalers. Prescalers são circuitos que dividem um sinal de entrada por $N$ ou $(N+1)$, de acordo com o valor de um sinal de controle, e são utilizados em Sintetizadores de Freqüência. Duas características deles são importantes para nós: os Prescalers devem funcionar em freqüências tão altas como a do oscilador do Sintetizador (que pode chegar a GHz no caso de sistemas de radio freqüência); na maior parte dos Prescalers, parte do circuito pode ser vista como uma máquina de estados finitos. Em vista disso, este circuito é bastante adequado para a avaliação de técnicas de projeto de circuitos digitais rápidos.

\subsection{Organização da dissertação}

Esta dissertação está divida em cinco capítulos. No primeiro capítulo foram dadas as motivações e os objetivos deste trabalho. O segundo capítulo apresenta considerações sobre circuitos CMOS digital e a descrição da técnica E-TSPC utilizada nos Prescalers. O terceiro capítulo descreve as três implementações dos Prescalers, tanto o seu funcionamento como o seu projeto. O quarto capítulo apresenta o projeto final dos Prescalers e de buffers utilizados para a entrada e saída de sinais. Neste capítulo também são apresentados os resultados de simulações e feitas algumas análises sobre estes. O quinto capítulo mostra como foi realizado o teste do C.I. (circuito integrado) e seus resultados. O sexto capítulo apresenta as conclusões do trabalho e sugestões para sua continuidade. 


\section{ASPÉCTOS TEÓRICOS}

Este capítulo apresenta a técnica Extended True Single Phase Clock, E-TSPC, usada para a implementação de circuitos digitais Register Transfer Systems, RTS. Essa técnica é uma evolução da True Single Phase Clock, TSPC, e acrescenta novas regras de projeto e mudanças na topologia de alguns blocos lógicos e registradores de forma a melhorar a velocidade dos circuitos

A seguir discutiremos sobre os Register Transfer Systems, mostrando suas implementações com portas lógicas e registradores. Também discutiremos alguns problemas das política de clock dos circuitos RTS, mostrando técnicas que ajudam a eliminá-las. Verificaremos algumas deficiências da antiga técnica TSPC e discutiremos a E-TSPC, apresentando seus blocos e as regras de conexão destes blocos. Por fim, novas estruturas possíveis para o $E-T S P C$ serão mostradas.

\subsection{Register Transfer System (RTS)}

Um conjunto de portas lógicas e registradores que executam a função de armazenamento, processamento e transferência de dados digitais complexos são denominados Register Transfer System (RTS). Com eles podemos implementar circuitos como máquinas de estados finitos e pipelined systems. Isto mostra sua importância, pois os sistemas VLSI (VeryLarge-Scale of Integration) são, a grosso modo, combinações destes [We93].

Os sinais de clock no RTS servem para sincronizar as transferências de dados entre os registradores. Dependendo da política de clock escolhida, utilizam-se diferentes blocos, tanto registradores como portas lógicas, e diferente quantidade de sinais de clock.

A figura 1 mostra o diagrama esquemático de um RTS que possui em sua composição vários circuitos combinatórios (lógica combinatória) e registradores. Estes blocos podem ser divididos duas categorias [Ra96]:

- Estáticos - a saída do circuito está sempre conectada a $\mathrm{V}_{\mathrm{DD}}$ (por um conjunto de transistores PMOS), a $\mathrm{V}_{\mathrm{SS}}$ (por um conjunto de transistores NMOS) ou a ambas (neste caso, um conjuntos domina e impõe o valor da saída); 
- Dinâmicos - a saída do circuito pode ser desconectada de $\mathrm{V}_{\mathrm{DD}}$ e $\mathrm{V}_{\mathrm{SS}}$ durante uma fase de operação. Neste caso o sinal lógico permanecerá armazenado em capacitâncias parasitárias na saída.

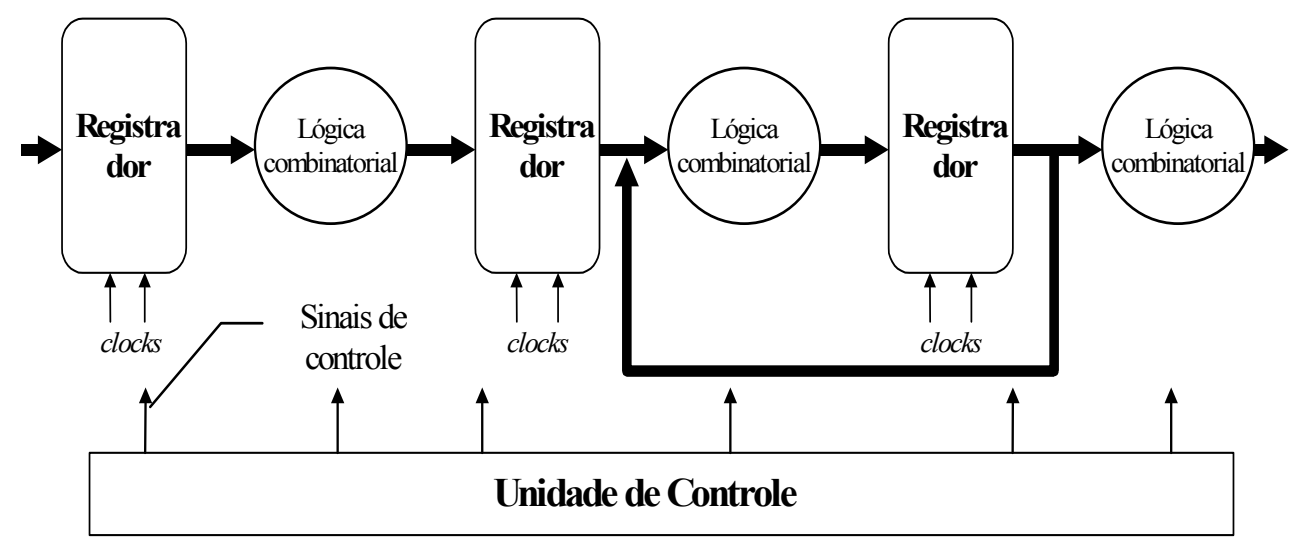

Figura 1. Representação genérica de um Register Transfer System (RTS).

\subsection{Lógica Combinatória}

No bloco de lógica combinatória a saída é uma função lógica dos sinais aplicados na entrada. A seguir descrevemos vários tipos de portas lógicas que servem para a sua implementação.

\subsubsection{Porta Estática Complementar CMOS}

A porta estática complementar CMOS apresenta em sua composição um conjunto de transistores PMOS chamado de pull-up network (PUN), que conecta $\mathrm{V}_{\mathrm{DD}}$ à saída, e um conjunto de transistores NMOS chamado de pull-down network (PDN), que conecta $\mathrm{V}_{\mathrm{SS}}$ à saída [Ra96]. Como mostrado na figura 2, o PUN apresenta o mesmo número de transistores do $P D N$, porém, sua lógica é invertida. Eles devem trabalhar de tal forma que, enquanto um conjunto conduz, o outro esta cortado e vice-versa.

Os circuitos que utilizam esse tipo de portas lógicas apresentam baixo consumo estático de potência, altos valores de margens de ruído, tempos de subida e descida que podem ser aproximados, baixa sensibilidade a variações de processos e são fáceis de serem 
projetados. Por outro lado ocupam maior área no circuito e têm limitações de velocidade para funções lógicas complexas.

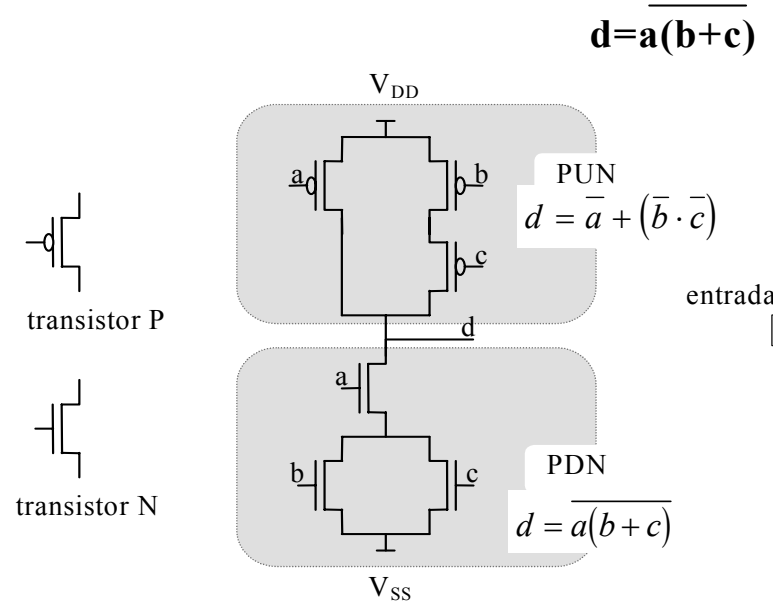

a)

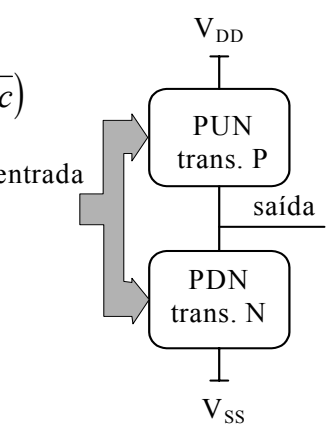

b)

Figura 2. Porta lógica estática complementar CMOS: a), representação com transistores e b), sua representação esquemática.

\subsubsection{Porta Estática Pseudo NMOS}

Pseudo NMOS são portas lógicas que utilizam somente a estrutura $P D N$, ou seja, a função lógica é realizada pelo conjunto de transistores NMOS [Ra96]. No lugar da estrutura PUN é utilizado um transistor PMOS em condução constante. Para que isto ocorra, o terminal de porta (gate) do transistor PMOS dever estar ligado a um potencial de valor $\mathrm{V}_{\mathrm{L}}$ inferior a $\left(\mathrm{V}_{\mathrm{DD}}-\left|\mathrm{V}_{\mathrm{Tp}}\right|\right)$, onde $\mathrm{V}_{\mathrm{Tp}}$ é a tensão de threshold do transistor PMOS, como mostra a figura 3. $\mathrm{O}$ transistor PMOS garante a tensão $\mathrm{V}_{\mathrm{DD}}$ na saída da porta, com exceção dos momentos em que a estrutura $P D N$ conduz, o que força então a saída para $\mathrm{V}_{\mathrm{SS}}$.

Existem duas características que dão a este tipo de porta lógica maior velocidade em comparação a complementar $C M O S$. Uma é a diminuição da carga capacitiva na entrada da porta antecedente. A outra é a ausência da estrutura PUN que tem maior tempo de chaveamento devido a ser composta por transistores PMOS. Em contrapartida ao aumento da velocidade, há aqui o consumo de potência estática quando a saída estiver em nível lógico BAIXO (há um curto entre $\mathrm{V}_{\mathrm{DD}}$ e $\mathrm{V}_{\mathrm{SS}}$ ). 


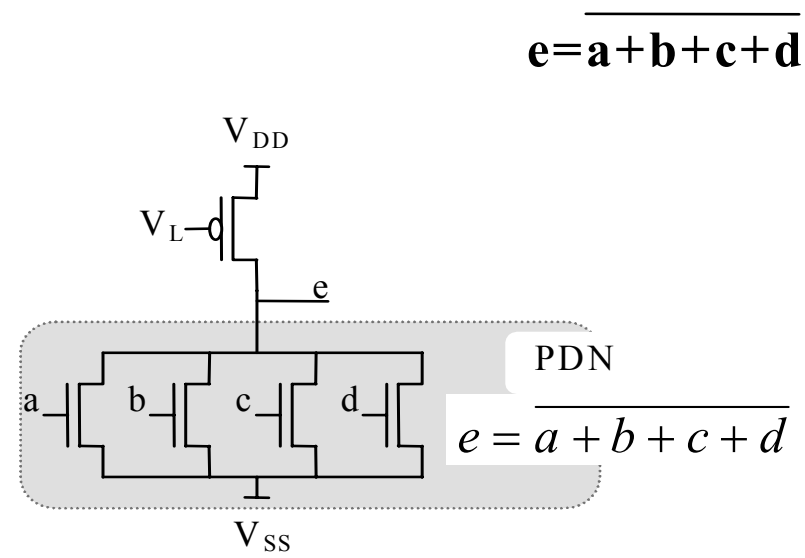

a)

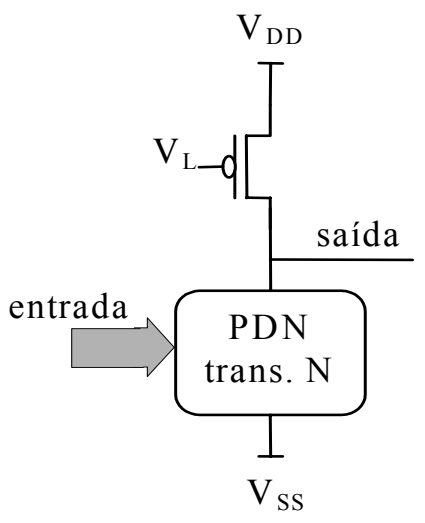

b)

Figura 3. Porta lógica estática Pseudo NMOS: a), representação com transistores e b), sua representação esquemática.

\subsubsection{Porta dinâmica CMOS}

Esse tipo de porta lógica é constituído por apenas uma das estruturas $P D N$ ou $P U N$ (figura 4). Essa porta lógica opera em duas fases [Ra96]:

- $\quad$ Fase de pré-carga - A saída da porta é conectada a $\mathrm{V}_{\mathrm{DD}}$, quando se utiliza a estrutura $P D N$, ou a $\mathrm{V}_{\mathrm{SS}}$, quando se utiliza a estrutura $P U N$, em uma das fases do sinal de clock, carregando o nó de saída com $\mathrm{V}_{\mathrm{DD}}$ ou $\mathrm{V}_{\mathrm{SS}}$;

- $\quad$ Fase de avaliação - $\mathrm{A}$ saída será descarregada para $\mathrm{V}_{\mathrm{SS}}$ ou $\mathrm{V}_{\mathrm{DD}}$ dependendo da estrutura utilizada ( $P D N$ ou $P U N)$, dos sinais de entrada e da função lógica implementada.

Um exemplo de pré-carga e avaliação pode ser analisado com auxílio da figura 4 (c), uma porta lógica p-dinâmica. Na fase de pré-carga, o clock está em nível lógico ALTO, levando a saída a $\mathrm{V}_{\mathrm{SS}}$. Já na fase de avaliação, o clock está em nível lógico BAIXO, e a saída pode ser descarregada ou não, dependendo da lógica $P U N$. Na porta n-dinâmica, utiliza-se uma análise inversa a da p-dinâmica, sendo sua fase de pré-carga realizada no nível lógico BAIXO do clock, levando a saída a $\mathrm{V}_{\mathrm{DD}}$, e sua fase de avaliação realizada no nível lógico ALTO do clock, descarregando ou não a saída, dependendo da lógica $P D N$. 


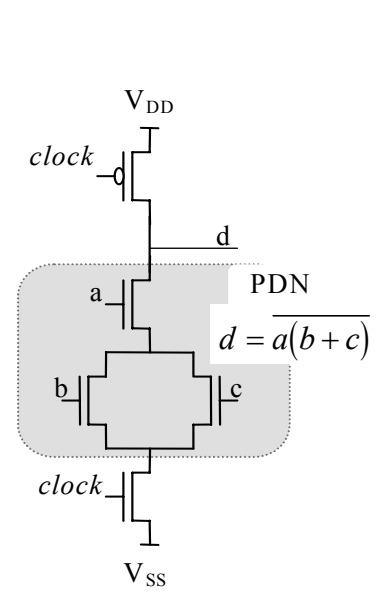

a)

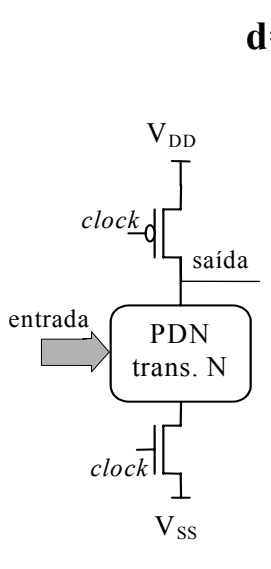

b) $\mathbf{d}=\overline{\mathbf{a}(\mathbf{b}+\mathbf{c})}$

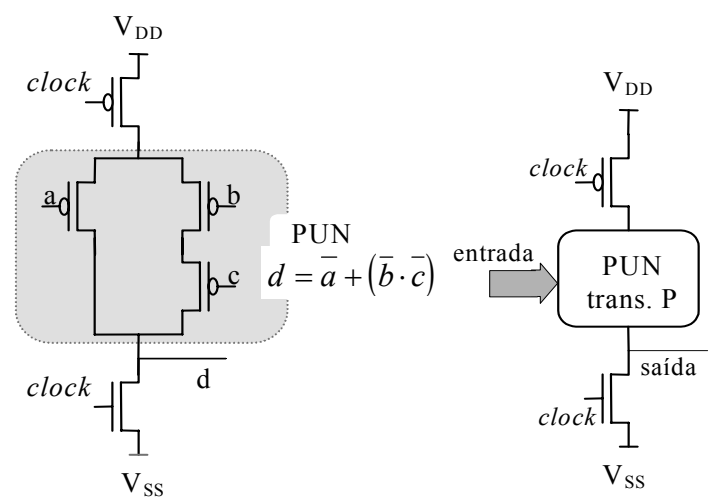

d)

Figura 4. Portas lógicas dinâmicas: a), representação com transistores da porta n-dinâmica e b), sua representação esquemática; c), representação com transistores da porta lógica p-dinâmica e d), sua representação esquemática.

As portas dinâmicas apresentam inúmeras vantagens tais como a independência das dimensões dos transistores para o correto funcionamento (nas portas estáticas complementar), consumo de potência somente na pré-carga, menor número de transistores, carga capacitiva de entrada pequena. Em parte estas vantagens acarretam maior velocidade para avaliação.

Por outro lado, na fase de avaliação podem existir alguns problemas que comprometem o funcionamento correto do circuito. Um desses problemas é a redistribuição da carga armazenada na saída para as estruturas PDN e PUN (Charge Sharing). Outro problema é a perda da carga, que deve ficar armazenada na saída, por correntes de fuga o que restringe a mínima freqüência que pode ser utilizada no sinal de clock.

Tais problemas com cargas afetam o funcionamento das portas dinâmica, pois seus nós de saída podem estar em alta impedância na fase de avaliação. Isto ocorre na porta ndinâmica quando a saída está no nível lógico ALTO ou, na porta p-dinâmica quando a saída está no nível lógico BAIXO.

As portas dinâmicas também requerem alguns cuidados em sua utilização para evitar problemas com a pré-carga. Para explicar isso tomemos como exemplo duas portas ndinâmicas que estão ligadas diretamente, figura 5(a). Neste caso o nó $\mathrm{S}_{\mathrm{i}}$, levado para $\mathrm{V}_{\mathrm{DD}}$ durante a pré-carga, poderá, na fase de avaliação, descarregar indevidamente a segunda porta dinâmica. Acontecerá o erro quando a entrada $\boldsymbol{a}$ da primeira porta n-dinâmica estiver no nível lógico ALTO, o que causará uma transição de ALTO para BAIXO em $\mathrm{S}_{\mathrm{i}}$. Esta transição ocorre com um atraso, que pode ser suficiente para que haja a descarga da segunda porta (não 
podem haver transições de ALTO para BAIXO na entrada de portas n-dinâmicas em avaliação ou transições de BAIXO para ALTO na entrada de portas p-dinâmicas em avaliação).

Duas soluções são sugeridas para resolver este problema. Uma delas é a Lógica dominó [We93] [Ra96] [Yu87], mostrada na figura 5 (b), que utiliza inversores em número ímpar, entre duas portas n-dinâmicas e evita que ocorram transições do nível lógico ALTO para o nível lógico BAIXO na entrada da segunda porta. A outra solução proposta é a implementação da lógica np-CMOS da técnica NORA [Ra96] que discutiremos mais para frente. A lógica np-CMOS consiste na utilização alternada de portas n-dinâmicas e pdinâmicas, mostrada na figura 5 (c). A porta n-dinâmica não tem, na fase de avaliação, transições do nível lógico BAIXO para o ALTO na saída o que evita a descarga incorreta da porta p-dinâmica seguinte. Devemos tomar cuidados neste tipo de configuração com o sinal de clock e seu inverso, ou seja, as duas fases de clock, para que, devido a atrasos, não ocorra a pré-carga de um bloco enquanto o outro ainda faz a avaliação.

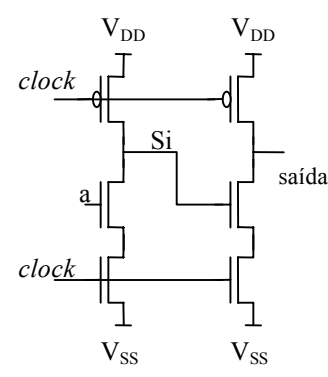

a)

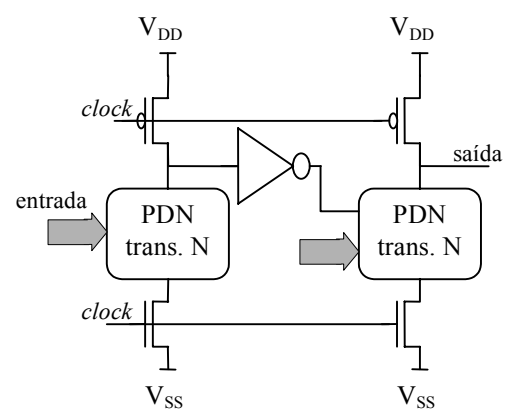

b)

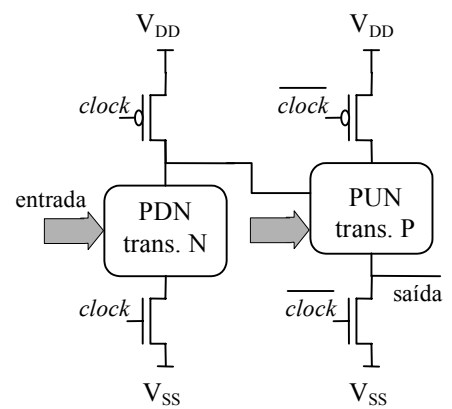

c)

Figura 5. Ligação de portas lógicas n-dinâmicas; a), ligação sujeita a descarga indesejáda, b), lógica dominó e c), projeto np-CMOS (NORA).

\subsubsection{Porta Dinâmica Clocked CMOS ( $\left.\mathrm{C}^{2} \mathrm{MOS}\right)$}

A porta $\mathrm{C}^{2} \mathrm{MOS}$ [Ra96] possui em sua composição tanto a estrutura PUN como também a $P D N$. O que difere esta porta da complementar $C M O S$ é a ligação de um transistor PMOS, entre a estrutura PUN e a saída, e de outro transistor NMOS, entre a estrutura $P D N$ e a saída. Como mostra a figura 6, o sinal de clock é ligado no terminal de porta (gate) do transistor NMOS e seu sinal inverso no terminal de porta do transistor PMOS.

Existem nessa porta duas fases de operação: 
- Fase de avaliação - o circuito funciona como uma porta complementar CMOS pois, nesta fase, o clock está no nível lógico ALTO e, portanto, os dois transistores adicionados estão conduzindo;

- Fase de holding - o circuito funciona como um registrador pois, nesta fase, o clock está no nível lógico BAIXO e, portanto, os dois transistores adicionados estarão cortados, retendo a informação na saída.

Observamos que a porta dinâmica $\mathrm{C}^{2} \mathrm{MOS}$ funciona tanto como uma porta complementar CMOS como um latch registrador. Podemos considerar esse fato como uma vantagem sobre outras portas lógicas. Além dessa vantagem, relacionamos também outras como, baixo consumo de potência, baixa sensibilidade à variações de processo, facilidade de projeto. Em contrapartida há desvantagens semelhantes às das portas dinâmicas relativas a perda de sinal além de menor de velocidade operação.

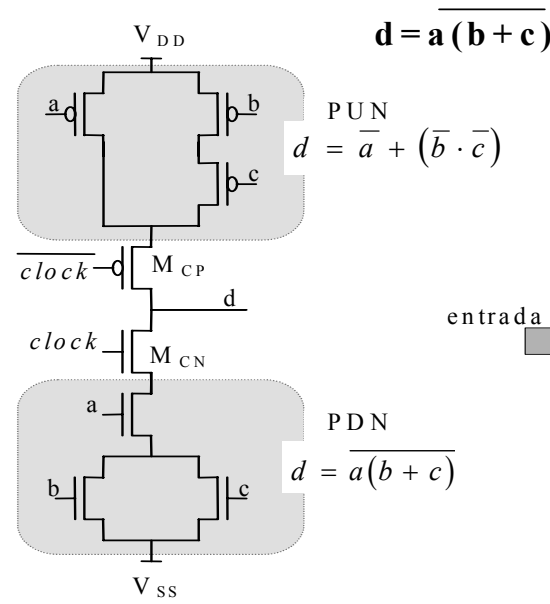

a)

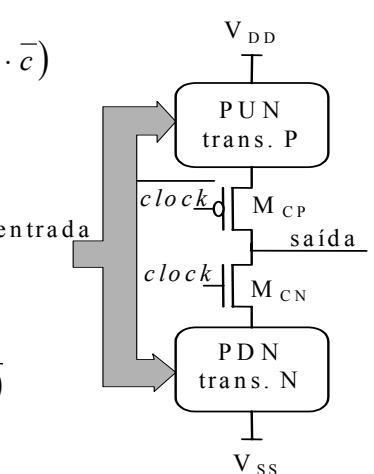

b )

Figura 6. Porta dinâmica $C^{2} \mathrm{MOS}$ : a), representação com transistores e b), sua representação simplificada. 


\subsection{Registradores}

Os registradores são blocos que armazenam os dados em circuitos digitais [Ra96]. Como vimos dividem-se em estáticos e dinâmicos. Os registradores estáticos garantem o armazenamento da informação através de realimentação (feedback) entre a entrada e a saída. Nos registradores dinâmicos são as cargas de capacitores, capacitores parasitas de saída, que retém por um breve intervalo de tempo as informações. Os registradores dinâmicos têm a vantagem sobre os estáticos de apresentar um número menor de transistores e, consequentemente, uma menor complexidade de projeto.

\subsubsection{Registradores Estáticos}

Esse tipo de registrador pode ser implementado com inversores e uma realimentação da saída para a entrada, conforme exemplificado na figura 7. Observando a operação do circuito da figura 7, percebemos que quando o clock está no nível lógico ALTO, o sinal da entrada será transferido para a saída. Quando o clock está no nível lógico BAIXO, a realimentação entre a entrada e a saída ocorrerá, mantendo a informação armazenada no registrador. Essa informação só poderá ser mudada, quando ocorrer a alteração no clock novamente. Podemos chamar esse registrador estático de latch pseudo-estático que utiliza transistores de passagem.

Quando este registrador é utilizado, dois deles colocados em seqüência devem trabalhar com sinais de clock de fases contrárias. Para o correto funcionamento deve-se garantir, no entanto, que não haja nenhuma sobreposição destas fases de clock pois, neste caso, a informação poderia ser passada pelos latches incorretamente.

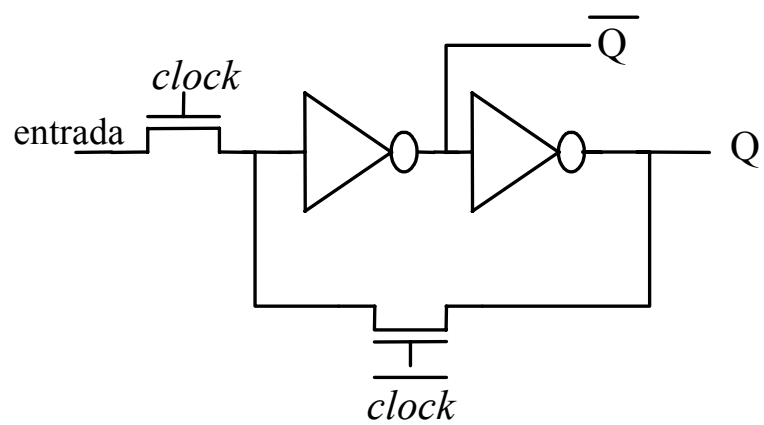

Figura 7. Registrador estático: latch pseudo-estático com transistores de passagem. 


\subsubsection{Registradores Dinâmicos}

Os registradores dinâmicos mantém a informação armazenada, por um breve intervalo de tempo, em uma capacitância vinculada à entrada do próximo bloco. Um exemplo destes é mostrado na figura 8 (a) onde está implementado um latch com transistor de passagem para controle da transferência da informação.

Para melhorar as características de condução, do nível lógico BAIXO e principalmente do nível lógico ALTO, pode-se também utilizar na porta de passagem dois transistores em paralelo, um PMOS e outro NMOS, figura 8 (b). A chave formada por estes dois transistores é chamada de Double Transmission Gates.

$\mathrm{O}$ circuito $\mathrm{C}^{2} \mathrm{MOS}$, além de realizar a função de porta lógica, também é considerado um registrador dinâmico como já mencionado.

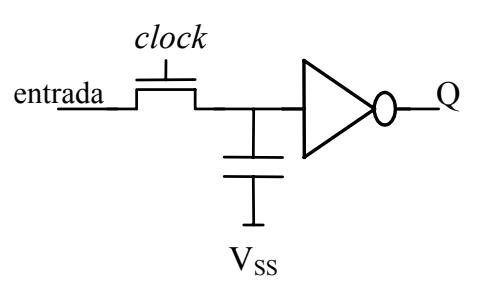

a)

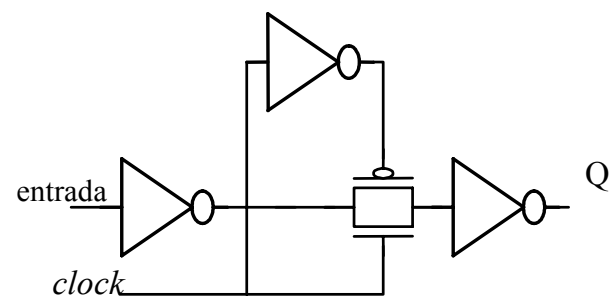

b)

Figura 8. Registrador latch dinâmico com transistor de passagem: a), porta de passagem com um transistor $\mathrm{N}$ e b), com transistores N e P (Double Transmission Gates).

\subsection{Políticas de Clock}

Nas implementações de RTS são possíveis diversas políticas clocks, utilizando uma ou mais fases [We93] [Ra96]. Políticas com múltiplas fases permitem um melhor aproveitamento do tempo, porém, apresentam problemas com a possível sobreposição das fases. Mostraremos a seguir algumas políticas de clock e técnicas utilizadas para evitar problemas. 


\subsection{Técnica NORA}

A técnica NORA, No-Race CMOS Technique [Go84], permite a utilização de portas lógicas estáticas complementar CMOS, portas dinâmicas e portas $\mathrm{C}^{2} \mathrm{MOS}$. Como registrador são empregados apenas blocos $\mathrm{C}^{2} \mathrm{MOS}$. São usadas duas fases complementares de clock no NORA, $\phi_{1}$ e $\phi_{2}$. Devido a isto são possíveis 4 diferentes configurações de portas lógicas dinâmicas: duas configurações de portas n-dinâmicas, uma controlada pela fase $\phi_{1}$ e outra pela $\phi_{2}$; duas configurações de portas p-dinâmicas, analogamente. Também são disponíveis duas configurações diferentes para os latches $\mathrm{C}^{2} \mathrm{MOS}$. Regras de composição para as portas e registradores completam a técnica. Estas foram criadas para evitar os problemas de race: os delay race errors e os clock skew race errors. O delay dos sinais que chegam aos blocos dinâmicos pode causar a perda do valor pré-carregado na sua saída e, em conseqüência, a incorreta avaliação do bloco. Este é o chamado delay race error. O clock skew entre as duas fases do clock de um circuito NORA pode, por sua vez, causar avaliação incorreta tanto em circuitos dinâmicos como em $\mathrm{C}^{2} \mathrm{MOS}$ latches. Este é o chamado clock skew race error.

Uma vez obedecidas às regras de composição, o circuito projetado tolerará sobreposição das fases, podendo ser, dessa forma, empregado direto $\phi_{1}=$ clock e $\phi_{2}=\overline{\text { clock }}$. Por esta razão, muitas vezes, o NORA é dito ser uma estratégia de uma única fase de clock ([We93], [Ra96]).

As regras do NORA são aplicadas sobre os chamados data chains, $\phi_{1}$-data chains e $\phi_{2}$-data chains. Um $\phi_{1}$-data chain é um caminho de propagação de dados, signal propagation path, onde, durante a fase $\phi_{1}=" 1 "$, todas as portas e registradores estão em avaliação e, durante a fase $\phi_{1}=" 0 "$, todas as portas e registradores estão em pré-carga ou em holding. Um $\phi_{2}$-data chain faz avaliação durante a fase $\phi_{2}=" 1 "$ e pré-carga/holding durante a fase $\phi_{2}=" 0 "$. A Figura 9 apresenta um exemplo de circuito NORA com data chains assinalados, um $\phi_{1^{-}}$ data chain e um $\phi_{2}$-data chain. 


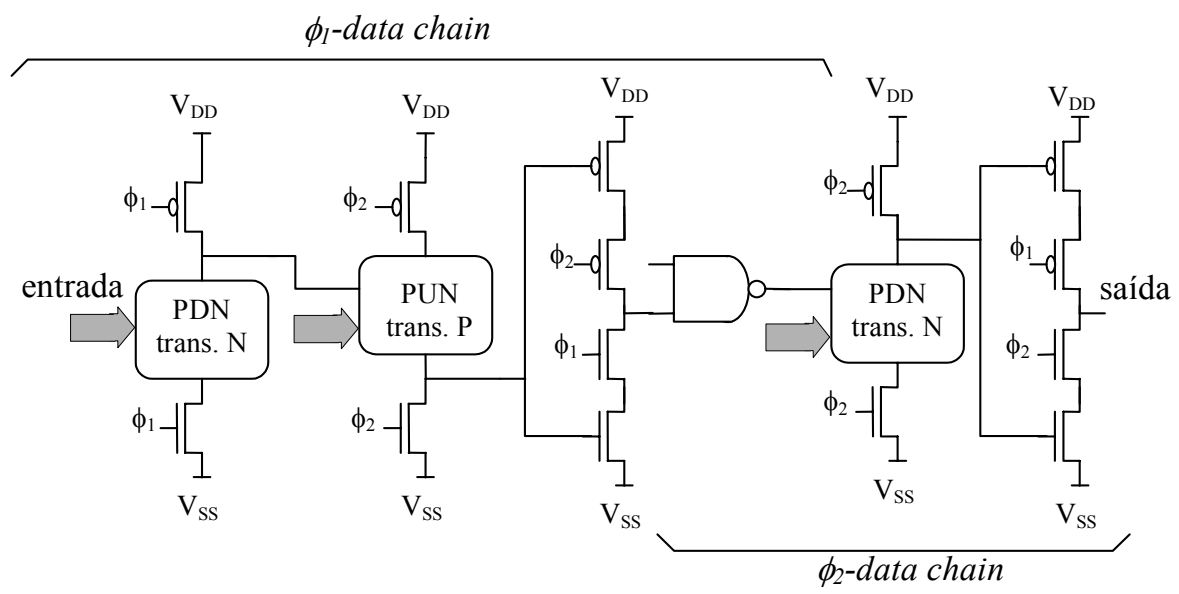

Figura 9. Exemplo de circuito NORA.

A técnica NORA permite melhora na velocidade, menores áreas, redução no consumo de potência além de evitar disputa de sinais. Em contrapartida, a utilização de elementos dinâmicos, portas lógicas e registradores, traz problemas de charge sharing, charge leakage, acoplamento capacitivo e maior sensibilidade ao ruído. Isto dificulta sua aplicação, devendo a técnica ser aplicada somente quando máxima performance é necessária.

\subsection{Técnica TSPC}

A técnica NORA pode ser simplificada para que seja utilizado apenas um clock na composição dos circuitos. A técnica True Single Phase Clock (TSPC) [Sv87], que não utiliza latches $\mathrm{C}^{2} \mathrm{MOS}$, que necessitam de duas fase de clock, mas sim blocos chamados de $\mathrm{n}$-latch $\mathrm{e}$ p-latch [Na98], figura 10, é uma das possíveis simplificações. Para entender o funcionamento destes blocos, considere o n-latch, figura 10(a); enquanto o clock é ALTO, o latch está no modo avaliação e quando o clock é BAIXO, o latch está desabilitado, ou no modo holding. Este holding é verdadeiro apenas se não houver alterações do nível lógico ALTO para o nível lógico BAIXO nos sinais de entrada do bloco. Isto é garantido com $n$-latches ou com portas lógicas dinâmicas colocadas antes o bloco. A técnica TSPC, por utilizar somente um único clock, elimina os problemas de geração e sobreposição de fases existentes nas políticas de várias fases de relógio (race). 


$$
\boldsymbol{d}=\overline{\boldsymbol{a b}}
$$

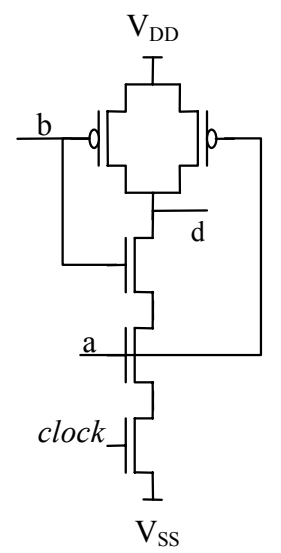

a)

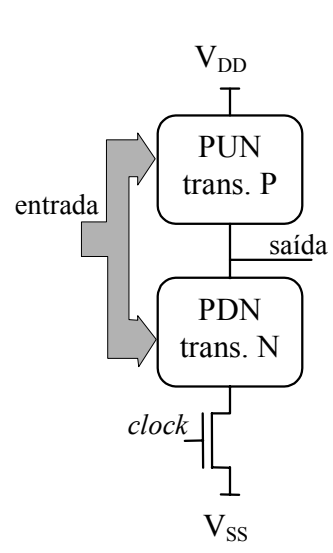

b)

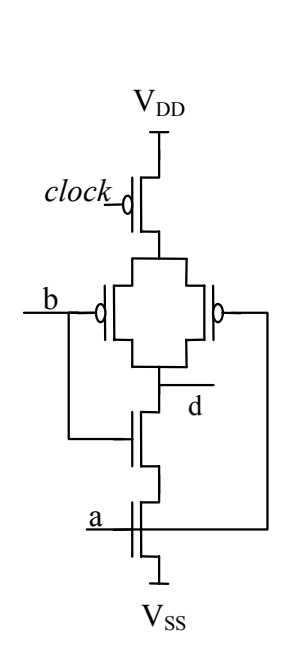

c)

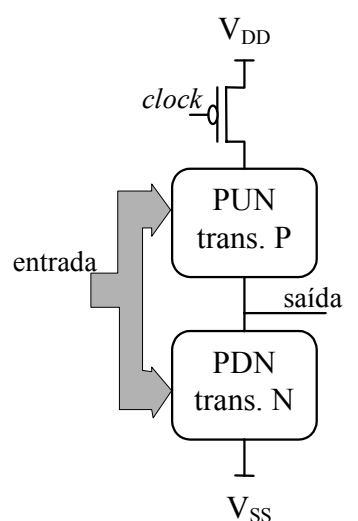

d)

Figura 10. Circuitos n-latch e p-latch: a), representação com transistores e b), representação esquemática do nlatch; c), representação com transistores e d), representação esquemática do p-latch.

\subsubsection{Regras de Composição}

As ligações entre blocos permitidas no TSPC estão resumidas no diagrama fornecido na figura 11 [La95]. Ele nos fornece adicionalmente informações sobre os problemas que podem acontecer devido aos atrasos diferenciados nos sinais de clock que chegam aos blocos interligados. Consideremos, por exemplo, uma porta n-dinâmica com saída ligada a um nlatch. Devido aos atrasos diferenciados no circuito de distribuição de clock, o bloco dinâmico pode entrar em pré-carga enquanto o n-latch está ainda em avaliação, causando erros. Esses atrasos devem ser evitados no TSPC através de uma cuidadosa distribuição do sinal de clock. 


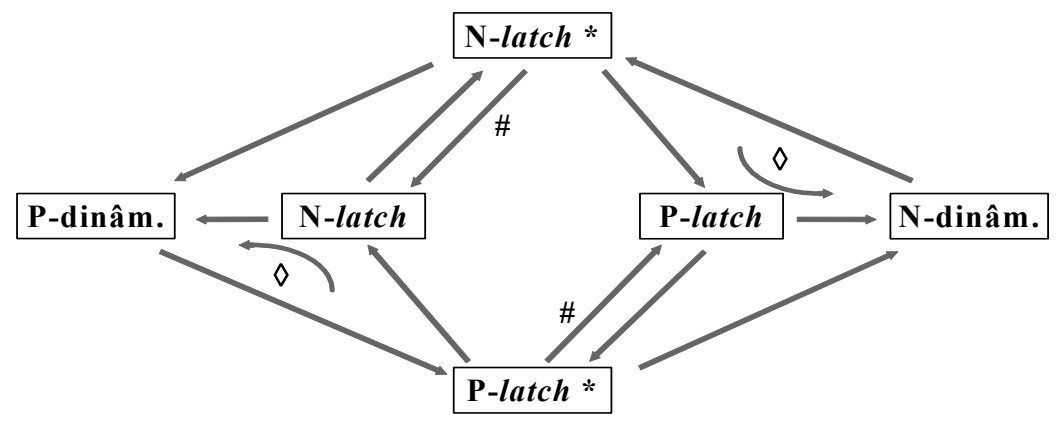

Figura 11. Gráfico de conexões para o TSPC. As portas e circuitos são representados pelos quadrados. O fluxo de dados permitido é indicado pelo sentido das setas. \# indica ligações onde atrasos diferenciados do clock nos blocos não causam problemas (skew safe communication); * indica pontos de latch depois dos quais portas estáticas complementar CMOS podem ser inseridas; $\diamond$ indica ligações onde há problemas potenciais de violação de holding time.

Outra questão assinalada são as configurações onde há o perigo de violação de hold time. Um caso dessa violação é a do flip-flop tipo D clássico da TSPC, mostrado na figura 12. Podemos examinar essa violação considerando um estado inicial onde clock $=$ entrada $=$ saída_a $=$ BAIXO. Os blocos $\mathrm{B}_{\mathrm{L} 1}$ e $\mathrm{B}_{\mathrm{L} 4}$ estarão avaliando nesse instante. No final desta avaliação, ambas saídas, $\mathbf{a}_{1}$ e $\mathbf{b}_{1}$, estarão no nível lógico ALTO. Em seqüência, quando o clock muda para o nível lógico ALTO, os outros blocos irão para a avaliação. Suponhamos que $\mathbf{a}_{1}$ funcione propriamente e retenha o valor ALTO. Para este caso, o nó $\mathbf{a}_{2}$ vai para o nível lógico BAIXO, a saída_a, para o nível lógico ALTO e b $\mathbf{b}_{\mathbf{1}}$ vai para o nível lógico BAIXO. Em conseqüência o transistor $\mathrm{N}_{1}$ é cortado e o valor na saída do bloco $\mathrm{B}_{\mathrm{L} 5}, \mathbf{b}_{2}$, dependerá do holding time deste bloco. Caso a mudança em $\mathbf{b}_{1}$ seja rápida demais, a saída de $\mathrm{B}_{\mathrm{L} 5}$ ficará com o nível lógico ALTO e teremos um erro na avaliação. Caso ocorra o contrário, o que é o esperado, o bloco $\mathrm{B}_{\mathrm{L} 5}$ e o flip-flop tipo D avaliarão corretamente.

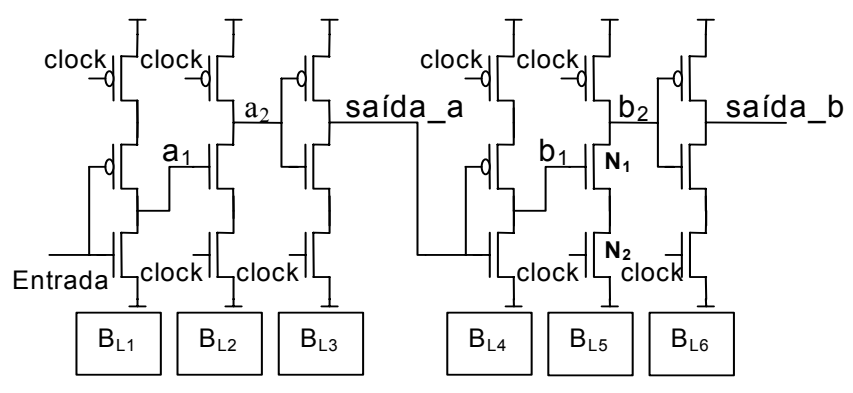

Figura 12. Dois flip-flops tipo D TSPC conectados em série. 


\subsection{E-TSPC}

Está técnica é uma extensão da TSPC e propõe novas regras de ligações e mudanças na topologia de alguns blocos lógicos e registradores de forma a melhorar a velocidade dos circuitos [Na97].

Esta técnica utiliza os seguintes blocos em sua composição:

- Portas lógicas estáticas complementares $C M O S$;

- Portas lógicas dinâmicas, n-dinâmicas e p-dinâmicas;

- $\quad$ Latches, n-latches e p-latches.

Também podem ser utilizados blocos semelhantes aos pseudo-nMOS chamados de NMOS like [Na99]. Os blocos N-MOS like são construídos através da modificação de portas n e p dinâmicas e latches $\mathrm{n}$ e p. Um exemplo desta modificação dos blocos para N-MOS like pode ser observado no circuito da figura 13 (b): ele é formado pela retira do transistor NMOS ligado ao clock do bloco n-dinâmico da figura 13(a). Devido a essa modificação, as dimensões do transistor PMOS devem ser ajustadas para garantir o nível lógico ALTO na précarga, mesmo quando as entradas estiverem todas com nível lógico ALTO. Outros exemplos de modificações são indicados na figura 13 (o transistor ou bloco com maiores dimensões é desenhado com linhas mais grossas).

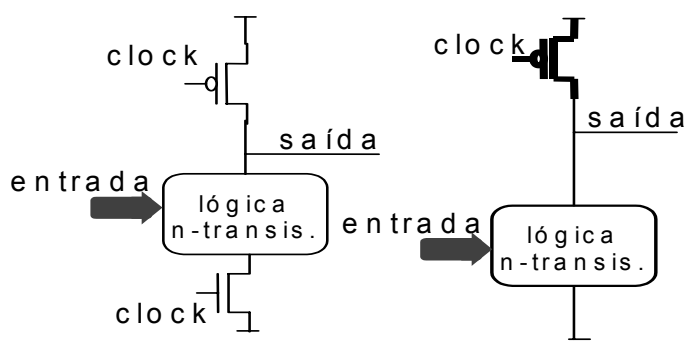

a) n-din â m ic a b) NMOS like $\mathrm{n}$ - $\mathrm{d}$ in â $\mathrm{m}$ ic a

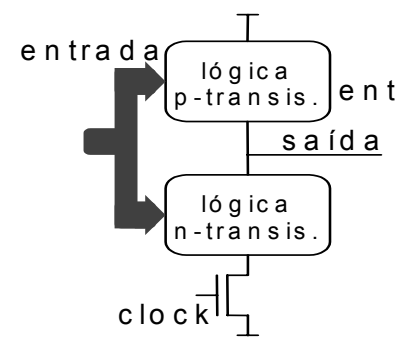

e) $n-l a t c h$

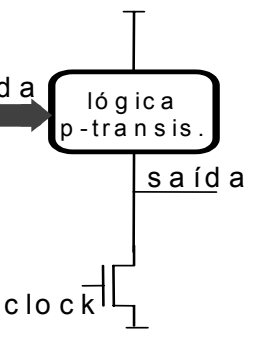

f) NMOS like $\mathrm{n}-\mathrm{latch}$

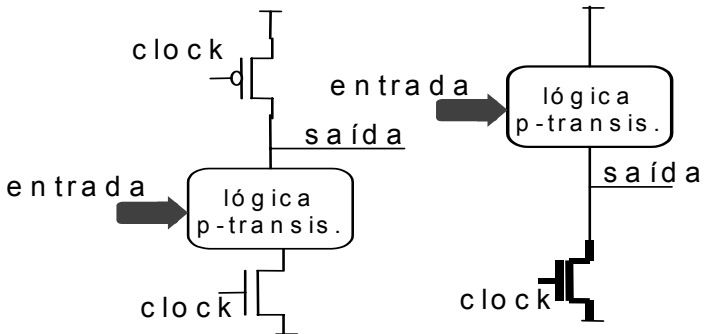

c) p-din â m ic a d) NMOS like $p$ - d in â $m$ ic a

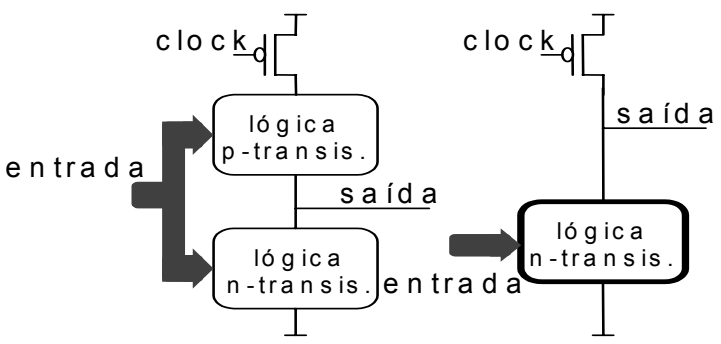

g) $p-l a t c h$

h) NMOS like p-latch

Figura 13. Conversão dos blocos N-MOS like. 
Estes blocos N-MOS like são mais velozes por reduzirem o números de transistores e por isso são usados em alguns dos Dual-Modulus Prescalers. Por outro lado, eles apresentam, na maioria das aplicações, um alto consumo de potência o que sugere cautela nas sua utilização.

É utilizada também nessa técnica o conceito data chain [Na99], n-data chain ou pdata chain.

Um n-data chain é um caminho de propagação de dados onde durante a fase em que o clock está no nível lógico ALTO, todas as portas e registradores estão em avaliação; durante a fase em que o clock está no nível lógico BAIXO, todas as portas e registradores dinâmicos estão em pré-carga ou em holding. Se convenientemente construído, o valor do sinal da saída do data chain mantém-se constante durante esta fase e diremos que o data chain está em holding.

No caso do p-data chain ocorre o inverso do n-data chain, ocorrendo o holding durante nível lógico ALTO do clock.

Mais formalmente podemos definir o n-data chain como um caminho de propagação de dados com as seguintes características:

- Deve conter pelo menos um bloco n-latch ou um bloco n-dinâmico;

- Deve começar em uma entrada externa do circuito ou na saída de algum bloco p-latch ou p-dinâmico;

- Deve conter apenas blocos estáticos, n-dinâmicos ou n-latches;

- Não importa a ordem ou o número destes blocos;

- Deve terminar na entrada de um bloco p-latch ou p-dinâmico ou ser saída do circuito.

No caso do p-data chain, pode-se repetir a definição, trocando n por p e vice-versa.

\subsubsection{Regras de Composição}

Para o correto funcionamento de um data-chain, ou seja fazer a avaliação em uma fase do clock e armazenar a informação na outra, é necessário que ele tenha uma das duas configurações a seguir:

- Deve possuir ao menos dois blocos, um bloco dinâmico e um bloco latch, e um número par de blocos (inversores) entre eles, ou 
- Deve possuir ao menos dois latch e um número par de blocos (inversores) entre eles.

Adicionalmente, blocos adjacentes no caminho de propagação necessitam ter um número par ou ímpar de blocos (inversores), de acordo com o estipulado na tabela 2 (dois blocos são chamados de adjacentes se somente blocos estáticos estão colocados entre eles).

Tabela 1. Regras para ligação entre blocos.

\begin{tabular}{|c|c|c|c|}
\hline & $\begin{array}{c}\text { Entrada do } \\
\text { latch }\end{array}$ & $\begin{array}{c}\text { Entrada do } \\
\text { n-dinâmico }\end{array}$ & $\begin{array}{c}\text { Entrada do } \\
\text { p-dinâmico }\end{array}$ \\
\hline Entrada do data chain & n.r. & n.r. & n.r. \\
\hline Saída do latch & n.r. & n.p. & n.p. \\
\hline Saída do n-dinâmico & n.r. & ímpar & n.p. \\
\hline Saída do p-dinâmico & n.r. & n.p. & ímpar \\
\hline
\end{tabular}

n.r.: não há restrições; n.p.: esta conexão não é permitida; par: um número par dos blocos é requerido; ímpar: um número ímpar dos blocos é requerido.

Podemos exemplificar as ligações de $\mathrm{n}$-data chains com a figura 14. Um n-data chain é iniciado na entrada $i_{\mathrm{a}}$ e segue pelos blocos $B_{A}, B_{C}, B_{E}$ e $B_{I}$. Outro n-data chain é iniciado na entrada $\mathrm{i}_{\mathrm{C}}$ e segue pelos blocos $B_{C}, B_{E}, B_{F}, B_{H}$ e $B_{K}$.

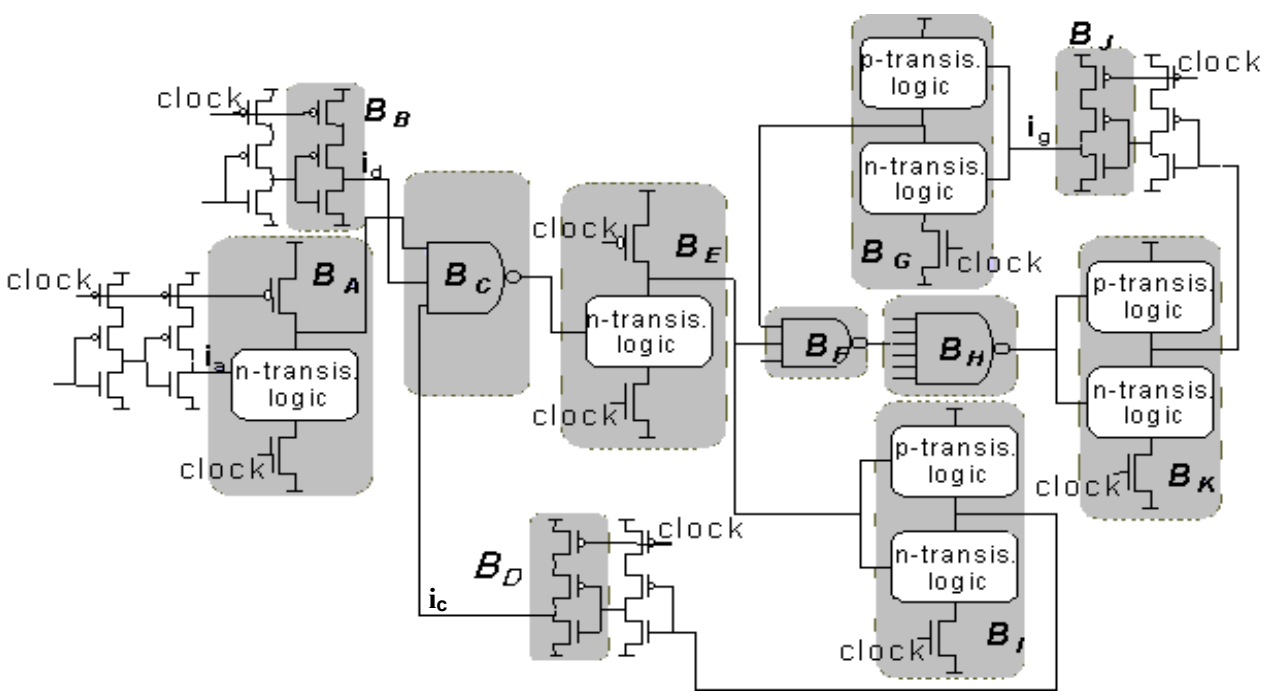

Figura 14. Exemplos de n-data chains. Os blocos mencionados no texto são nomeados e indicados na figura. 


\subsubsection{Novas estruturas para a E-TSPC}

São acrescentadas ao E-TSPC novas estruturas cujo funcionamento correto se dá devido a certas características de operação de alguns data chains [Na02]. Tais características aparecem em data chains, $\mathrm{n}$ ou $\mathrm{p}$, que possuem um único latch e que também é o último bloco do data chain. Para estes data chains, que denominaremos de fo-data chains (data chains com a saída fundível), durante a fase de holding a saída mantém o resultado avaliado, desde que tenham sido observadas as regras de composição dos data-chains, e se encontra em um estado de alta impedância.

Devido a esse estado de alta impedância os fo-data chains podem ser utilizados para dobrar a velocidade de processamento. Unindo as saídas de dois fo-data chains, um p e outro $\mathrm{n}$, obtemos uma estrutura que avalia os sinais de entrada a cada meio ciclo do sinal de clock. O circuito da figura 15 exemplifica a utilização desta estrutura: durante a fase em que o clock está em ALTO, o fo-n data chain está em avaliação e impõe o resultado em out, pois o fo-p data chain tem sua saída em alta impedância; durante a fase em que o clock está em BAIXO, o fo-p data chain está em avaliação e impõe o resultado em out, pois, agora, o fo-n data chain está em alta impedância.

Estrutura semelhante a esta foi utilizada em um dos circuitos que implementamos para o Prescaler.

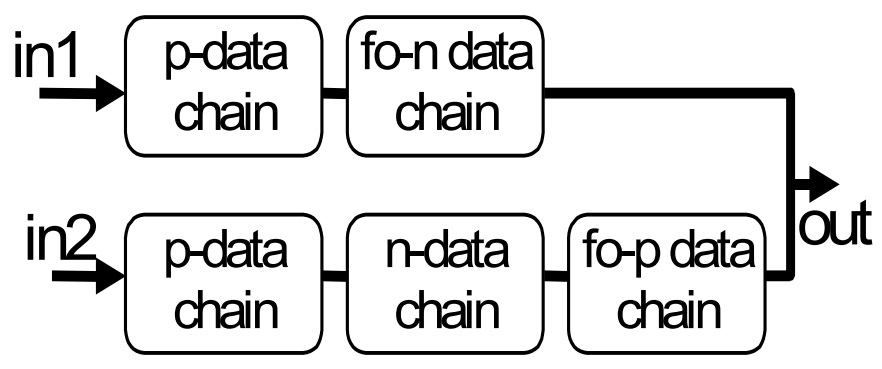

Figura 15. Estrutura com dupla conexão para saída de dados. 


\section{DESCRIÇÃO DOS CIRCUITOS DUAL-MODULUS PRESCALERS}

Mostraremos nesse capítulo três implementações do circuito Dual-Modulus Prescaler construídos com a técnica E-TSPC e fabricados na tecnologia CMOS 0,35 $\mu \mathrm{m}$ da AMS para a comparação de resultados.

Prescalers são circuitos que dividem um sinal de entrada por $N$ ou $(N+1)$, de acordo com o valor de um sinal de controle, o Modulus Control. Eles constituem parte integrante de circuitos Sintetizadores de Freqüências utilizados em transmissão e recepção de sinais rádio freqüência $(\mathrm{RF})$.

\subsection{Descrição de um PLL}

O PLL é um circuito que sincroniza, em fase e em freqüência, o sinal gerado por um VCO com um sinal de entrada (sinal de referência) [Ar03]. No estado de sincronia ou locked, o erro de fase entre o sinal de saída do oscilador e o sinal de referência deve ser zero ou próximo desse valor.

Existem três blocos em um PLL: um detector ou comparador de fase $(P D)$, um filtro passa-baixo $(L P F)$ e um oscilador controlado por voltagem $(V C O)$, figura 16. Seu funcionamento é descrito a seguir: o erro de fase entre $\mathrm{x}(\mathrm{t})$, sinal de referência, e $\mathrm{y}(\mathrm{t})$, sinal gerado pelo $V C O$, é medido no detector de fase que gera um sinal de erro $\Delta_{\varnothing}$. O sinal $\Delta_{\varnothing}$ passa pelo filtro passa-baixos, que elimina as componentes de alta freqüência, e é, em seguida, aplicado ao $V C O$. O circuito tenta estabilizar o sinal y(t) para que $\Delta_{\varnothing}$ seja constante ( $P L L$ no estado locked). Neste momento resultará que o sinal de referência e o sinal de saída do $V C O$ têm a mesma freqüência.

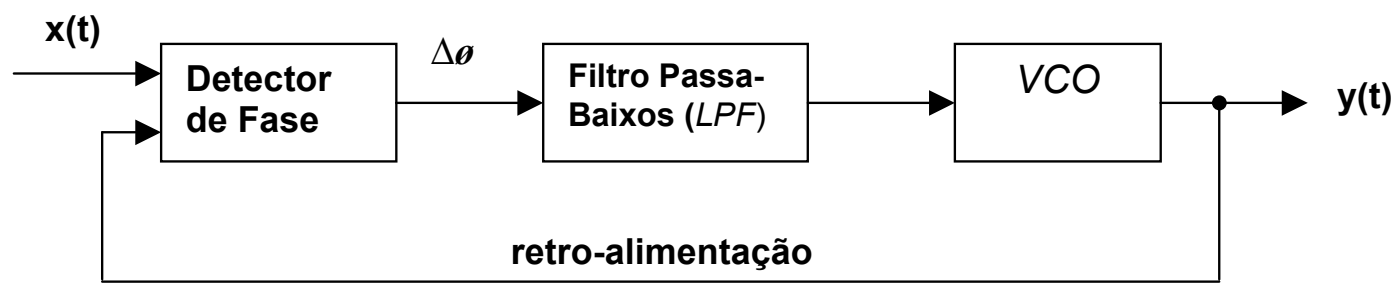

Figura 16. PLL básico. 


\subsection{Sintetizador de Freqüências}

O Sintetizador de Freqüências, figura 17, é um bloco utilizado em circuitos de recepção e transmissão de sinais em RF. Ele gera um sinal periódico, senoidal, para um mixer que realiza a translação em freqüência para baixo (downconversion), ou para cima (upconversion), do sinal recebido, ou transmitido, pelo sistema de RF. Algumas arquiteturas de Sintetizadores utilizam um PLL com a retro-alimentação (feedback) passando por um contador programável. O contador programável divide a freqüência do sinal vindo do VCO, gerando um novo sinal, com freqüência menor, que será comparado ao sinal de referência. Desta forma, a freqüência do sinal de saída dependerá do valor programado neste contador.

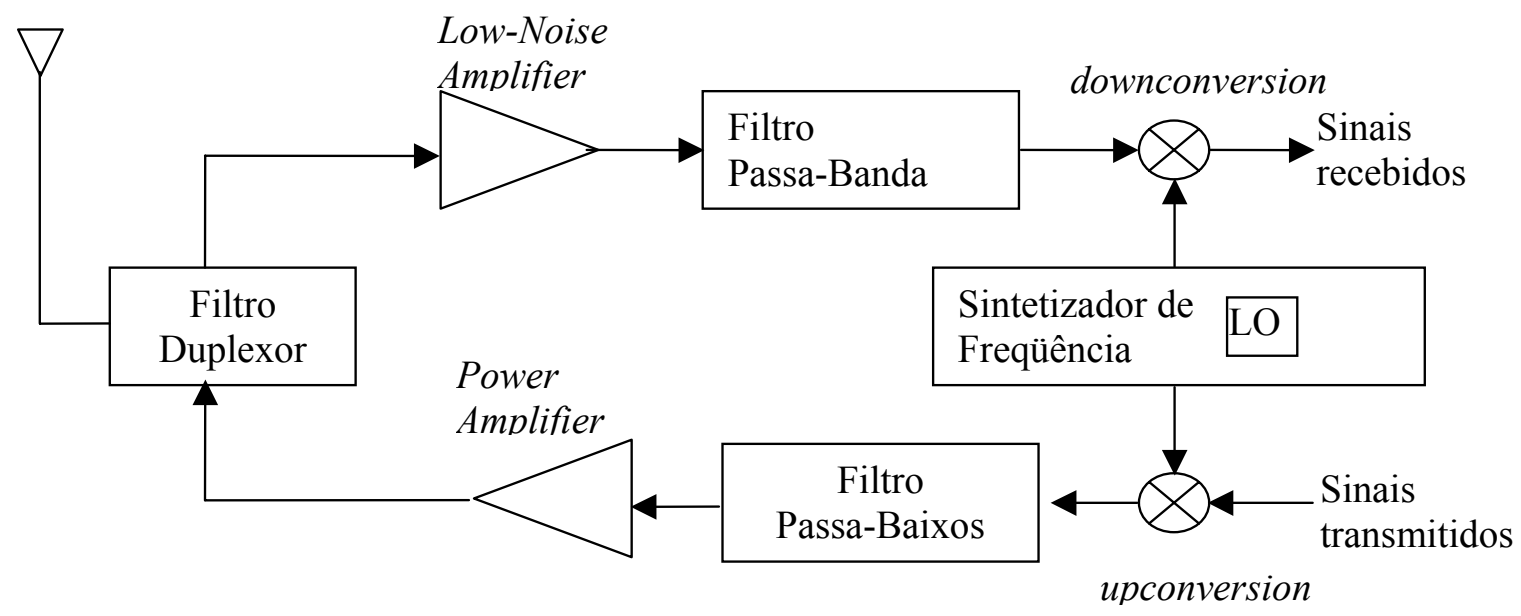

Figura 17. Transceptor genérico de RF.

\subsection{Arquiteturas para Sintetizadores de Freqüências}

Existem diversas arquiteturas de Sintetizadores de Freqüência, dentre elas, discutiremos duas que utilizam um circuito Dual-Modulus Prescaler, a Integer- $N$ e a Fractional-N.

\subsubsection{Arquitetura Integer- $N$}

A arquitetura Integer-N utiliza na retro-alimentação do $P L L$, um circuito divisor chamado de Pulse Swallow, figura 18. Este divisor é implementado com um Prescaler, um contador programável chamado Swallow Counter e um contador principal. O funcionamento 
desse circuito inicia-se com o carregamento dos dois contadores, o principal, com um valor fixo P, e o Swallow Counter, com um valor programável S. O valor S deve ser menor ou igual a $\mathrm{P}, \mathrm{S} \leq \mathrm{P}$. No estado inicial o valor do sinal Modulus Control está no nível lógico ALTO, o que faz com que o circuito Prescaler divida a freqüência do sinal de saída do $V C O$ por $\mathrm{N}+1$. A cada $\mathrm{N}+1$ ciclos, os valores dos contadores principal e Swallow Counter serão reduzidos em um, até que o Swallow Counter chegue a zero. Neste momento o valor do sinal Modulus Control é alterado e o Prescaler passa a dividir por $\mathrm{N}$ o sinal de saída do VCO. Agora, a cada $\mathrm{N}$ ciclos, o contador principal será reduzido em um, até que também chegue a zero. Os contadores nesse instante são reinicializados com $\mathrm{P}$ e $\mathrm{S}$ e o processo é repetido. Com isso teremos que em um ciclo completo de operação do circuito Sintetizador o Prescaler divide por $\mathrm{N}+1$ em $\mathrm{S}$ vezes e divide por $\mathrm{N}$ em P-S vezes. O resultado final na saída do Pulse Swallow será a divisão do seu sinal de entrada, que é a saída do $V C O$, por $\mathrm{M}$, onde

$$
\mathrm{M}=(\mathrm{N}+1) \mathrm{S}+\mathrm{N}(\mathrm{P}-\mathrm{S})=\mathrm{NP}+\mathrm{S}
$$

Quando o Sintetizador de Freqüências estiver no estado locked, ele apresentará uma freqüência de saída igual a

$$
\mathrm{f}_{\mathrm{OSC}}=\mathrm{M} \mathrm{f}_{\mathrm{REF}}=(\mathrm{NP}+\mathrm{S}) \mathrm{f}_{\mathrm{REF}} .
$$

Podemos controlar, portanto, a freqüência de saída do $V C O$ com o valor S programado no Swallow Counter.

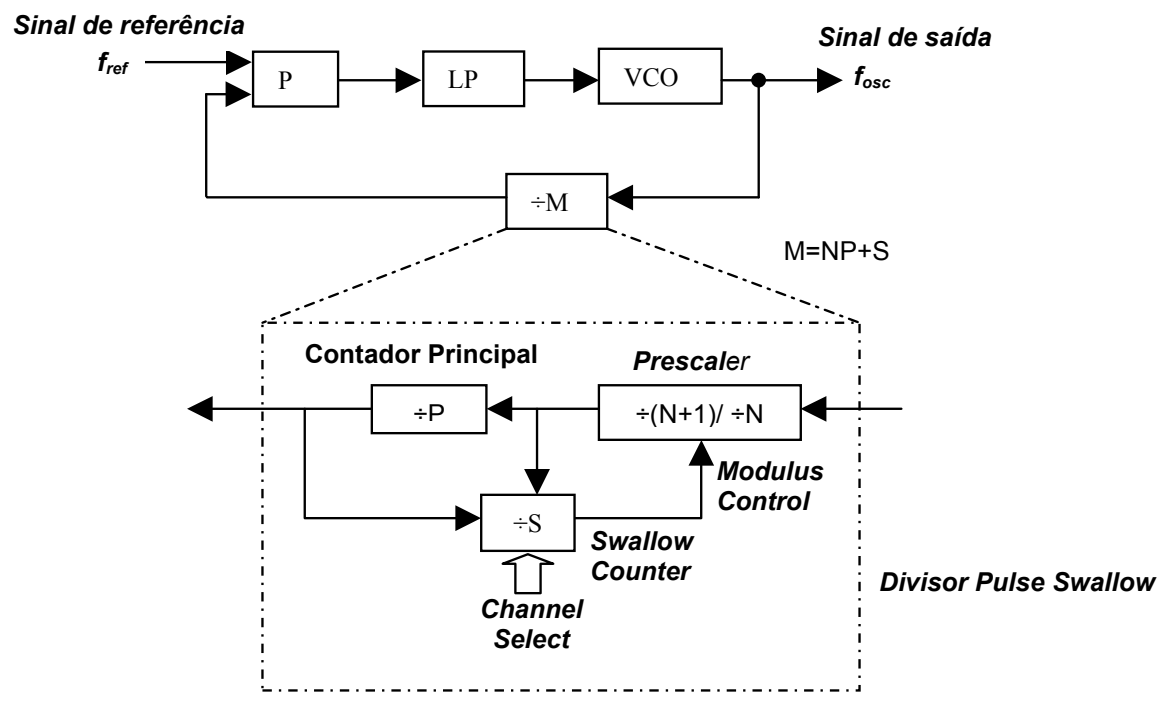

Figura 18. Arquitetura Integer-N. 


\subsubsection{Arquitetura Fractional-N}

$\mathrm{Na}$ arquitetura Fractional-N, figura 19, um pulso do sinal de saída do VCO é removido por um circuito removedor de pulsos. A remoção dos pulsos é controlada por um comando "remove" gerado por um circuito de controle e feita com freqüência programável de $1 / \mathrm{T}_{\mathrm{P}}$. A saída do removedor de pulsos é ligada a um divisor por $\mathrm{N}$ e apresentará, no estado locked do $P L L$, uma freqüência igual a $\mathrm{Nf}_{\mathrm{REF}}$. A saída do $V C O$ terá, por sua vez, freqüência de $f_{O S C}=N f_{R E F}+1 / T_{P}$. A freqüência de saída, portanto, é ajustada por $T_{P}$.

Esta arquitetura difere da anterior, pois o passo de variação da freqüência do sinal de saída não depende de $f_{\mathrm{REF}}$ e $\operatorname{sim}$ de $1 / \mathrm{T}_{\mathrm{P}}$. Esta característica dá maior liberdade de projeto, facilita a escolha da banda de loop, diminui o transiente de estabilização e reduz o ruído de fase no $V C O$.
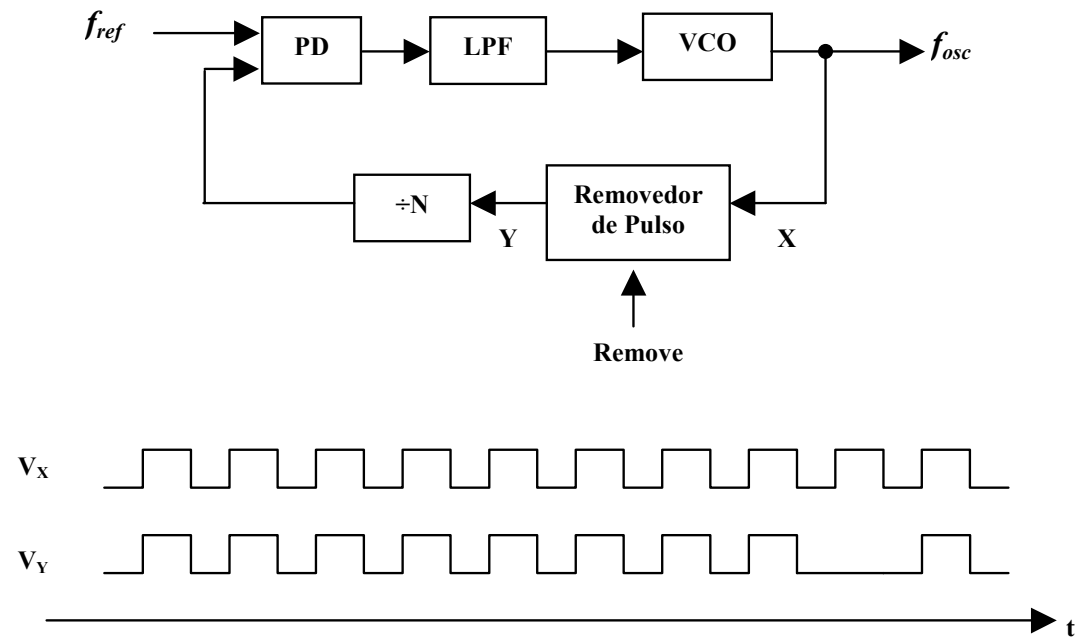

Figura 19. Arquitetura Fractional-N com circuito Removedor de Pulso.

A arquitetura Fractional- $N$ também pode ser implementada utilizando um Prescaler, como mostrado figura 20. O terminal Modulus Control receberá o sinal de controle de tal maneira que em uma parte do tempo a saída do $V C O$ será dividida por $\mathrm{N}$ e na outra, por $\mathrm{N}+1$. Durante a divisão por $\mathrm{N}+1$ é que ocorrerá a remoção do pulso mostrado na figura 19. Esta implementação é em realidade menos utilizada do que a anterior devido ao seu grau de complexidade. 


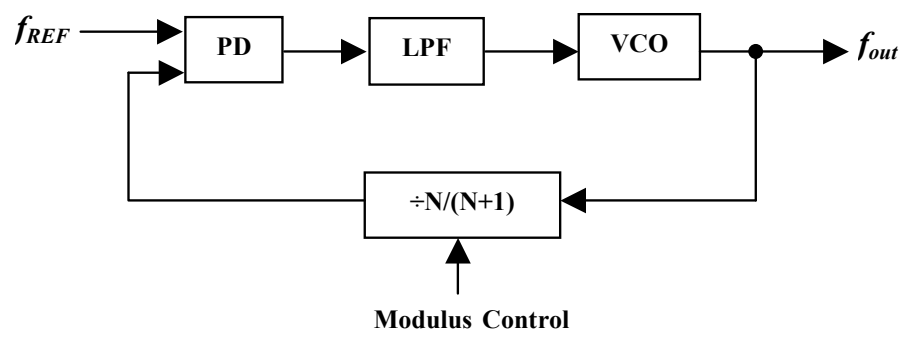

Figura 20. Uso de um Dual-Modulus Prescaler como Pulse Remover.

\subsection{Dual-Modulus Prescaler 32/33}

O Dual-Modulus Prescaler implementado tem valor de divisão de 32 ou 33, figura 21. Este circuito divide o sinal recebido em seu terminal clock, normalmente proveniente de um $V C O$. Quem definirá o valor da divisão é o sinal aplicado em um terminal chamado SM; quando SM estiver no nível lógico BAIXO o Prescaler dividirá por 32 e quando SM estiver no nível lógico ALTO, dividirá por 33.

Esse circuito é composto de duas partes:

- Parte síncrona: contador síncrono que realiza a divisão da freqüência do clock por 4 ou 5, dependo do valor do sinal chamado MC, que é a saída de uma NAND (parte hachurada da figura 21);

- Parte assíncrona: contador assíncrono que realiza a divisão da freqüência do sinal proveniente da parte síncrona por 8 (os três D-flip flops, $D-F F$ s, na porção inferior da figura 21).

O contador síncrono opera na maior velocidade do sistema, pois recebe como sinal de entrada a saída direta de um $V C O$. Por isso deve ser projetado com o máxima de cuidado em sistemas onde o VCO trabalha em altas freqüências. 


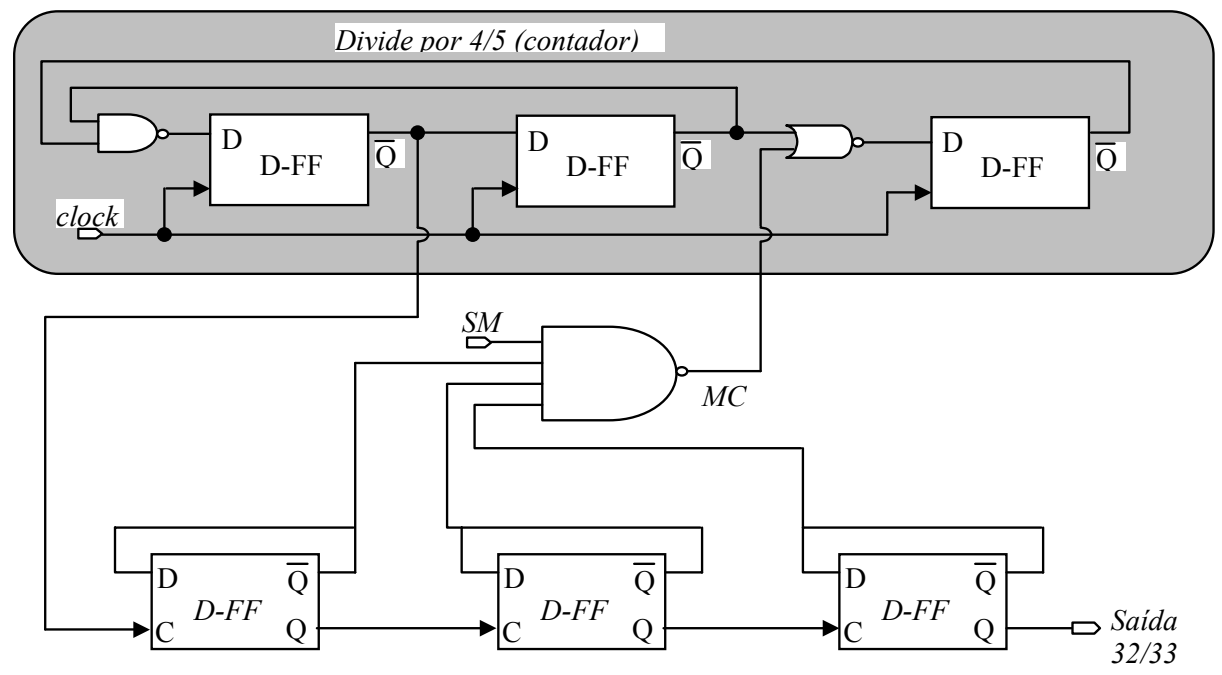

Figura 21. Esquemático de um Dual-Modulus Prescaler 32/33.

\subsection{Implementações do circuito Dual-Modulus Prescaler 32/33}

Várias implementações de Dual-Modulus Prescalers são possíveis, com fatores de divisão variados $(16 / 17,32 / 33$, etc.). Este fator de divisão dependerá do número de $D-F F s$ dispostos no circuito. Este número influencia pouco ou nada na velocidade máxima e pouco na potência dissipada pelo circuito, como veremos. Discutiremos à seguir três diferentes implementações de Prescalers na técnica E-TSPC, mostrando a lógica de estados e os diagramas esquemáticos de seus contadores síncronos. As três implementações, que diferem praticamente apenas na parte síncrona, são:

- Implementação com $3 D-F F$ na parte síncrona;

- Implementação com $2 D-F F$ na parte síncrona;

- Implementação que utiliza fo-data chains na parte síncrona.

A primeiras e a terceira destas implementações foram projetadas à partir das configurações encontrados em [Na99] e [Na02] respectivamente. Elas utilizam as mesmas configurações de transistores, porém, ajustados à tecnologia de $0,35 \mu \mathrm{m}$. As figuras 22 e 23 mostram os contadores síncronos usados nestes trabalhos. 


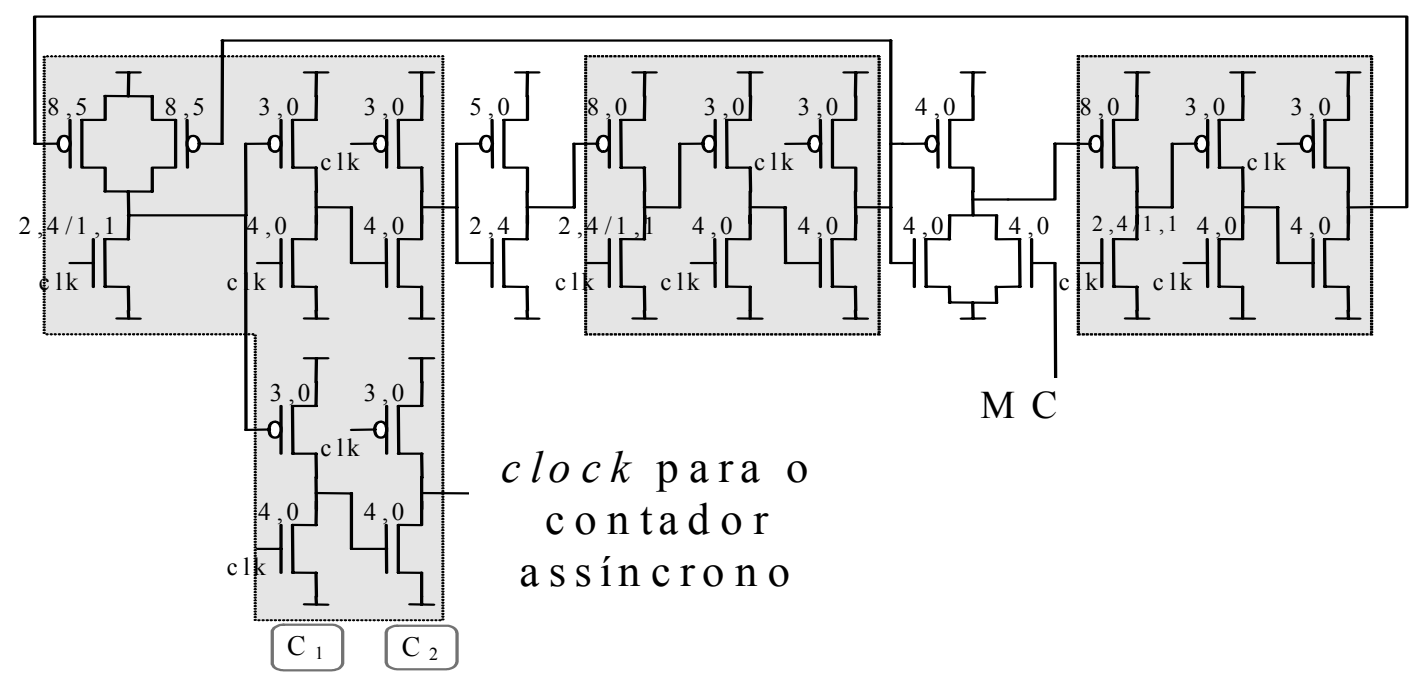

Figura 22. Diagrama esquemático dos transistores da implementação com três $D-F F$ s no contador síncrono. As dimensões de $\mathrm{W}$ em $\mu \mathrm{m}$ dos transistores estão indicadas na figura. A dimensão L é a mínima da tecnologia para todos os transistores, $\mathrm{L}=0,8 \mu \mathrm{m}[\mathrm{Na} 99]$.

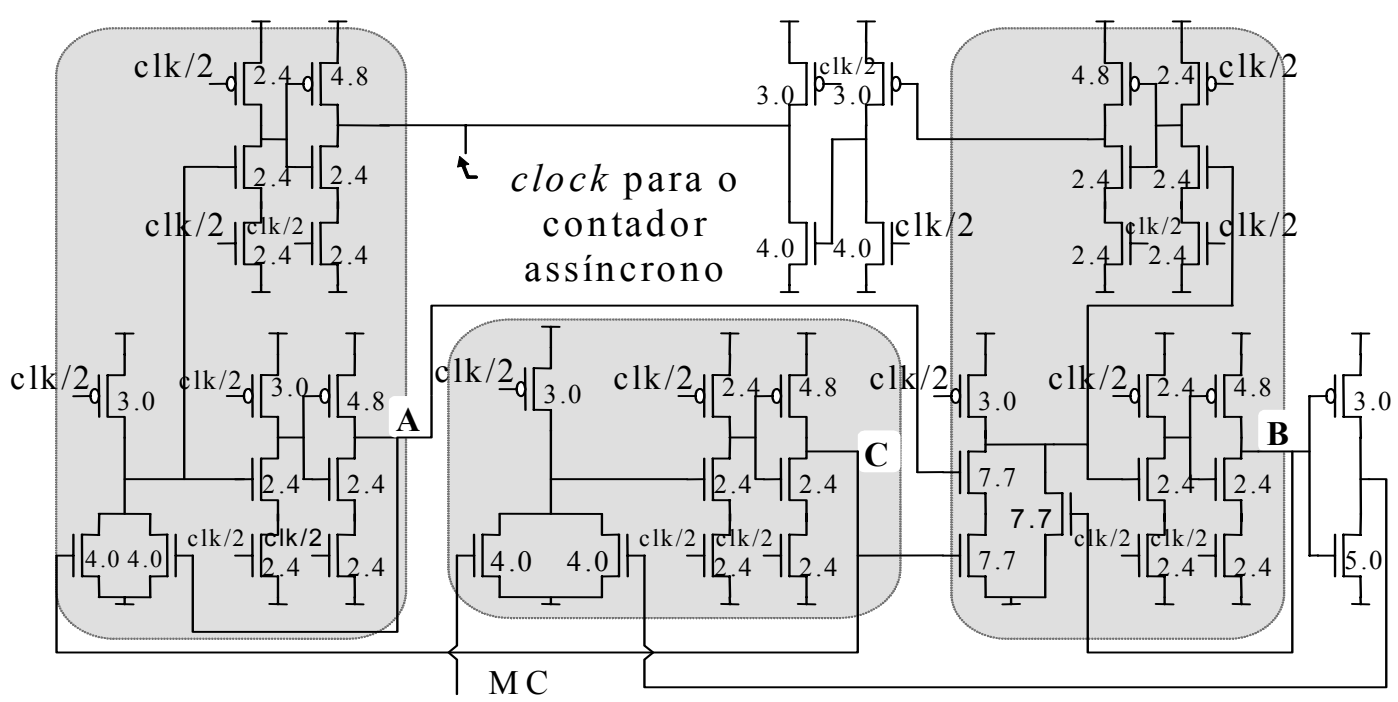

Figura 23. Diagrama esquemático dos transistores da implementação com três $D-F F \mathrm{~s}$ e clock dividido por dois no contador síncrono. As dimensões de $\mathrm{W}$ em $\mu \mathrm{m}$ dos transistores estão indicadas na figura. A dimensão L é a mínima da tecnologia para todos os transistores, $\mathrm{L}=0,8 \mu \mathrm{m}[\mathrm{Na} 02]$.

\subsubsection{Dual-Modulus Prescaler 32/33 (versão com 3 D-FFs)}

Esta versão do Prescaler [Mi04a] [Mi04b] utiliza três $D$-FFs para implementar o contador síncrono que divide seu clock por 4 ou por 5, dependendo do valor lógico de um sinal de controle MC. O contador síncrono foi projetado de forma a trabalhar como uma 
máquina de estados que obedece ao diagrama de estados da figura 24a. Esta máquina tem como entrada o sinal MC e saída o sinal A, o bit mais a esquerda dos três bits que nomeiam os estados.

Este contador, quando a entrada MC tiver o nível lógico ALTO (1), passará pelos seguintes estados: 000 ou $001 \rightarrow 011 \rightarrow 111 \rightarrow 101 \rightarrow 000$. Neste caso o circuito síncrono está dividindo o clock por 4. Por outro lado, quando a entrada MC tiver o nível lógico BAIXO (0), o contador passará pelos seguintes estados: 000 ou $001 \rightarrow 010 \rightarrow 011 \rightarrow 111 \rightarrow 101 \rightarrow$ 000. Agora o circuito síncrono está dividindo o clock por 5. É no estado 000 que será definida qual divisão, por 4 ou 5, o circuito realizará. Portanto, o sinal MC deve estar com o nível lógico correto antes da borda de subida do clock que marca a saída do estado 000. Isso garante a seqüência correta de estados. A figura $24 \mathrm{~b}$ mostra os sinais MC e A no tempo.

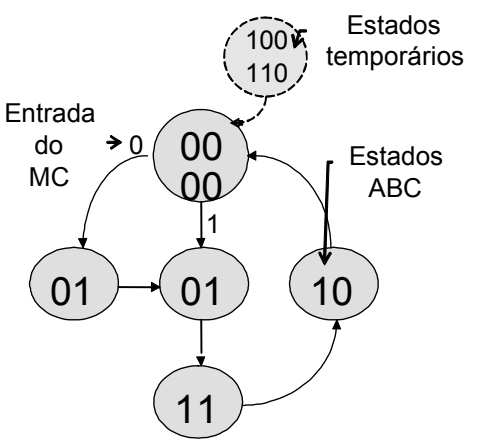

a)

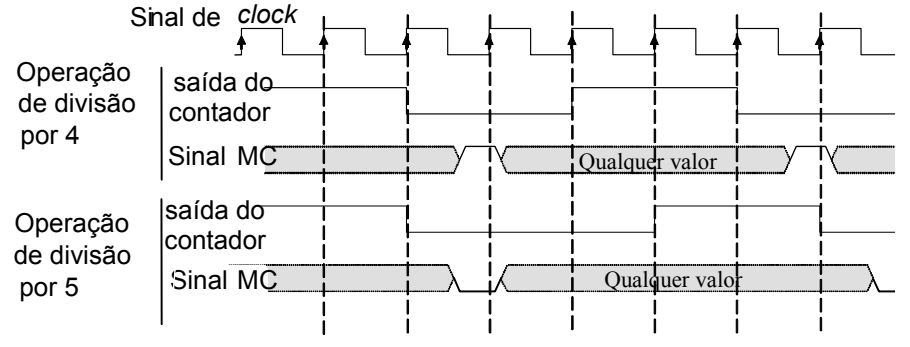

b)

Figura 24. Máquina de estados para o contador síncrono: a), diagrama de estados e b), sinais no tempo (versão com $3 D-F F \mathrm{~s})$.

O bloco $D-F F$ utilizado no contador síncrono é uma adaptação do $D-F F$ sensível à borda de descida descrita em [Na99] (figura 22). Este $D-F F$, por sua vez, é construído a partir de modificações feitas no $D-F F$ clássico da técnica TSPC (figura 25a), para transformar cada um dos seus três blocos em blocos N-MOS like (figura 25b). Este $D-F F$ modificado tem a vantagem de alcançar altas freqüências porém apresenta um maior consumo de potência. Observemos que o $D-F F$ modificado sensível a borda de descida é mais veloz do que seria o $D-F F$ modificado sensível a borda de subida. Isso se deve ao fato de que no primeiro a utilização de blocos N-MOS like exige que os transistores $\mathrm{N}$ tenham maior capacidade de drenar corrente, o que é obtido com transistores $\mathrm{N}$ e P de dimensões próximas. Por outro lado, no $D-F F$ modificado sensível a borda de subida, os blocos N-MOS like exigem que os transistores $\mathrm{P}$ tenham maior capacidade de drenar, o que demandará transistores $\mathrm{P}$ bastante 
maiores do que os N. Com isso são aumentadas as capacitâncias do circuito e é reduzida sua velocidade. Para o $D-F F$ não modificados, o circuito sensível a borda de subida é mais veloz.

As dimensões dos transistores do $D-F F$ utilizado estão indicadas na figura 25 e devem obedecer a vários condições para garantir a correta operação. Estas são:

- quando os transistores M1 e M2 estão simultaneamente ativados, o sinal $a$ deve ser ALTO;

- quando os transistores M3 e M4 estão simultaneamente ativados, o sinal $b$ deve ser BAIXO;

- quando os transistores M5 e M6 estão simultaneamente ativados, o sinal $c$ deve ser BAIXO.

As dimensões do $D-F F$ foram ajustadas por simulações de forma a serem mínimas, reduzindo ao máximo o consumo, e a obedecerem as condições acima.

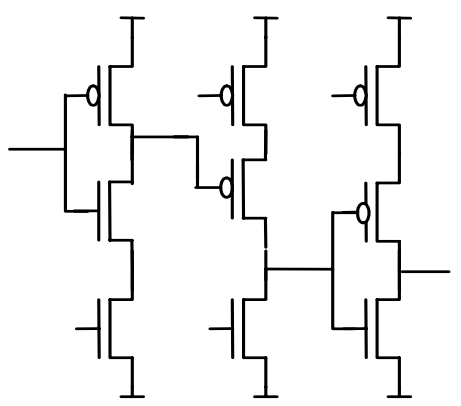

a)

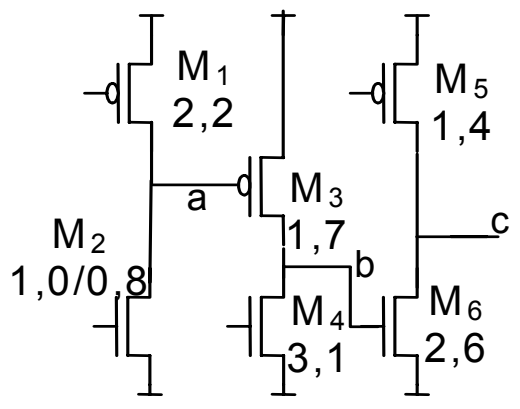

b)

Figura 25. $D-F F S$ sensíveis a borda de descida: a), $D-F F$ da técnica TSPC e b), $D-F F$ modificado. As dimensões de $\mathrm{W}$ em $\mu \mathrm{m}$ dos transistores do circuito modificado estão indicadas na figura. A dimensão L é a mínima da tecnologia para todos os transistores, $\mathrm{L}=0,35 \mu \mathrm{m}$, exceção nos transistores onde aparecem duas dimensões.

A implementação do contador síncrono é mostrada na figura 26. Pode-se observar na figura os três $D-F F$ utilizados, hachurados, e que parte da lógica do circuito esta embutida nos $D-F F s$ (ver bloco mais a esquerda)

O contador assíncrono, por sua vez, utiliza três $D-F F$ s sensíveis a borda de subida. O primeiro destes $D-F F$ recebe como sinal de clock o sinal A do contador síncrono e sua saída será o clock do segundo $D-F F$; a saída do segundo, por sua vez, será o clock do terceiro. Como este circuito trabalha com freqüências menores, quatro ou mais vezes menor do que a do contador síncrono, é possível utilizar aqui os $D-F F$ da técnica TSPC (figura 27),

No projeto destes $D-F F s$ se utilizou transistores com largura de canal de $1 \mu \mathrm{m}$, quase a mínima da tecnologia. A exceção é um transistor $\mathrm{P}$ na saída, que tem $\mathrm{W}=3 \mu \mathrm{m}$ para garantir tempos de subida e descida simétricos. 
As saídas invertidas dos $D-F F s$ do contador assíncrono são usadas, junto com um sinal de controle SM, para gerar o sinal MC que controla o funcionamento do contador síncrono (figura 21). Assim quando o sinal SM for ALTO, MC deverá ter valor ALTO durante $7 / 8$ do período de contagem do contador assíncrono e, valor BAIXO durante 1/8, fazendo com que o Prescaler divida por 33; quando o sinal SM for BAIXO, MC deverá ter sempre valor ALTO, fazendo com que o Prescaler divida por 32.

A escolha do sinal que serve de clock para o primeiro $D-F F$ do contador assíncrono, da borda de funcionamento dos $D-F F$ s do contador assíncrono e dos sinais que são usados para gerar MC foi feita de forma a garantir a maior margem de tempo para a preparação deste sinal. Na configuração utilizada, o sinal MC começa a ser gerado no inicio do estado 111 e deverá estar pronto, como dito, ao fim do estado 000.

O Prescaler foi todo projetado na tecnologia AMS CMOS de $0,35 \mu \mathrm{m}$.

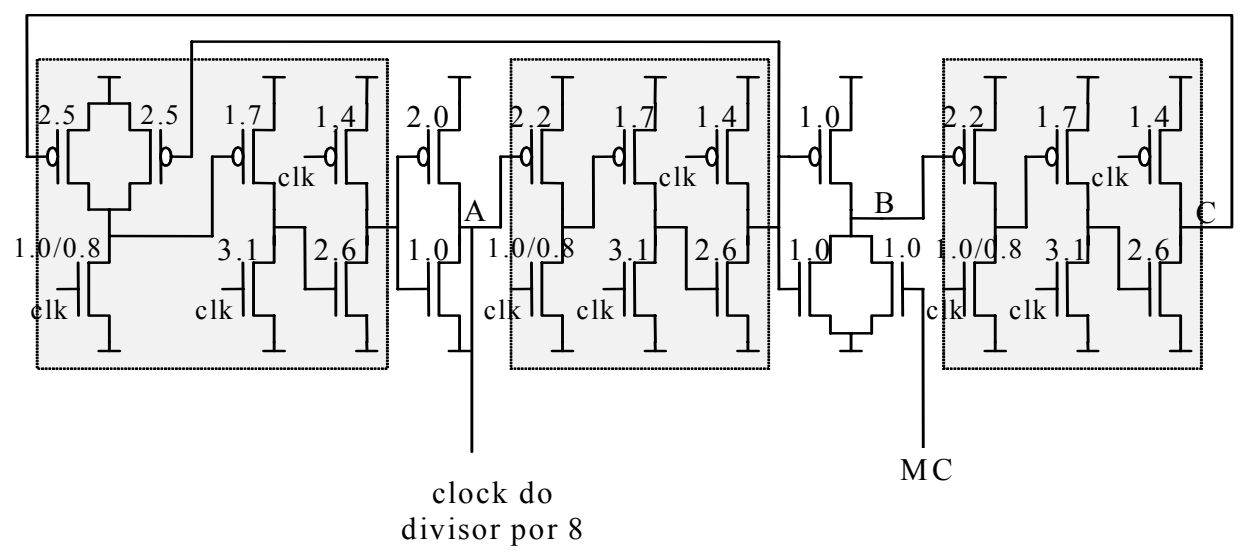

Figura 26. Diagrama esquemático dos transistores da implementação com três $D-F F$ s no contador síncrono. As dimensões de $\mathrm{W}$ em $\mu \mathrm{m}$ dos transistores estão indicadas na figura. A dimensão L é a mínima da tecnologia para todos os transistores, $\mathrm{L}=0,35 \mu \mathrm{m}$, exceção nos transistores onde aparecem duas dimensões.

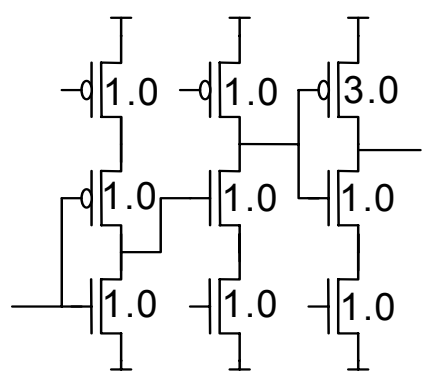

Figura 27. Configuração dos $D-F F \mathrm{~s}$ TSPC sensíveis à borda subida do clock. As dimensões de $\mathrm{W}$ em $\mu \mathrm{m}$ dos transistores estão indicadas na figura. A dimensão $\mathrm{L}$ é a mínima da tecnologia para todos os transistores $(\mathrm{L}=0,35$ $\mu \mathrm{m})$. 
3.5.2 Dual-Modulus Prescaler 32/33 (versão com 2 D-FFs)

Este Prescaler é uma modificação de [Le04] e difere do anterior por possuir somente dois $D-F F$ s no contador síncrono, figura 28, dividindo o sinal de clock por 2 ou por 3 , dependendo do valor lógico do sinal no terminal MC. O contador síncrono foi projetado de forma a trabalhar como uma máquina de estados que obedece ao diagrama de estados da figura 29a. Esta máquina tem como entrada o sinal MC e saída o sinal B, o bit mais a direita dos dois bits que nomeiam os estados.

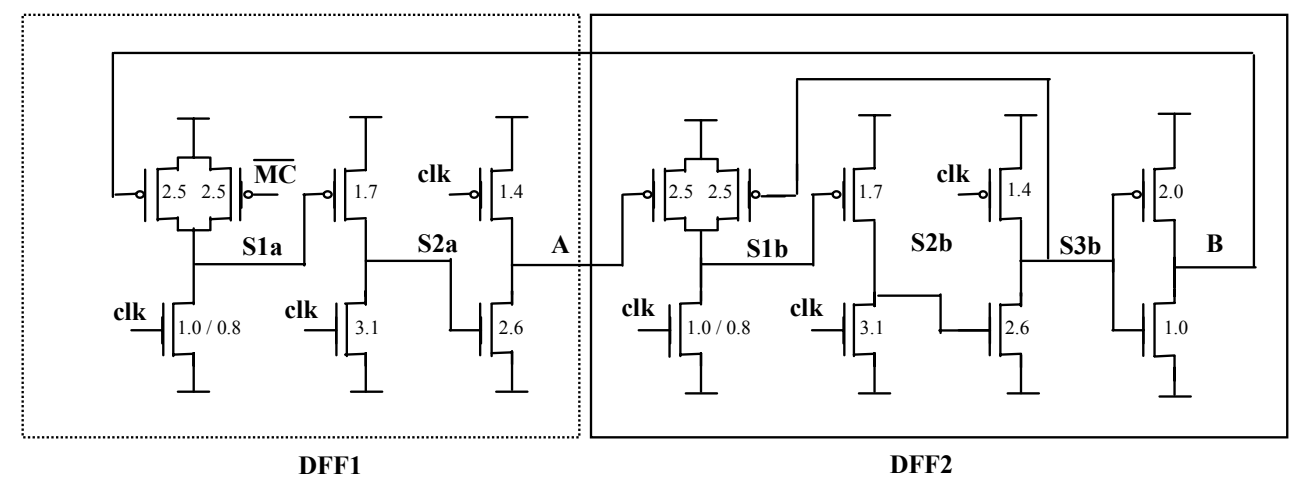

Figura 28. Diagrama esquemático de transistores da implementação com dois $D-F F$ s do contador síncrono. As dimensões de $\mathrm{W}$ dos transistores estão indicadas na figura. A dimensão L é a mínima da tecnologia

Este contador, quando a entrada MC tiver o nível lógico ALTO (1), passará pelos seguintes estados: $10 \rightarrow 11 \rightarrow 10$. Neste caso o circuito síncrono está dividindo o clock por 2 . Por outro lado, quando a entrada MC tiver o nível lógico BAIXO (0), o contador passará pelos seguintes estados: $10 \rightarrow 01 \rightarrow 11 \rightarrow 10$. Agora o circuito síncrono está dividindo o clock por 3. É no estado 10 que será definida qual divisão, por 2 ou 3, o circuito realizará. Portanto, o sinal MC deve atingir o nível lógico correto antes da borda de subida do clock que marca a saída do estado 10. Isso garante a seqüência correta de estados. A figura $29 \mathrm{~b}$ mostra os sinais MC e B no tempo.

Para o contador síncrono desta implementação, utilizaram-se os mesmos $D-F F$ sensíveis a borda de descida do contador síncrono da versão com 3 D-FFs (mesmas topologia e dimensões).

O contador assíncrono, por sua vez, utiliza quatro $D-F F$ s sensíveis a borda de descida. Novamente, por trabalhar com freqüências menores, foram utilizados $D-F F S$ da técnica TSPC, figura 30, com dimensões quase mínimas. Como a divisão realizada pelo contador síncrono, por 2 ou 3, é inferior a realizada anteriormente, a velocidade do sinal de entrada dos 
$D-F F$ s do circuito assíncrono é superior, causando degradação do nível do sinal de suas saídas. Para evitar qualquer problema, utilizaram-se inversores nas saídas dos $D-F F$ s e, para a geração do sinal $\mathrm{MC}$, utilizou-se uma porta $A N D$ em vez de uma porta $N A N D$. Essas mudanças influenciam na máxima velocidade de operação do Prescaler.

O presente Prescaler também foi todo projetado na tecnologia AMS CMOS de 0,35 $\mu \mathrm{m}$.

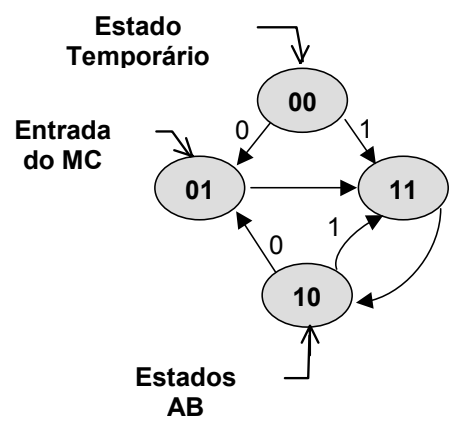

a)

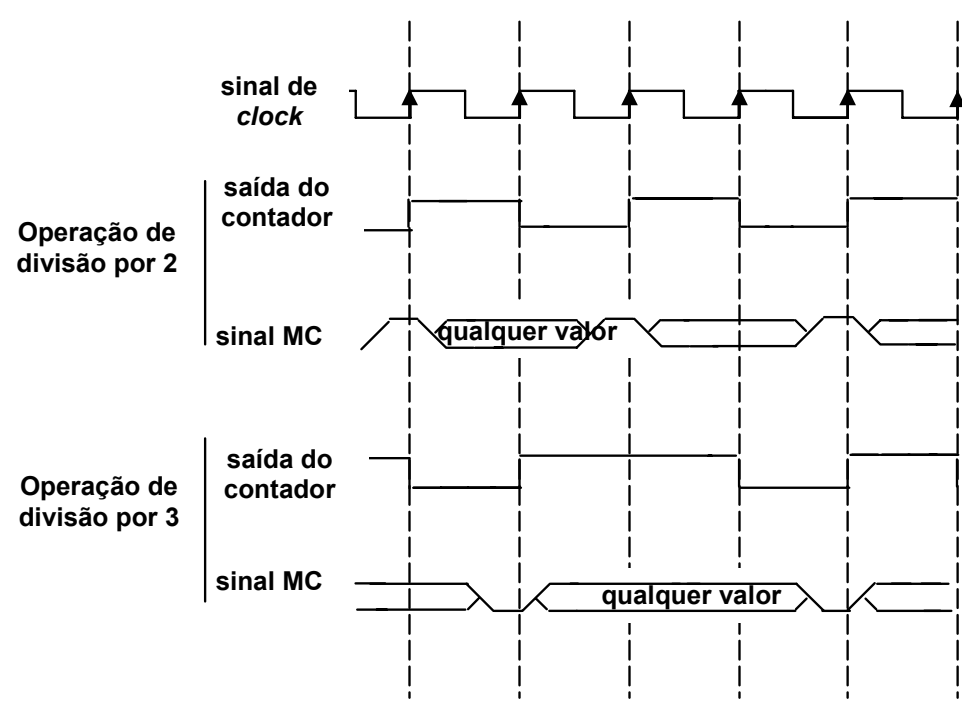

b)

Figura 29. Máquina de estados para o contador síncrono: a), diagrama de estados e b), sinais no tempo (versão com $2 D-F F \mathrm{~s})$.

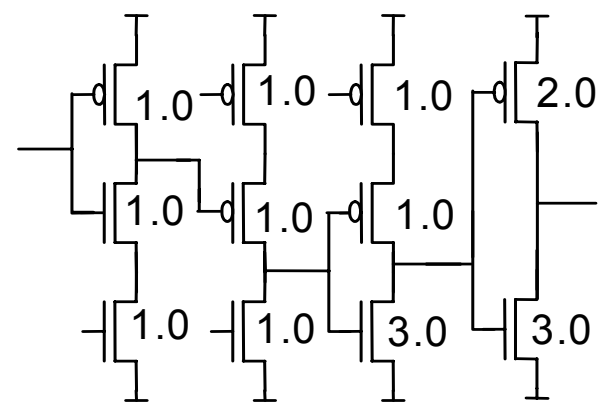

Figura 30. Configuração dos $D-F F$ S TSPC sensíveis à descida de clock para o circuito assíncrono. As dimensões de $\mathrm{W}$ em $\mu \mathrm{m}$ dos transistores estão indicadas na figura. A dimensão L é a mínima da tecnologia para todos os transistores $(\mathrm{L}=0,35 \mu \mathrm{m})$.

\subsubsection{Dual-Modulus Prescaler 32/33 (versão com $3 D-F F$ s e clock dividido por 2)}

$\mathrm{Na}$ terceira versão do Prescaler [Mi04a] [Mi04b], o contador síncrono é obtido através de modificações do contador anterior de $3 D-F F$ s. São utilizadas aqui os fo-data chains para gerar o sinal desejado (clock dividido por 4 ou 5). Estas data chains, como visto 
no capítulo 2, apresentam suas saídas em alta impedância quando em fase de holding. Utilizou-se essa característica para dobrar a velocidade da saída do contador síncrono.

O contador síncrono foi projetado de forma a trabalhar como uma máquina de estados que obedece ao diagrama de estados da figura 31a. Esta máquina tem como entrada o sinal MC e utilizaremos como saída a combinação do sinal A, o bit mais a esquerda dos três bits que nomeiam o estado, com o sinal B, o segundo bit mais a esquerda (A quando o clock for ALTO e B quando o clock for BAIXO). Observemos que nesta máquina o clock tem freqüência $f_{\text {clock }}$ igual a metade da freqüência do sinal que desejamos dividir por 4 ou 5 .

Este contador, quando a entrada MC tiver o nível lógico ALTO (1), percorre a seqüência de estados $000 \rightarrow 110 \rightarrow 000$ ou a seqüência de estados $100 \rightarrow 010 \rightarrow 100$. Teremos então na saída a seqüência de sinais $\underline{00110011} \underline{0011}$... ou $1 \underline{001100110011}$..., cada valor aparecendo com uma taxa duas vezes menor do que a do clock do Prescaler. A saída, em qualquer um dos casos, terá freqüência igual a $2 f_{\text {clock }} / 4$, ou seja estaremos realizando a divisão por 4. Por outro lado, quando a entrada MC tiver o nível lógico BAIXO (0), o contador síncrono percorre a seqüência de estados $000 \rightarrow 110 \rightarrow 001 \rightarrow 010 \rightarrow 101 \rightarrow 000$. Teremos

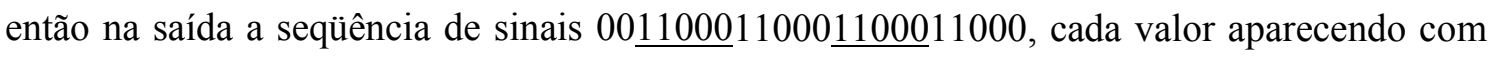
uma taxa duas vezes menor do que a do clock do Prescaler. Teremos na saída, portanto, um sinal com freqüência igual a $2 f_{\text {clock }} / 5$, ou seja estaremos realizando a divisão por 5 . A figura $31 \mathrm{~b}$ mostra os sinais MC, A e B e a saída do contador no tempo.

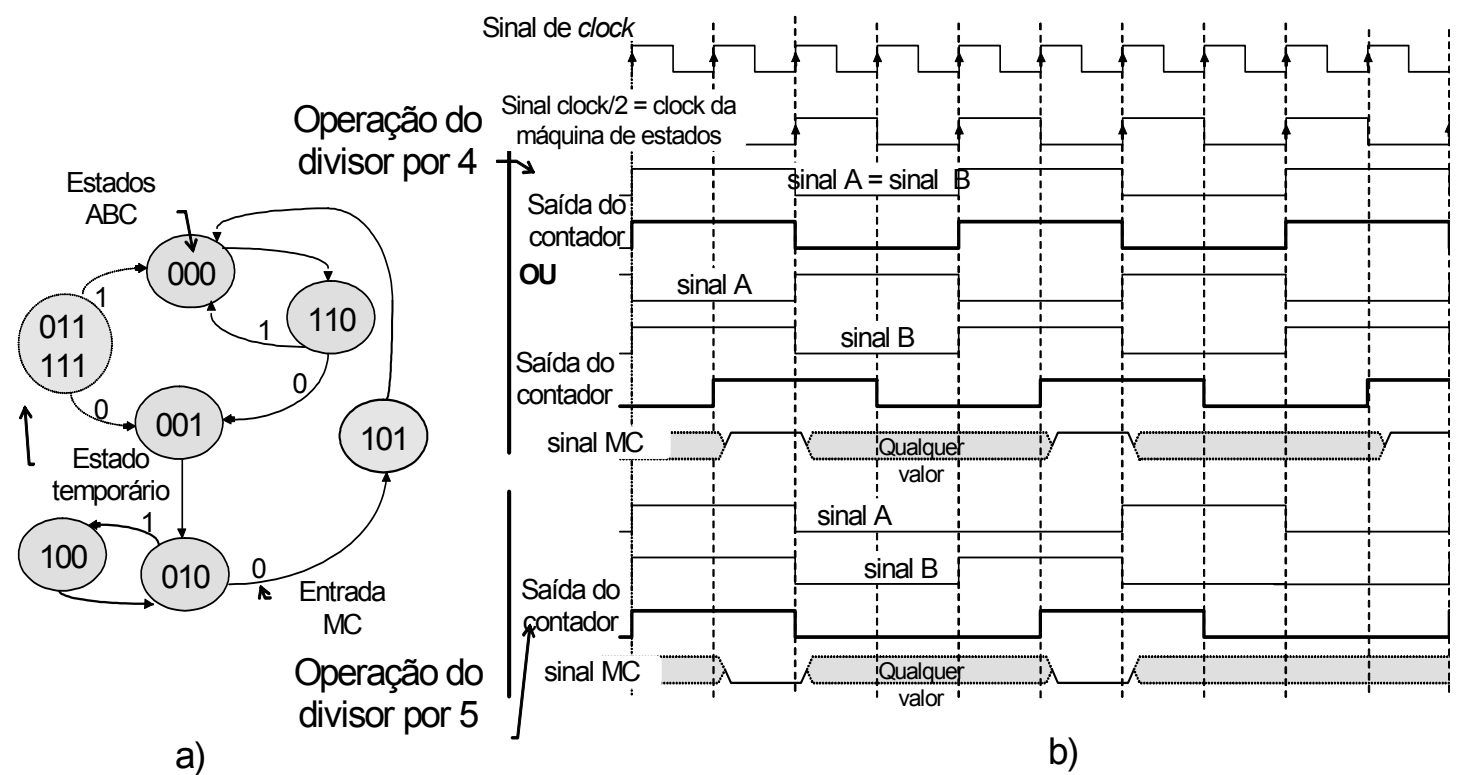

Figura 31. Máquina de estados para o contador síncrono: a), diagrama de estados e b), sinais no tempo (versão com $3 D-F F$ s e clock dividido por 2). 
A implementação do contador síncrono é mostrada na figura 32 e utiliza $D-F F s$ sensíveis a borda de subida iguais ao da figura 27. As portas lógicas necessárias foram embutidas dentro dos próprios $D-F F s$, primeiro bloco do $D-F F$, mas são construídas como um bloco do tipo N-MOS like. Para a escolha das dimensões dos transistores temos:

- para os dois blocos a direita de cada $D-F F$ foram utilizadas as mesmas dimensões mostradas no circuito da figura 27 ;

- para os transistores PMOS dos blocos lógicos embutidos foram utilizadas dimensões próximas da mínima da tecnologia;

- para os transistores NMOS dos blocos lógicos embutidos se determinou, a partir das dimensões dos transistores PMOS, as dimensões que garantem o funcionamento do $\mathrm{N}$ MOS like.

A configuração do contador assíncrono deste Prescaler é idêntica a do contador assíncrono da versão com $3 D-F F$ s.

Para determinação da borda de funcionamento dos $D-F F \mathrm{~s}$ e do circuito para gerar o sinal MC levaram-se em conta considerações semelhantes as utilizadas anteriormente, a saber, em que situação o sinal MC é gerado com maior margem de tempo.

O projeto desta versão do Prescaler também foi na tecnologia AMS CMOS de 0,35 $\mu \mathrm{m}$.

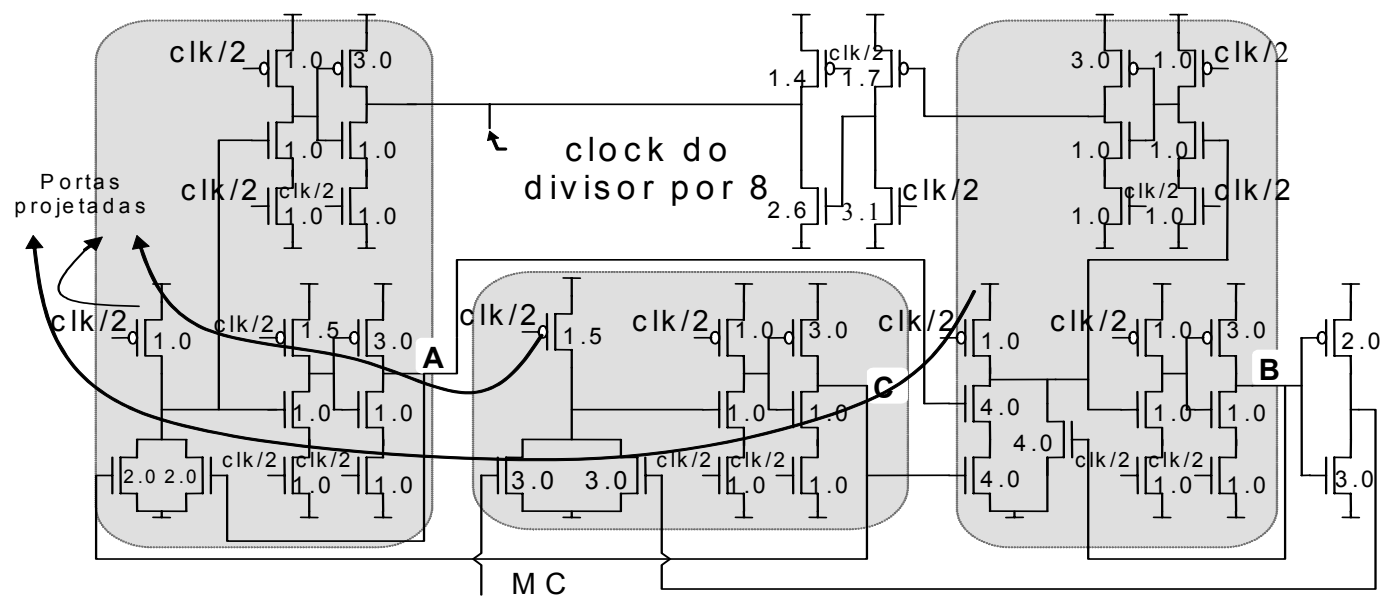

Figura 32. Diagrama esquemático dos transistores da implementação com três $D-F F \mathrm{~s}$ e clock dividido por dois no contador síncrono. As dimensões de $\mathrm{W}$ em $\mu \mathrm{m}$ dos transistores estão indicadas na figura. A dimensão L é a mínima da tecnologia para todos os transistores, $L=0,35 \mu \mathrm{m}$, exceção nos transistores onde aparecem duas dimensões. 


\section{PROJETO E SIMULAÇÕES}

Concluída a etapa de estudo e dimensionamento das arquiteturas de Prescaler escolhidas para implementação, passamos a etapa de desenho do layout e simulações elétricas. Estas etapas foram realizadas utilizando dados da tecnologia CMOS 0,35 $\mu \mathrm{m}$ da foundry AustriaMicrosystems (AMS) [Au03a] [Au03b].

\subsection{Projeto dos circuitos Dual-Modulus Prescaler}

As figuras 33, 34 e 35 mostram os diagramas esquemáticos, com as dimensões de todos os transistores, das três versões do circuito Dual-Modulus Prescaler. A figura 36 mostras os layouts das três versões do circuito Dual-Modulus Prescaler, com as dimensões de cada um deles. Esses layouts foram feitos com o software IC Station-Mentor. O Circuito da figura 33, Prescaler com $3 \mathrm{D}-\mathrm{FFs}$, foi desenhado em grande parte pelo Eng. Angel Maria Gómez Argüello, pois foi utilizado no Sintetizador de Freqüências por ele desenvolvido [Ar03].

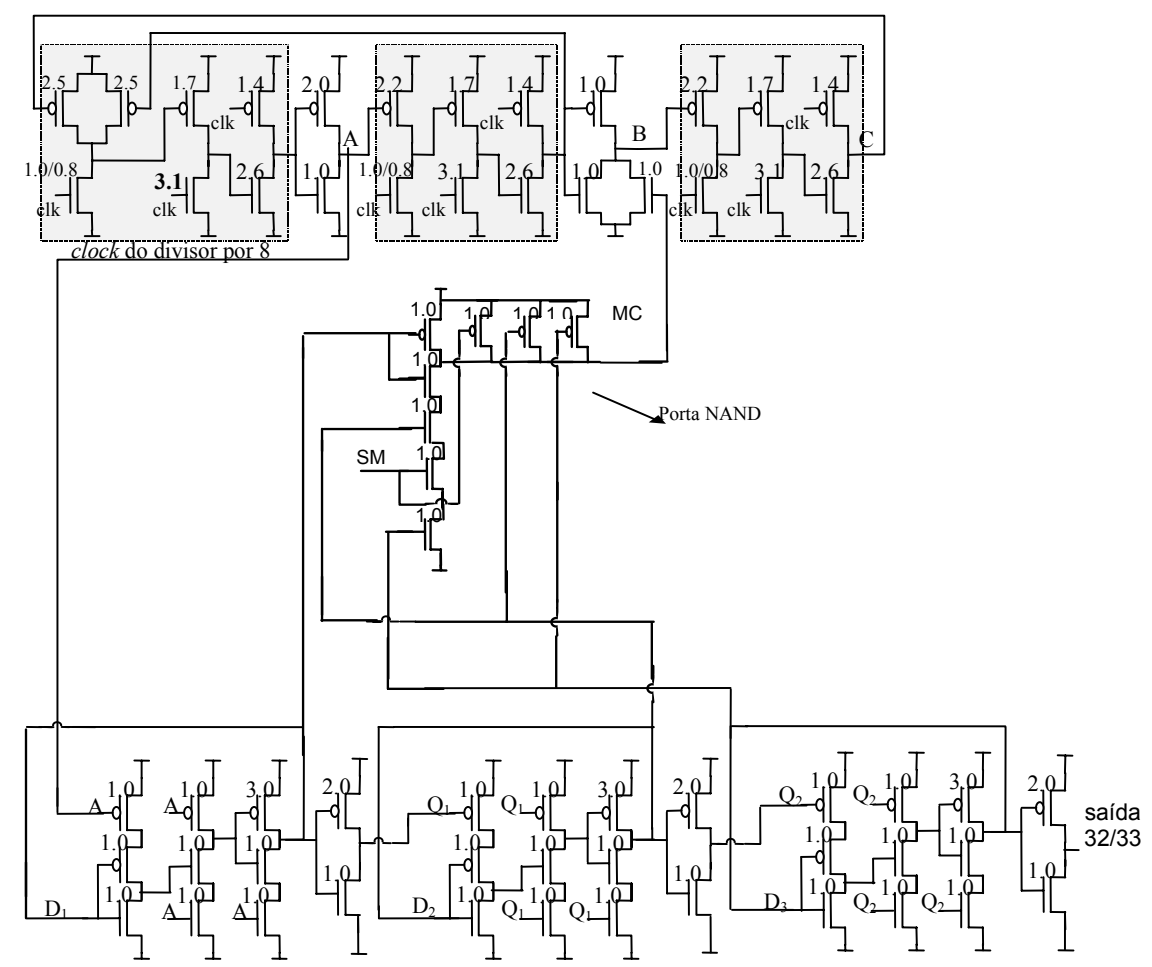

Figura 33. Diagrama esquemático completo do Dual-Modulus Prescaler 32/33 (versão com 3 D-FFs). 


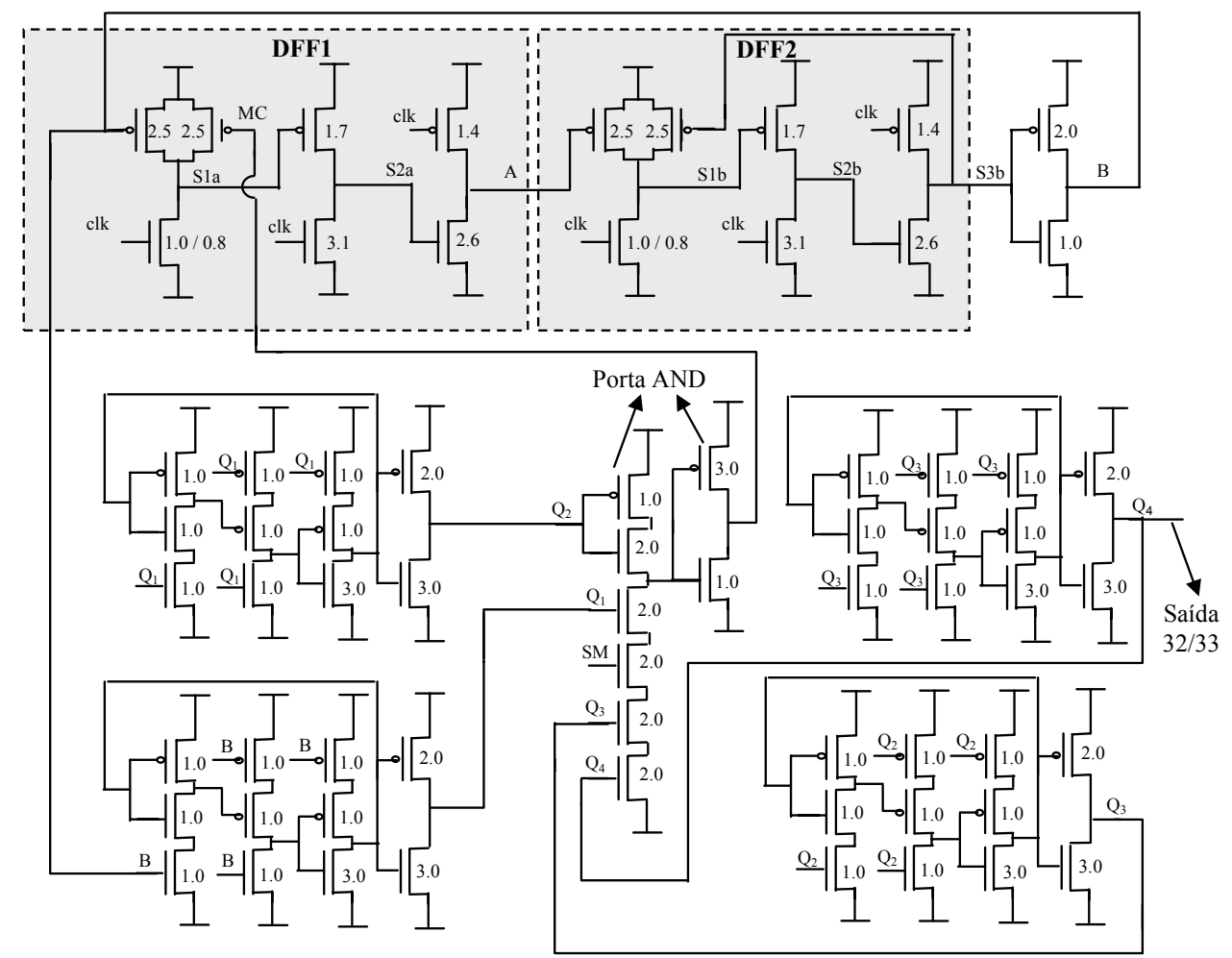

Figura 34. Diagrama esquemático completo do Dual-Modulus Prescaler 32/33 (versão com 2 D-FFs).

\subsection{Projeto dos Buffers}

Para obtermos nas entradas (clock), mesmo com altas freqüências, e nas saídas (clock/32), mesmo com grande carga capacitiva, sinais com excursão satisfatória nos três Prescalers, foram utilizados buffers para as entradas e saídas de sinais. Os buffers consistem de cadeias de inversores com um fator de aumento fixo entre eles. No projeto do buffer de entrada, foi considerado um valor de capacitância de carga igual a 60 fF, devido ao Prescaler, mais as capacitâncias da linha do clock (conexão entre o Pad de entrada e os terminais de clock dos Prescalers). Como não se sabia ao certo o valor das capacitâncias da linha, se consideraram três valores para a capacitância de carga, 60 fF, 100fF e $200 \mathrm{fF}$. Com a capacitância definida podemos determinar, por meio de cálculo, o número de estágios e o fator de aumento dos inversores utilizados nos buffers. Para se obter a maior velocidade de operação, a relação abaixo, que relaciona o fator de aumento dos buffers com número de inversores, deve ser obedecida (relação proposta e utilizada em trabalhos realizados no LSI mas não publicada):

$$
\mathrm{X}^{\mathrm{n}}=\mathrm{C}_{\mathrm{L}} /\left[\mathrm{C}_{\mathrm{OX}}\left(\mathrm{W}_{\mathrm{P}}+\mathrm{W}_{\mathrm{N}}\right) \mathrm{L}_{\mathrm{ef}}\right]
$$


onde:

$\mathrm{C}_{\mathrm{OX}}$ - É a capacitância do óxido de porta pela área e que é igual a $4,54 \mathrm{fF} / \mu \mathrm{m}^{2}$;

$\mathrm{W}_{\mathrm{P}}$ - É a largura de canal do transistor PMOS do primeiro inversor do buffer;

$\mathrm{W}_{\mathrm{N}}$ - É a largura de canal do transistor NMOS do primeiro inversor do buffer;

$\mathrm{L}_{\mathrm{EF}}$ - É o comprimento do canal dos transistores MOS, igual a $0,40 \mu \mathrm{m}$ (comprimento efetivo);

$\mathrm{C}_{\mathrm{L}}-$ É a capacitância da entrada de um Prescalers;

$\mathrm{X}$ - É o fator de aumento dos inversores no buffer;

n-É o número de inversores utilizados no buffer.

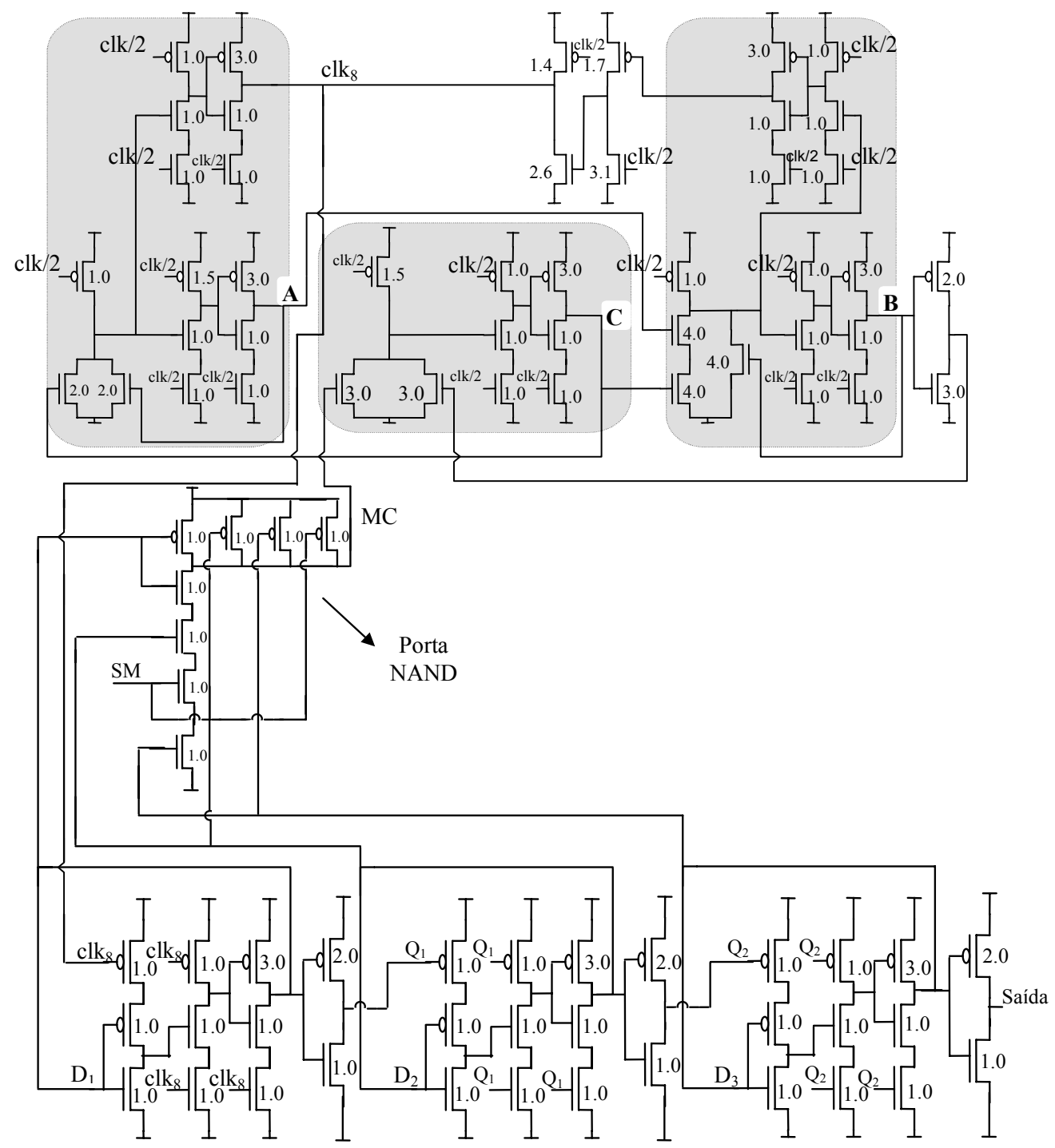

Figura 35. Diagrama esquemático completo do Dual-Modulus Prescaler 32/33 (versão com $3 D-F F$ s). 


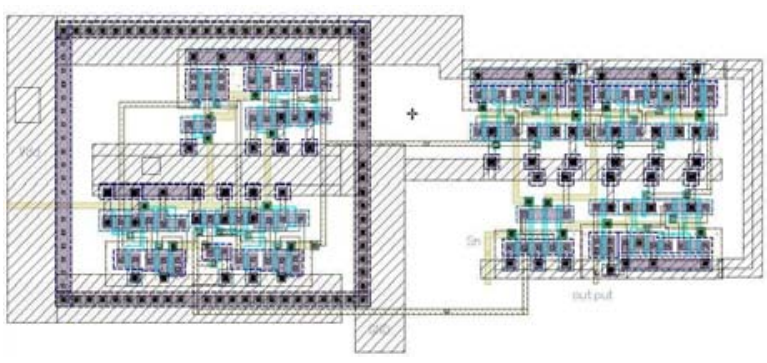

a)

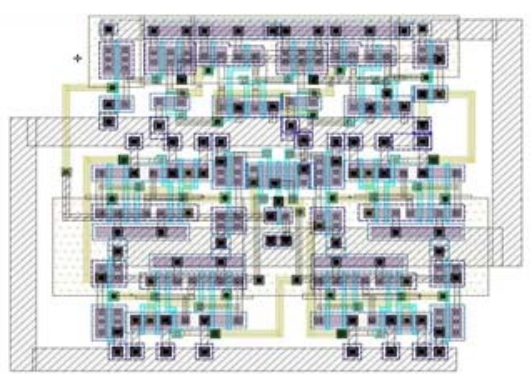

b)

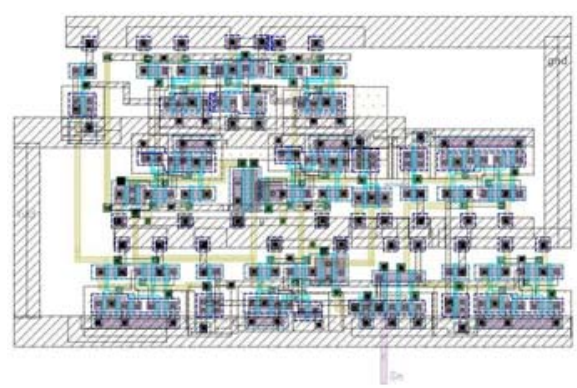

c)

Figura 36. Layout dos circuitos Dual-Modulus Prescaler 32/33: a) versão com $3 D-F F$ s (dimensões de $82 \mu \mathrm{m} x$ $35 \mu \mathrm{m})$; b) versão com $2 D-F F$ s (dimensões de $47 \mu \mathrm{m}$ x $36 \mu \mathrm{m}$.); c) versão com $3 D-F F$ s e clock dividido por 2 (dimensões de $65 \mu \mathrm{m} \times 38 \mu \mathrm{m}$ ).

Vamos fixar a soma $\left(\mathrm{W}_{\mathrm{P}}+\mathrm{W}_{\mathrm{N}}\right)$ em $12 \mu \mathrm{m}$, o que implica em um primeiro inversor de pequenas dimensões (mas não mínimas). Podemos então determinar valores de $\mathrm{X}$ para alguns valores distintos de $\mathrm{n}$ (tabela 2).

Tabela 2. Valor do número de estágios e do fator de aumento para o buffer.

\begin{tabular}{|c|c|c|c|}
\hline $\mathbf{n}$ & $\mathbf{X}$ & $\mathbf{X}$ & $\mathbf{X}$ \\
$\left(\mathbf{C}_{\mathbf{L}}=\mathbf{6 0} \mathbf{f F}\right)$ & $\left(\mathbf{C}_{\mathbf{L}}=\mathbf{1 0 0} \mathbf{f F}\right)$ & $\left(\mathbf{C}_{\mathbf{L}}=\mathbf{2 0 0} \mathbf{f F}\right)$ \\
\hline 1 & 2,90 & 7,25 & 9,66 \\
\hline 2 & 1,70 & 2,69 & 3,11 \\
\hline 3 & 1,43 & 1,93 & 2,13 \\
\hline $\mathbf{4}$ & 1,30 & $\mathbf{1 , 6 4}$ & $\mathbf{1 , 7 6}$ \\
\hline 5 & 1,24 & 1,48 & 1,57 \\
\hline
\end{tabular}

Das possibilidades apresentadas na tabela acima, o buffer com $\mathrm{n}=2$ e $\mathrm{X}=1,7$ apresentou o melhor desempenho, sinal com melhores características de amplitude, nas simulações elétricas para carga de $60 \mathrm{fF}$. Para cargas de $100 \mathrm{fF}$ e de $200 \mathrm{fF}$, por outro lado, o sinal com maior excursão (aproximadamente de 0,05 à 3,3 V) e melhor forma de onda foi obtido com um buffer de 4 inversores $(\mathrm{n}=4)$. A figura 37 apresenta as forma de onda na saída 
do buffer com $\mathrm{n}=4$ e $\mathrm{X}=1,7$ e sinal de entrada em $3 \mathrm{GHz}$ (simulação com parâmetros típicos). Este foi o buffer utilizado aqui, sendo as dimensões dos transistores do primeiro estágio iguais a $\mathrm{W}_{\mathrm{N}}=4 \mu \mathrm{m}$ e $\mathrm{W}_{\mathrm{P}}=8 \mu \mathrm{m}\left(\mathrm{W}_{\mathrm{N}}=2 \mathrm{~W}_{\mathrm{P}}\right)$.

Observemos que o ganho de 1,7 utilizado está longe do 2,7 normalmente empregado para minimizar o atraso. Lembremos que a função dos buffers nesse projeto é somente de melhorar a forma de onda do sinal de clock, ou seja, reduzir atenuações.

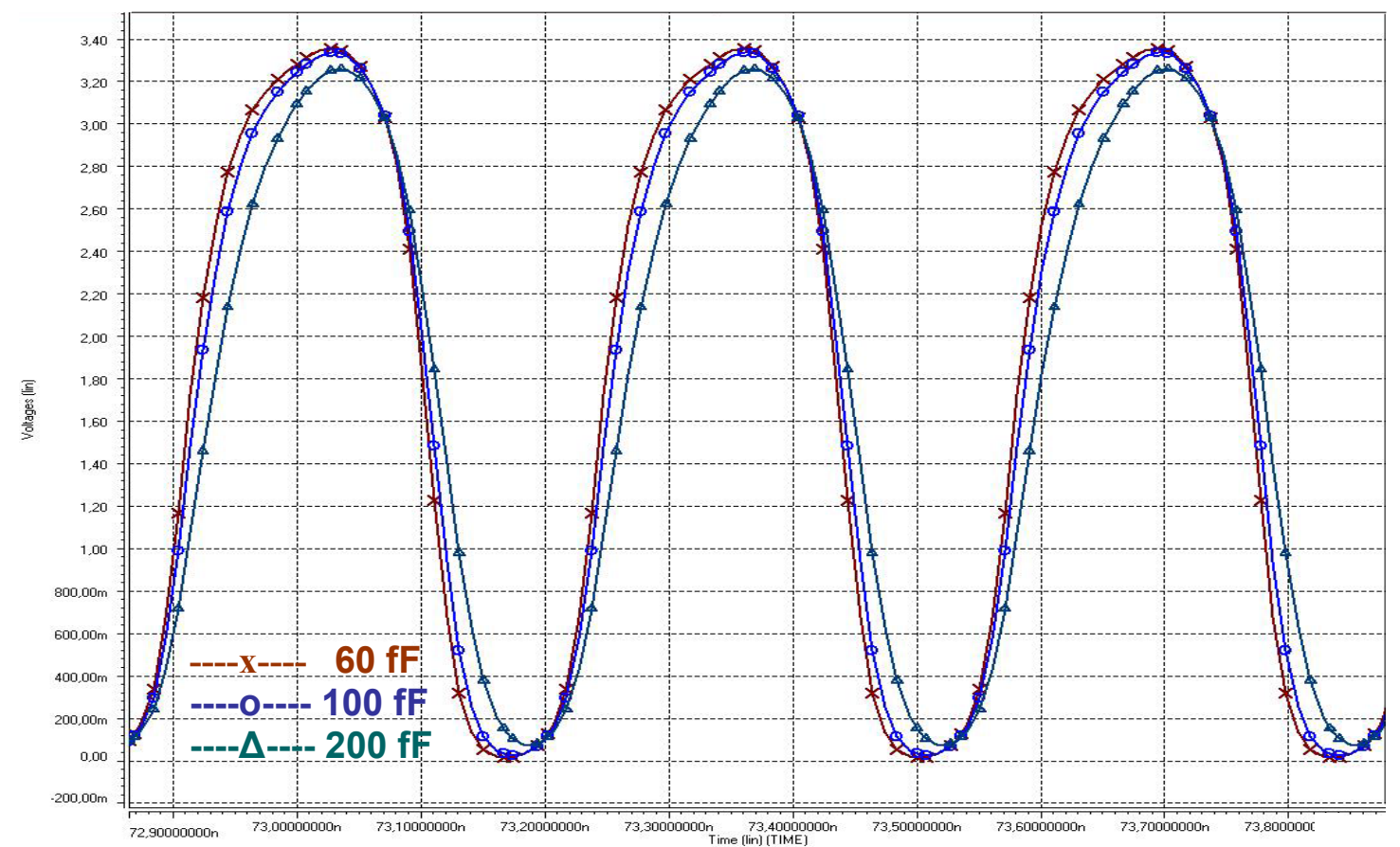

Figura 37. Simulações elétricas do buffer de entrada com valores distintos de capacitâncias de saída. . O buffer tem $n=4$ e $X=1,7$ e o sinal de entrada esta na freqüência de $3 \mathrm{GHz}$.

No projeto do buffer de saída utilizou-se o mesmo procedimento para determinação da melhor configuração, porém com capacitâncias de carga de $5 \mathrm{pF}, 10 \mathrm{pF}$ e $15 \mathrm{pF}$, figura 38 (a capacitância de saída real é algo difícil de se estimar). O buffer que teve melhor desempenho apresenta fator de aumento de $X=2,23$ e número de estágios de $n=4$. As dimensões dos transistores do primeiro estágio são $\mathrm{W}_{\mathrm{N}}=4 \mu \mathrm{m}$ e $\mathrm{W}_{\mathrm{P}}=8 \mu \mathrm{m}$. A figura 38 apresenta as forma de onda na saída deste buffer para sinal de entrada do buffer na freqüência de $125 \mathrm{MHz}$ (maior freqüência esperada nos sinais provenientes das saídas dos Prescalers). O layout dos buffers de entrada e saída estão mostrados na figura 39. 


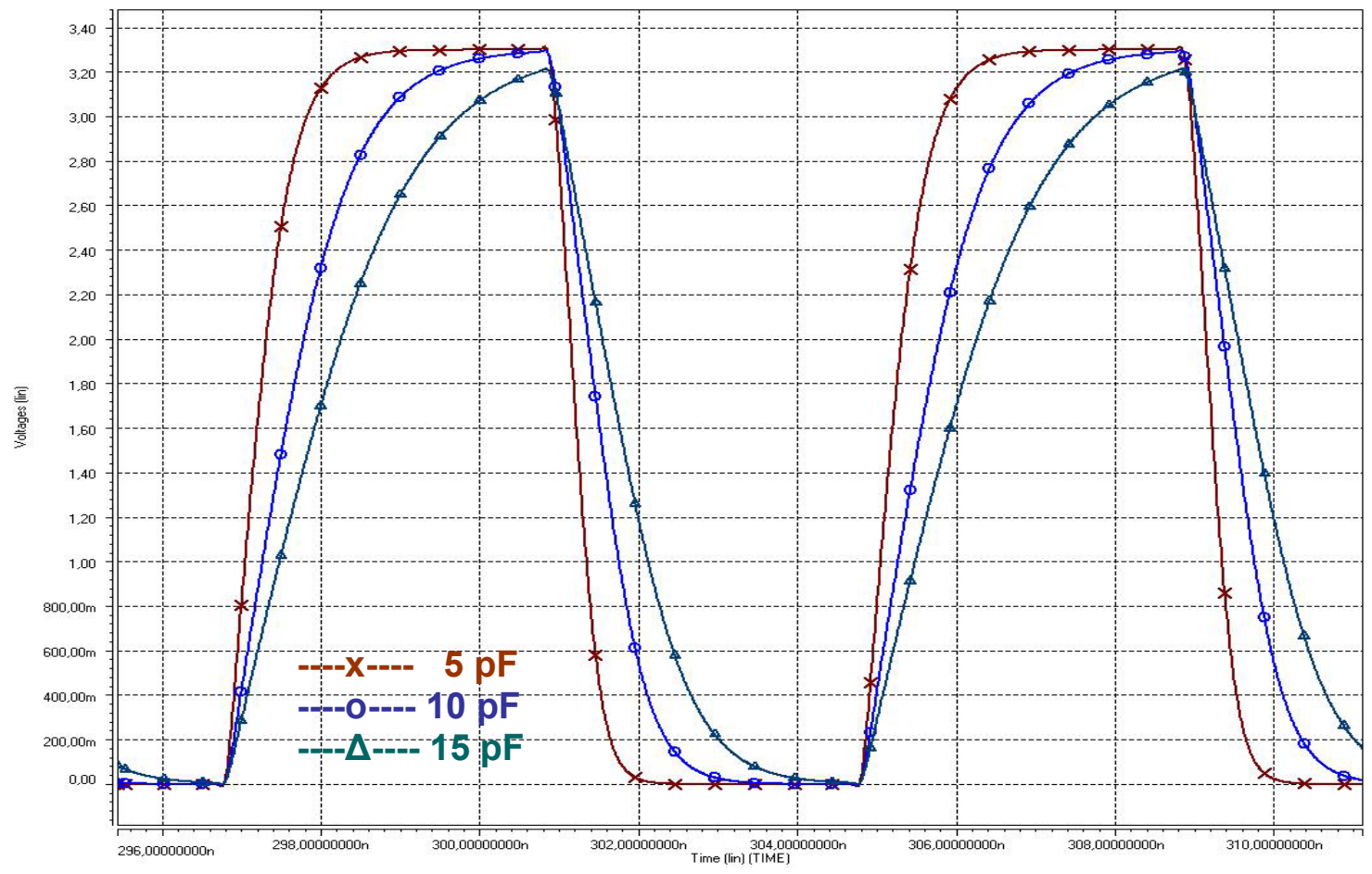

Figura 38. Simulação elétrica do buffer de saída com valores distintos de capacitâncias de saída. O buffer tem $\mathrm{n}$ $=4 \mathrm{e} \mathrm{X}=2,23$ e o sinal de entrada esta na freqüência de $125 \mathrm{MHz}$.

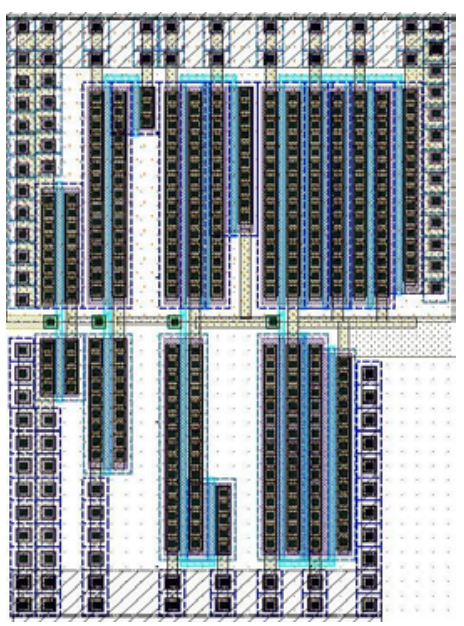

a)

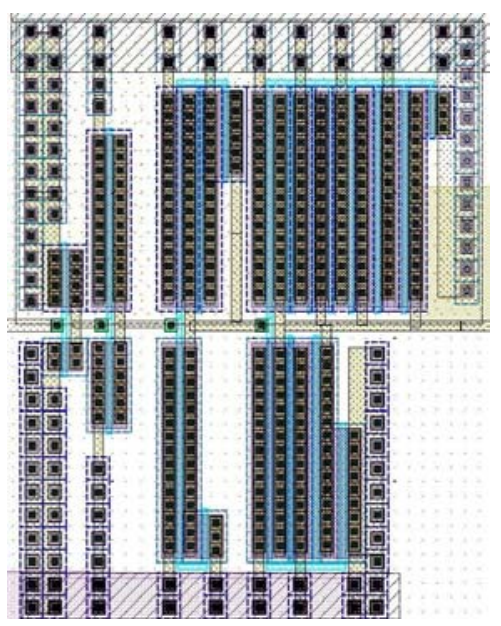

b)

Figura 39. Layout dos buffers: a), para o buffer de entrada e b), para o buffer de saída. 


\subsection{Layout do C.I. completo para teste}

Após a conclusão dos layouts dos Prescalers e seus respectivos buffers desenhou-se a estrutura completa do C.I. para as os testes, figura 40. O C.I. apresenta além dos circuitos citados anteriormente, as seguintes estruturas:

- $\quad$ Pads de sinal para clock do Prescaler (micropontas de prova de alta freqüência do tipo terra-sinal-terra, GSG);

- $\quad$ Pads de saída para cada Prescaler (micropontas de prova de alta freqüência, GSG);

- $\quad$ Pads de $\mathrm{V}_{\mathrm{SS}}($ ground comum);

- $\quad$ Pads de $\mathrm{V}_{\mathrm{DD}}$ distintos para cada Prescaler;

- $\quad$ Pad de $\mathrm{V}_{\mathrm{DD}}$ separado para os buffers;

- $\quad$ Pad para a entrada SM dos Prescalers;

- Seis resistores de silício policristalino no valor de $300 \Omega$ para casamento de impedância na entrada do sinal de clock.

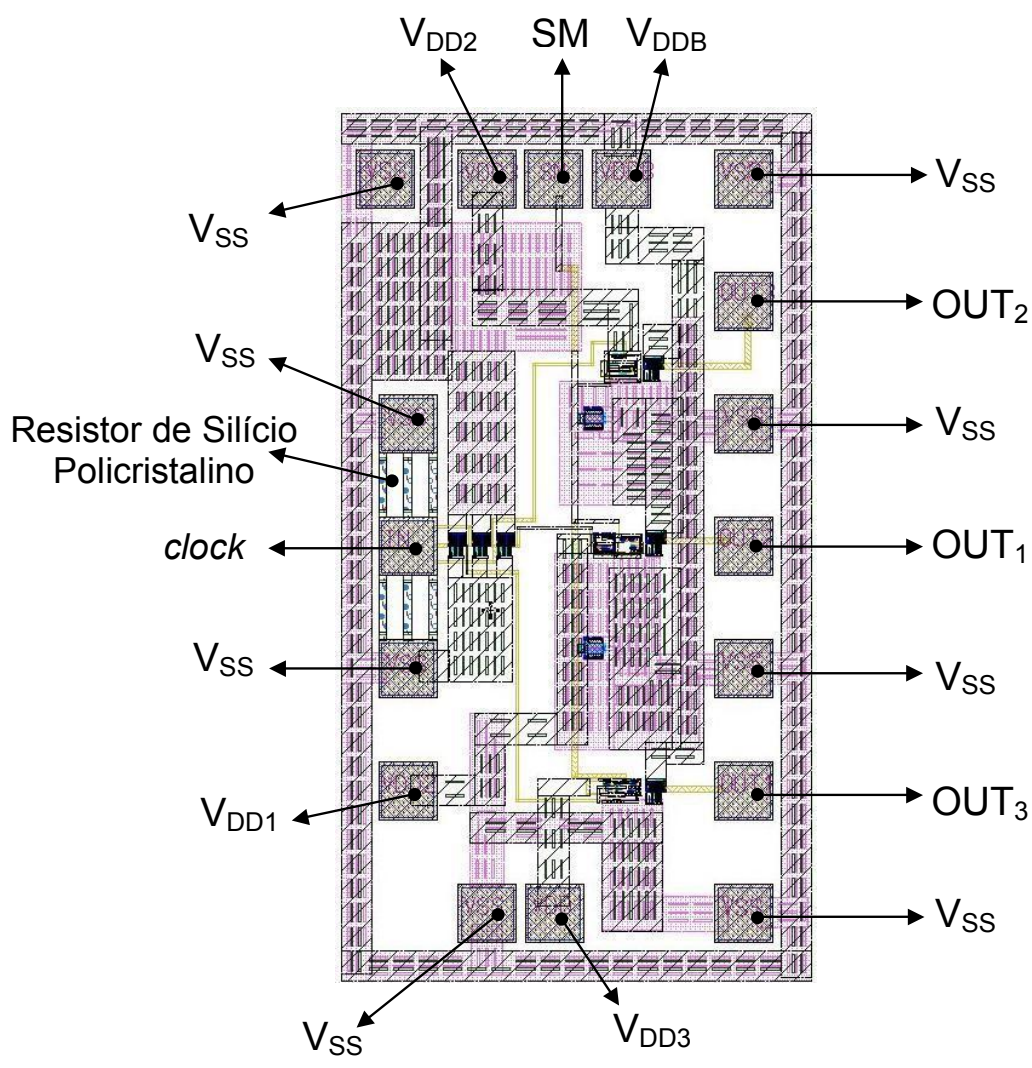

Figura 40. Layout do C.I. completo e seus respectivos Pads com dimensões de $1420 \mu \mathrm{m}$ X $769 \mu \mathrm{m}$. 
Na tecnologia disponível a camada de silício policristalino tem resistividade igual a 50 $\Omega / \square$ sqr, o que permitiu construir os resistores de $300 \Omega$ com linhas de $80 \mu \mathrm{m}$ de comprimento e $13 \mu \mathrm{m}$ de largura. Os seis resistores foram colocados em paralelo entre os Pads de entrada do clock e $\mathrm{V}_{\mathrm{SS}}$, formando uma resistência equivalente de $50 \Omega$. Esta resistência equivalente na entrada serve para o casamento da impedância com o gerador de entrada. Os resistores paralelos estão espaçados de $27,5 \mu \mathrm{m}$.

\subsection{Simulações Elétricas e Resultados}

No projeto dos circuitos Dual-Modulus Prescaler foram realizadas duas etapas de simulações elétricas: a primeira etapa, utilizando o software ELDO, foi realizada para definir as dimensões dos transistores, otimizando-os para a melhor performance dos circuitos. A figura 41 mostra formas de ondas do sinal de clock e do sinal de saída do circuito DualModulus Prescaler 32/33 (versão com 3 D-FFs e clock dividido por 2) obtidas nesta etapa.

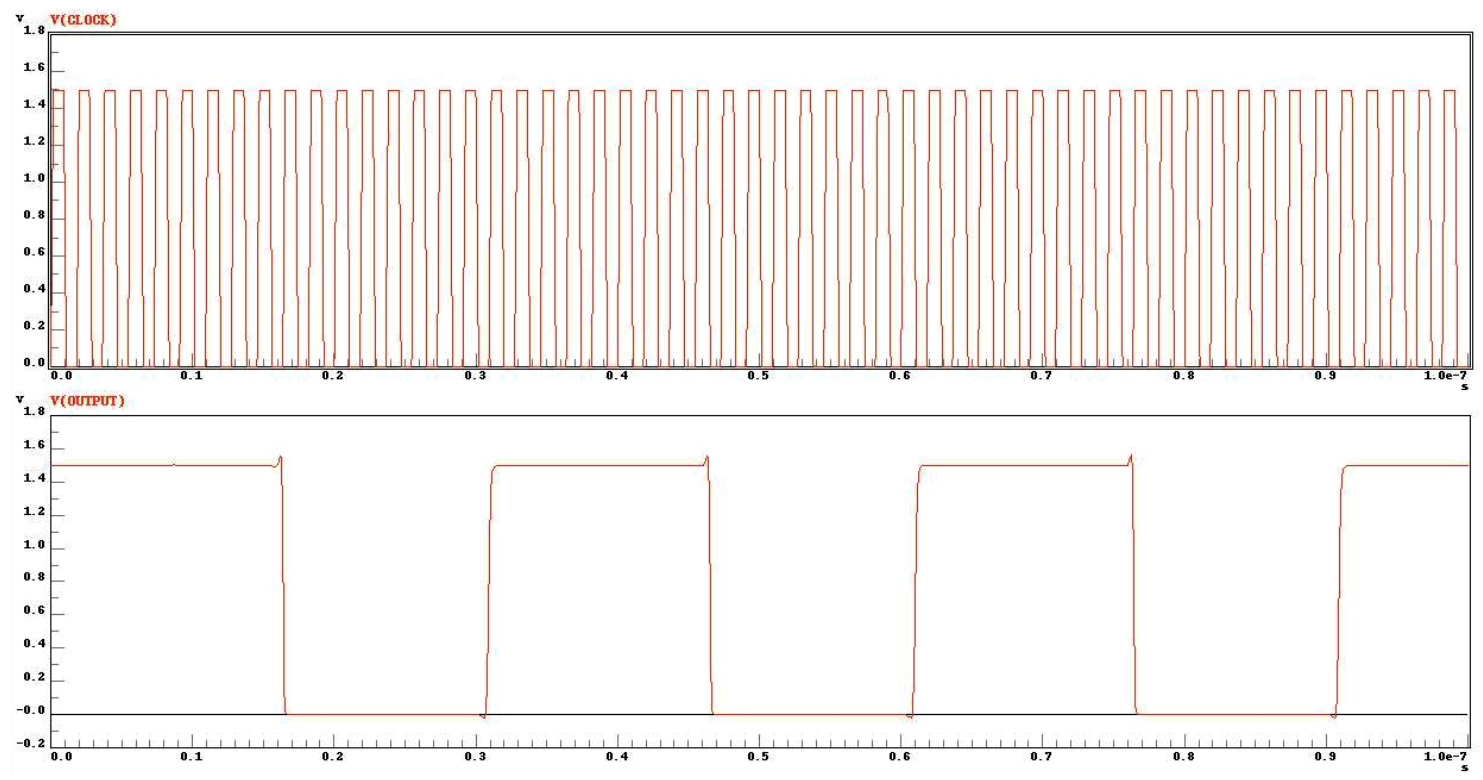

Figura 41. Sinal de saída do circuito Dual-Modulus Prescaler 32/33 simulado no ELDO (Versão com 3 D-FFs e clock dividido por 2).

A segunda etapa de simulações foi realizada com o propósito de observar o funcionamento dos circuitos pós-layout, obtendo valores de máxima freqüência de operação e consumo de potência. Neste caso foi utilizado o software HSPICE devido a problemas de licenças, o que também possibilitou a comparação dos resultados dos dois simuladores. As 
simulações foram feitas a partir de netlists obtidos da extração dos circuitos do layout (e portanto incluindo as capacitâncias parasitas).

Para esta segunda etapa de simulações, foram utilizados modelos de transistores com parâmetros típicos (Ty), slow (Sl), para caracterizar os piores desempenhos em velocidade, e fast $(\mathrm{Fa})$, para caracterizar os melhores desempenhos em velocidade. Foram medidas em cada circuito a máxima velocidade e a potência consumida para situações diversas. No anexo A encontramos as medidas feitas através das simulações para todos os modelos nos três circuitos. Alguns dos resultados estão apresentados em gráficos para observarmos e compararmos o comportamento dos três circuitos (figuras 42 a 48).

Obs: Nos gráficos abaixo, os nomes Prescaler 1, Prescaler 2, Prescaler 3 referem-se aos circuitos com $3 D-F F$ s, $2 D-F F$ s e $3 D-F F$ s com clock dividido por 2, respectivamente.

A figura 42 apresenta o gráfico da Freqüência Máxima de Operação dos circuitos em função da Tensão de Alimentação para parâmetros típicos, obtido à partir dos valores da tabela 4 do anexo A. Nele podemos observar que o Prescaler 3 leva vantagem sobre o Prescaler 1 em relação à freqüência máxima de operação, cerca de 1,3 GHz em quase todas as tensões. O Prescaler 1, por sua vez, apresenta em geral uma performance superior ao Prescaler 2, mas não com uma diferença tão acentuada (no máximo $700 \mathrm{MHz}$ mais veloz).

A figura 43 apresenta o gráfico da Potência Consumida em função da Freqüência Máxima de Operação obtida para varias tensões de alimentação e parâmetros típicos, obtido à partir dos valores da tabela 4 do anexo A . Nela podemos ver que quando é permitido variar a tensão de alimentação, o Prescaler 3, na mesma freqüência de operação dos outros circuitos, consome menor potência. Os Prescalers 1 e 2 apresentam valores muito próximos de consumo de potência para freqüências inferiores $1,5 \mathrm{GHz}$ e tensões de alimentação na faixa de 1,5 à 2V. Para valores superiores a aquela freqüência, o Prescaler 1 tem um menor consumo. 
Modelo Típico

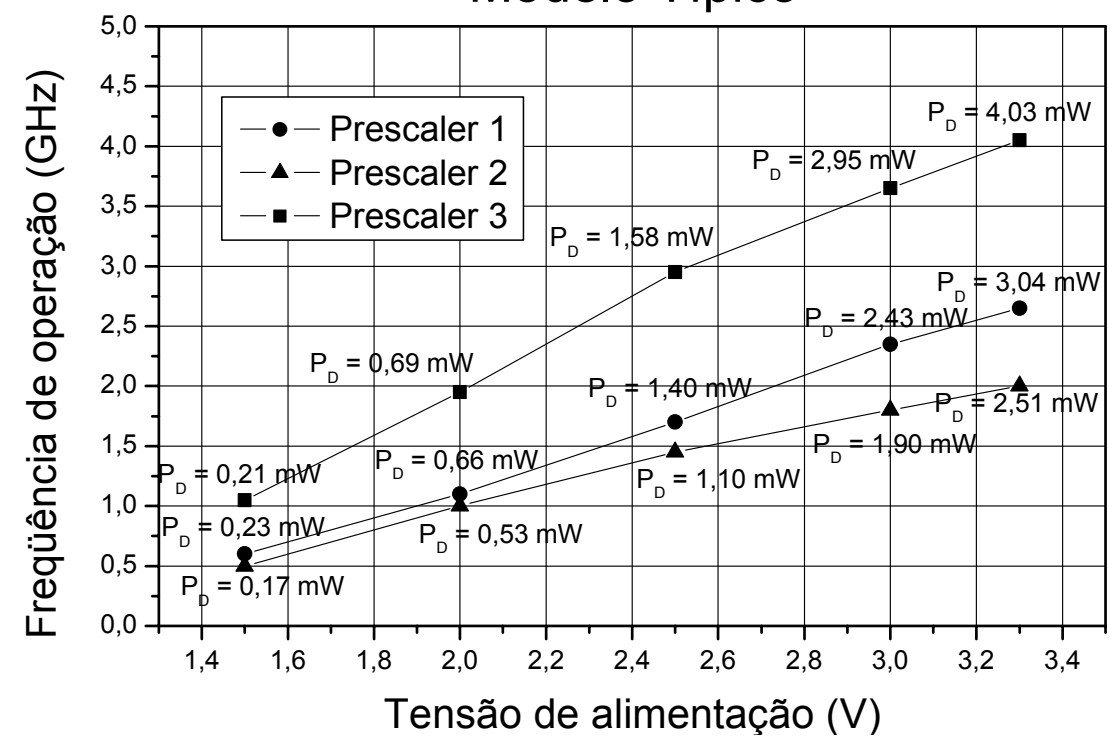

Figura 42. Gráfico da Freqüência de Operação x Tensão de Alimentação (modelo típico).

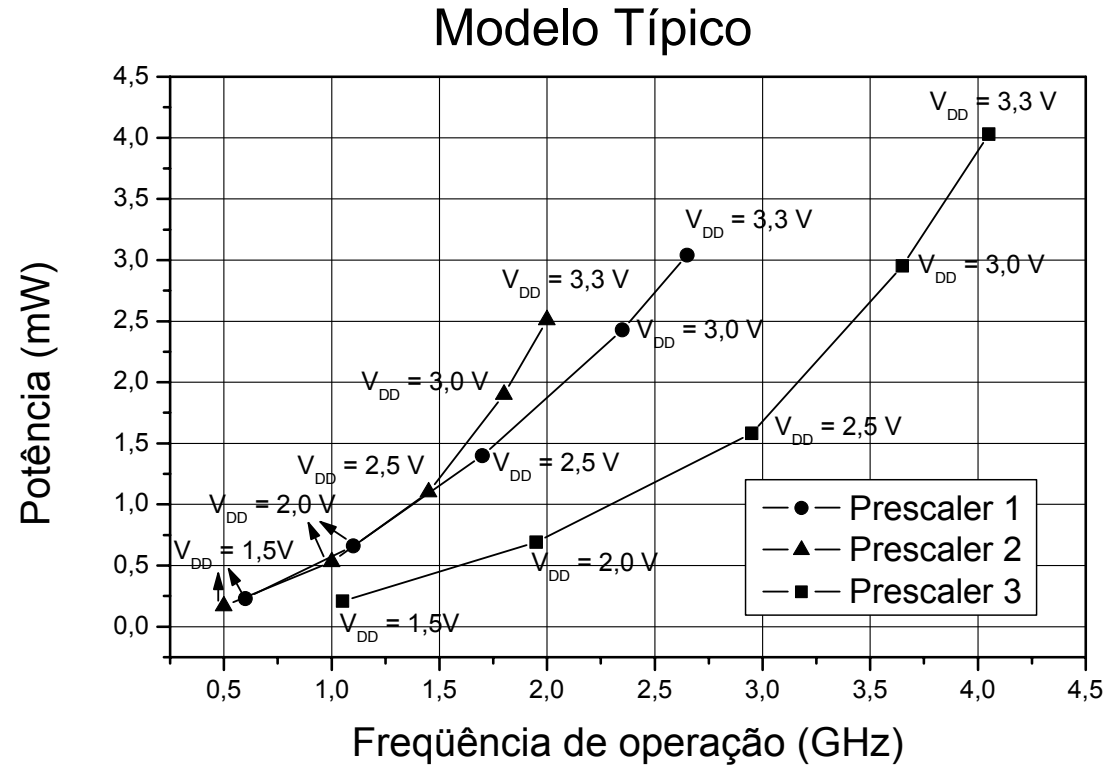

Figura 43. Gráfico da Potência x Freqüência de Operação (para diferentes valores de tensão de alimentação utilizando o modelo típico).

As figuras 44 e 45 são semelhantes as figuras 42 e 43 mas agora são utilizados os modelos slow para os transistores (obtidas à partir dos valores da tabela 5 no anexo A). No gráfico da figura 44, a vantagem que o Prescaler 3 leva sobre o Prescaler 1, em relação à freqüência máxima de operação, se reduz a $700 \mathrm{MHz}$. A diferença entre máximas freqüências de operação dos Prescalers 1 e 2 sofreu uma pequena redução. Diante destes resultados conclui-se que o desempenho do Prescaler 3 é mais influenciado pela mudança do modelo do 
que o desempenho dos Prescalers 1 e 2. O Prescaler 3, no entanto, ainda se mostra como a melhor opção para se atingir maiores velocidades.

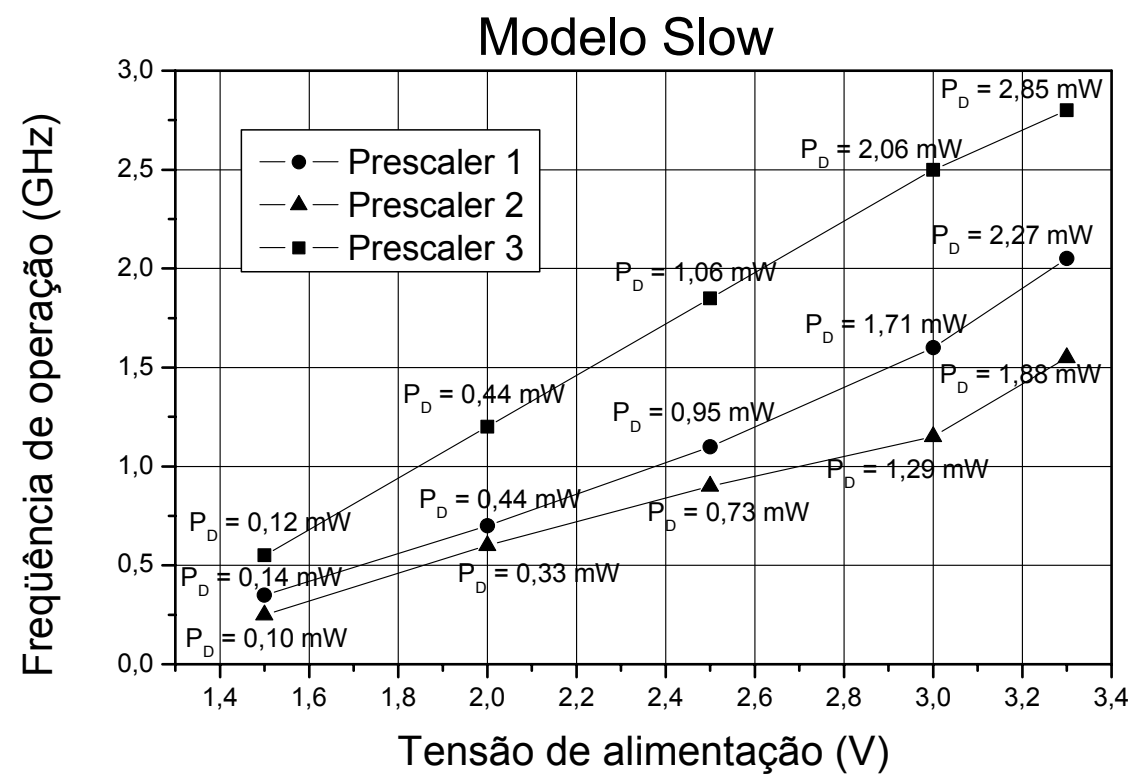

Figura 44. Gráfico da Freqüência de Operação x Tensão de Alimentação (modelo slow).

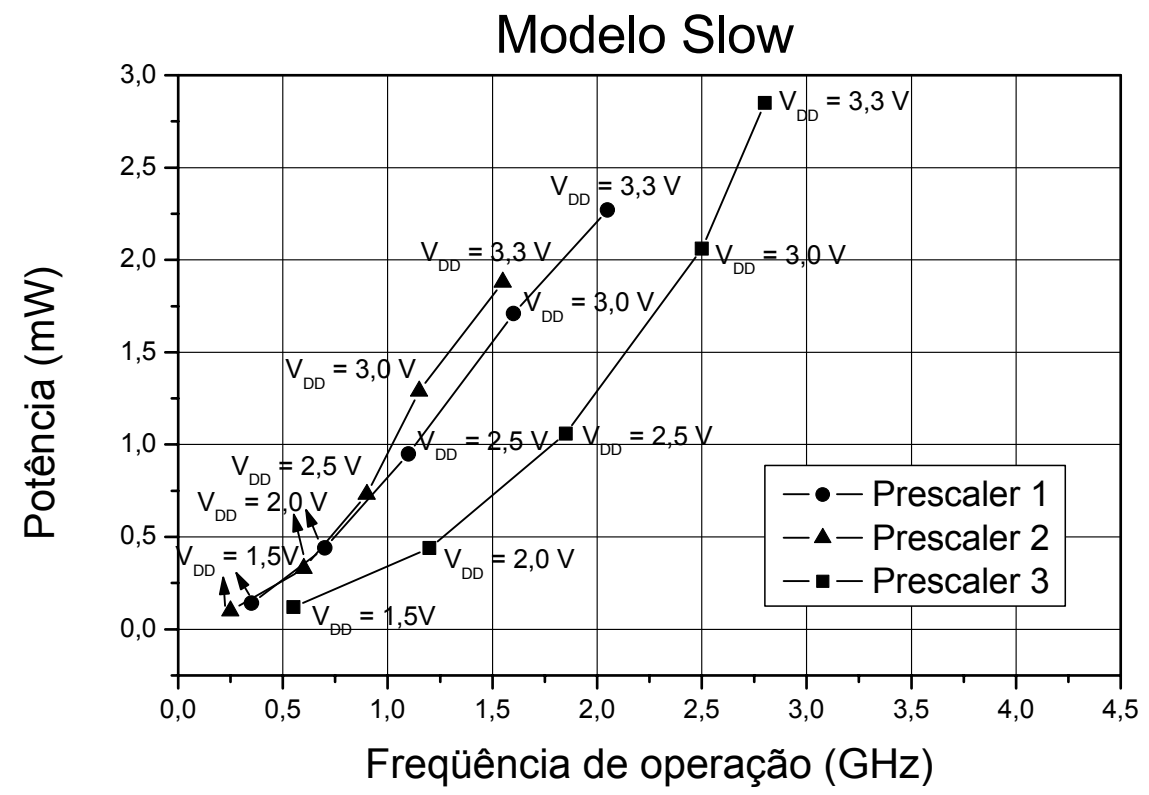

Figura 45. Gráfico da Potência x Freqüência de Operação (para diferentes valores de tensão de alimentação utilizando o modelo slow).

No gráfico da figura 45, o Prescaler 3 continua tendo o menor consumo de potência para freqüências de operação iguais, comparado aos outros circuitos. Os Prescalers 1 e 2 apresentam valores semelhantes de potência para freqüências inferiores à $900 \mathrm{MHz}$ e tensões 
de alimentação na faixa de 1,5 à 2V. Para valores superiores a aquela freqüência, o Prescaler 1 continua tendo menor consumo de potência.

As figuras 46 e 47 são semelhantes às figuras 42 e 43, obtidas à partir dos valores da tabela 6 no anexo A, mas agora são utilizados os modelos fast para os transistores MOS.

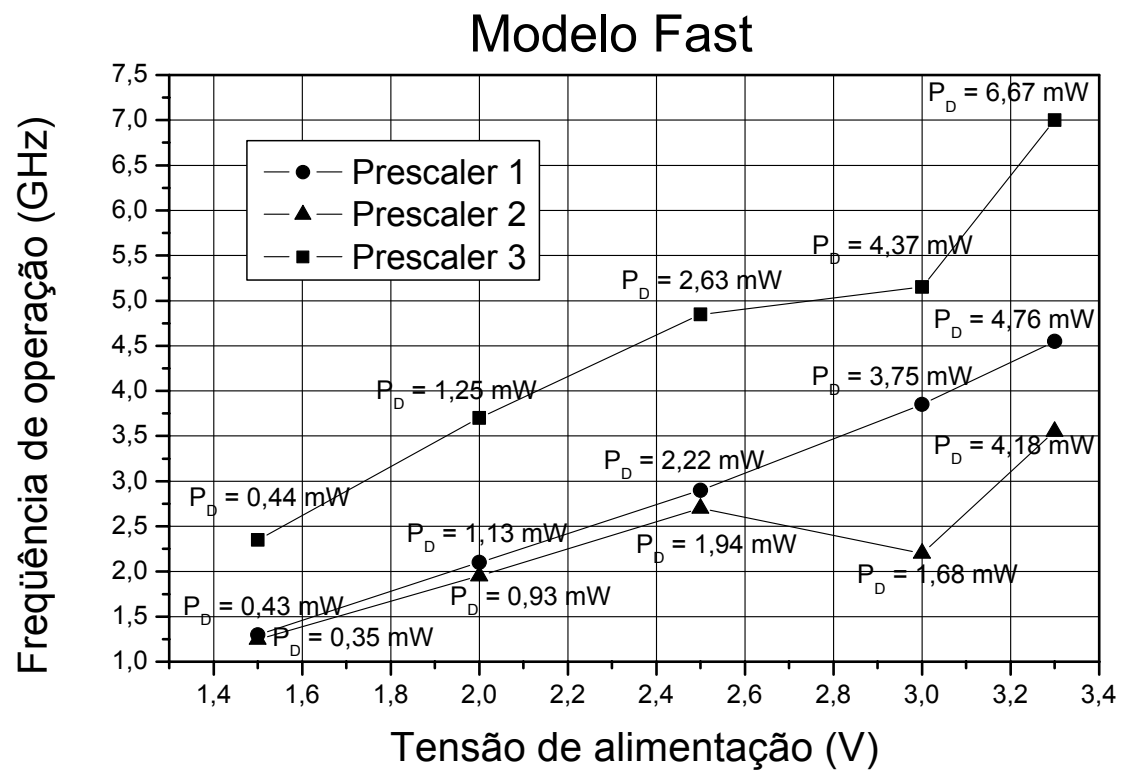

Figura 46. Gráfico da Freqüência de Operação x Tensão de Alimentação (modelo fast).

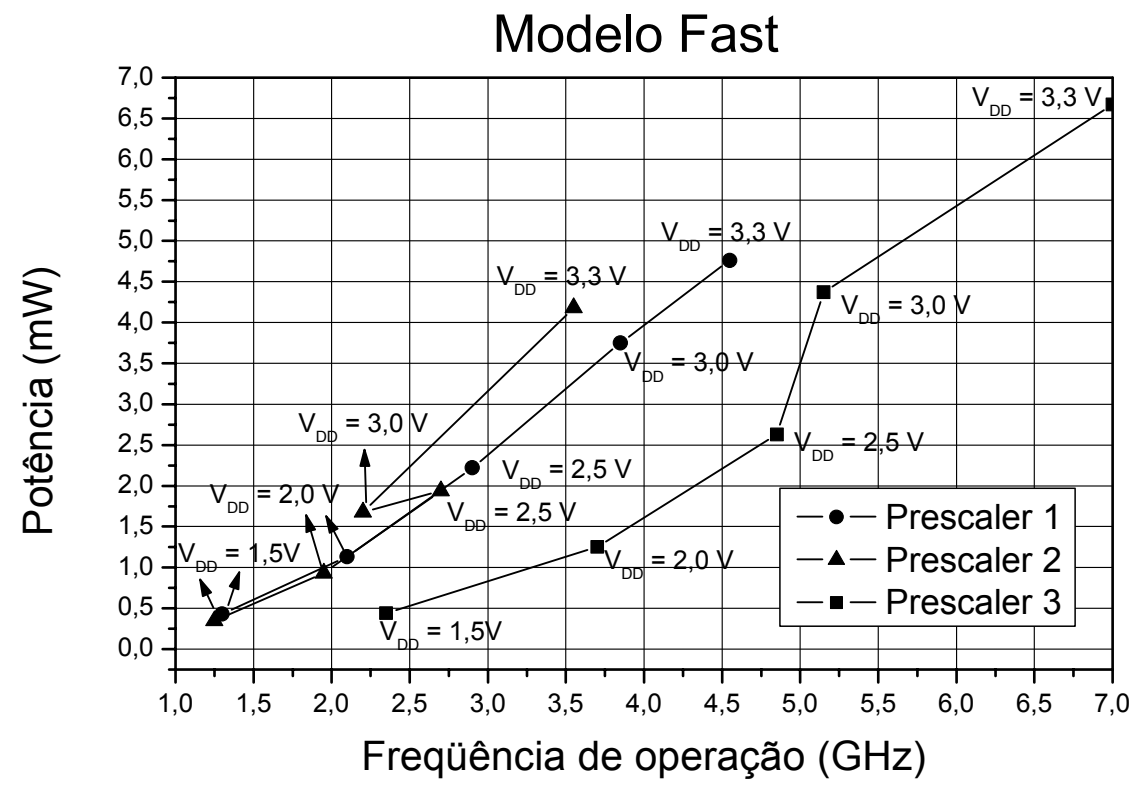

Figura 47. Gráfico da Potência x Freqüência de operação (para diferentes valores de tensão de alimentação utilizando o modelo fast). 
No gráfico da figura 46, a vantagem que o Prescaler 3 leva sobre o Prescaler 1, em relação à freqüência máxima de operação, é a maior, cerca de 2,5 GHz. A diferença entre máximas freqüências de operação dos Prescalers 1 e 2 é de $1 \mathrm{GHz}$.

No gráfico da figura 47, o Prescaler 3 continua tendo o menor consumo de potência, para freqüências iguais de operação, quando comparado aos outros circuitos. Os Prescalers 1 e 2 apresentam valores próximos de potência para freqüências inferiores à $900 \mathrm{MHz}$ e tensões de alimentação na faixa de 1,5 à 2V. Para valores superiores a aquela freqüência, o Prescaler 1 continua tendo melhor consumo de potência. Podemos perceber também nesse gráfico duas anomalias. A primeira está relacionada à potência do Prescaler 3 que apresentou um salto grande, cerca de 2,30 mW, para um pequeno aumento na freqüência de operação, cerca de $400 \mathrm{MHz}$ em torno do ponto de $5 \mathrm{GHz}$ (tensão de alimentação entre os valores $2,5 \mathrm{~V}$ e $3 \mathrm{~V}$ ). A segunda anomalia é à queda da freqüência de operação do Prescaler 2 quando a tensão de alimentação passa de 2,5 V para 3,0 V, mesmas tensões de alimentação onde se verificou a primeira anomalia. Foram refeitas as simulações nestes pontos, e os resultados persistiram. Investigações mais detalhadas devem ser realizadas para encontrar o que houve nesses pontos de simulação.

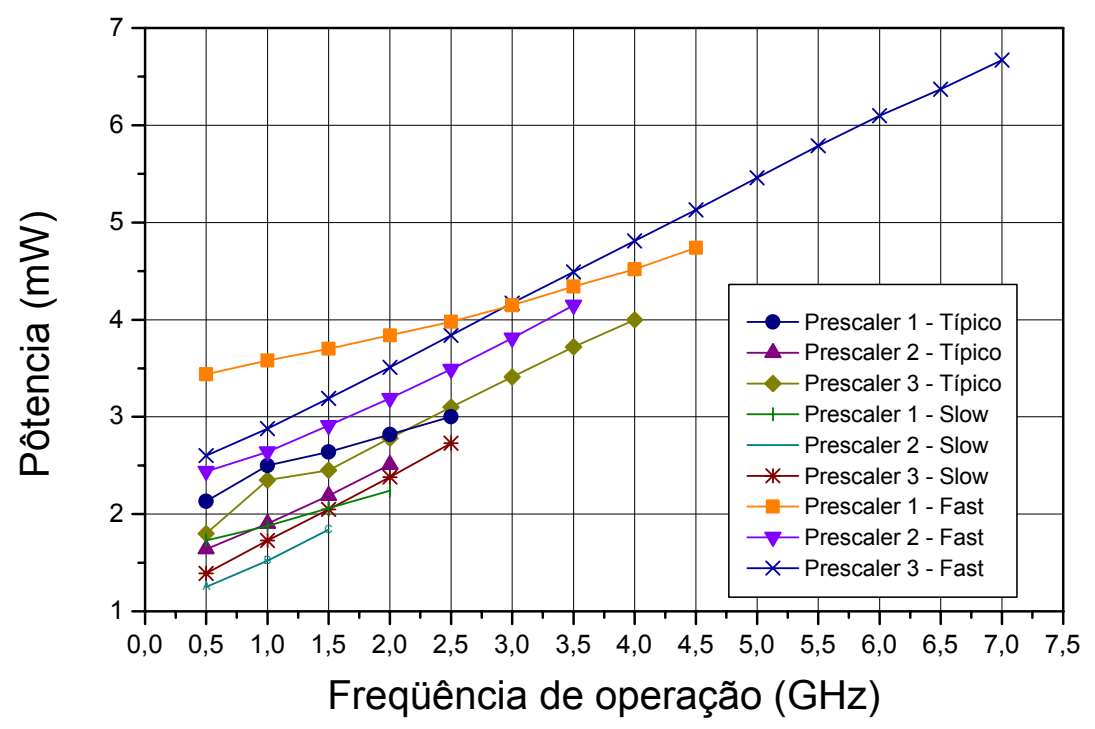

Figura 48. Gráfico da Potência x Freqüência de Operação para uma tensão de alimentação fixa de 3,3 V.

No gráfico da figura 48 é apresentada a Potência Consumida em função da Freqüência de Operação para os três modelos do transistor, típico, slow e fast (valores obtidos à partir das 
tabelas 7, 8 e 9 no anexo A). Neste caso a tensão de alimentação esta fixa em 3,3 V. Por este gráficos temos que:

- Modelo típico: primeiramente, analisando as curvas do modelo típico, percebe-se que para freqüências de operação acima de $2 \mathrm{GHz}$, o Prescaler 1 consome menor potência comparado com o Prescaler 3, porém o Prescaler 3 atinge a freqüências de operação superiores (4 GHz). Para freqüências de operação abaixo de $2 \mathrm{GHz}$, a situação se inverte, apresentando o Prescaler 3 menores valores de potência do que os do Prescaler 1. O Prescaler 2, por sua vez, apresentou a menor dissipação de potência entre os três, porém opera apenas em freqüências inferiores a $2 \mathrm{GHz}$.

- Modelo slow: na análise para o modelo slow, observa-se que utilizando uma freqüência de operação acima de 1,5 GHz, o Prescaler 1 consome menor potência do que o Prescaler 3. Já em freqüências abaixo desse valor, o Prescaler 3 apresenta o menor consumo, comparado ao Prescaler 1. O Prescaler 3 atinge a maiores freqüências de operação (2,5 GHz). O Prescaler 2 neste caso também apresenta os menores valores de potência e de freqüência de operação, chegando à apenas 1,5 GHz.

- Modelo fast: no modelo fast, observa-se que utilizando uma freqüência de operação acima de $3 \mathrm{GHz}$, o Prescaler 1 consome menor potência comparado ao Prescaler 3. Já em freqüências abaixo desse valor, o Prescaler 3 apresenta os melhores valores de potência, comparado ao Prescaler 1. O Prescaler 3 atinge freqüências de operação tão altas quanto $7 \mathrm{GHz}$. O Prescaler 2 apresenta os menores valores de potência e de freqüência de operação, chegando à $3,5 \mathrm{GHz}$.

Para uma melhor definição sobre o uso dos Prescalers, devemos antes saber em qual situação os circuitos devem funcionar:

- Em situações onde é necessário uma ampla faixa de freqüências de operação, devemos utilizar o Prescaler 3, pois apresentou um valor máximo de freqüência de $4 \mathrm{GHz}$ no modelo típico, superior aos dos dois outros Prescalers;

- $\quad$ Em situações com $\mathrm{V}_{\mathrm{DD}}=3,3 \mathrm{~V}$ e onde é necessário menor dissipação de potência, é aconselhável o uso do Prescaler 2, desde de que sua faixa de freqüências de operação seja aceitável.

Comparações destas implementações com a de outros trabalhos serão feitas no próximo capitulo. 


\section{TESTE DO CIRCITO INTEGRADO E RESULTADOS}

\subsection{Montagem para a realização das medidas no circuito integrado}

Para a realização das medidas no circuito integrado projetado nesse trabalho o chip foi montada diretamente sobre uma placa cerâmica de alumina $\left(\mathrm{Al}_{2} \mathrm{O}_{3}\right)$, com técnicas de chip on board. A utilização desta montagem é necessária para evitar o encapsulamento do C.I. que introduz elementos parasitas e compromete o funcionamento dos circuitos em altas freqüências.

A alumina é um material isolante que possui constantes elétricas e magnéticas que variam pouco com a freqüência. A placa apresenta uma fina camada de metal nas duas faces que serve para definir trilhas para sinais. A definição das trilhas na placa foi realizada no Laboratório de Microeletrônica da Universidade de São Paulo (LME-USP), com um processo litográfico que parte de uma mascará como a mostrada na figura 49a. A escolha da placa de alumina para o teste do C.I. foi feita porque o LME trabalha com esse tipo de material. Foi utilizado para ligar os Pads do C.I. às trilhas da placa de alumina fios colocados através de um processo de micro-soldagem. Na figura 49a podemos ver os vários sinais que são conectados a placa e ligados ao C.I. pelas micro-soldas (figura 49b). Os sinais são $\mathrm{V}_{\mathrm{SS}}$ (ground comum), $\mathrm{V}_{\mathrm{DD} 1}$ (tensão alimentação para o Prescaler 1), $\mathrm{V}_{\mathrm{DD} 2}$ (tensão alimentação para o Prescaler 2), $\mathrm{V}_{\mathrm{DD} 3}$ (tensão alimentação para o Prescaler 3), $\mathrm{V}_{\mathrm{DDB}}$ (tensão alimentação para os buffers de entrada e saída) e SM (sinal para definir se conta 32 ou 33)(ver figura 40). Os sinais de clock na entrada e os sinais de saída são conectados via micropontas.

Inicialmente as micro-soldas foram realizadas no LME e a figura 50a apresenta a foto delas. A placa preparada desta forma, no entanto, apresentou problemas pois os circuitos testados nela funcionaram a freqüências inferiores a $500 \mathrm{MHz}$. Após várias análise se optou por realizar novas micro-soldas, desta vez no CENPRA (figura 50b). A qualidade das novas soldas foi bastante superior e os resultados obtidos, completamente diferentes (desta vez atingindo velocidade próxima dos $4 \mathrm{GHz}$, que foi obtida em simulação). 


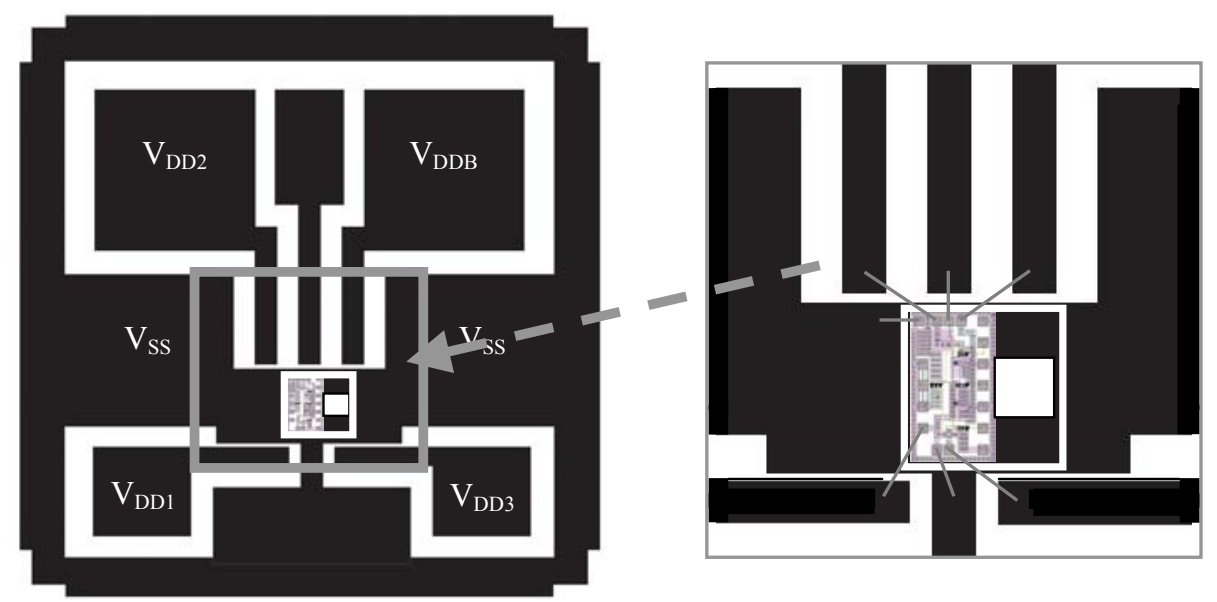

a)

b)

Figura 49. Layout para placa de alumina: a) layout completo com os sinais externos, b) detalhe da região onde fica o C.I. e indicações das micro-soldas.

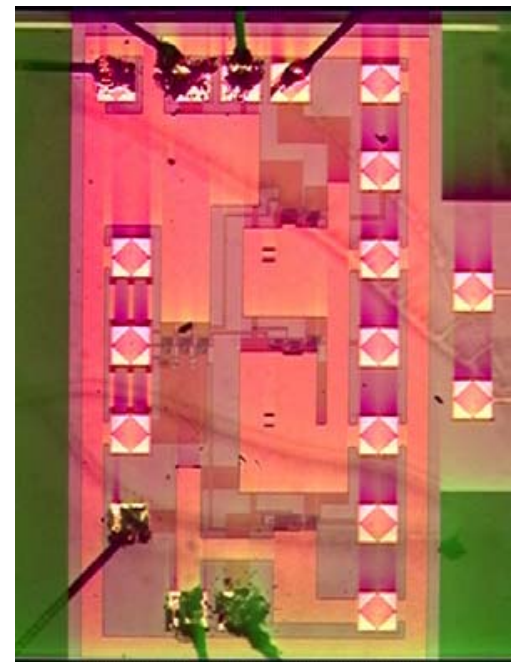

a)

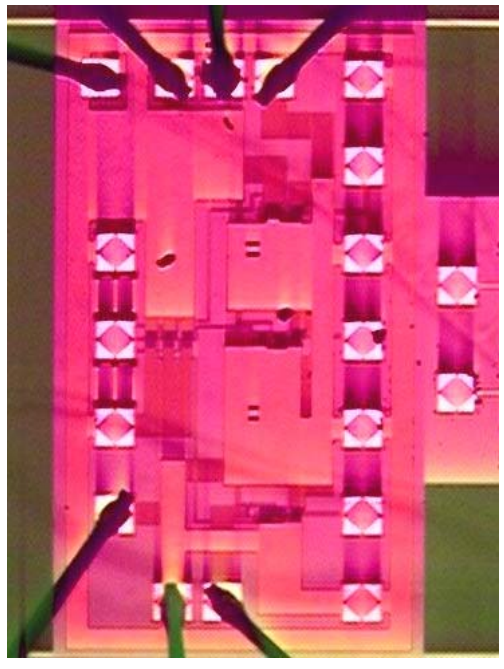

b)

Figura 50. Fotos da micro-soldagem dos C.Is.: a) micro-soldagem realizada no LME, b) micro-soldagem realizada no CENPRA.

Um cuidado extra tomado para a realização das medidas foi a colocação de capacitores de desacoplamento externos na placa. Os circuitos digitais normalmente geram pulsos de corrente nos instantes de transição e estes pulsos causam oscilações na tensão de alimentação, degradando a performance. Capacitores servem para absorver esses pulsos e reduzem as possíveis oscilações. Foram utilizados dois tipos de capacitores nesta tarefa: 
- capacitores SMD de dimensões (modelo 0603) e valores $(1 \mu \mathrm{F})$ pequenos: por causa das dimensões pequenas a indutância série é também pequena, o que os fazem ser adequados para filtrar pulsos rápidos; por outro lado, como o valor do capacitor é pequeno, se apenas eles fossem utilizados haveria significativa variação na sua carga e tensão para correntes maiores aplicadas em freqüências baixas;

- capacitores de dimensões (modelo $\mathrm{BX}$ ) e valores maiores (47 $\mu \mathrm{F})$ : neste caso a indutância série é bem maior, não sendo adequados para filtrar pulsos rápidos; por outro lado permitirão que grandes correntes sejam aplicadas sem que haja maiores variações na tensão.

Foram colocados dois capacitores pequenos em paralelo entre cada terminal de tensão de alimentação $\left(\mathrm{V}_{\mathrm{DD}}\right)$ e o terminal de terra $\left(\mathrm{V}_{\mathrm{SS}}\right)$, figura 51. Foram também utilizados capacitores maiores de Tântalum nos terminais de $\mathrm{V}_{\mathrm{DD} 3}$ e $\mathrm{V}_{\mathrm{DDB}}$. Nos outros terminais, $\mathrm{V}_{\mathrm{DD} 1} \mathrm{e}$ $\mathrm{V}_{\mathrm{DD} 2}$, não foi possível utilizar este capacitor apenas por falta de espaço na placa.

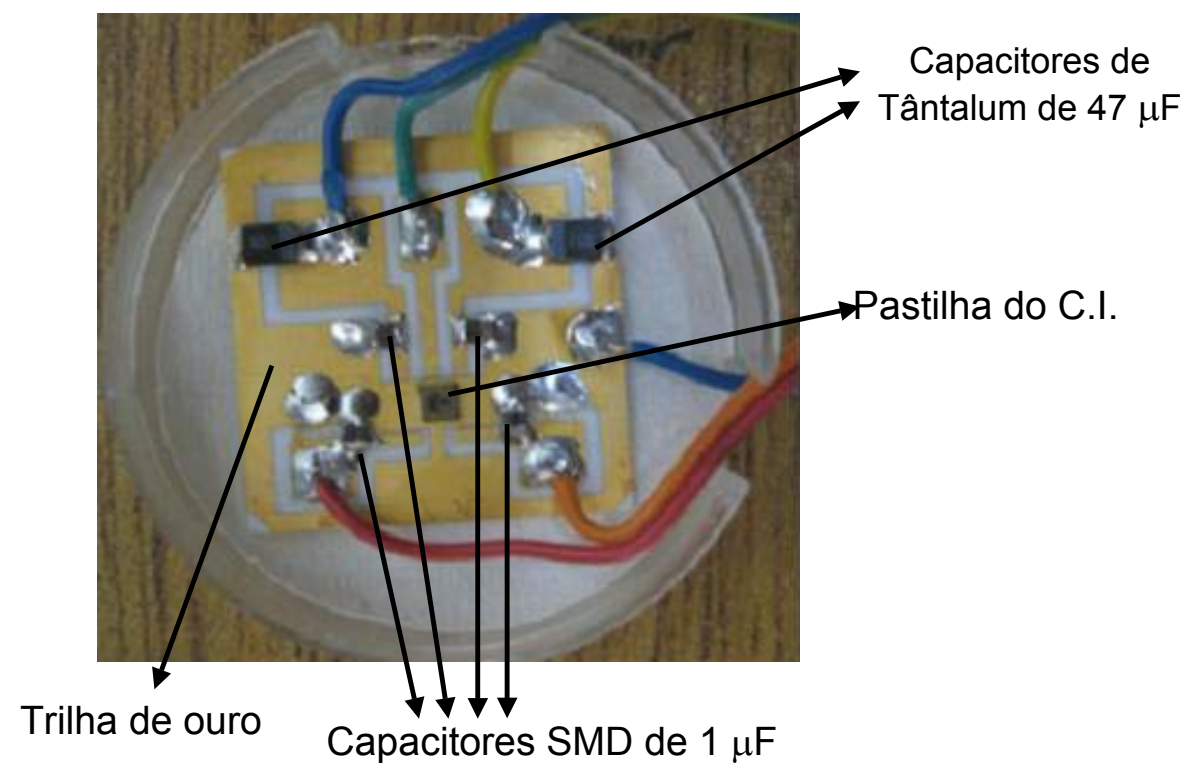

Figura 51. Placa de alumina montada com o C.I. e os diversos componentes para a realização de testes.

Após a confecção e montagem da placa de alumina, foi preparada a bancada para a realização das medidas, como mostra a figura 52. Nesta bancada temos: a mesa para suporte das micro-pontas de prova; um osciloscópio digital; duas fontes de alimentação; um gerador de sinais digitais (modelo HP 8133A, para 3GHz); dois multímetros digitais. A figura 53 mostra as micro-pontas colocadas sobre o C.I.: a micro-ponta da esquerda serve para aplicar o sinal de clock e a da esquerda esta posicionada para medir a saída do Prescaler 3. 
As fontes de alimentação foram utilizadas para fornecer a tensão de alimentação $V_{D D}$ de cada Prescaler e dos Buffers e para fornecer o sinal DC do terminal de controle SM. O sinal de clock foi fornecido pelo gerador digital (modelo HP 8133A, para 3GHz) que atinge freqüências de até $3 \mathrm{GHz}$ com excursão de saída máxima de $3 \mathrm{~V}_{\mathrm{PP}}$. Este gerador tem impedância de saída de $50 \Omega$.

Com o osciloscópio digital realizou-se a medida do sinal de saída dos Prescalers, verificando as freqüências máximas de funcionamento. Com os dois multímetros digitais realizou-se a medida da corrente de cada Prescaler e de todos os buffers. Observemos que para executar as medidas em um Prescaler, qualquer um deles, os outros dois eram desativados.

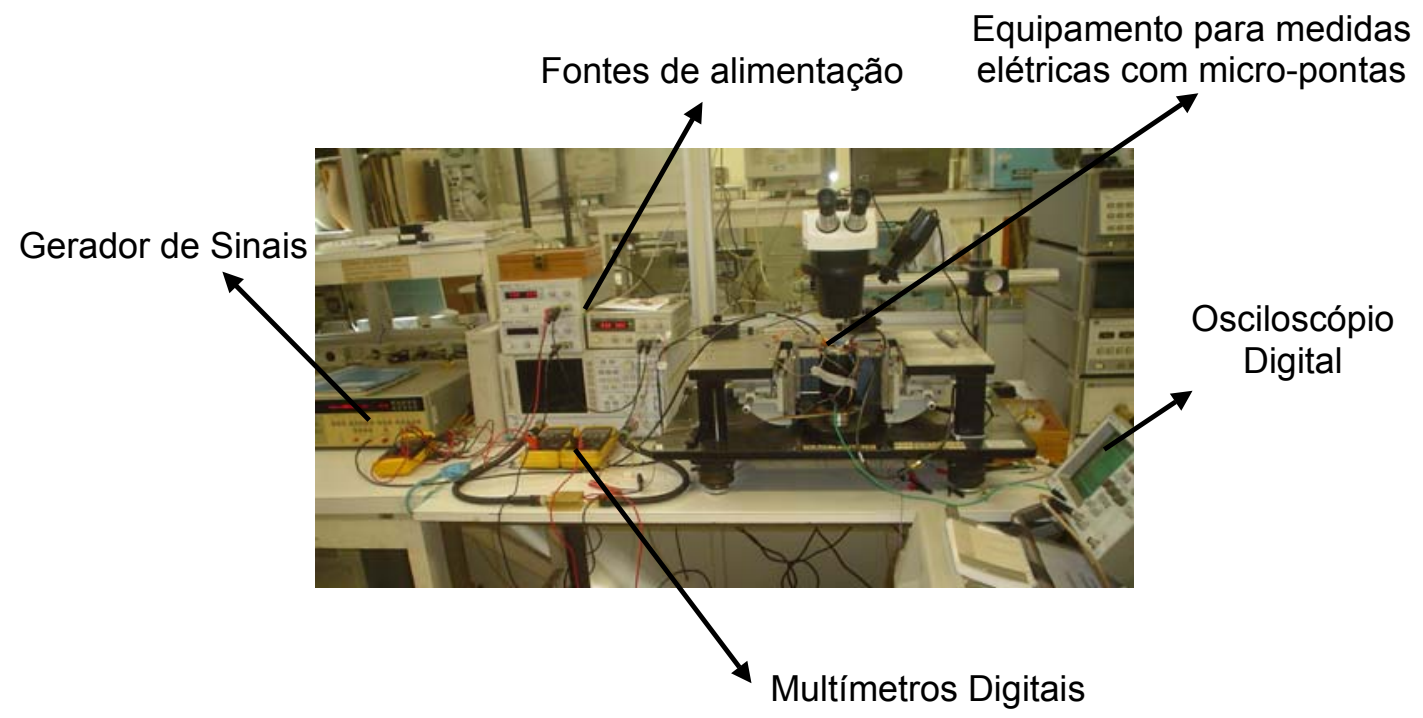

Figura 52. Foto da bancada montada para a realização das medidas.

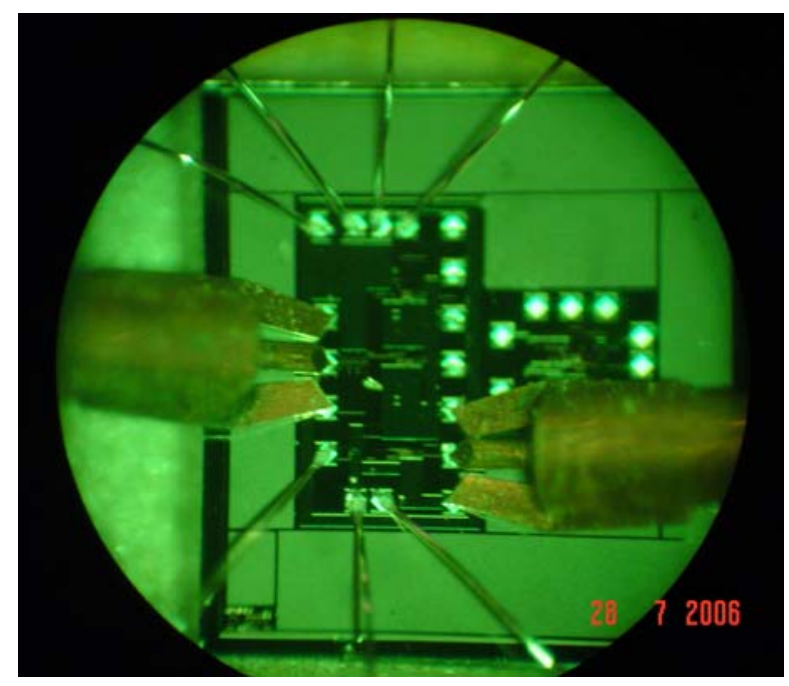

Figura 53. Foto das micro-pontas em contato com os Pads do C.I.. 


\subsection{Resultados das medidas realizadas no circuito integrado}

Foram medidas as três implementações do circuito Dual-Modulus Prescaler com a montagem descrita anteriormente. No Anexo A, tabelas 9, 10, 11 e 12, estão os resultados das medidas. Devido as dificuldades em montar as placas e testá-las e devido aos atrasos que ocorreram em função dos problemas com as micro-solda, foi medido apenas um C.I.

Obs.: Nos gráficos abaixo, os nomes Prescaler 1, Prescaler 2, Prescaler 3, também estão relacionados aos circuitos com $3 D-F F s, 2 D-F F s$ e $3 D-F F$ s com clock dividido por 2, respectivamente.

A figura 54 mostra o gráfico da Freqüência de Operação em função da Tensão de Alimentação para o Prescaler 3, com resultados de simulações nos modelos típico, slow e fast e, também, resultados das medidas no C.I. (valores obtidos à partir das tabelas 7, 8, 9 e 12 no anexo A). Podemos observar que os resultados das medidas elétricas ficaram próximos dos de simulação com o modelo típico (pouco abaixo do modelo típico e bem acima do modelo slow). Isso mostra que as medidas no circuito implementado estão dentro do esperado e que, na rodada de fabricação, os parâmetros dos transistores ficaram próximos do típico. Observemos que o menor valor de tensão de alimentação utilizado nas medidas foi de $2 \mathrm{~V}$, valor mínimo que garante o funcionamento dos Prescalers.

Freqüência de Operação X Tensão de Alimentação (Prescaler 3 - Tipical/Fast/Slow/Medido)

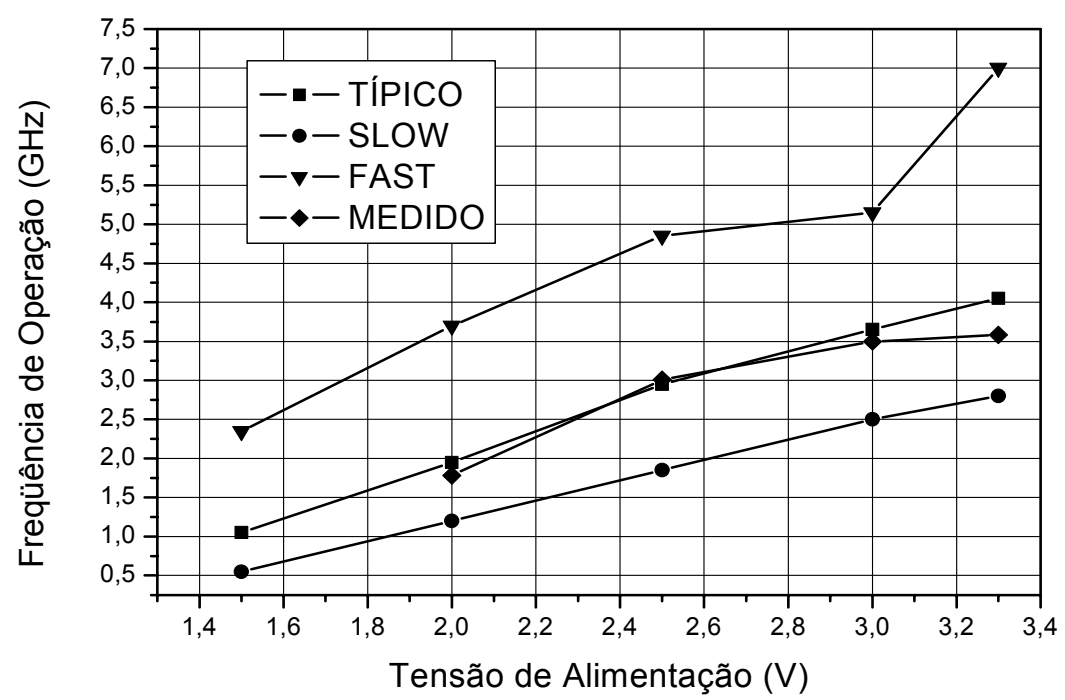

Figura 54. Gráfico da Freqüência de Operação x Tensão de Alimentação do Prescaler 3. Resultados obtidos através das simulações elétricas nos modelos típico, slow, fast e das medidas elétricas realizadas. 
A figura 55 apresenta o gráfico Freqüência Máxima de Operação dos circuitos em função da Tensão de Alimentação, obtida à partir dos valores da tabela 12 no anexo A. Nele podemos observar que o Prescaler 3 leva vantagem sobre o Prescaler 1 em relação à Freqüência máxima de operação, cerca de 1,5 GHz em quase todas as tensões de alimentação. O Prescaler 1, por sua vez, apresenta em geral uma performance superior ao Prescaler 2, mas com uma diferença não tão acentuada (no máximo $260 \mathrm{MHz}$ mais veloz).

A figura 56 apresenta o gráfico Potência Consumida em função da Freqüência Máxima de Operação, obtida à partir dos valores da tabela 12 no anexo $\mathrm{A}$, para várias tensões de alimentação. Nele podemos ver que quando é permitido variar a tensão de alimentação, o Prescaler 3, na mesma freqüência de operação dos outros circuitos representados no gráfico, consome menor potência. Observemos que a potência apresentada não inclui as potências dos buffers de entrada ou de saída.

Freqüência de operação x Tensão de alimentação

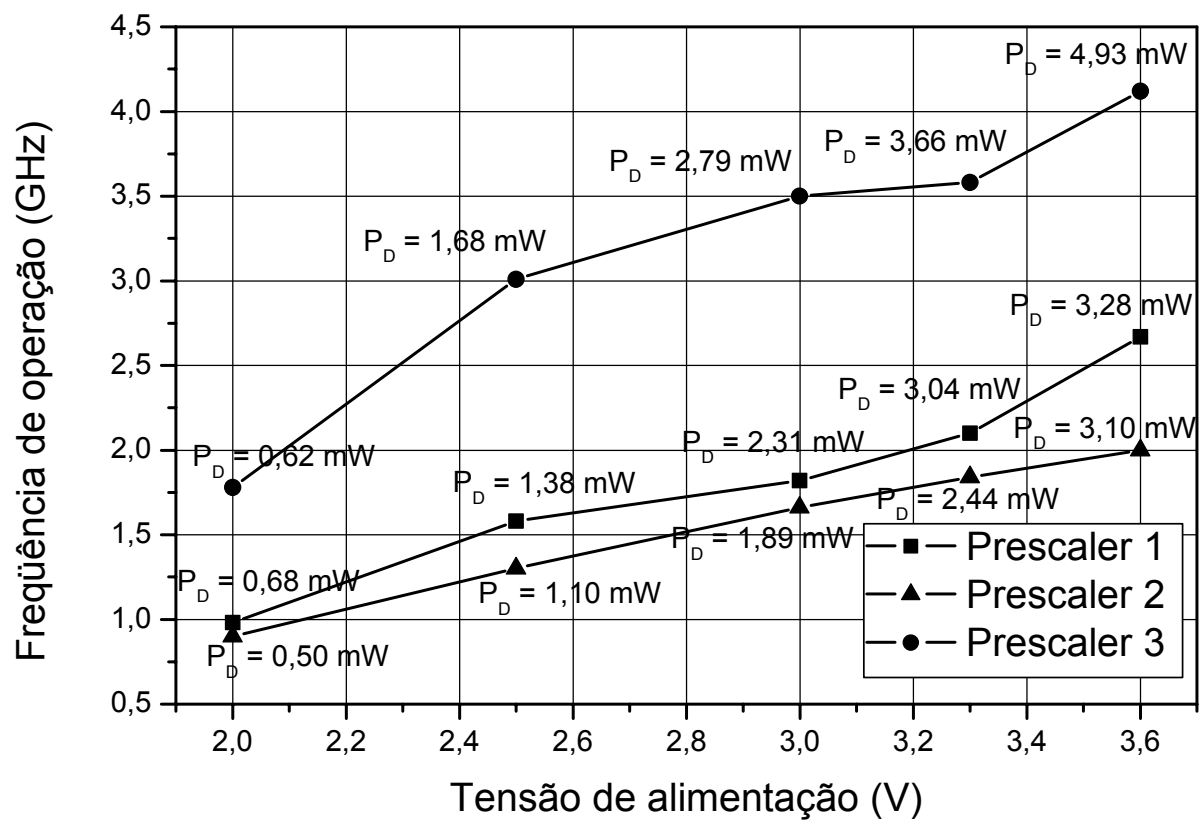

Figura 55. Gráfico da Freqüência de Operação x Tensão de Alimentação obtido à partir das medidas elétricas realizadas. 
Potência x Freqüência de Operação

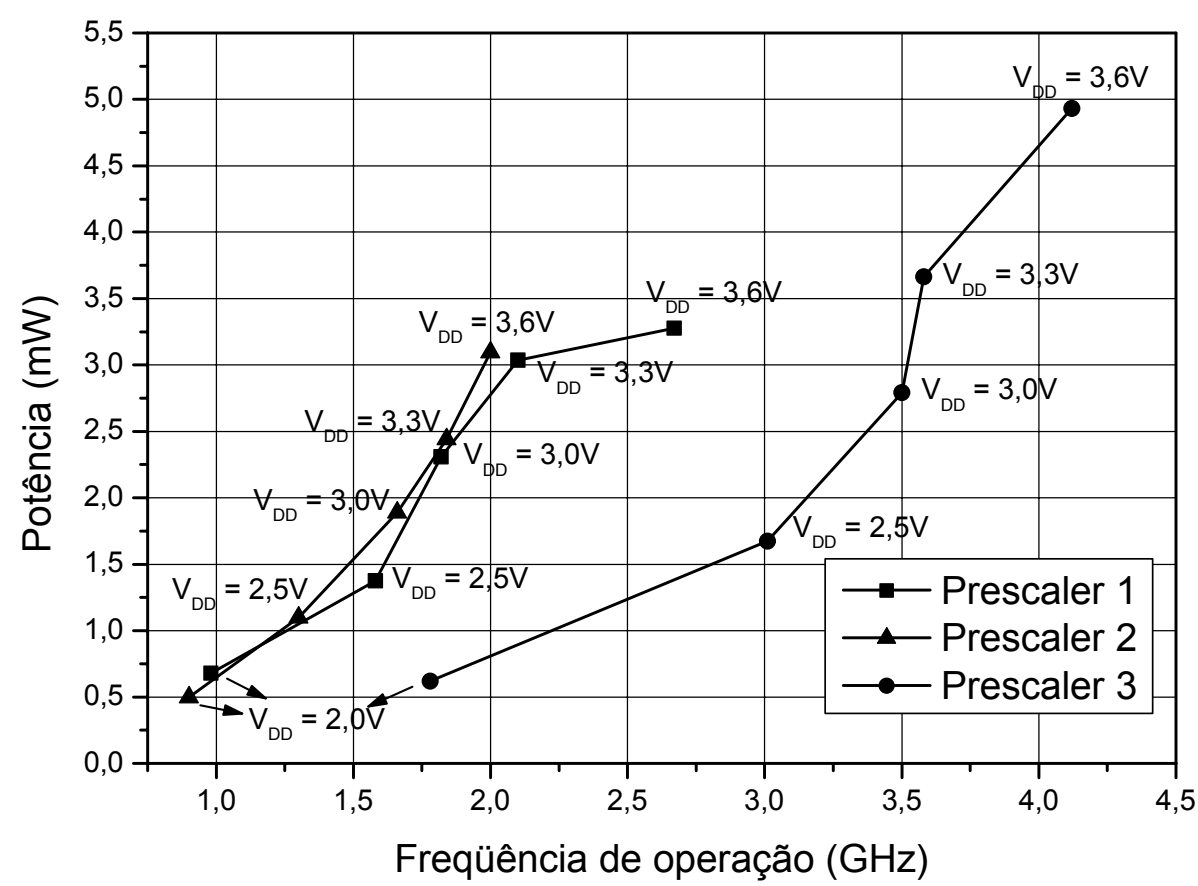

Figura 56. Gráfico da Potência x Freqüência de Operação obtida a partir das medidas elétricas realizadas.

Para uma melhor comparação dos Prescalers, devemos antes saber em qual situação o circuito deve trabalhar:

- Em situações onde é necessário uma ampla faixa de freqüência de operação, devemos utilizar o Prescaler 3, pois apresentou um valor máximo de freqüência de 3,58 GHz, para uma tensão de alimentação de 3,3 V, superior aos dos demais Prescalers;

- Em situações com $\mathrm{V}_{\mathrm{DD}}=3,3 \mathrm{~V}$, onde é necessário menor dissipação de potência é aconselhável o uso do Prescaler 2, desde que ele atinja a velocidade requerida.

A figura 57 mostra fotos das formas de onda da saída do Prescaler 3. Uma delas apresenta a forma de onda para uma entrada de $3,58 \mathrm{GHz}$, máxima velocidade de funcionamento do Prescaler 3, e a outra apresenta a forma de onda para uma entrada de 100 MHz. 


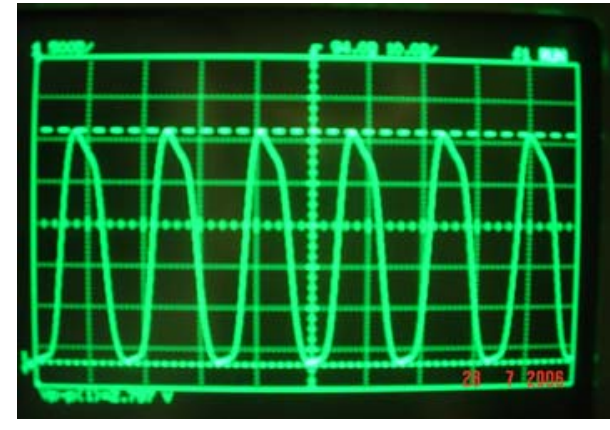

a)

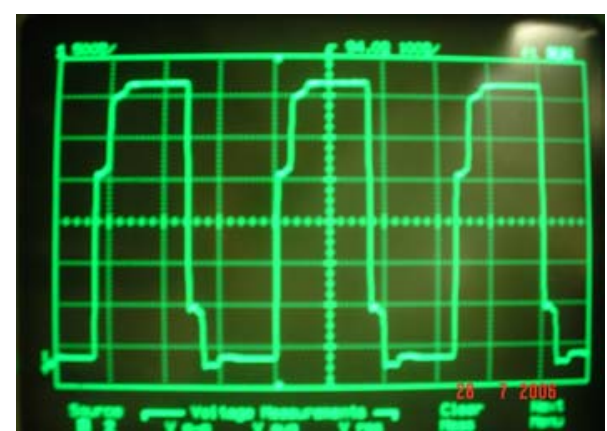

b)

Figura 57. Formas de onda do sinal de saída do Prescaler 3: a) clock na freqüência de $3,58 \mathrm{GHz}$ e b), na freqüência de $100 \mathrm{MHz}$.

Tabela 3. Características de várias implementações de circuitos Dual-Modulus Prescalers.

\begin{tabular}{|c|c|c|c|c|c|c|}
\hline Referência & Prescaler & $\begin{array}{l}\text { Contador } \\
\text { Síncrono }\end{array}$ & $\begin{array}{c}\text { Tecnologia } \\
(\mu \mathrm{m})\end{array}$ & $\begin{array}{c}\text { Tensão de } \\
\text { Alimentação } \\
\text { (V) }\end{array}$ & $\begin{array}{l}\text { Máxima } \\
\text { freqüência } \\
\text { (GHz) }\end{array}$ & $\begin{array}{c}\text { Potência } \\
\text { consumida } \\
\text { (sem buffer } \\
\text { de clock.) } \\
\text { (mW/GHz) }\end{array}$ \\
\hline [Ch96] & $128 / 129$ & $4 / 5$ & 0.8 & $\begin{array}{l}5 \\
3 \\
\end{array}$ & $\begin{array}{l}1.22 \\
0.64\end{array}$ & $\begin{array}{c}20.9 \\
9.3\end{array}$ \\
\hline [Ya98] & $128 / 129$ & $4 / 5$ & 0.8 & $\begin{array}{l}5 \\
3\end{array}$ & $\begin{array}{c}1.8 \\
1.34\end{array}$ & $\begin{array}{c}29.4 \\
-\end{array}$ \\
\hline [Ya99] & $128 / 129$ & $2 / 3$ & 0.8 & 3 & 1.3 & 7.5 \\
\hline \multirow[b]{2}{*}{ [Na99] } & \multirow{2}{*}{$128 / 129$} & \multirow{2}{*}{$4 / 5$} & \multirow[b]{2}{*}{0.8} & $\begin{array}{l}5 \\
3\end{array}$ & $\begin{array}{l}1.59 \\
0.78\end{array}$ & $\begin{array}{l}8.0 \\
3.5\end{array}$ \\
\hline & & & & $\begin{array}{l}5 \\
3\end{array}$ & $\begin{array}{l}1.46 \\
0.81\end{array}$ & $\begin{array}{c}11.2 \\
3.9\end{array}$ \\
\hline [Cr96] & $128 / 129$ & $4 / 5$ & 0.7 & $\begin{array}{l}5 \\
3\end{array}$ & $\begin{array}{l}2.65 \\
1.75\end{array}$ & $13.7^{*}$ \\
\hline [Na02] & $128 / 129$ & $4 / 5$ & 0.8 & $\begin{array}{l}5 \\
3 \\
\end{array}$ & $\begin{array}{l}2.19 \\
1.35 \\
\end{array}$ & $\begin{array}{l}- \\
-\end{array}$ \\
\hline [Rm05] & $127 / 128$ & $3 / 4$ & 0.35 & 3 & 2.4 & 2.0 \\
\hline [Le04] & $8 / 9$ & $2 / 3$ & 0.25 & 2.5 & 2.7 & 1.12 \\
\hline \multirow{2}{*}{ Prescaler 1} & \multirow{2}{*}{$32 / 33$} & \multirow{2}{*}{$4 / 5$} & \multirow{2}{*}{0.35} & 3 & 1.82 & 1.27 \\
\hline & & & & 3 & 2.35 & 1.03 \\
\hline \multirow{2}{*}{ Prescaler 2} & \multirow{2}{*}{$32 / 33$} & \multirow{2}{*}{$2 / 3$} & \multirow{2}{*}{0.35} & 3 & 1.66 & 1.14 \\
\hline & & & & 3 & 1.80 & 1.05 \\
\hline \multirow{2}{*}{ Prescaler 3} & \multirow{2}{*}{$32 / 33$} & \multirow{2}{*}{$4 / 5$} & \multirow{2}{*}{0.35} & 3 & 3.50 & 0.80 \\
\hline & & & & 3 & 3.65 & 0.81 \\
\hline
\end{tabular}

* Neste circuito não é clara a informação se esta ou não sendo considerada a potência do buffer para o clock.

Obs.: os valores descritos na parte hachurada da tabela são resultados de simulações elétricas.

A tabela 3 apresenta características de diversas implementações de Prescalers encontradas na literatura, além dos resultados obtidos neste trabalho. Dois comentários preliminares são importantes antes de qualquer comparação entre as diversas implementações: 
- $\quad$ Na tabela estão apresentados Prescalers módulo 128/129, módulo 32/33 e módulo 8/9. A comparação entre eles, em relação a velocidade e consumo de potência, é possível pois é o contador síncrono, que poderia ser igual em todos eles, quem limita estas características. O contador assíncrono trabalha com velocidades baixas e consome pouca potência. Por exemplo, no Prescaler 1 a potência do contador síncrono, para uma tensão de alimentação de 3,3 V, é de 2,60 mW, enquanto a do contador assíncrono é de apenas $0,31 \mathrm{~mW}$ (potências obtidas em simulação elétrica);

- Na tabela estão apresentados Prescalers implementados com tecnologias diferentes (de $0,8 \mu \mathrm{m}, 0,7 \mu \mathrm{m}, 0,35 \mu \mathrm{m}$ e $0,25 \mu \mathrm{m})$. Para podermos comparar os resultados medidos aqui com os das tecnologias de $0,8 \mu \mathrm{m}$ e $0,7 \mu \mathrm{m}$, usaremos os trabalhos [Na99] e [Na02], que apresentam implementações similares ao Prescaler 1 e ao Prescaler 3, como ponte. Podemos observar que entre as implementações feitas em 0,8 $\mu \mathrm{m}$, aquela apresentada em [Na99] é a que tem menor consumo de potência. Sua velocidade é apenas superada por [Cr96] e por [Na02].

Comparando os resultados podemos ver que:

- $\quad$ O ganho de velocidade do Prescaler 1 paro o Prescaler 3 na tecnologia 0,35 $\mu$ m está muito próximo do ganho de velocidade do Prescaler da referência [Na99] para o Prescaler da referência [Na02], ambos implementados em na mesma tecnologia de 0,8 $\mu \mathrm{m}$. Isto indica que a melhora que se obtém de uma configuração para outra não depende da tecnologia;

- O consumo de potência obtido nas três implementações é bastante reduzido. Isto mostra que estes circuitos, utilizando a técnica E-TSPC, são excelentes para aplicações em low power;

- Olhando para o Prescaler 3, vemos que ele apresenta maior velocidade e menor consumo entre todas as implementações realizadas em tecnologia de 0,35 $\mu \mathrm{m}$ ou superior (a de 0,25 $\mu \mathrm{m}$ ). Como o Prescaler 3 é cerca de 70\% mais veloz do que o Prescaler 1 e consome menor potência, podemos supor que esta implementação é a mais veloz, exceção talvez da apresentada em [Cr96], e a de menor consumo entre todas implementações propostas na literatura que conhecemos. 
- Devemos chamar atenção que nos testes do Prescaler 3 o clock externo aplicado foi utilizado como $c l k / 2$ da contador síncrono (ver figura 32). Isto facilitou a realização dos testes pois pudemos executá-los com um gerador de sinais que fornece sinais até $3 \mathrm{GHz}$. Em função deste procedimento não se considerou, no Prescaler 3, a potência consumida na divisão do clock por dois. Para que isto fosse realizado deveríamos implementar o divisor, basicamente um $D-F F$, e um buffer para ligar a saída dele ao contador síncrono. Neste caso, no entanto, os buffers de clock de todos os Prescalers deveriam ser projetados e sua potência também considerada. Fazer isto apresenta duas complicações:

- Os critérios utilizados no projeto dos buffers influem bastante no resultado de seu consumo. Visto que o consumo do buffer é tão grande quanto o resto do Prescaler, teríamos resultados que não dependeriam apenas da implementação deste;

- Há poucos resultados publicados sobre implementação e consumo dos buffers de clock de Prescalers para se realizar as comparações desejadas. 


\section{CONCLUSÕES}

$\mathrm{Na}$ transmissão e recepção de sinais RF, um bloco importante é o Sintetizador de Freqüências que é responsável pela geração de sinais em freqüências diversas. Para a construção dos Sintetizadores são utilizados circuitos Dual-Modulus Prescalers que dividem um sinal de entrada por um valor $\mathrm{N}$ ou $(\mathrm{N}+1)$.

Neste trabalho foram projetados circuitos Prescalers modulo 32/33 utilizando a técnica E-TSPC, uma extensão da TSPC, que propõe novas topologias, aplicando novas configurações de portas lógicas e registradores, e permite atingir maiores velocidades de operação nos circuitos.

Três diferentes versões de Prescaler foram desenhadas no software IC Station, da Mentor Grafics, e seu funcionamento foi verificado com o software HSPICE de simulação, utilizando os modelos típico, slow e fast. Posteriormente foram fabricados na tecnologia CMOS 0,35 $\mu \mathrm{m}$ da AMS e caracterizados. Os resultados obtidos ficaram dentro do esperado e próximos dos resultados simulados com os modelos típicos.

Verificou-se que dentre os Prescalers implementados neste trabalho, o Prescaler 3 (versão com $3 \mathrm{D}$-FFs e clock dividido por 2) foi o melhor, apresentando o maior valor de freqüência máxima de operação, $4 \mathrm{GHz}$ no modelo típico de simulação e 3,6 GHz nas medidas do C.I. para tensão de alimentação de 3,6 V, e o menor valor de potência consumida, 0,80 mW/GHz, em simulação e em medidas. Ainda, na comparação deste Prescaler com outros da literatura, ele se mostrou ser o que atinge as maiores velocidades e o menor consumo de potência.

Não foi implementado no Prescaler 3 o circuito divisor por 2, porque a comparação de resultados com relação as outras implementações de Prescalers, referenciadas neste trabalho, seria difícil de ser feita. Este trabalho deverá ser realizado em futuros estudos.

Por fim, o desenvolvimento feito aqui mostrou que a técnica E-TSPC produz excelentes resultados em aplicações que requerem circuitos digitais trabalhando em altíssima velocidade. 


\section{REFERÊNCIAS BIBLIOGRÁFICAS}

[Ar03] A. M. G. ARGÜELlO, Estudo e Projeto de um Sintetizador de Freqüência CMOS para RF (qualificação para a dissertação para 0 mestrado). Departamento de Engenharia de Sistemas Eletrônicos. Escola Politécnica da Universidade de São Paulo. São Paulo - Brasil. Jun. 2003.

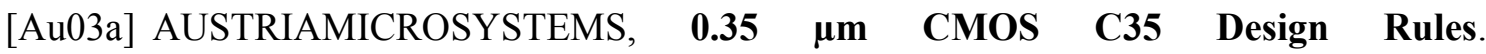
AustrianMicroSystems, 2003.

[Au03b] AUSTRIAMICROSYSTEMS, (2003, June) 0.35 m m CMOS process technology. [Online]. Available: http://www.austriamicrosystems.com/05foundry/indexc35.htm.

[Br98] J.E. BREWER, A new and improved roadmap. IEEE Circuits \& Devices, vol.14, n.2, pp.13-18, 1988.

[Ch96] B. CHANG and J. YUAN, A 1.2 GHz CMOS dual-modulus prescaler using new dynamic D-type flip-flops. IEEE J. Solid-State Circuits, vol. 31, pp. 749-752, May 1996.

[Cr96] J. CRANINCKX and M. S. J. STEYAERT, A 1.75-GHz/3-V dual-modulus divideby-128/129 prescaler in $0.7 \mu$ m CMOS. IEEE J. Solid-State Circuits, vol. 31, pp. 890-897, July 1996.

[Mi04a] F. P. H. MIRANDA and J. NAVARRO, A 4-Ghz Dual Modulus Prescaler Circuit with a $0.35 \mu$ m CMOS Technology. IWS'2004 X IBERCHIP Workshop, pp. 571577, Mar. 2004.

[Mi04b] F. P. H. MIRANDA, J. NAVARRO and W. VAN NOIJE, A 4-Ghz Dual Modulus Divider-by 32/33 Prescaler in $0.35 \mu \mathrm{m}$ CMOS Technology. 17th Symposium on integrated circuits and systems design chip on the reefs - SBCCI / IEEE, pp. 94-99, Sep. 2004.

[Go84] N. F. GONÇALVES, Nora: A Racefree CMOS Technique for Register Transfer Systems (tese de doutorado). Katholieke Universiteit Leuven Faculteit der Toegepaste Wetenschappen Departament Elektrotechiniek, Nov. 1984.

[La95] P. LARSSON, Skew safety and logic flexibility in a true single phase clock system. International Symposium on Circuits and Systems, 1995. pp.941-944. 
[Le04] S. PELLERANO and S.LEVANTINO, A 13.5-mW 5-GHz Frequency Synthesizer With Dynamic-Logic Frequency Divider. IEEE J. Solid-State Circuits, vol. 39, pp. 378-383, Feb. 2004.

[Na97] J. NAVARRO and W. VAN NOIJE, E-TSPC: Extended True Single Phase Clock CMOS circuit technique for high speed applications. SBMICRO J. Solid-State Devices and Circuits, vol.5, pp.21-26, 1997.

[Na98] J. NAVARRO, Técnicas para projetos de ASICs CMOS de alta velocidade (tese de doutorado). Departamento de Engenharia de Sistemas Eletrônicos. Escola Politécnica da Universidade de São Paulo. São Paulo - Brasil. 1998.

[Na99] J. NAVARRO and W. VAN NOIJE, A 1.6-Ghz Dual Modulus Prescaler Using the Extended True-Single-Phase-Clock CMOS Circuit Tecnique (E-TSPC). IEEE J. Solid-State Circuits. vol. 34, pp.97-102, Jan. 1999.

[Na02] J. NAVARRO and W. VAN NOIJE, Extended TSPC Structures With Doublé Input/Output Data Throughput for Gigahertz CMOS Circuit Design. IEEE Trans. on VLSI Systems, vol. 10, pp. (301-308), June 2002.

[Ra96] J. M. RABAEY, Digital Integrated Circuits: a design perspective. Upper saddle Prentice, New Jersey, 1996. (Eletronics and VLSI series).

[Rm05] R. S. RANA, Dual-Modulus 127/128 FOM Enhanced PrescalerDesign in 0.35 $\mu$ m CMOS Technology, IEEE J. Solid-State Circuits, vol.40, pp.1662-1670, Aug. 2005.

[We93] N. H. E. WESTE and K. ESHRAGHIAN, Principles of CMOS VLSI design. 2. ed. Reading, Addison - Wesley, 1993.

[Se97] SEMICONDUCTOR INDUSTRY ASSOCIATION (SIA), The national technology roadmap for semiconductors. San Jose , Nov. 1997.

[Sv87] I. KARLSSON and C. A. SVENSSON, A True Single-Phase-Clock Dynamic CMOS Circuit Technique. IEEE J. Solid-State Circuits, vol.22, pp.899-901, Oct. 1987.

[Ya98] C. Y. YANG, G. K. DEHNG, J.-M. HSU and S.-I. LIU, New dynamic flip-flop for high-speed dual-modulus prescaler. IEEE J. Solid-State Circuits, vol. 33, pp. 1568-1571, Oct. 1998. 
[Ya99] H. YAN H. and K.K. O, A high-speed CMOS dual-phase-dynamic-pseudo NMOS ((DP) ${ }^{2}$ latch and its application in a dual-modulus prescaler. IEEE J. Solid-State Circuits, vol.34, pp.1400-1404, Oct. 1999.

[Yu87] J. R. YUAN, New domino logic precharged by clock and data. Eletronics Letters, v.29, pp.2188-2189, Dec. 1993. 


\section{ANEXO A}

Tabelas com resultados de simulação e de medidas elétricas.

Tabela 4. Valores de Freqüência Máxima de Operação e Potência Consumida, utilizando várias tensões de alimentação, para o modelo típico.

\begin{tabular}{|c|c|c|c|c|c|c|}
\hline \multicolumn{7}{|c|}{ Modelo Típico } \\
\hline \multirow{2}{*}{$\mathbf{V}_{\mathbf{D D}}(\mathbf{V})$} & \multicolumn{2}{|c|}{ Prescaler 1 } & \multicolumn{2}{c|}{ Prescaler 2 } & \multicolumn{2}{c|}{ Prescaler 3 } \\
\cline { 2 - 7 } & $\begin{array}{c}\text { Máxima } \\
\text { Freqüência } \\
(\mathbf{G H z})\end{array}$ & $\begin{array}{c}\text { Potência } \\
\text { Consumida } \\
(\mathbf{m W})\end{array}$ & $\begin{array}{c}\text { Máxima } \\
\text { Freqüência } \\
(\mathbf{G H z})\end{array}$ & $\begin{array}{c}\text { Potência } \\
\text { Consumida } \\
(\mathbf{m W})\end{array}$ & $\begin{array}{c}\text { Máxima } \\
\text { Freqüência } \\
(\mathbf{G H z})\end{array}$ & $\begin{array}{c}\text { Potência } \\
\text { Consumida } \\
(\mathbf{m W})\end{array}$ \\
\hline 3,30 & 2,65 & 3,04 & 2,00 & 2,51 & 4,05 & 4,03 \\
\hline 3,00 & 2,35 & 2,43 & 1,80 & 1,90 & 3,65 & 2,95 \\
\hline 2,50 & 1,70 & 1,40 & 1,45 & 1,10 & 2,95 & 1,58 \\
\hline 2,00 & 1,10 & 0,66 & 1,00 & 0,53 & 1,95 & 0,69 \\
\hline 1,50 & 0,60 & 0,23 & 0,50 & 0,17 & 1,05 & 0,21 \\
\hline
\end{tabular}

Tabela 5. Valores de Freqüência Máxima de Operação e Consumo de Potências, utilizando várias tensões de alimentação, para o modelo slow.

\begin{tabular}{|c|c|c|c|c|c|c|}
\hline \multicolumn{7}{|c|}{ Modelo Slow } \\
\hline \multirow{2}{*}{$\mathbf{V}_{\mathbf{D D}}(\mathbf{V})$} & \multicolumn{2}{|c|}{ Prescaler 1 } & \multicolumn{2}{c|}{ Prescaler 2 } & \multicolumn{2}{c|}{ Prescaler 3 } \\
\cline { 2 - 7 } & $\begin{array}{c}\text { Máxima } \\
\text { Freqüêencia } \\
(\mathbf{G H z})\end{array}$ & $\begin{array}{c}\text { Potência } \\
\text { Consumida } \\
(\mathbf{m W})\end{array}$ & $\begin{array}{c}\text { Máxima } \\
\text { Freqüência } \\
(\mathbf{G H z})\end{array}$ & $\begin{array}{c}\text { Potência } \\
\text { Consumida } \\
(\mathbf{m W})\end{array}$ & $\begin{array}{c}\text { Máxima } \\
\text { Freqüência } \\
(\mathbf{G H z})\end{array}$ & $\begin{array}{c}\text { Potência } \\
\text { Consumida } \\
(\mathbf{m W})\end{array}$ \\
\hline 3,30 & 2,05 & 2,27 & 1,55 & 1,88 & 2,80 & 2,85 \\
\hline 3,00 & 1,60 & 1,71 & 1,15 & 1,29 & 2,50 & 2,06 \\
\hline 2,50 & 1,10 & 0,95 & 0,90 & 0,73 & 1,85 & 1,06 \\
\hline 2,00 & 0,70 & 0,44 & 0,60 & 0,33 & 1,20 & 0,44 \\
\hline 1,50 & 0,35 & 0,14 & 0,25 & 0,10 & 0,55 & 0,12 \\
\hline
\end{tabular}

Tabela 6. Valores de Freqüência Máxima Operação e Potência Consumida, utilizando várias tensões de alimentação, para o modelo fast.

\begin{tabular}{|c|c|c|c|c|c|c|}
\hline \multicolumn{7}{|c|}{ Modelo Fast } \\
\hline \multirow[b]{2}{*}{$V_{D D}(V)$} & \multicolumn{2}{|c|}{ Prescaler 1} & \multicolumn{2}{|c|}{ Prescaler 2} & \multicolumn{2}{|c|}{ Prescaler 3} \\
\hline & $\begin{array}{l}\text { Máxima } \\
\text { Freqüência } \\
\text { (GHz) }\end{array}$ & $\begin{array}{c}\text { Potência } \\
\text { Consumida } \\
(\mathrm{mW})\end{array}$ & $\begin{array}{l}\text { Máxima } \\
\text { Freqüiência } \\
\text { (GHz) }\end{array}$ & $\begin{array}{c}\text { Potência } \\
\text { Consumida } \\
(\mathrm{mW})\end{array}$ & $\begin{array}{l}\text { Máxima } \\
\text { Freqüiência } \\
\text { (GHz) }\end{array}$ & $\begin{array}{l}\text { Potência } \\
\text { Consumida } \\
(\mathrm{mW})\end{array}$ \\
\hline 3,30 & 4,55 & 4,76 & 3,55 & 4,18 & 7,00 & 6,67 \\
\hline 3,00 & 3,85 & 3,75 & 2,20 & 1,68 & 5,15 & 4,37 \\
\hline 2,50 & 2,90 & 2,22 & 2,70 & 1,94 & 4,85 & 2,63 \\
\hline 2,00 & 2,10 & 1,13 & 1,95 & 0,93 & 3,70 & 1,25 \\
\hline 1,50 & 1,30 & 0,43 & 1,25 & 0,35 & 2,35 & 0,44 \\
\hline
\end{tabular}


Tabela 7. Valores de Freqüência de Operação e Potência Consumida, para uma tensão de alimentação igual a 3,3V e modelo típico.

\begin{tabular}{|c|c|c|c|}
\hline \multicolumn{4}{|c|}{ Modelo Típico para $V_{D D}=3,3 V$} \\
\hline \multirow[b]{2}{*}{$\begin{array}{l}\text { Freqüência de } \\
\text { Operação } \\
\text { (GHz) }\end{array}$} & Prescaler 1 & Prescaler 2 & Prescaler 3 \\
\hline & $\begin{array}{c}\text { Potência } \\
\text { Consumida } \\
(\mathrm{mW})\end{array}$ & $\begin{array}{l}\text { Potência } \\
\text { Consumida } \\
(\mathrm{mW})\end{array}$ & $\begin{array}{c}\text { Potência } \\
\text { Consumida } \\
(\mathrm{mW})\end{array}$ \\
\hline 0,50 & 2,13 & 1,64 & 1,80 \\
\hline 1,00 & 2,50 & 1,90 & 2,35 \\
\hline 1,50 & 2,64 & 2,19 & 2,45 \\
\hline 2,00 & 2,82 & 2,51 & 2,78 \\
\hline 2,50 & 3,00 & - & 3,10 \\
\hline 3,00 & - & - & 3,41 \\
\hline 3,50 & - & - & 3,72 \\
\hline 4,00 & - & - & 4,00 \\
\hline
\end{tabular}

Tabela 8. Valores de Freqüência Operação e Potência Consumida, para uma tensão de alimentação igual a $3,3 \mathrm{~V}$, para o modelo slow.

\begin{tabular}{|c|c|c|c|}
\hline \multicolumn{4}{|c|}{ Modelo Slow para $\mathrm{V}_{\mathrm{DD}}=\mathbf{3 , 3 \mathrm { V }}$} \\
\hline & Prescaler 1 & Prescaler 2 & Prescaler 3 \\
\hline $\begin{array}{c}\text { Operação } \\
\text { (GHz) }\end{array}$ & $\begin{array}{c}\text { Potência } \\
\text { Consumida } \\
(\mathrm{mW})\end{array}$ & $\begin{array}{c}\text { Potência } \\
\text { Consumida } \\
(\mathrm{mW})\end{array}$ & $\begin{array}{c}\text { Potência } \\
\text { Consumida } \\
(\mathrm{mW})\end{array}$ \\
\hline 0,50 & 1,73 & 1,25 & 1,39 \\
\hline 1,00 & 1,88 & 1,52 & 1,73 \\
\hline 1,50 & 2,06 & 1,84 & 2,05 \\
\hline 2,00 & 2,24 & - & 2,38 \\
\hline 2,50 & - & - & 2,73 \\
\hline
\end{tabular}


Tabela 9. Valores de Freqüência de Operação e Potência Consumida, para uma tensão de alimentação igual a $3,3 \mathrm{~V}$, para o modelo fast.

\begin{tabular}{|c|c|c|c|}
\hline \multicolumn{4}{|c|}{ Modelo Fast para $\mathbf{V}_{\text {DD }}=\mathbf{3 , 3 V}$} \\
\hline $\begin{array}{c}\text { Freqüência de } \\
\text { Operação } \\
\text { (GHz) }\end{array}$ & $\begin{array}{c}\text { Prescaler 1 } \\
\text { Potência } \\
\text { Consumida } \\
\text { (mW) }\end{array}$ & $\begin{array}{c}\text { Prescaler 2 } \\
\begin{array}{c}\text { Potência } \\
\text { Consumida } \\
\text { (mW) }\end{array}\end{array}$ & $\begin{array}{c}\text { Prescaler 3 } \\
\begin{array}{c}\text { Potência } \\
\text { Consumida } \\
\text { (mW) }\end{array}\end{array}$ \\
\hline 0,50 & 3,44 & 2,44 & 2,60 \\
\hline 1,00 & 3,58 & 2,64 & 2,88 \\
\hline 1,50 & 3,70 & 2,91 & 3,19 \\
\hline 2,00 & 3,84 & 3,19 & 3,51 \\
\hline 2,50 & 3,98 & 3,49 & 3,84 \\
\hline 3,00 & 4,15 & 3,81 & 4,17 \\
\hline 3,50 & 4,34 & 4,15 & 4,49 \\
\hline 4,00 & 4,52 & 4,18 & 4,81 \\
\hline 4,50 & 4,74 & - & 5,13 \\
\hline 5,00 & 4,76 & - & 5,46 \\
\hline 5,50 & - & - & 5,79 \\
\hline 6,00 & - & - & 6,10 \\
\hline 6,50 & - & - & 6,37 \\
\hline 7,00 & - & - & 6,67 \\
\hline
\end{tabular}

Tabela 10. Valores de Freqüência de Operação e Potência Consumida, medidas realizadas no C.I. para uma tensão de alimentação igual a 2,0V.

\begin{tabular}{|c|c|c|c|}
\hline \multicolumn{4}{|c|}{ Medidas realizadas no C.I. para $V_{D D}=2,0 \mathrm{~V}$} \\
\hline \multirow[b]{2}{*}{$\begin{array}{c}\text { Freqüência de } \\
\text { Operação } \\
\text { (GHz) }\end{array}$} & Prescaler 1 & Prescaler 2 & Prescaler 3 \\
\hline & $\begin{array}{c}\text { Potência } \\
\text { Consumida } \\
(\mathbf{m W})\end{array}$ & $\begin{array}{c}\text { Potência } \\
\text { Consumida } \\
(\mathbf{m W})\end{array}$ & $\begin{array}{c}\text { Potência } \\
\text { Consumida } \\
(\mathrm{mW})\end{array}$ \\
\hline 0,10 & 0,82 & 0,50 & 0,46 \\
\hline 0,20 & 0,86 & 0,53 & 0,50 \\
\hline 0,40 & 0,92 & 0,63 & 0,56 \\
\hline 0,60 & 0,96 & 0,69 & 0,63 \\
\hline 0,80 & 1,06 & 0,79 & 0,69 \\
\hline 0,90 & 1,09 & 0,82 & - \\
\hline 0,98 & 1,12 & - & - \\
\hline 1,00 & - & - & 0,79 \\
\hline 1,20 & - & - & 0,86 \\
\hline 1,40 & - & - & 0,92 \\
\hline 1,60 & - & - & 0,96 \\
\hline 1,70 & - & - & 1,02 \\
\hline
\end{tabular}


Tabela 11. Valores de Freqüência de Operação e Potência Consumida, medidas realizadas no C.I. para uma tensão de alimentação igual a 3,3V.

\begin{tabular}{|c|c|c|c|}
\hline \multicolumn{4}{|c|}{ Medidas realizadas no C.I. para $V_{D D}=3,3 \mathrm{~V}$} \\
\hline \multirow[b]{2}{*}{$\begin{array}{l}\text { Freqüência de } \\
\text { Operação } \\
\text { (GHz) }\end{array}$} & Prescaler 1 & Prescaler 2 & Prescaler 3 \\
\hline & $\begin{array}{c}\text { Potência } \\
\text { Consumida } \\
(\mathrm{mW})\end{array}$ & $\begin{array}{c}\text { Potência } \\
\text { Consumida } \\
(\mathrm{mW})\end{array}$ & $\begin{array}{c}\text { Potência } \\
\text { Consumida } \\
(\mathrm{mW})\end{array}$ \\
\hline 0,10 & 2,31 & 1,39 & 1,42 \\
\hline 0,20 & 2,34 & 1,45 & 1,49 \\
\hline 0,40 & 2,38 & 1,58 & 1,62 \\
\hline 0,60 & 2,41 & 1,68 & 1,75 \\
\hline 0,80 & 2,51 & 1,82 & 1,88 \\
\hline 1,00 & 2,54 & 1,91 & 2,01 \\
\hline 1,20 & 2,64 & 2,08 & 2,11 \\
\hline 1,40 & 2,67 & 2,18 & 2,24 \\
\hline 1,60 & 2,71 & 2,24 & 2,38 \\
\hline 1,80 & 2,74 & 2,41 & 2,51 \\
\hline 1,84 & - & 2,44 & - \\
\hline 2,00 & 2,90 & - & 2,64 \\
\hline 2,10 & 3,04 & - & - \\
\hline 2,20 & - & - & 2,77 \\
\hline 2,40 & - & - & 2,90 \\
\hline 2,60 & - & - & 3,04 \\
\hline 2,80 & - & - & 3,17 \\
\hline 3,00 & - & - & 3,33 \\
\hline 3,20 & - & - & 3,46 \\
\hline 3,40 & - & - & 3,56 \\
\hline 3,58 & - & - & 3,66 \\
\hline
\end{tabular}

Tabela 12. Valores de Freqüência Máxima de Operação e Potência Consumida, utilizando várias tensões de alimentação, medidas realizadas no C.I..

\begin{tabular}{|c|c|c|c|c|c|c|}
\hline \multicolumn{7}{|c|}{ Medidas realizadas no C.I. } \\
\hline \multirow{2}{*}{$\mathbf{V}_{\mathbf{D D}}(\mathbf{V})$} & \multicolumn{2}{|c|}{ Prescaler 1 } & \multicolumn{2}{c|}{ Prescaler 2 } & \multicolumn{2}{c|}{ Prescaler 3 } \\
\cline { 2 - 7 } & $\begin{array}{c}\text { Máxima } \\
\text { Freqüência } \\
(\mathbf{G H z})\end{array}$ & $\begin{array}{c}\text { Potência } \\
\text { Consumida } \\
(\mathbf{m W})\end{array}$ & $\begin{array}{c}\text { Máxima } \\
\text { Freqüência } \\
(\mathbf{G H z})\end{array}$ & $\begin{array}{c}\text { Potência } \\
\text { Consumida } \\
(\mathbf{m W})\end{array}$ & $\begin{array}{c}\text { Máxima } \\
\text { Freqüência } \\
(\mathbf{G H z})\end{array}$ & $\begin{array}{c}\text { Potência } \\
\text { Consumida } \\
(\mathbf{m W})\end{array}$ \\
\hline 3,60 & 2,67 & 3,28 & 2,00 & 3,10 & 4,12 & 4,93 \\
\hline 3,30 & 2,10 & 3,04 & 1,84 & 2,44 & 3,58 & 3,66 \\
\hline 3,00 & 1,82 & 2,31 & 1,66 & 1,89 & 3,50 & 2,79 \\
\hline 2,50 & 1,58 & 1,38 & 1,30 & 1,10 & 3,01 & 1,68 \\
\hline 2,00 & 0,98 & 0,68 & 0,90 & 0,50 & 1,78 & 0,62 \\
\hline
\end{tabular}




\section{ANEXO B}

Arquivo extraído para simulação no HSPICE dos três Prescalers:

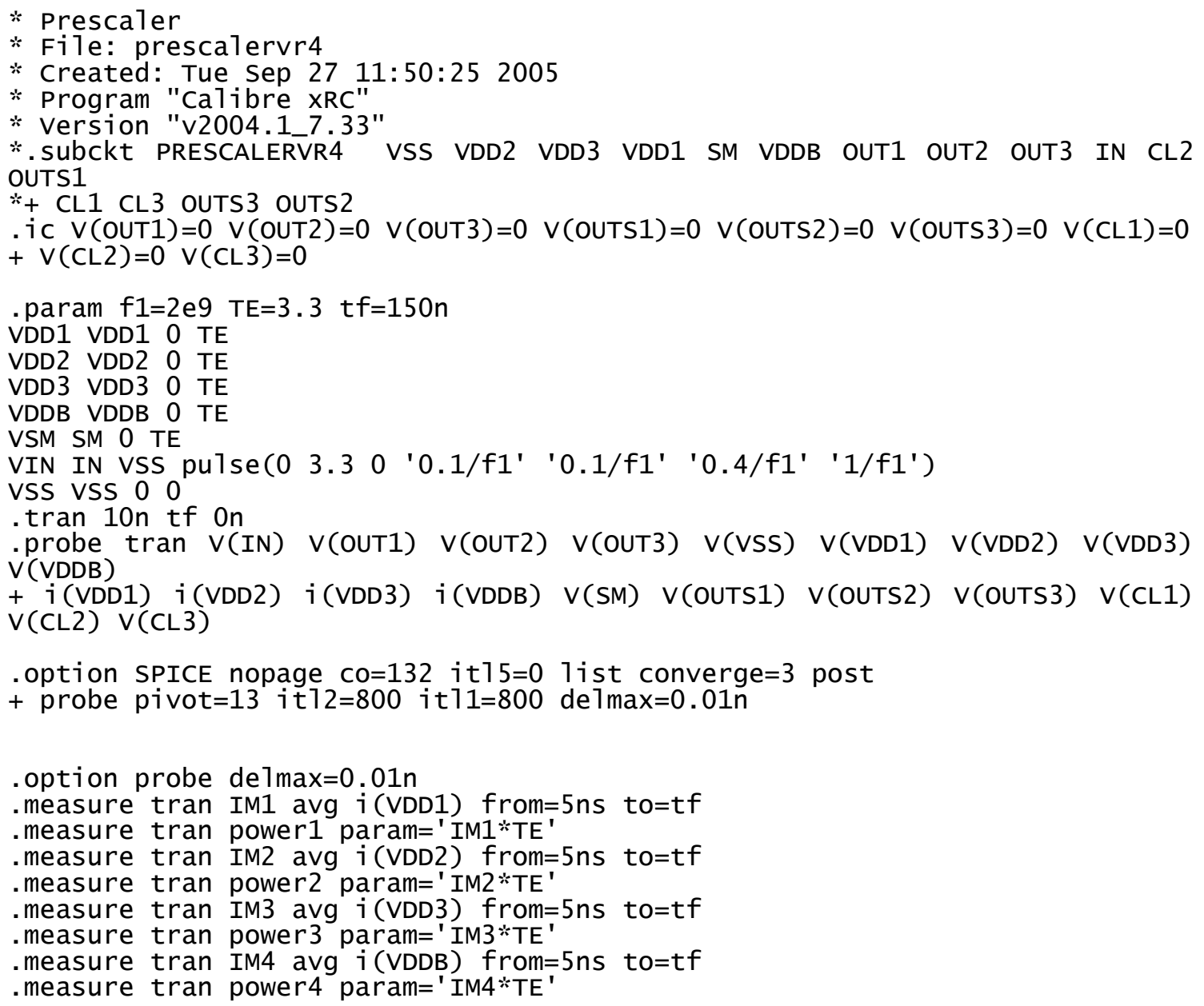

mM0 VSS SM VSS VSS MODN $L=1.5 \mathrm{e}-05 \mathrm{~W}=3 \mathrm{e}-05 \quad \mathrm{AD}=1.1625 \mathrm{e}-10 \quad \mathrm{AS}=1.1625 \mathrm{e}-10$ $+\mathrm{PD}=7.75 \mathrm{e}-06 \mathrm{PS}=7.75 \mathrm{e}-06 \mathrm{NRD}=0.0141667 \mathrm{NRS}=0.0141667$

$m \times 5 \_M 0 \times 5 \_4$ IN VSS VSS MODN L=3.5e-07 $W=4 e-06 \quad A D=4.3 e-12 \quad A S=4.3 e-12$ $+\mathrm{PD}=6.15 \overline{\mathrm{e}}-06 \mathrm{PS}=6.15 \mathrm{e}-06 \mathrm{NRD}=0.10625 \mathrm{NRS}=0.10625$ mX5_M1 X5_5 X5_4 VSS VSS MODN L $=3.5 \mathrm{e}-07 \mathrm{~W}=9 \mathrm{e}-06$ AD $=9.675 \mathrm{e}-12$ AS $=9.675 \mathrm{e}-12$ $+\mathrm{PD}=1.115 \mathrm{e}-05 \mathrm{PS}=1.115 \mathrm{e}-05 \mathrm{NRD}=0.0472222 \mathrm{NRS}=0.0472222$ $\mathrm{m} \times 5$ 5 2 X5_6 X5_5 VSS VSS MODN L=3.5e-07 $W=1.5 \mathrm{e}-05 \quad \mathrm{AD}=1.3875 \mathrm{e}-11$ AS $=1.65 \mathrm{e}-11$ $+\mathrm{PD}=9.75 \mathrm{e}-06 \mathrm{PS}=1.72 \mathrm{e}-05 \mathrm{NRD}=0.0283333 \mathrm{NRS}=0.0283333$ $m \times 5 \_M 3$ VSS X5_5 X5_6 VSS MODN L $=3.5 e-07 \quad W=5 e-06 \quad A D=5.25 e-12 \quad A S=4.625 e-12$ $+\mathrm{PD}=7.1 \mathrm{e}-06 \mathrm{PS}=3.25 \mathrm{e}-06 \mathrm{NRD}=0.085 \mathrm{NRS}=0.085$ $\mathrm{m} \times 5$ 54 CL1 X5_6 VSS VSS MODN L=3.5e-07 $\mathrm{W}=1.5 \mathrm{e}-05$ AD=8.25e-12 AS=1.65e-11 $+\mathrm{PD}=1.1 \mathrm{e}-06 \mathrm{PS}=1.72 \mathrm{e}-05 \mathrm{NRD}=0.0283333 \mathrm{NRS}=0.0283333$ mX5_M5 VSS X5_6 CL1 VSS MODN L=3.5e-07 W=1.5e-05 AD=1.1431e-11 AS=8.25e-12 
$+\mathrm{PD}=2.06897 \mathrm{e}-06 \mathrm{PS}=1.1 \mathrm{e}-06 \mathrm{NRD}=0.0283333 \mathrm{NRS}=0.0283333$

mX5_M6 CL1 X5_6 VSS VSS MODN L=3.5e-07 W=1.4e-05 AD=1.47e-11 AS=1.0669e-11 $+\mathrm{PD}=1.61 \mathrm{e}-05 \mathrm{PS}=1.93103 \mathrm{e}-06 \mathrm{NRD}=0.0303571 \mathrm{NRS}=0.0303571$

$\mathrm{m} \times 5$ 57 X5_4 IN VDDB VDDB MODP $\mathrm{L}=3.5 \mathrm{e}-07 \mathrm{~W}=8 \mathrm{e}-06 \quad \mathrm{AD}=8.8 \mathrm{e}-12 \quad \mathrm{AS}=8.4 \mathrm{e}-12$ $+\mathrm{PD}=1.02 \mathrm{e}-05 \mathrm{PS}=1.01 \mathrm{e}-05 \mathrm{NRD}=0.053125 \mathrm{NRS}=0.053125$

$\mathrm{mX5}$ ×M8 X5_5 X5_4 VDDB VDDB MODP L=3.5e-07 $\mathrm{W}=1.5 \mathrm{e}-05 \quad \mathrm{AD}=1.475 \mathrm{e}-11$ AS $=1.65 \mathrm{e}-$ 11

$+\mathrm{PD}=1.25 \mathrm{e}-05 \mathrm{PS}=1.72 \mathrm{e}-05 \mathrm{NRD}=0.0283333 \mathrm{NRS}=0.0283333$

$\mathrm{m} \times 5$ 599 VDDB X5_4 X5_5 VDDB MODP $\mathrm{L}=3.5 \mathrm{e}-07 \quad \mathrm{~W}=3 \mathrm{e}-06 \quad \mathrm{AD}=3.15 \mathrm{e}-12 \quad \mathrm{AS}=2.95 \mathrm{e}-12$

$+\mathrm{PD}=5.1 \mathrm{e}-06 \mathrm{PS}=2.5 \mathrm{e}-06 \mathrm{NRD}=0.141667 \mathrm{NRS}=0.141667$

mX5_M10 X5_6 X5_5 VDDB VDDB MODP L=3.5e-07 $\mathrm{W}=1.5 \mathrm{e}-05 \quad \mathrm{AD}=8.25 \mathrm{e}-12$ AS=1.65e11

$+\mathrm{PD}=1.1 \mathrm{e}-06 \mathrm{PS}=1.72 \mathrm{e}-05 \mathrm{NRD}=0.0283333 \mathrm{NRS}=0.0283333$

$\mathrm{m} \times 5$ 511 VDDB X5_5 X5_6 VDDB MODP L=3.5e-07 $\mathrm{W}=1.5 \mathrm{e}-05$ AD $=1.23 \mathrm{e}-11$ AS $=8.25 \mathrm{e}-$ 12

$+\mathrm{PD}=4.8 \mathrm{e}-06 \mathrm{PS}=1.1 \mathrm{e}-06 \mathrm{NRD}=0.0283333 \mathrm{NRS}=0.0283333$

$\mathrm{m} \times 5$ 512 X5_6 X5_5 VDDB VDDB MODP $\mathrm{L}=3.5 \mathrm{e}-07 \mathrm{~W}=1 \mathrm{e}-05 \mathrm{AD}=1.05 \mathrm{e}-11 \quad \mathrm{AS}=8.2 \mathrm{e}-12$

$+\mathrm{PD}=1.21 \mathrm{e}-05 \mathrm{PS}=3.2 \mathrm{e}-06 \mathrm{NRD}=0.0425 \mathrm{NRS}=0.0425$

$\mathrm{mX5}$ 513 CL1 X5_6 VDDB VDDB MODP $L=3.5 \mathrm{e}-07 \quad \mathrm{~W}=1.5 \mathrm{e}-05 \quad \mathrm{AD}=8.25 \mathrm{e}-12 \quad \mathrm{AS}=1.65 \mathrm{e}-11$

$+\mathrm{PD}=1.1 \mathrm{e}-06 \mathrm{PS}=1.72 \mathrm{e}-05 \mathrm{NRD}=0.0283333 \mathrm{NRS}=0.0283333$

$\mathrm{m} \times 5$ 514 VDDB X5_6 CL1 VDDB MODP $\mathrm{L}=3.5 \mathrm{e}-07 \mathrm{~W}=1.5 \mathrm{e}-05 \mathrm{AD}=8.25 \mathrm{e}-12 \mathrm{AS}=8.25 \mathrm{e}-12$

$+\mathrm{PD}=1.1 \mathrm{e}-06 \mathrm{PS}=1.1 \mathrm{e}-06 \mathrm{NRD}=0.0283333 \mathrm{NRS}=0.0283333$

$\mathrm{m} \times 5$ M15 CL1 X5_6 VDDB VDDB MODP $\mathrm{L}=3.5 \mathrm{e}-07 \mathrm{~W}=1.5 \mathrm{e}-05 \quad \mathrm{AD}=8.25 \mathrm{e}-12 \quad \mathrm{AS}=8.25 \mathrm{e}-12$

$+\mathrm{PD}=1.1 \mathrm{e}-06 \mathrm{PS}=1.1 \mathrm{e}-06 \mathrm{NRD}=0.0283333 \mathrm{NRS}=0.0283333$

$\mathrm{m} \times 5$ 516 VDDB X5_6 CL1 VDDB MODP $\mathrm{L}=3.5 \mathrm{e}-07 \mathrm{~W}=1.5 \mathrm{e}-05 \quad \mathrm{AD}=8.25 \mathrm{e}-12 \quad \mathrm{AS}=8.25 \mathrm{e}-12$ $+\mathrm{PD}=1.1 \mathrm{e}-06 \mathrm{PS}=1.1 \mathrm{e}-06 \mathrm{NRD}=0.0283333 \mathrm{NRS}=0.0283333$

$\mathrm{m} \times 5$ 517 CL1 X5_6 VDDB VDDB MODP $\mathrm{L}=3.5 \mathrm{e}-07 \mathrm{~W}=1.5 \mathrm{e}-05 \mathrm{AD}=1.1431 \mathrm{e}-11 \mathrm{AS}=8.25 \mathrm{e}-$ 12

$+\mathrm{PD}=2.06897 \mathrm{e}-06 \mathrm{PS}=1.1 \mathrm{e}-06 \mathrm{NRD}=0.0283333 \mathrm{NRS}=0.0283333$

mX5_M18 VDDB X5_6 CL1 VDDB MODP L=3.5e-07 W=1.4e-05 AD=1.47e-11 AS=1.0669e11

$+\mathrm{PD}=1.61 \mathrm{e}-05 \mathrm{PS}=1.93103 \mathrm{e}-06 \mathrm{NRD}=0.0303571 \mathrm{NRS}=0.0303571$

$\mathrm{m} \times 58 \mathrm{M} 0 \times 58 \quad 4$ IN VSS VSS MODN L=3.5e-07 $\mathrm{W}=4 \mathrm{e}-06 \quad \mathrm{AD}=4.3 \mathrm{e}-12 \quad \mathrm{AS}=4.3 \mathrm{e}-12$

$+\mathrm{PD}=6.15 \mathrm{e}-06 \mathrm{PS}=6.15 \mathrm{e}-06 \mathrm{NRD}=0.10625 \mathrm{NRS}=0.10625$

$\mathrm{m} \times 58 \_M 1 \times 58 \_5 \times 58 \_4$ VSS VSS MODN L=3.5e-07 $\mathrm{W}=9 \mathrm{e}-06$ AD $=9.675 \mathrm{e}-12$ AS $=9.675 \mathrm{e}-$ 12

$+\mathrm{PD}=1.115 \mathrm{e}-05 \mathrm{PS}=1.115 \mathrm{e}-05 \mathrm{NRD}=0.0472222 \mathrm{NRS}=0.0472222$

$\mathrm{m} \times 58$ 52 2 58_6 $658 \_5$ VSS VSS MODN L=3.5e-07 W=1.5e-05 AD=1.3875e-11 $\mathrm{AS}=1.65 \mathrm{e}-11$

$+\mathrm{PD}=9.75 \mathrm{e}-06 \mathrm{PS}=1.72 \mathrm{e}-05 \mathrm{NRD}=0.0283333 \mathrm{NRS}=0.0283333$

$\mathrm{m} \times 58 \_M 3$ VSS X58_5 X58_6 VSS MODN L=3.5e-07 $W=5 e-06 \quad A D=5.25 e-12 \quad A S=4.625 e-12$ $+\mathrm{PD}=7.1 \mathrm{e}-06 \mathrm{PS}=3.25 \mathrm{e}-06 \mathrm{NRD}=0.085 \mathrm{NRS}=0.085$

$\mathrm{m} \times 58 \_M 4$ CL3 X58_6 VSS VSS MODN $\mathrm{L}=3.5 \mathrm{e}-07 \mathrm{~W}=1.5 \mathrm{e}-05$ AD $=8.25 \mathrm{e}-12$ AS $=1.65 \mathrm{e}-11$ $+\mathrm{PD}=1.1 \mathrm{e}-06 \mathrm{PS}=1.72 \mathrm{e}-05 \mathrm{NRD}=0.0283333 \mathrm{NRS}=0.0283333$

mX58_M5 VSS X58_6 CL3 VSS MODN L=3.5e-07 $W=1.5 e-05$ AD $=1.1431 e-11$ AS $=8.25 e-$ 12

$+\mathrm{PD}=2.06897 \mathrm{e}-06 \mathrm{PS}=1.1 \mathrm{e}-06 \mathrm{NRD}=0.0283333 \mathrm{NRS}=0.0283333$

mX58_M6 CL3 X58_6 VSS VSS MODN L=3.5e-07 $W=1.4 \mathrm{e}-05 \quad A D=1.47 \mathrm{e}-11 \quad A S=1.0669 \mathrm{e}-$ 11

$+\mathrm{PD}=1.61 \mathrm{e}-05 \mathrm{PS}=1.93103 \mathrm{e}-06 \mathrm{NRD}=0.0303571 \mathrm{NRS}=0.0303571$

$\mathrm{m} \times 58 \_M 7 \times 58 \_4$ IN VDDB VDDB MODP $\mathrm{L}=3.5 \mathrm{e}-07 \quad \mathrm{~W}=8 \mathrm{e}-06 \quad \mathrm{AD}=8.8 \mathrm{e}-12 \quad \mathrm{AS}=8.4 \mathrm{e}-12$

$+\mathrm{PD}=1.02 \mathrm{e}-05 \mathrm{PS}=1.01 \mathrm{e}-05 \mathrm{NRD}=0.053125 \mathrm{NRS}=0.053125$

$\mathrm{m} \times 58 \_M 8 \times 58 \_5 \times 58 \_4$ VDDB VDDB MODP $\mathrm{L}=3.5 \mathrm{e}-07 \mathrm{~W}=1.5 \mathrm{e}-05 \quad \mathrm{AD}=1.475 \mathrm{e}-11$

$+\mathrm{AS}=1.65 \mathrm{e}-11 \mathrm{PD}=1.25 \mathrm{e}-05 \mathrm{PS}=1.72 \mathrm{e}-05 \mathrm{NRD}=0.0283333 \mathrm{NRS}=0.0283333$

$\mathrm{m} \times 58 \_$M9 VDDB $\times 58 \_4$ X58_5 VDDB MODP $\mathrm{L}=3.5 \mathrm{e}-07 \mathrm{~W}=3 \mathrm{e}-06 \quad \mathrm{AD}=3.15 \mathrm{e}-12$ AS=2.95e12

$+\mathrm{PD}=5.1 \mathrm{e}-06 \mathrm{PS}=2.5 \mathrm{e}-06 \mathrm{NRD}=0.141667 \mathrm{NRS}=0.141667$

$\mathrm{m} \times 58 \_\mathrm{M} 10 \times 58 \_6 \times 58 \_5$ VDDB VDDB MODP $\mathrm{L}=3.5 \mathrm{e}-07 \mathrm{~W}=1.5 \mathrm{e}-05 \mathrm{AD}=8.25 \mathrm{e}-12$

$+\mathrm{AS}=1.65 \mathrm{e}-11 \mathrm{PD}=1.1 \mathrm{e}-06 \mathrm{PS}=1.72 \mathrm{e}-05 \mathrm{NRD}=0.0283333 \mathrm{NRS}=0.0283333$

$\mathrm{m} \times 58 \_$M11 VDDB X58_5 X58_6 VDDB MODP $\mathrm{L}=3.5 \mathrm{e}-07 \mathrm{~W}=1.5 \mathrm{e}-05 \quad \mathrm{AD}=1.23 \mathrm{e}-11$

$+\mathrm{AS}=8.25 \mathrm{e}-12 \mathrm{PD}=4.8 \mathrm{e}-0 \overline{6} \mathrm{PS}=1.1 \mathrm{e}-06 \mathrm{NRD}=0.0283333 \mathrm{NRS}=0.0283333$

$\mathrm{m} \times 58 \_$M12 X58_6 X58_5 VDDB VDDB MODP $L=3.5 \mathrm{e}-07 \mathrm{~W}=1 \mathrm{e}-05 \mathrm{AD}=1.05 \mathrm{e}-11$ AS $=8.2 \mathrm{e}-$ 12

$+\mathrm{PD}=1.21 \mathrm{e}-05 \mathrm{PS}=3.2 \mathrm{e}-06 \mathrm{NRD}=0.0425 \mathrm{NRS}=0.0425$

$\mathrm{m} \times 58 \_$M13 CL3 X58_6 VDDB VDDB MODP $L=3.5 \mathrm{e}-07 \mathrm{~W}=1.5 \mathrm{e}-05$ AD=8.25e-12 AS=1.65e11

$+\mathrm{PD}=1.1 \mathrm{e}-06 \mathrm{PS}=1.72 \mathrm{e}-05 \mathrm{NRD}=0.0283333 \mathrm{NRS}=0.0283333$

$\mathrm{m} \times 58 \_$M14 VDDB $\times 58 \_6$ CL3 VDDB MODP $\mathrm{L}=3.5 \mathrm{e}-07 \mathrm{~W}=1.5 \mathrm{e}-05 \mathrm{AD}=8.25 \mathrm{e}-12$ AS=8.25e12

$+\mathrm{PD}=1.1 \mathrm{e}-06 \mathrm{PS}=1.1 \mathrm{e}-06 \mathrm{NRD}=0.0283333 \mathrm{NRS}=0.0283333$ 
mX58_M15 CL3 X58_6 VDDB VDDB MODP L=3.5e-07 W=1.5e-05 AD=8.25e-12 AS=8.25e12

$+\mathrm{PD}=1.1 \mathrm{e}-06 \mathrm{PS}=1.1 \mathrm{e}-06 \mathrm{NRD}=0.0283333 \mathrm{NRS}=0.0283333$

$m \times 58 \_M 16$ VDDB X58_6 CL3 VDDB MODP $L=3.5 \mathrm{e}-07 \mathrm{~W}=1.5 \mathrm{e}-05 \quad \mathrm{AD}=8.25 \mathrm{e}-12 \quad \mathrm{AS}=8.25 \mathrm{e}-$ 12

$+\mathrm{PD}=1.1 \mathrm{e}-06 \mathrm{PS}=1.1 \mathrm{e}-06 \mathrm{NRD}=0.0283333 \mathrm{NRS}=0.0283333$

$m \times 58 \_M 17$ CL3 X58_6 VDDB VDDB MODP $L=3.5 \mathrm{e}-07 \quad \mathrm{~W}=1.5 \mathrm{e}-05 \quad \mathrm{AD}=1.1431 \mathrm{e}-11$

$+\mathrm{AS}=8.25 \mathrm{e}-12 \mathrm{PD}=2.06897 \mathrm{e}-06 \mathrm{PS}=1.1 \mathrm{e}-06 \mathrm{NRD}=0.0283333 \mathrm{NRS}=0.0283333$

$m \times 58 \_M 18$ VDDB X58_6 CL3 VDDB MODP $L=3.5 \mathrm{e}-07 \mathrm{~W}=1.4 \mathrm{e}-05 \quad \mathrm{AD}=1.47 \mathrm{e}-11$

$+\mathrm{AS}=1.0669 \mathrm{e}-11 \mathrm{PD}=1.61 \mathrm{e}-05 \mathrm{PS}=1.93103 \mathrm{e}-06 \mathrm{NRD}=0.0303571 \mathrm{NRS}=0.0303571$

mX59_M0 X59_4 IN VSS VSS MODN $L=3.5 e-07 \quad W=4 e-06 \quad A D=4.3 e-12 \quad A S=4.3 e-12$

$+\mathrm{PD}=6.15 \mathrm{e}-06 \mathrm{PS}=6.15 \mathrm{e}-06 \mathrm{NRD}=0.10625 \mathrm{NRS}=0.10625$

mX59_M1 X59_5 X59_4 VSS VSS MODN L=3.5e-07 W=9e-06 AD=9.675e-12 AS=9.675e12

$+P D=1.115 \mathrm{e}-05 \quad P S=1.115 \mathrm{e}-05 \mathrm{NRD}=0.0472222 \mathrm{NRS}=0.0472222$

mX59_M2 X59_6 X59_5 VSS VSS MODN $L=3.5 \mathrm{e}-07 \quad W=1.5 \mathrm{e}-05 \quad A D=1.3875 \mathrm{e}-11$ $\mathrm{AS}=1.65 \mathrm{e}-11$

$+\mathrm{PD}=9.75 \mathrm{e}-06 \mathrm{PS}=1.72 \mathrm{e}-05 \mathrm{NRD}=0.0283333 \mathrm{NRS}=0.0283333$

mX59_M3 VSS X59_5 X59_6 VSS MODN $L=3.5 e-07 \quad W=5 e-06 \quad A D=5.25 e-12 \quad A S=4.625 e-12$ $+\mathrm{PD}=7.1 \mathrm{e}-06 \mathrm{PS}=3.25 \mathrm{e}-06 \mathrm{NRD}=0.085 \mathrm{NRS}=0.085$

mX59_M4 CL2 X59_6 VSS VSS MODN L=3.5e-07 $\mathrm{W}=1.5 \mathrm{e}-05 \quad \mathrm{AD}=8.25 \mathrm{e}-12 \quad \mathrm{AS}=1.65 \mathrm{e}-11$

$+\mathrm{PD}=1.1 \mathrm{e}-06 \mathrm{PS}=1.72 \mathrm{e}-05 \mathrm{NRD}=0.0283333 \mathrm{NRS}=0.0283333$

mX59_M5 VSS X59_6 CL2 VSS MODN L=3.5e-07 W=1.5e-05 AD =1.1431e-11 AS $=8.25 \mathrm{e}-$ 12

$+\mathrm{PD}=2.06897 \mathrm{e}-06 \mathrm{PS}=1.1 \mathrm{e}-06 \mathrm{NRD}=0.0283333 \mathrm{NRS}=0.0283333$

mX59_M6 CL2 X59_6 VSS VSS MODN L=3.5e-07 W=1.4e-05 AD=1.47e-11 AS=1.0669e11

$+\mathrm{PD}=1.61 \mathrm{e}-05 \mathrm{PS}=1.93103 \mathrm{e}-06 \mathrm{NRD}=0.0303571 \mathrm{NRS}=0.0303571$

mX59_M7 X59_4 IN VDDB VDDB MODP $L=3.5 \mathrm{e}-07 \quad \mathrm{~W}=8 \mathrm{e}-06 \quad \mathrm{AD}=8.8 \mathrm{e}-12 \quad \mathrm{AS}=8.4 \mathrm{e}-12$

$+\mathrm{PD}=1.02 \mathrm{e}-05 \mathrm{PS}=1.01 \mathrm{e}-05 \mathrm{NRD}=0.053125 \mathrm{NRS}=0.053125$

$m \times 59 \_8 \times 595 \times 594$ VDDB VDDB MODP $L=3.5 \mathrm{e}-07 \quad W=1.5 \mathrm{e}-05 \quad \mathrm{AD}=1.475 \mathrm{e}-11$

$+A S=1.65 \mathrm{e}-11 \mathrm{PD}=1.25 \mathrm{e}-05 \mathrm{PS}=1.72 \mathrm{e}-05 \mathrm{NRD}=0.0283333 \mathrm{NRS}=0.0283333$

$m \times 59 \_M 9$ VDDB X59_4 X59_5 VDDB MODP $L=3.5 e-07 \quad W=3 e-06 \quad A D=3.15 e-12 \quad A S=2.95 e-$ 12

$+\mathrm{PD}=5.1 \mathrm{e}-06 \mathrm{PS}=2.5 \mathrm{e}-06 \mathrm{NRD}=0.141667 \mathrm{NRS}=0.141667$

$\mathrm{m} \times 59$ M10 X59 6 X59 5 VDDB VDDB MODP $\mathrm{L}=3.5 \mathrm{e}-07 \mathrm{~W}=1.5 \mathrm{e}-05 \quad \mathrm{AD}=8.25 \mathrm{e}-12$

$+\mathrm{AS}=1.65 \mathrm{e}-11 \mathrm{PD}=1.1 \mathrm{e}-06 \mathrm{PS}=1.72 \mathrm{e}-05 \mathrm{NRD}=0.0283333 \mathrm{NRS}=0.0283333$

mX59_M11 VDDB X59_5 X59_6 VDDB MODP $L=3.5 \mathrm{e}-07 \mathrm{~W}=1.5 \mathrm{e}-05$ AD $=1.23 \mathrm{e}-11$

$+\mathrm{AS}=8.25 \mathrm{e}-12 \mathrm{PD}=4.8 \mathrm{e}-06 \mathrm{6S}=1.1 \mathrm{e}-06 \mathrm{NRD}=0.0283333 \mathrm{NRS}=0.0283333$

mX59_M12 X59_6 X59_5 VDDB VDDB MODP $L=3.5 \mathrm{e}-07 \mathrm{~W}=1 \mathrm{e}-05 \quad \mathrm{AD}=1.05 \mathrm{e}-11$ AS $=8.2 \mathrm{e}-$ 12

$+\mathrm{PD}=1.21 \mathrm{e}-05 \mathrm{PS}=3.2 \mathrm{e}-06 \mathrm{NRD}=0.0425 \mathrm{NRS}=0.0425$

mX59_M13 CL2 X59_6 VDDB VDDB MODP L=3.5e-07 W=1.5e-05 AD=8.25e-12 AS=1.65e11

$+\mathrm{PD}=1.1 \mathrm{e}-06 \mathrm{PS}=1.72 \mathrm{e}-05 \mathrm{NRD}=0.0283333 \mathrm{NRS}=0.0283333$

mX59_M14 VDDB X59_6 CL2 VDDB MODP $L=3.5 \mathrm{e}-07 \quad W=1.5 \mathrm{e}-05 \quad \mathrm{AD}=8.25 \mathrm{e}-12 \quad \mathrm{AS}=8.25 \mathrm{e}-$ 12

$+\mathrm{PD}=1.1 \mathrm{e}-06 \mathrm{PS}=1.1 \mathrm{e}-06 \mathrm{NRD}=0.0283333 \mathrm{NRS}=0.0283333$

mX59_M15 CL2 X59_6 VDDB VDDB MODP $L=3.5 \mathrm{e}-07 \mathrm{~W}=1.5 \mathrm{e}-05 \quad \mathrm{AD}=8.25 \mathrm{e}-12 \quad \mathrm{AS}=8.25 \mathrm{e}-$ 12

$+\mathrm{PD}=1.1 \mathrm{e}-06 \mathrm{PS}=1.1 \mathrm{e}-06 \mathrm{NRD}=0.0283333 \mathrm{NRS}=0.0283333$

mX59_M16 VDDB X59_6 CL2 VDDB MODP $L=3.5 \mathrm{e}-07 \mathrm{~W}=1.5 \mathrm{e}-05 \quad \mathrm{AD}=8.25 \mathrm{e}-12 \quad \mathrm{AS}=8.25 \mathrm{e}-$ 12

$+\mathrm{PD}=1.1 \mathrm{e}-06 \mathrm{PS}=1.1 \mathrm{e}-06 \mathrm{NRD}=0.0283333 \mathrm{NRS}=0.0283333$

mX59_M17 CL2 X59_6 VDDB VDDB MODP $L=3.5 \mathrm{e}-07 \mathrm{~W}=1.5 \mathrm{e}-05 \quad \mathrm{AD}=1.1431 \mathrm{e}-11$

$+A S=8.25 \mathrm{e}-12 \quad \mathrm{PD}=2.06897 \mathrm{e}-06 \mathrm{PS}=1.1 \mathrm{e}-06 \mathrm{NRD}=0.0283333 \mathrm{NRS}=0.0283333$

mX59_M18 VDDB X59_6 CL2 VDDB MODP $L=3.5 \mathrm{e}-07 \quad \mathrm{~W}=1.4 \mathrm{e}-05 \quad \mathrm{AD}=1.47 \mathrm{e}-11$

$+\mathrm{AS}=1.0669 \mathrm{e}-11 \mathrm{PD}=1.61 \mathrm{e}-05 \mathrm{PS}=1.93103 \mathrm{e}-06 \mathrm{NRD}=0.0303571 \mathrm{NRS}=0.0303571$

mX1385_M0 X1385_14 X1385_12 VSS VSS MODN L=3.5e-07 $W=1.3 \mathrm{e}-06 \quad A D=7.475 \mathrm{e}-13$

$+\mathrm{AS}=1.3975 \mathrm{e}-12 \mathrm{PD}=1.15 \mathrm{e}-06 \quad \mathrm{PS}=3.45 \mathrm{e}-06 \mathrm{NRD}=0.326923 \mathrm{NRS}=0.326923$

mX1385_M1 VSS X1385_12 X1385_14 VSS MODN L=3.5e-07 $W=1.3 \mathrm{e}-06$ AD $=7.58904 \mathrm{e}-13$

$+\mathrm{AS}=7.475 \mathrm{e}-13 \mathrm{PD}=1.16316 \mathrm{e}-0 \overline{6} \mathrm{PS}=1.15 \mathrm{e}-06 \mathrm{NRD}=0.326923 \mathrm{NRS}=0.326923$

mX1385_M2 X1385_12 CL2 VSS VSS MODN L=3.5e-07 W=1.55e-06 AD=8.9125e-13

$+A S=9.04846 \mathrm{e}-1 \overline{3} P D=1.15 \mathrm{e}-06 \quad P S=1.38684 \mathrm{e}-06 \quad \mathrm{NRD}=0.274194 \quad \mathrm{NRS}=0.274194$

$m \times 1385 \_M 3$ VSS CL2 X1385_12 VSS MODN $L=3.5 \mathrm{e}-07 \quad W=1.55 \mathrm{e}-06 \quad A D=9.39877 \mathrm{e}-13$

$+\mathrm{AS}=8.9125 \mathrm{e}-13 \mathrm{PD}=1.76275 \mathrm{e}-06 \mathrm{PS}=1.15 \mathrm{e}-06 \quad \mathrm{NRD}=0.274194 \mathrm{NRS}=0.274194$

mX1385_M4 X1385_13 CL2 VSS VSS MODN $L=8 \mathrm{e}-07 \mathrm{~W}=1 \mathrm{e}-06 \quad \mathrm{AD}=1.1 \mathrm{e}-12 \mathrm{AS}=6.06373 \mathrm{e}-$ 13

$+P D=3.2 \mathrm{e}-06 \mathrm{PS}=1.13725 \mathrm{e}-06 \mathrm{NRD}=0.425 \mathrm{NRS}=0.425$

mX1385_M5 X1385_8 CL2 VSS VSS MODN L=8e-07 W=1e-06 AD=1.1e-12 AS=1.1e-12 
$+\mathrm{PD}=3.2 \mathrm{e}-06 \mathrm{PS}=3.2 \mathrm{e}-06 \mathrm{NRD}=0.425 \mathrm{NRS}=0.425$

$\mathrm{m} \times 1385 \_M 6$ X1385_7 X1385_20 VSS VSS MODN L=3.5e-07 $\mathrm{W}=1 \mathrm{e}-06 \quad \mathrm{AD}=5.75 \mathrm{e}-13$ $+\mathrm{AS}=1.075 \mathrm{e}-12 \mathrm{PD}=1.15 \mathrm{e}-06 \mathrm{PS}=3.15 \mathrm{e}-06 \mathrm{NRD}=0.425 \mathrm{NRS}=0.425$ mX1385_M7 VSS X1385_15 X1385_7 VSS MODN L=3.5e-07 W=1e-06 AD=6.31522e-13 $+\mathrm{AS}=5.75 \mathrm{e}-13 \mathrm{PD}=1.21739 \mathrm{e}-06 \mathrm{PS}=1.15 \mathrm{e}-06 \mathrm{NRD}=0.425 \mathrm{NRS}=0.425$ mX1385_M8 X1385_15 X1385_16 VSS VSS MODN L=3.5e-07 $W=1.3 e-06 \quad A D=7.475 e-13$ $+\mathrm{AS}=8.20978 \mathrm{e}-13 \mathrm{PD}=1.15 \mathrm{e}-06 \mathrm{PS}=1.58261 \mathrm{e}-06 \mathrm{NRD}=0.326923 \mathrm{NRS}=0.326923$ $m \times 1385 \_M 9$ VSS X1385_16 X1385_15 VSS MODN L =3.5e-07 W=1.3e-06 AD=8.775e-13 $+\mathrm{AS}=7.475 \mathrm{e}-13 \mathrm{PD}=1.52807 \mathrm{e}-06 \mathrm{PS}=1.15 \mathrm{e}-06 \mathrm{NRD}=0.326923 \mathrm{NRS}=0.326923$ mX1385_M10 X1385_17 CL2 VSS VSS MODN L=3.5e-07 $W=1.55 e-06 \quad A D=8.9125 e-13$ $+\mathrm{AS}=1.66625 \mathrm{e}-12 \mathrm{PD}=1.15 \mathrm{e}-06 \mathrm{PS}=3.7 \mathrm{e}-06 \mathrm{NRD}=0.274194 \mathrm{NRS}=0.274194$ mX1385_M11 X1385_16 CL2 VSS VSS MODN $L=3.5 \mathrm{e}-07 \mathrm{~W}=1.55 \mathrm{e}-06 \mathrm{AD}=8.9125 \mathrm{e}-13$ $+\mathrm{AS}=1.04625 \mathrm{e}-12 \mathrm{PD}=1.15 \mathrm{e}-06 \mathrm{PS}=1.82193 \mathrm{e}-06 \quad \mathrm{NRD}=0.274194 \mathrm{NRS}=0.274194$ $\mathrm{mX1385}$ M12 VSS CL2 X1385_17 VSS MODN L=3.5e-07 $\mathrm{W}=1.55 \mathrm{e}-06 \mathrm{AD}=9.04846 \mathrm{e}-13$ $+\mathrm{AS}=8.9125 \mathrm{e}-13 \mathrm{PD}=1.38684 \mathrm{e}-06 \mathrm{PS}=1.15 \mathrm{e}-06 \mathrm{NRD}=0.274194 \mathrm{NRS}=0.274194$ $\mathrm{mX1385}$ M13 VSS CL2 X1385_16 VSS MODN L=3.5e-07 W=1.55e-06 AD =9.39877e-13 $+\mathrm{AS}=8.9125 \mathrm{e}-13 \mathrm{PD}=1.76275 \mathrm{e}-06 \mathrm{PS}=1.15 \mathrm{e}-06 \mathrm{NRD}=0.274194 \mathrm{NRS}=0.274194$ $\mathrm{m} \times 1385 \_M 14 \times 1385 \_19 \times 1385 \_17$ VSS VSS MODN L=3.5e-07 W=1.3e-06 AD=7.475e-13 $+\mathrm{AS}=7.58904 \mathrm{e}-13 \mathrm{PD}=1.15 \mathrm{e}-06 \mathrm{PS}=1.16316 \mathrm{e}-06 \mathrm{NRD}=0.326923 \mathrm{NRS}=0.326923$ $\mathrm{m} \times 1385$ M15 X1385_18 CL2 VSS VSS MODN L=8e-07 W=1e-06 AD $=1.1 \mathrm{e}-12$ $\mathrm{AS}=6.06373 \mathrm{e}-13$

$+\mathrm{PD}=3.2 \mathrm{e}-06 \mathrm{PS}=1.13725 \mathrm{e}-06 \mathrm{NRD}=0.425 \mathrm{NRS}=0.425$ mX1385_M16 VSS X1385_17 X1385_19 VSS MODN L=3.5e-07 W=1.3e-06 AD=8.20978e13

$+\mathrm{AS}=7.475 \mathrm{e}-13 \mathrm{PD}=1.58261 \mathrm{e}-06 \mathrm{PS}=1.15 \mathrm{e}-06 \mathrm{NRD}=0.326923 \mathrm{NRS}=0.326923$

$m \times 1385 \_M 17$ OUTS2 X1385_19 VSS VSS MODN $L=3.5 \mathrm{e}-07 \mathrm{~W}=1 \mathrm{e}-06 \quad \mathrm{AD}=1.075 \mathrm{e}-12$

$+\mathrm{AS}=6.31522 \mathrm{e}-13 \mathrm{PD}=3.15 \mathrm{e}-06 \mathrm{PS}=1.21739 \mathrm{e}-06 \mathrm{NRD}=0.425 \mathrm{NRS}=0.425$

$m \times 1385 \_M 18 \times 1385 \_23 \times 1385 \_9 \times 1385 \_20$ VSS MODN L $=3.5 e-07 \quad W=1 e-06 \quad A D=5.75 e-13$ $+\mathrm{AS}=1.075 \mathrm{e}-12 \mathrm{PD}=1.15 \mathrm{e}-06 \mathrm{PS}=3.15 \mathrm{e}-06 \mathrm{NRD}=0.425 \mathrm{NRS}=0.425$ mX1385_M19 X1385_24 X1385_11 x1385_23 VSS MODN L=3.5e-07 W=1e-06 AD=5.75e13

$+\mathrm{AS}=5.75 \mathrm{e}-13 \mathrm{PD}=1.15 \mathrm{e}-06 \mathrm{PS}=1.15 \mathrm{e}-06 \mathrm{NRD}=0.425 \mathrm{NRS}=0.425$

mX1385_M20 VSS X1385_10 X1385_24 VSS MODN L=3.5e-07 W=1e-06 AD=1.075e-12 $+\mathrm{AS}=5.75 \mathrm{e}-13 \mathrm{PD}=3.15 \mathrm{e}-06 \mathrm{PS}=1.15 \mathrm{e}-06 \mathrm{NRD}=0.425 \mathrm{NRS}=0.425$

mX1385_M21 VDD2 CL2 X1385_14 VDD2 MODP L=3.5e-07 W=1.4e-06 AD=1.505e-12 $+\mathrm{AS}=1.505 \mathrm{e}-12 \mathrm{PD}=3.55 \mathrm{e}-0 \overline{6} \mathrm{PS}=3.55 \mathrm{e}-06 \mathrm{NRD}=0.303571 \mathrm{NRS}=0.303571$

mX1385_M22 VDD2 X1385_13 X1385_12 VDD2 MODP L=3.5e-07 W=1.7e-06 $\mathrm{AD}=9.99295 \mathrm{e}-13$

$+\mathrm{AS}=1.8275 \mathrm{e}-12 \mathrm{PD}=1.22051 \mathrm{e}-06 \mathrm{PS}=3.85 \mathrm{e}-06 \mathrm{NRD}=0.25 \mathrm{NRS}=0.25$

$\mathrm{m} \times 1385 \_M 23 \times 1385 \_13 \times 1385 \_7$ VDD2 VDD2 MODP $\mathrm{L}=3.5 \mathrm{e}-07 \mathrm{~W}=2.2 \mathrm{e}-06 \mathrm{AD}=2.365 \mathrm{e}-12$ $+\mathrm{AS}=1.29321 \mathrm{e}-12 \mathrm{PD}=4.35 \mathrm{e}-06 \mathrm{PS}=1.57949 \mathrm{e}-06 \quad \mathrm{NRD}=0.193182 \mathrm{NRS}=0.193182$ $m \times 1385 \_M 24$ X1385_8 X1385_14 VDD2 VDD2 MODP $L=3.5 \mathrm{e}-07 \quad W=2.5 \mathrm{e}-06 \quad A D=1.4375 \mathrm{e}-$ 12

$+\mathrm{AS}=2.6875 \mathrm{e}-12 \mathrm{PD}=1.15 \mathrm{e}-06 \mathrm{PS}=4.65 \mathrm{e}-06 \mathrm{NRD}=0.17 \mathrm{NRS}=0.17$

mX1385_M25 VDD2 X1385_15 X1385_8 VDD2 MODP L=3.5e-07 $W=2.5 e-06 \quad A D=2.6875 e-$ 12

$+\mathrm{AS}=1.4375 \mathrm{e}-12 \mathrm{PD}=4.65 \mathrm{e}-06 \mathrm{PS}=1.15 \mathrm{e}-06 \mathrm{NRD}=0.17 \mathrm{NRS}=0.17$

$\mathrm{m} \times 1385 \_M 26$ VDD2 X1385_20 X1385_7 VDD2 MODP L $=3.5 \mathrm{e}-07 \mathrm{~W}=1 \mathrm{e}-06$ AD $=1.075 \mathrm{e}-12$

$+\mathrm{AS}=1.075 \mathrm{e}-12 \mathrm{PD}=3.15 \mathrm{e}-06 \mathrm{PS}=3.15 \mathrm{e}-06 \mathrm{NRD}=0.425 \mathrm{NRS}=0.425$

$\mathrm{m} \times 1385 \_$M27 VDD2 CL2 X1385_15 VDD2 MODP $\mathrm{L}=3.5 \mathrm{e}-07 \mathrm{~W}=1.4 \mathrm{e}-06$ AD=1.505e-12

$+\mathrm{AS}=1.505 \mathrm{e}-12 \mathrm{PD}=3.55 \mathrm{e}-0 \overline{6} \mathrm{PS}=3.55 \mathrm{e}-06 \mathrm{NRD}=0.303571 \mathrm{NRS}=0.303571$

$m \times 1385 \_M 28 \times 1385 \_17 \times 1385 \_8$ VDD2 VDD2 MODP L $=3.5 \mathrm{e}-07 \mathrm{~W}=1.7 \mathrm{e}-06 \quad \mathrm{AD}=1.8275 \mathrm{e}-$ 12

$+\mathrm{AS}=1.8275 \mathrm{e}-12 \mathrm{PD}=3.85 \mathrm{e}-06 \mathrm{PS}=3.85 \mathrm{e}-06 \mathrm{NRD}=0.25 \mathrm{NRS}=0.25$

mX1385_M29 VDD2 X1385_18 X1385_16 VDD2 MODP L=3.5e-07 W=1.7e-06 $\mathrm{AD}=9.99295 \mathrm{e}-13$

$+\mathrm{AS}=1.8275 \mathrm{e}-12 \mathrm{PD}=1.22051 \mathrm{e}-06 \mathrm{PS}=3.85 \mathrm{e}-06 \mathrm{NRD}=0.25 \mathrm{NRS}=0.25$

$\mathrm{m} \times 1385 \_M 30 \times 1385 \_19 \mathrm{CL2}$ VDD2 VDD2 MODP $\mathrm{L}=3.5 \mathrm{e}-07 \mathrm{~W}=1.4 \mathrm{e}-06 \quad \mathrm{AD}=1.505 \mathrm{e}-12$

$+\mathrm{AS}=1.505 \mathrm{e}-12 \mathrm{PD}=3.55 \mathrm{e}-06 \mathrm{PS}=3.55 \mathrm{e}-06 \mathrm{NRD}=0.303571 \mathrm{NRS}=0.303571$

$m \times 1385 \_M 31 \times 1385 \_18$ OUTS2 VDD2 VDD2 MODP $L=3.5 \mathrm{e}-07 \mathrm{~W}=2.2 \mathrm{e}-06 \quad \mathrm{AD}=2.365 \mathrm{e}-12$

$+\mathrm{AS}=1.29321 \mathrm{e}-12 \mathrm{PD}=4.35 \mathrm{e}-06 \mathrm{PS}=1.57949 \mathrm{e}-06 \mathrm{NRD}=0.193182 \mathrm{NRS}=0.193182$

mX1385_M32 OUTS2 X1385_19 VDD2 VDD2 MODP $L=3.5 \mathrm{e}-07 \mathrm{~W}=2 \mathrm{e}-06 \quad \mathrm{AD}=2.15 \mathrm{e}-12$

$+\mathrm{AS}=2.15 \mathrm{e}-12 \mathrm{PD}=4.15 \mathrm{e}-06 \mathrm{PS}=4.15 \mathrm{e}-06 \mathrm{NRD}=0.2125 \mathrm{NRS}=0.2125$

$m \times 1385 \_M 33$ X1385_20 SM VDD2 VDD2 MODP $L=3.5 e-07 w=1 e-06$ AD $=5.75 e-13$

$+\mathrm{AS}=1.075 \mathrm{e}-12 \mathrm{PD}=1.15 \mathrm{e}-06 \mathrm{PS}=3.15 \mathrm{e}-06 \mathrm{NRD}=0.425 \mathrm{NRS}=0.425$

$\mathrm{m} \times 1385$ 1334 VDD2 X1385_9 X1385_20 VDD2 MODP L=3.5e-07 $W=1 \mathrm{e}-06$ AD $=5.75 \mathrm{e}-13$

$+\mathrm{AS}=5.75 \mathrm{e}-13 \mathrm{PD}=1.15 \mathrm{e}-06 \mathrm{PS}=1.15 \mathrm{e}-06 \mathrm{NRD}=0.425 \mathrm{NRS}=0.425$

$m \times 1385 \_M 35 \times 1385 \_20 \times 1385 \_11$ VDD2 VDD2 MODP $L=3.5 e-07 \mathrm{~W}=1 \mathrm{e}-06$ AD $=5.75 \mathrm{e}-13$

$+\mathrm{AS}=5.75 \mathrm{e}-13 \mathrm{PD}=1.15 \mathrm{e}-06 \mathrm{PS}=1.15 \mathrm{e}-06 \mathrm{NRD}=0.425 \mathrm{NRS}=0.425$

mx1385_M36 VDD2 X1385_10 X1385_20 VDD2 MODP L=3.5e-07 $\mathrm{W}=1 \mathrm{e}-06$ AD $=1.075 \mathrm{e}-12$ 
$+\mathrm{AS}=5.75 \mathrm{e}-13 \mathrm{PD}=3.15 \mathrm{e}-06 \mathrm{PS}=1.15 \mathrm{e}-06 \mathrm{NRD}=0.425 \mathrm{NRS}=0.425$

$\mathrm{m} \times 1385 \_\times 112 \_M 0$ VSS X1385_9 X1385_x112_4 VSS MODN L=3.5e-07 W=1e-06 $\mathrm{AD}=5.7 \overline{5} \mathrm{e}-13$

$+\mathrm{AS}=1.075 \mathrm{e}-12 \mathrm{PD}=1.15 \mathrm{e}-06 \mathrm{PS}=3.15 \mathrm{e}-06 \mathrm{NRD}=0.425 \mathrm{NRS}=0.425$

mX1385_X112_M1 X1385_X112_7 OUTS2 VSS VSS MODN L=3.5e-07 W=1e-06 AD=3.25e13

$+\mathrm{AS}=5.75 \mathrm{e}-13 \mathrm{PD}=6.5 \mathrm{e}-07 \mathrm{PS}=1.15 \mathrm{e}-06 \mathrm{NRD}=0.425 \mathrm{NRS}=0.425$

$\mathrm{m} \times 1385 \_X 112 \_\mathrm{M} 2$ X1385_X112_5 X1385_X112_4 X1385_X112_7 VSS MODN L $=3.5 \mathrm{e}-07$

$+\quad W=1 \mathrm{e}-06 \quad A D=1.075 \mathrm{e}-12 \quad \mathrm{AS}=3.25 \mathrm{e}-13 \quad \mathrm{PD}=3.15 \mathrm{e}-06 \quad \mathrm{PS}=6.5 \mathrm{e}-07 \quad \mathrm{NRD}=0.425$ $\mathrm{NRS}=0.425$

mX1385_X112_M3 X1385_X112_8 OUTS2 VSS VSS MODN L=3.5e-07 W=1e-06 AD=3.25e13

$+\mathrm{AS}=1.075 \mathrm{e}-12 \mathrm{PD}=6.5 \mathrm{e}-07 \mathrm{PS}=3.15 \mathrm{e}-06 \mathrm{NRD}=0.425 \mathrm{NRS}=0.425$

$\mathrm{mX1385 \_ X112 \_ M4}$ X1385_9 X1385_X112_5 X1385_X112_8 VSS MODN L=3.5e-07 W=1e-06 $+\mathrm{AD}=1.075 \mathrm{e}-12 \mathrm{AS}=3.25 \mathrm{e}-13 \mathrm{PD}=3.15 \mathrm{e}-06 \mathrm{PS}=6.5 \mathrm{e}-07 \mathrm{NRD}=0.425 \mathrm{NRS}=0.425$

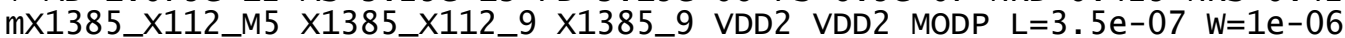
$+A D=3.25 \mathrm{e}-13 \mathrm{AS}=1.075 \mathrm{e}-12 \mathrm{PD}=6.5 \mathrm{e}-07 \mathrm{PS}=3.15 \mathrm{e}-06 \mathrm{NRD}=0.425 \mathrm{NRS}=0.425$ $m \times 1385 \_X 112 \_M 6 \times 1385 \_X 112 \_4$ OUTS2 X1385_X112_9 VDD2 MODP L=3.5e-07 W=1e-06 $+\mathrm{AD}=1.075 \mathrm{e}-12 \mathrm{AS}=3.25 \mathrm{e}-13 \mathrm{PD}=3.15 \mathrm{e}-06 \mathrm{PS}=6.5 \mathrm{e}-07 \mathrm{NRD}=0.425 \mathrm{NRS}=0.425$ $\mathrm{m} \times 1385 \_x 112 \_M 7$ VDD2 OUTS2 X1385_x112_5 VDD2 MODP L=3.5e-07 W=1e-06 $A D=5.95 e-13$

$+\mathrm{AS}=1.075 \mathrm{e}-12 \mathrm{PD}=1.12 \mathrm{e}-06 \mathrm{PS}=3.15 \mathrm{e}-06 \mathrm{NRD}=0.425 \mathrm{NRS}=0.425$ $m \times 1385$ X112_M8 X1385_9 X1385_X112_5 VDD2 VDD2 MODP L=3.5e-07 W=1.5e-06 $+\quad A D=8.625 \mathrm{e}-13 \quad \mathrm{AS}=8.925 \mathrm{e}-13 \quad \mathrm{PD}=1.15 \mathrm{e}-06 \quad \mathrm{PS}=1.68 \mathrm{e}-06 \quad \mathrm{NRD}=0.283333$ $\mathrm{NRS}=0.283333$

mX1385_X112_M9 VDD2 X1385_X112_5 X1385_9 VDD2 MODP L=3.5e-07 W=1.5e-06 $+\quad A D=1.6125 \mathrm{e}-12 \quad A S=8.625 \mathrm{e}-13 \quad P D=3.65 \mathrm{e}-06 \quad P S=1.15 \mathrm{e}-06 \quad \mathrm{NRD}=0.283333$ NRS $=0.283333$

$\mathrm{mX1385} \times 173$ M0 X1385 $21 \times 13859$ VSS VSS MODN $\mathrm{L}=3.5 \mathrm{e}-07 \mathrm{~W}=1 \mathrm{e}-06 \quad \mathrm{AD}=1.075 \mathrm{e}-12$ $+\mathrm{AS}=1.075 \mathrm{e}-12 \mathrm{PD}=3 . \overline{15 \mathrm{e}-06} \mathrm{PS}=3.15 \mathrm{e}-06 \mathrm{NRD}=0.425 \mathrm{NRS}=0.425$ mX1385_X173_M1 X1385_21 X1385_9 VDD2 VDD2 MODP L=3.5e-07 W=2e-06 AD=2.15e12

$+\mathrm{AS}=2.15 \mathrm{e}-12 \mathrm{PD}=4.15 \mathrm{e}-06 \mathrm{PS}=4.15 \mathrm{e}-06 \mathrm{NRD}=0.2125 \mathrm{NRS}=0.2125$

$\mathrm{m} \times 1385 \_\times 192 \_M 018 \times 1385 \_10$ VSS VSS MODN L $=3.5 \mathrm{e}-07 \mathrm{~W}=1 \mathrm{e}-06$ AD $=1.075 \mathrm{e}-12$

$+\mathrm{AS}=1.075 \mathrm{e}-12 \mathrm{PD}=3.15 \mathrm{e}-06 \mathrm{PS}=3.15 \mathrm{e}-06 \mathrm{NRD}=0.425 \mathrm{NRS}=0.425$

$m \times 1385+X 192=M 118 \times 1385 \_10$ VDD2 VDD2 MODP $L=3.5 \mathrm{e}-07 \quad W=2 \mathrm{e}-06 \quad A D=2.15 \mathrm{e}-12$

$+\mathrm{AS}=2.15 \mathrm{e}-12 \mathrm{PD}=4.15 \mathrm{e}-06 \mathrm{PS}=4.15 \mathrm{e}-06 \mathrm{NRD}=0.2125 \mathrm{NRS}=0.2125$

$\mathrm{m} \times 1385 \times 193$ M0 VSS X1385 $11 \times 1385 \times 1934$ VSS MODN $L=3.5 \mathrm{e}-07 \mathrm{~W}=1 \mathrm{e}-06$

$+\mathrm{AD}=5.75 \mathrm{e}-13 \mathrm{AS}=1.075 \mathrm{e}-12 \mathrm{PD}=1.15 \mathrm{e}-06 \mathrm{PS}=3.15 \mathrm{e}-06 \mathrm{NRD}=0.425 \mathrm{NRS}=0.425$

$m \times 1385 \_x 193 \_M 1$ X1385_X193_7 X1385_21 VSS VSS MODN L $=3.5 \mathrm{e}-07 \mathrm{~W}=1 \mathrm{e}-06$

$+A D=3.25 \mathrm{e}-13 \quad A S=5.75 \mathrm{e}-13 \quad \mathrm{PD}=6.5 \mathrm{e}-07 \quad \mathrm{PS}=1.15 \mathrm{e}-06 \mathrm{NRD}=0.425 \mathrm{NRS}=0.425$ mX1385_X193_M2 X1385_X193_5 X1385_X193_4 X1385_X193_7 VSS MODN L $=3.5 e-07$ $+\quad W=1 \mathrm{e}-06 \quad A D=1.075 \mathrm{e}-12 \quad \mathrm{AS}=3.25 \mathrm{e}-13 \quad \mathrm{PD}=3.15 \mathrm{e}-06 \quad \mathrm{PS}=6.5 \mathrm{e}-07 \quad \mathrm{NRD}=0.425$ $\mathrm{NRS}=0.425$

mX1385_X193_M3 X1385_X193_8 X1385_21 VSS VSS MODN L=3.5e-07 W=1e-06 $+A D=3.25 \mathrm{e}-13 \mathrm{AS}=1.075 \mathrm{e}-12 \mathrm{PD}=6.5 \mathrm{e}-07 \mathrm{PS}=3.15 \mathrm{e}-06 \mathrm{NRD}=0.425 \mathrm{NRS}=0.425$ mX1385_X193_M4 X1385_11 X1385_X193_5 X1385_X193_8 VSS MODN L=3.5e-07 W=1e06

$+\mathrm{AD}=1.075 \mathrm{e}-12 \mathrm{AS}=3.25 \mathrm{e}-13 \mathrm{PD}=3.15 \mathrm{e}-06 \mathrm{PS}=6.5 \mathrm{e}-07 \mathrm{NRD}=0.425 \mathrm{NRS}=0.425$ mX1385_X193_M5 X1385_X193_9 X1385_11 VDD2 VDD2 MODP L=3.5e-07 W=1e-06 $+A D=3.25 \mathrm{e}-13 \quad A S=1.075 \mathrm{e}-1 \overline{2} \mathrm{PD}=6.5 \mathrm{e}-07 \quad \mathrm{PS}=3.15 \mathrm{e}-06 \mathrm{NRD}=0.425 \mathrm{NRS}=0.425$ mX1385_X193_M6 X1385_X193_4 X1385_21 X1385_X193_9 VDD2 MODP L=3.5e-07 W=1e06

$+\mathrm{AD}=1.075 \mathrm{e}-12 \mathrm{AS}=3.25 \mathrm{e}-13 \mathrm{PD}=3.15 \mathrm{e}-06 \mathrm{PS}=6.5 \mathrm{e}-07 \mathrm{NRD}=0.425 \mathrm{NRS}=0.425$ mX1385_X193_M7 VDD2 X1385_21 X1385_X193_5 VDD2 MODP L=3.5e-07 W=1e-06 $+A D=5.95 \mathrm{e}-13 \quad A S=1.075 \mathrm{e}-12 \quad P D=1.12 \mathrm{e}-06 \quad P S=3.15 \mathrm{e}-06 \quad \mathrm{NRD}=0.425 \quad \mathrm{NRS}=0.425$ mX1385_X193_M8 X1385_11 X1385_X193_5 VDD2 VDD2 MODP L=3.5e-07 W=1.5e-06 $+\quad A D=8.625 \mathrm{e}-13 \quad \mathrm{AS}=8.925 \mathrm{e}-13 \quad \mathrm{PD}=1.15 \mathrm{e}-06 \quad \mathrm{PS}=1.68 \mathrm{e}-06 \quad \mathrm{NRD}=0.283333$ $\mathrm{NRS}=0.283333$

mX1385_X193_M9 VDD2 X1385_x193_5 x1385_11 VDD2 MODP L=3.5e-07 W=1.5e-06 $+\quad A D=1.6125 \mathrm{e}-12 \quad A S=8.625 \mathrm{e}-13 \quad \mathrm{PD}=3.65 \mathrm{e}-06 \quad \mathrm{PS}=1.15 \mathrm{e}-06 \quad \mathrm{NRD}=0.283333$ $\mathrm{NRS}=0.283333$

$m \times 1385 \_X 212 \_M 0$ VSS X1385_10 X1385_X212_4 VSS MODN L $=3.5 e-07$ W $=1 \mathrm{e}-06$ $+\mathrm{AD}=5.75 \mathrm{e}-13 \mathrm{AS}=1.075 \mathrm{e}-12 \mathrm{PD}=1.15 \mathrm{e}-06 \mathrm{PS}=3.15 \mathrm{e}-06 \mathrm{NRD}=0.425 \mathrm{NRS}=0.425$ $\mathrm{mX1385 \_ X212 \_ M1}$ X1385_X212_7 X1385_22 VSS VSS MODN L=3.5e-07 W=1e-06 $+A D=3.25 \mathrm{e}-13 \quad A S=5.75 \mathrm{e}-13 \quad P D=6.5 \mathrm{e}-07 \quad P S=1.15 \mathrm{e}-06 \quad \mathrm{NRD}=0.425 \mathrm{NRS}=0.425$ $\mathrm{m} \times 1385 \_\times 212 \_M 2 \times 1385 \_\times 212 \_5 \times 1385 \_\times 212 \_4 \times 1385 \_\times 212 \_7$ VSS MODN L $=3.5 \mathrm{e}-07$ $+\quad W=1 \mathrm{e}-06 \quad \mathrm{AD}=1.075 \mathrm{e}-12 \quad \mathrm{AS}=3.25 \mathrm{e}-13 \quad \mathrm{PD}=3.15 \mathrm{e}-06 \quad \mathrm{PS}=6.5 \mathrm{e}-07 \quad \mathrm{NRD}=0.425$ $\mathrm{NRS}=0.425$

mX1385_X212_M3 X1385_X212_8 X1385_22 VSS VSS MODN L=3.5e-07 W=1e-06 
$+A D=3.25 e-13 \quad A S=1.075 e-12 \quad P D=6.5 e-07 \quad P S=3.15 e-06 \quad N R D=0.425 \quad N R S=0.425$ mX1385_X212_M4 X1385_10 X1385_X212_5 X1385_X212_8 VSS MODN L=3.5e-07 W=1e06

$+A D=1.075 \mathrm{e}-12 \quad A S=3.25 \mathrm{e}-13 \quad \mathrm{PD}=3.15 \mathrm{e}-06 \quad \mathrm{PS}=6.5 \mathrm{e}-07 \quad \mathrm{NRD}=0.425 \quad \mathrm{NRS}=0.425$ mX1385_X212_M5 X1385_X212_9 X1385_10 VDD2 VDD2 MODP L=3.5e-07 $\mathrm{W}=1 \mathrm{e}-06$ $+A D=3.25 \mathrm{e}-13 \quad A S=1.075 \mathrm{e}-12 \quad P D=6.5 \mathrm{e}-07 \quad P S=3.15 \mathrm{e}-06 \quad \mathrm{NRD}=0.425 \quad \mathrm{NRS}=0.425$ mX1385_X212_M6 X1385_X212_4 X1385_22 X1385_X212_9 VDD2 MODP L=3.5e-07 W=1e06

$+A D=1.075 \mathrm{e}-12 \quad A S=3.25 \mathrm{e}-13 \quad \mathrm{PD}=3.15 \mathrm{e}-06 \quad \mathrm{PS}=6.5 \mathrm{e}-07 \quad \mathrm{NRD}=0.425 \mathrm{NRS}=0.425$ $\mathrm{mX1385 \_ X212-M7}$ VDD2 X1385_22 X1385_X212_5 VDD2 MODP $L=3.5 \mathrm{e}-07 \mathrm{~W}=1 \mathrm{e}-06$ $+A D=5.95 \mathrm{e}-13 \quad \mathrm{AS}=1.075 \mathrm{e}-12 \quad \mathrm{PD}=1.12 \mathrm{e}-06 \mathrm{PS}=3.15 \mathrm{e}-06 \quad \mathrm{NRD}=0.425 \mathrm{NRS}=0.425$ $m \times 1385 \_X 212 \_M 8$ X1385_10 X1385_X212_5 VDD2 VDD2 MODP $L=3.5 \mathrm{e}-07 \mathrm{~W}=1.5 \mathrm{e}-06$ $+\quad \mathrm{AD}=8.625 \mathrm{e}-13 \quad \mathrm{AS}=8.925 \mathrm{e}-13 \quad \mathrm{PD}=1.15 \mathrm{e}-06 \quad \mathrm{PS}=1.68 \mathrm{e}-06 \quad \mathrm{NRD}=0.283333$ NRS $=0.283333$

mX1385_X212_M9 VDD2 X1385_X212_5 X1385_10 VDD2 MODP L=3.5e-07 W=1.5e-06 $+\quad A D=1.6125 \mathrm{e}-12 \quad A S=8.625 \mathrm{e}-13 \quad \mathrm{PD}=3.65 \mathrm{e}-06 \quad \mathrm{PS}=1.15 \mathrm{e}-06 \quad \mathrm{NRD}=0.283333$ $\mathrm{NRS}=0.283333$

mX1385_X255_M0 X1385_22 X1385_11 vSS VSS MODN L=3.5e-07 W=1e-06 AD=1.075e12

$+\mathrm{AS}=1.075 \mathrm{e}-12 \mathrm{PD}=3.15 \mathrm{e}-06 \mathrm{PS}=3.15 \mathrm{e}-06 \mathrm{NRD}=0.425 \mathrm{NRS}=0.425$ mX1385_X255_M1 X1385_22 X1385_11 VDD2 VDD2 MODP L=3.5e-07 W=2e-06 AD=2.15e12

$+A S=2.15 \mathrm{e}-12 \quad \mathrm{PD}=4.15 \mathrm{e}-06 \mathrm{PS}=4.15 \mathrm{e}-06 \mathrm{NRD}=0.2125 \mathrm{NRS}=0.2125$ mX2420_M0 X2420_20 X2420_7 VSS VSS MODN L=3.5e-07 $W=2 \mathrm{e}-06$ AD $=1.025 \mathrm{e}-12$ $+\mathrm{AS}=2.15 \mathrm{e}-12 \mathrm{PD}=1.025 \mathrm{e}-06 \mathrm{PS}=4.15 \mathrm{e}-06 \mathrm{NRD}=0.2125 \mathrm{NRS}=0.2125$ $m \times 2420 \_M 1$ VSS X2420_13 X2420_20 VSS MODN $L=3.5 \mathrm{e}-07 \quad W=2 \mathrm{e}-06 \quad A D=1.63333 \mathrm{e}-12$ $+\mathrm{AS}=1.025 \mathrm{e}-12 \mathrm{PD}=3 \mathrm{e}-06 \mathrm{PS}=1.025 \mathrm{e}-06 \mathrm{NRD}=0.2125 \mathrm{NRS}=0.2125$ $m \times 2420 \_M 2$ X2420_26 CL1 VSS VSS MODN $L=3.5 \mathrm{e}-07 \mathrm{~W}=1 \mathrm{e}-06 \quad \mathrm{AD}=3.125 \mathrm{e}-13$ $+\mathrm{AS}=8.16667 \mathrm{e}-13 \mathrm{PD}=6.25 \mathrm{e}-07 \mathrm{PS}=1.5 \mathrm{e}-06 \mathrm{NRD}=0.425 \mathrm{NRS}=0.425$ $\mathrm{m} \times 2420 \_M 3 \times 2420 \_21 \times 2420 \_20 \times 2420 \_26$ VSS MODN $L=3.5 \mathrm{e}-07 \mathrm{~W}=1 \mathrm{e}-06 \quad \mathrm{AD}=9.25 \mathrm{e}-13$ $+\mathrm{AS}=3.125 \mathrm{e}-13 \mathrm{PD}=2.85 \mathrm{e}-06 \mathrm{PS}=6.25 \mathrm{e}-07 \mathrm{NRD}=0.425 \mathrm{NRS}=0.425$ $m \times 2420 \_M 4$ X2420_27 CL1 VSS VSS MODN L=3.5e-07 $W=1 \mathrm{e}-06 \quad A D=3.25 \mathrm{e}-13 \quad A S=9.75 \mathrm{e}-$ 13

$+\mathrm{PD}=6.5 \mathrm{e}-07 \mathrm{PS}=2.95 \mathrm{e}-06 \mathrm{NRD}=0.425 \mathrm{NRS}=0.425$

mX2420_M5 X2420_7 X2420_21 X2420_27 VSS MODN L=3.5e-07 W=1e-06 AD=1.075e-12 $+\mathrm{AS}=3.25 \mathrm{e}-13 \mathrm{PD}=3.15 \mathrm{e}-06 \mathrm{PS}=6.5 \mathrm{e}-07 \mathrm{NRD}=0.425 \mathrm{NRS}=0.425$

mX2420_M6 VSS X2420_22 OUTS1 VSS MODN L=3.5e-07 W=1.3e-06 AD=7.44079e-13 $+A S=1.235 \mathrm{e}-12 \quad P D=1.14035 \mathrm{e}-06 \mathrm{PS}=3.2 \mathrm{e}-06 \mathrm{NRD}=0.326923 \mathrm{NRS}=0.326923$ mX2420_M7 X2420_22 CL1 VSS VSS MODN L=3.5e-07 W=1.55e-06 AD =8.9125e-13 $+\mathrm{AS}=8.87171 \mathrm{e}-1 \overline{3} \mathrm{PD}=1.15 \mathrm{e}-06 \mathrm{PS}=1.35965 \mathrm{e}-06 \mathrm{NRD}=0.274194 \mathrm{NRS}=0.274194$ mX2420_M8 X2420_28 X2420_7 VSS VSS MODN L=3.5e-07 W=4.4e-06 AD=1.1e-12 $+\mathrm{AS}=5.17 \mathrm{e}-12 \mathrm{PD}=5 \mathrm{e}-07 \mathrm{PS}=6.75 \mathrm{e}-06 \mathrm{NRD}=0.0965909 \mathrm{NRS}=0.0965909$ mX2420_M9 X2420_14 X2420_13 X2420_28 VSS MODN L=3.5e-07 W=4.4e-06 AD=2.86e12

$+\mathrm{AS}=1.1 \mathrm{e}-12 \mathrm{PD}=3.3 \mathrm{e}-06 \mathrm{PS}=5 \mathrm{e}-07 \mathrm{NRD}=0.0965909 \mathrm{NRS}=0.0965909$

$\mathrm{m} \times 2420 \_M 10$ VSS CLi $\times 2420 \_22$ VSS MODN L $=3.5 \mathrm{e}-07 \mathrm{~W}=1.55 \mathrm{e}-06 \quad \mathrm{AD}=1.97625 \mathrm{e}-12$ $+\mathrm{AS}=8.9125 \mathrm{e}-13 \mathrm{PD}=4.1 \mathrm{e}-06 \mathrm{PS}=1.15 \mathrm{e}-06 \mathrm{NRD}=0.274194 \mathrm{NRS}=0.274194$ mX2420_M11 X2420_29 X2420_23 X2420_13 VSS MODN L=3.5e-07 $W=1 \mathrm{e}-06 \quad A D=3.25 \mathrm{e}-$ 13

$+\mathrm{AS}=1.075 \mathrm{e}-12 \mathrm{PD}=6.5 \mathrm{e}-07 \mathrm{PS}=3.15 \mathrm{e}-06 \mathrm{NRD}=0.425 \mathrm{NRS}=0.425$ mX2420_M12 VSS X2420_15 X2420_14 VSS MODN $L=3.5 \mathrm{e}-07 \quad W=2.2 \mathrm{e}-06$ AD $=3.25531 \mathrm{e}-$ 12

$+\mathrm{AS}=1.43 \mathrm{e}-12 \mathrm{PD}=4.57187 \mathrm{e}-06 \mathrm{PS}=1.65 \mathrm{e}-06 \mathrm{NRD}=0.193182 \mathrm{NRS}=0.193182$

$\mathrm{m} \times 2420 \_\mathrm{M} 13$ VSS CL1 $\mathrm{X} 2420 \_29$ VSS MODN $\mathrm{L}=3.5 \mathrm{e}-07 \quad \mathrm{~W}=1 \mathrm{e}-06 \quad \mathrm{AD}=9.75 \mathrm{e}-13$ $\mathrm{AS}=3.25 \mathrm{e}-13$

$+\mathrm{PD}=2.95 \mathrm{e}-06 \mathrm{PS}=6.5 \mathrm{e}-07 \mathrm{NRD}=0.425 \mathrm{NRS}=0.425$

mX2420_M14 X2420_30 CL1 VSS VSS MODN L=3.5e-07 $\mathrm{W}=1 \mathrm{e}-06 \quad \mathrm{AD}=3.125 \mathrm{e}-13$

$+\mathrm{AS}=1.47969 \mathrm{e}-12 \mathrm{PD}=6.25 \mathrm{e}-07 \mathrm{PS}=2.07813 \mathrm{e}-06 \mathrm{NRD}=0.425 \mathrm{NRS}=0.425$

mX2420_M15 X2420_31 X2420_25 X2420_23 vSS MODN L=3.5e-07 W=1e-06 AD=3.125e13

$+\mathrm{AS}=9.25 \mathrm{e}-13 \mathrm{PD}=6.25 \mathrm{e}-07 \mathrm{PS}=2.85 \mathrm{e}-06 \mathrm{NRD}=0.425 \mathrm{NRS}=0.425$

mX2420_M16 X2420_24 X2420_14 X2420_30 VSS MODN L=3.5e-07 W=1e-06 AD=9.25e13

$+\mathrm{AS}=3.125 \mathrm{e}-13 \mathrm{PD}=2.85 \mathrm{e}-06 \mathrm{PS}=6.25 \mathrm{e}-07 \mathrm{NRD}=0.425 \mathrm{NRS}=0.425$

$\mathrm{m} \times 2420 \_M 17$ VSS CL1 X2420_31 VSS MODN $L=3.5 \mathrm{e}-07 \mathrm{~W}=1 \mathrm{e}-06 \quad \mathrm{AD}=7 \mathrm{e}-13 \quad \mathrm{AS}=3.125 \mathrm{e}-$ 13

$+\mathrm{PD}=1.32895 \mathrm{e}-06 \mathrm{PS}=6.25 \mathrm{e}-07 \mathrm{NRD}=0.425 \mathrm{NRS}=0.425$

mX2420_M18 X2420_25 X2420_16 VSS VSS MODN L=3.5e-07 $W=2.8 \mathrm{e}-06 \quad A D=1.61 \mathrm{e}-12$

$+\mathrm{AS}=1.96 \mathrm{e}-12 \mathrm{PD}=1.15 \mathrm{e}-06 \mathrm{PS}=3.72105 \mathrm{e}-06 \mathrm{NRD}=0.151786 \mathrm{NRS}=0.151786$ 
$m \times 2420 \_M 19 \quad \times 2420 \_32$ CL1 VSS VSS MODN L=3.5e-07 $\omega=1 \mathrm{e}-06 \quad A D=3.25 \mathrm{e}-13$ $\mathrm{AS}=9.7 \overline{5} \mathrm{e}-13$

$+\mathrm{PD}=6.5 \mathrm{e}-07 \mathrm{PS}=2.95 \mathrm{e}-06 \mathrm{NRD}=0.425 \mathrm{NRS}=0.425$

mX2420_M20 VSS X2420_17 X2420_25 VSS MODN L $=3.5 \mathrm{e}-07 \mathrm{~W}=2.8 \mathrm{e}-06 \quad \mathrm{AD}=3.01 \mathrm{e}-12$

$+\mathrm{AS}=1.61 \mathrm{e}-12 \mathrm{PD}=4.95 \mathrm{e}-06 \mathrm{PS}=1.15 \mathrm{e}-06 \mathrm{NRD}=0.151786 \mathrm{NRS}=0.151786$

$m \times 2420 \_M 21$ X2420_15 X2420_24 X2420_32 VSS MODN L=3.5e-07 W=1e-06 AD=1.075e12

$+\mathrm{AS}=3.25 \mathrm{e}-13 \mathrm{PD}=3.15 \mathrm{e}-06 \mathrm{PS}=6.5 \mathrm{e}-07 \mathrm{NRD}=0.425 \mathrm{NRS}=0.425$

mX2420_M22 X2420_16 X2420_15 VSS VSS MODN L=3.5e-07 $W=1.5 \mathrm{e}-06 \quad A D=8.4375 \mathrm{e}-13$

$+\mathrm{AS}=1.575 \mathrm{e}-12 \mathrm{PD}=1.125 \mathrm{e}-06 \mathrm{PS}=3.6 \mathrm{e}-06 \mathrm{NRD}=0.283333 \mathrm{NRS}=0.283333$

mX2420_M23 VSS X2420_15 X2420_16 VSS MODN L=3.5e-07 $W=1.5 \mathrm{e}-06 \quad A D=1.65 \mathrm{e}-12$

$+\mathrm{AS}=8.4375 \mathrm{e}-13 \mathrm{PD}=3.7 \mathrm{e}-06 \mathrm{PS}=1.125 \mathrm{e}-06 \mathrm{NRD}=0.283333 \mathrm{NRS}=0.283333$

mX2420_M24 X2420_33 SM X2420_17 VSS MODN L=3.5e-07 W=1e-06 AD=5.75e-13

$+\mathrm{AS}=1.075 \mathrm{e}-12 \mathrm{PD}=1.15 \mathrm{e}-06 \mathrm{PS}=3.15 \mathrm{e}-06 \mathrm{NRD}=0.425 \mathrm{NRS}=0.425$

mX2420_M25 X2420_34 X2420_10 X2420_33 VSS MODN L=3.5e-07 W=1e-06 AD=5.75e13

$+\mathrm{AS}=5.75 \mathrm{e}-13 \mathrm{PD}=1.15 \mathrm{e}-06 \mathrm{PS}=1.15 \mathrm{e}-06 \mathrm{NRD}=0.425 \mathrm{NRS}=0.425$

$m \times 2420 \_M 26$ VSS X2420_19 X2420_34 VSS MODN $L=3.5 \mathrm{e}-07 \quad W=1 \mathrm{e}-06 \quad A D=1.075 \mathrm{e}-12$ $+\mathrm{AS}=5.75 \mathrm{e}-13 \mathrm{PD}=3.15 \mathrm{e}-06 \mathrm{PS}=1.15 \mathrm{e}-06 \mathrm{NRD}=0.425 \mathrm{NRS}=0.425$

$m \times 2420 \_M 27$ VSS X2420_19 X2420_18 VSS MODN L=3.5e-07 $\mathrm{W}=1 \mathrm{e}-06 \quad \mathrm{AD}=1.075 \mathrm{e}-12$ $+\mathrm{AS}=1.075 \mathrm{e}-12 \mathrm{PD}=3.15 \mathrm{e}-06 \mathrm{PS}=3.15 \mathrm{e}-06 \mathrm{NRD}=0.425 \mathrm{NRS}=0.425$

mX2420_M28 X2420_20 CL1 VDD1 VDD1 MODP $L=3.5 \mathrm{e}-07 \quad \mathrm{~W}=1 \mathrm{e}-06 \quad \mathrm{AD}=9 \mathrm{e}-13$ $\mathrm{AS}=1.075 \mathrm{e}-12$

$+\mathrm{PD}=2.8 \mathrm{e}-06 \mathrm{PS}=3.15 \mathrm{e}-06 \mathrm{NRD}=0.425 \mathrm{NRS}=0.425$

$\mathrm{m} \times 2420 \_M 29$ VDD1 CL1 X2420_21 VDD1 MODP $\mathrm{L}=3.5 \mathrm{e}-07 \mathrm{~W}=1.5 \mathrm{e}-06 \quad \mathrm{AD}=8.625 \mathrm{e}-13$

$+\mathrm{AS}=1.3125 \mathrm{e}-12 \mathrm{PD}=1.15 \mathrm{e}-06 \mathrm{PS}=3.25 \mathrm{e}-06 \mathrm{NRD}=0.283333 \mathrm{NRS}=0.283333$

$m \times 2420 \_M 30 \times 2420 \_7 \times 2420 \_21$ VDD1 VDD1 MODP $L=3.5 e-07 \quad W=1.5 e-06 \quad A D=8.625 e-13$ $+\mathrm{AS}=8.625 \mathrm{e}-13 \mathrm{PD}=1.15 \mathrm{e}-06 \mathrm{PS}=1.15 \mathrm{e}-06 \mathrm{NRD}=0.283333 \mathrm{NRS}=0.283333$

mX2420_M31 VDD1 X2420_21 X2420_7 VDD1 MODP L=3.5e-07 W=1.5e-06 AD=1.3875e12

$+\mathrm{AS}=8.625 \mathrm{e}-13 \mathrm{PD}=3.35 \mathrm{e}-06 \mathrm{PS}=1.15 \mathrm{e}-06 \mathrm{NRD}=0.283333 \mathrm{NRS}=0.283333$

$m \times 2420 \_M 32$ VDD1 CL1 OUTS1 VDD1 MODP $L=3.5 \mathrm{e}-07 \quad W=1.4 \mathrm{e}-06 \quad A D=1.4 \mathrm{e}-12$ $\mathrm{AS}=1.33 \mathrm{e}-12$

$+\mathrm{PD}=3.4 \mathrm{e}-06 \mathrm{PS}=3.3 \mathrm{e}-06 \mathrm{NRD}=0.303571 \mathrm{NRS}=0.303571$

$m \times 2420 \_M 33$ VDD1 X2420_8 X2420_22 VDD1 MODP $L=3.5 e-07 \quad W=1.7 e-06 \quad A D=1.615 e-12$ $+\mathrm{AS}=1.7 \mathrm{e}-12 \mathrm{PD}=3.6 \mathrm{e}-06 \mathrm{PS}=3 . \overline{\mathrm{e}}-06 \mathrm{NRD}=0.25 \mathrm{NRS}=0.25$

mX2420_M34 X2420_13 X2420_23 VDD1 VDD1 MODP L=3.5e-07 W=1.5e-06 AD=8.625e13

$+\mathrm{AS}=1.3875 \mathrm{e}-12 \mathrm{PD}=1.15 \mathrm{e}-06 \mathrm{PS}=3.35 \mathrm{e}-06 \mathrm{NRD}=0.283333 \mathrm{NRS}=0.283333$

mX2420_M35 VDD1 X2420_23 X2420_13 VDD1 MODP $L=3.5 \mathrm{e}-07 \mathrm{~W}=1.5 \mathrm{e}-06 \quad \mathrm{AD}=8.925 \mathrm{e}-$ 13

$+\mathrm{AS}=8.625 \mathrm{e}-13 \mathrm{PD}=1.68 \mathrm{e}-06 \mathrm{PS}=1.15 \mathrm{e}-06 \mathrm{NRD}=0.283333 \mathrm{NRS}=0.283333$

$m \times 2420 \_M 36$ X2420_23 CL1 VDD1 VDD1 MODP $L=3.5 e-07 \quad W=1 e-06 \quad A D=8.75 e-13$

$+\mathrm{AS}=5.95 \mathrm{e}-13 \mathrm{PD}=2.75 \mathrm{e}-06 \mathrm{PS}=1.12 \mathrm{e}-06 \mathrm{NRD}=0.425 \mathrm{NRS}=0.425$

mX2420_M37 X2420_14 CL1 VDD1 VDD1 MODP L=3.5e-07 W=1.2e-06 AD=1.08e-12

$+\mathrm{AS}=1.29 \mathrm{e}-12 \mathrm{PD}=3 \mathrm{e}-06 \mathrm{PS}=3.35 \mathrm{e}-06 \mathrm{NRD}=0.354167 \mathrm{NRS}=0.354167$

mX2420_M38 VDD1 CL1 X2420_25 VDD1 MODP L=3.5e-07 $\mathrm{W}=1.4 \mathrm{e}-06 \quad \mathrm{AD}=1.505 \mathrm{e}-12$

$+\mathrm{AS}=1.26 \mathrm{e}-12 \mathrm{PD}=3.55 \mathrm{e}-06 \mathrm{PS}=3.2 \mathrm{e}-06 \mathrm{NRD}=0.303571 \mathrm{NRS}=0.303571$

mX2420_M39 VDD1 CL1 X2420_24 VDD1 MODP L=3.5e-07 W=1e-06 AD=5.95e-13

$+\mathrm{AS}=8.75 \mathrm{e}-13 \mathrm{PD}=1.12 \mathrm{e}-06 \mathrm{PS}=2.75 \mathrm{e}-06 \mathrm{NRD}=0.425 \mathrm{NRS}=0.425$

mX2420_M40 X2420_15 X2420_24 VDD1 VDD1 MODP $L=3.5 \mathrm{e}-07 \quad \mathrm{~W}=1.5 \mathrm{e}-06 \quad \mathrm{AD}=8.625 \mathrm{e}-$ 13

$+A S=8.925 \mathrm{e}-13 \mathrm{PD}=1.15 \mathrm{e}-06 \mathrm{PS}=1.68 \mathrm{e}-06 \mathrm{NRD}=0.283333 \mathrm{NRS}=0.283333$

mX2420_M41 VDD1 X2420_24 X2420_15 VDD1 MODP $L=3.5 \mathrm{e}-07 \mathrm{~W}=1.5 \mathrm{e}-06 \quad \mathrm{AD}=1.3875 \mathrm{e}-$ 12

$+\mathrm{AS}=8.625 \mathrm{e}-13 \mathrm{PD}=3.35 \mathrm{e}-06 \mathrm{PS}=1.15 \mathrm{e}-06 \mathrm{NRD}=0.283333 \mathrm{NRS}=0.283333$

$m \times 2420 \_M 42$ VDD1 X2420_9 X2420_17 VDD1 MODP $L=3.5 \mathrm{e}-07 \mathrm{~W}=1 \mathrm{e}-06 \quad \mathrm{AD}=5.375 \mathrm{e}-13$

$+\mathrm{AS}=8.5 \mathrm{e}-13 \mathrm{PD}=1.075 \mathrm{e}-06 \mathrm{PS}=2.7 \mathrm{e}-06 \mathrm{NRD}=0.425 \mathrm{NRS}=0.425$

mX2420_M43 X2420_16 X2420_15 VDD1 VDD1 MODP L=3.5e-07 W=1.9e-06 AD=2.2325e12

$+\mathrm{AS}=1.8525 \mathrm{e}-12 \mathrm{PD}=4.25 \mathrm{e}-06 \mathrm{PS}=3.85 \mathrm{e}-06 \mathrm{NRD}=0.223684 \mathrm{NRS}=0.223684$

$m \times 2420 \_M 44$ X2420_17 X2420_9 VDD1 VDD1 MODP $L=3.5 e-07 \quad W=1 e-06 \quad A D=5.75 e-13$

$+\mathrm{AS}=5.375 \mathrm{e}-13 \mathrm{PD}=1.15 \mathrm{e}-06 \mathrm{PS}=1.075 \mathrm{e}-06 \mathrm{NRD}=0.425 \mathrm{NRS}=0.425$

$\mathrm{m} \times 2420$ M45 VDD1 SM $\times 242017$ VDDi MODP $\mathrm{L}=3.5 \mathrm{e}-07 \mathrm{~W}=1 \mathrm{e}-06 \quad \mathrm{AD}=5.75 \mathrm{e}-13$

$+\mathrm{AS}=5.75 \mathrm{e}-13 \mathrm{PD}=1.15 \mathrm{e}-0 \overline{6} \quad \mathrm{PS}=1.15 \mathrm{e}-06 \mathrm{NRD}=0.425 \mathrm{NRS}=0.425$

$\mathrm{m} \times 2420 \_$M46 X2420_17 X2420_10 VDD1 VDD1 MODP $\mathrm{L}=3.5 \mathrm{e}-07 \mathrm{~W}=1 \mathrm{e}-06 \quad \mathrm{AD}=5.75 \mathrm{e}-13$

$+\mathrm{AS}=5.75 \mathrm{e}-13 \mathrm{PD}=1.15 \mathrm{e}-06 \mathrm{PS}=1.15 \mathrm{e}-06 \mathrm{NRD}=0.425 \mathrm{NRS}=0.425$

mX2420_M47 VDD1 X2420_19 X2420_17 VDD1 MODP $L=3.5 \mathrm{e}-07 \mathrm{~W}=1 \mathrm{e}-06 \quad \mathrm{AD}=1.075 \mathrm{e}-12$

$+\mathrm{AS}=5.75 \mathrm{e}-13 \mathrm{PD}=3.15 \mathrm{e}-06 \mathrm{PS}=1.15 \mathrm{e}-06 \mathrm{NRD}=0.425 \mathrm{NRS}=0.425$

mX2420_M48 VDD1 X2420_19 X2420_18 VDD1 MODP $L=3.5 \mathrm{e}-07 \mathrm{~W}=2 \mathrm{e}-06 \quad \mathrm{AD}=2.15 \mathrm{e}-12$ 
$+\mathrm{AS}=2.15 \mathrm{e}-12 \mathrm{PD}=4.15 \mathrm{e}-06 \mathrm{PS}=4.15 \mathrm{e}-06 \mathrm{NRD}=0.2125 \mathrm{NRS}=0.2125$

mX2420_X61_M0 X2420_12 OUTS1 vSS VSS MODN L=3.5e-07 $W=1 \mathrm{e}-06$ AD $=1.075 \mathrm{e}-12$ $+\mathrm{AS}=1.075 \mathrm{e}-12 \mathrm{PD}=3.15 \mathrm{e}-06 \mathrm{PS}=3.15 \mathrm{e}-06 \mathrm{NRD}=0.425 \mathrm{NRS}=0.425$

$m \times 2420 \_X 61 \_M 1 \times 2420 \_12$ OUTS1 VDD1 VDD1 MODP $L=3.5 \mathrm{e}-07 \mathrm{~W}=2 \mathrm{e}-06 \quad \mathrm{AD}=2.15 \mathrm{e}-12$

$+\mathrm{AS}=2.15 \mathrm{e}-12$ PD $=4.15 \mathrm{e}-06 \mathrm{PS}=4.15 \mathrm{e}-06 \quad \mathrm{NRD}=0.2125 \mathrm{NRS}=0.2125$

mX2420_X71_M0 VSS X2420_9 X2420_X71_4 VSS MODN L=3.5e-07 W=1e-06 AD=5.75e13

$+\mathrm{AS}=1.075 \mathrm{e}-12 \mathrm{PD}=1.15 \mathrm{e}-06 \mathrm{PS}=3.15 \mathrm{e}-06 \mathrm{NRD}=0.425 \mathrm{NRS}=0.425$

mX2420_X71_M1 X2420_X71_7 X2420_12 VSS VSS MODN L=3.5e-07 W=1e-06 AD=3.25e13

$+\mathrm{AS}=5.75 \mathrm{e}-13 \mathrm{PD}=6.5 \mathrm{e}-07 \quad \mathrm{PS}=1.15 \mathrm{e}-06 \mathrm{NRD}=0.425 \mathrm{NRS}=0.425$

mX2420_X71_M2 X2420_X71_5 X2420_X71_4 X2420_X71_7 vSS MODN L=3.5e-07 W=1e06

$+A D=1.075 \mathrm{e}-12 \quad A S=3.25 \mathrm{e}-13 \quad \mathrm{PD}=3.15 \mathrm{e}-06 \quad \mathrm{PS}=6.5 \mathrm{e}-07 \quad \mathrm{NRD}=0.425 \mathrm{NRS}=0.425$ mX2420_X71_M3 X2420_X71_8 X2420_12 VSS VSS MODN L=3.5e-07 W=1e-06 AD=3.25e13

$+\mathrm{AS}=1.075 \mathrm{e}-12 \mathrm{PD}=6.5 \mathrm{e}-07 \mathrm{PS}=3.15 \mathrm{e}-06 \mathrm{NRD}=0.425 \mathrm{NRS}=0.425$

mX2420_X71_M4 X2420_9 X2420_X71_5 X2420_X71_8 vSS MODN L=3.5e-07 $\mathrm{W}=1 \mathrm{e}-06$ $+A D=1.075 \mathrm{e}-12 \quad A S=3.25 \mathrm{e}-13 \quad \mathrm{PD}=3.15 \mathrm{e}-06 \quad \mathrm{PS}=6.5 \mathrm{e}-07 \quad \mathrm{NRD}=0.425 \mathrm{NRS}=0.425$ mX2420_X71_M5 X2420_X71_9 X2420_9 VDD1 VDD1 MODP L=3.5e-07 W=1e-06 $\mathrm{AD}=3.25 \mathrm{e}-13$

$+\mathrm{AS}=1.075 \mathrm{e}-12 \mathrm{PD}=6.5 \mathrm{e}-07 \mathrm{PS}=3.15 \mathrm{e}-06 \mathrm{NRD}=0.425 \mathrm{NRS}=0.425$ $m \times 2420 \_x 71 \_M 6 \times 2420 \_71 \_4 \times 2420 \_12 \times 2420 \_x 719$ VDD1 MODP L=3.5e-07 W=1e-06 $+A D=1.075 \mathrm{e}-12 \quad A S=3.25 \mathrm{e}-13 \quad P D=3.15 \mathrm{e}-06 \quad P S=6.5 \mathrm{e}-07 \quad \mathrm{NRD}=0.425 \quad \mathrm{NRS}=0.425$ mX2420_X71_M7 VDD1 X2420_12 X2420_X71_5 VDD1 MODP L=3.5e-07 W=1e-06 $+A D=5.95 \mathrm{e}-13 \quad A S=1.075 \mathrm{e}-12 \quad P D=1.12 \mathrm{e}-0 \overline{6} \quad P S=3.15 \mathrm{e}-06 \quad \mathrm{NRD}=0.425 \quad \mathrm{NRS}=0.425$ $m \times 2420 \_x 71$ M8 X2420_9 X2420_X71_5 VDD1 VDD1 MODP $L=3.5 \mathrm{e}-07 \mathrm{~W}=1.5 \mathrm{e}-06$ $+\quad \mathrm{AD}=8.625 \mathrm{e}-13 \quad \mathrm{AS}=8.925 \mathrm{e}-13 \quad \mathrm{PD}=1.15 \mathrm{e}-06 \quad \mathrm{PS}=1.68 \mathrm{e}-06 \quad \mathrm{NRD}=0.283333$ $\mathrm{NRS}=0.283333$

mX2420_X71_M9 VDD1 X2420_X71_5 X2420_9 VDD1 MODP L=3.5e-07 W=1.5e-06 $+\quad A D=1.6125 \mathrm{e}-12 \quad \mathrm{AS}=8.625 \mathrm{e}-13 \quad \mathrm{PD}=3.65 \mathrm{e}-06 \quad \mathrm{PS}=1.15 \mathrm{e}-06 \quad \mathrm{NRD}=0.283333$ $\mathrm{NRS}=0.283333$

$m \times 2420 \times 83 \_$M0 X2420 X83 7 CL1 VSS VSS MODN L=3.5e-07 $W=1 e-06 \quad A D=2.5 e-13$ $+\mathrm{AS}=9.75 \mathrm{e}-13 \mathrm{PD}=5 \mathrm{e}-07 \mathrm{PS}=2.95 \mathrm{e}-06 \quad \mathrm{NRD}=0.425 \quad \mathrm{NRS}=0.425$ $m \times 2420 \_X 83 \_M 1$ X2420_X83_6 X2420_20 X2420_X83_7 vSS MODN L=3.5e-07 $\mathrm{w}=1 \mathrm{e}-06$ $+A D=1.125 \mathrm{e}-12 \quad A S=2.5 \mathrm{e}-13 \quad P D=3.25 \mathrm{e}-06 \quad P S=5 \mathrm{e}-07 \quad \mathrm{NRD}=0.425 \quad \mathrm{NRS}=0.425$ mX2420_X83_M2 X2420_X83_8 CL1 VSS VSS MODN L=3.5e-07 $W=1 \mathrm{e}-06$ AD $=3.25 \mathrm{e}-13$ $+\mathrm{AS}=1.075 \mathrm{e}-12 \mathrm{PD}=6.5 \mathrm{e}-07 \mathrm{PS}=3.15 \mathrm{e}-06 \mathrm{NRD}=0.425 \mathrm{NRS}=0.425$ mX2420_X83_M3 OUTS1 X2420_X83_6 X2420_X83_8 vSS MODN L=3.5e-07 W=1e-06 $+\mathrm{AD}=1.075 \mathrm{e}-12 \quad \mathrm{AS}=3.25 \mathrm{e}-13 \quad \mathrm{PD}=3.15 \mathrm{e}-06 \mathrm{6S}=6.5 \mathrm{e}-07 \quad \mathrm{NRD}=0.425 \quad \mathrm{NRS}=0.425$ $m \times 2420 \_X 83 \_M 4$ VDD1 CL1 X2420_X83_6 VDD1 MODP $L=3.5 e-07 \quad W=1 e-06 \quad A D=5.95 e-13$ $+\mathrm{AS}=9.25 \mathrm{e}-13 \mathrm{PD}=1.12 \mathrm{e}-06 \mathrm{PS}=2.8 \overline{\mathrm{e}} \mathrm{e}-06 \mathrm{NRD}=0.425 \mathrm{NRS}=0.425$ mX2420_X83_M5 OUTS1 X2420_X83_6 VDD1 VDD1 MODP L=3.5e-07 W=1.5e-06 $+\quad \mathrm{AD}=8.625 \mathrm{e}-13 \quad \mathrm{AS}=8.925 \mathrm{e}-13 \quad \mathrm{PD}=1.15 \mathrm{e}-06 \quad \mathrm{PS}=1.68 \mathrm{e}-06 \quad \mathrm{NRD}=0.283333$ $\mathrm{NRS}=0.283333$

mX2420_X83_M6 VDD1 X2420_X83_6 OUTS1 VDD1 MODP L=3.5e-07 W=1.5e-06 $+\quad A D=1.3875 \mathrm{e}-12 \quad A S=8.625 \mathrm{e}-13 \quad P D=3.35 \mathrm{e}-06 \quad P S=1.15 \mathrm{e}-06 \quad N R D=0.283333$ $\mathrm{NRS}=0.283333$

mX2420_X100_M0 X2420_11 X2420_9 VSS VSS MODN L=3.5e-07 W=1e-06 AD=1.075e-12 $+\mathrm{AS}=1.075 \mathrm{e}-12 \quad \mathrm{PD}=3.15 \mathrm{e}-06 \mathrm{PS}=3.15 \mathrm{e}-06 \mathrm{NRD}=0.425 \mathrm{NRS}=0.425$

mX2420_X100_M1 X2420_11 X2420_9 VDD1 VDD1 MODP L=3.5e-07 W=2e-06 AD=2.15e12

$+\mathrm{AS}=2.15 \mathrm{e}-12 \mathrm{PD}=4.15 \mathrm{e}-06 \mathrm{PS}=4.15 \mathrm{e}-06 \mathrm{NRD}=0.2125 \mathrm{NRS}=0.2125$

mX2420_X119_M0 X2420_X119_7 CL1 VSS VSS MODN L=3.5e-07 $W=1 \mathrm{e}-06 \quad \mathrm{AD}=2.5 \mathrm{e}-13$ $+\mathrm{AS}=9.75 \mathrm{e}-13 \mathrm{PD}=5 \mathrm{e}-07 \mathrm{PS}=2.95 \mathrm{e}-06 \mathrm{NRD}=0.425 \mathrm{NRS}=0.425$

mX2420_X119_M1 X2420_X119_6 X2420_14 X2420_X119_7 VSS MODN L=3.5e-07 W=1e06

$+\mathrm{AD}=1.125 \mathrm{e}-12 \quad \mathrm{AS}=2.5 \mathrm{e}-13 \quad \mathrm{PD}=3.25 \mathrm{e}-06 \quad \mathrm{PS}=5 \mathrm{e}-07 \mathrm{NRD}=0.425 \mathrm{NRS}=0.425$

$m \times 2420 \_X 119 \_M 2 \quad X 2420 \_X 119 \_8$ CL1 VSS VSS MODN L=3.5e-07 $W=1 \mathrm{e}-06 \quad A D=3.25 \mathrm{e}-13$ $+\mathrm{AS}=1.075 \mathrm{e}-12 \mathrm{PD}=6.5 \mathrm{e}-07 \quad \mathrm{PS}=3.15 \mathrm{e}-06 \mathrm{NRD}=0.425$ NRS $=0.425$

mX2420_X119_M3 X2420_8 X2420_X119_6 X2420_X119_8 VSS MODN L=3.5e-07 w=1e-06 $+\mathrm{AD}=1.075 \mathrm{e}-12 \quad \mathrm{AS}=3.25 \mathrm{e}-13 \quad \mathrm{PD}=3.15 \mathrm{e}-06 \quad \mathrm{PS}=6.5 \mathrm{e}-07 \quad \mathrm{NRD}=0.425 \quad \mathrm{NRS}=0.425$

mX2420_X119_M4 VDD1 CL1 X2420_X119_6 VDD1 MODP L=3.5e-07 W=1e-06 AD=5.95e13

$+\mathrm{AS}=9.25 \mathrm{e}-13 \mathrm{PD}=1.12 \mathrm{e}-06 \mathrm{PS}=2.85 \mathrm{e}-06 \mathrm{NRD}=0.425 \mathrm{NRS}=0.425$

mX2420_X119_M5 X2420_8 X2420_X119_6 VDD1 VDD1 MODP $L=3.5 \mathrm{e}-07 \mathrm{~W}=1.5 \mathrm{e}-06$

$+\quad A D=8.625 \mathrm{e}-13 \quad A S=8.925 \mathrm{e}-13 \quad P D=1.15 \mathrm{e}-06 \quad P S=1.68 \mathrm{e}-06 \quad N R D=0.283333$

$\mathrm{NRS}=0.283333$

mX2420_X119_M6 VDD1 X2420_X119_6 X2420_8 VDD1 MODP L=3.5e-07 W=1.5e-06 
$+\quad A D=1.3875 e-12 \quad A S=8.625 e-13 \quad P D=3.35 e-06 \quad P S=1.15 e-06 \quad N R D=0.283333$ $\mathrm{NRS}=0.283333$

$m \times 2420 \_156 \_M 017 \times 2420 \_10$ VSS VSS MODN $L=3.5 e-07 \quad W=1 e-06 \quad A D=1.075 e-12$ $+\mathrm{AS}=1.075 \mathrm{e}-12 \mathrm{PD}=3.15 \mathrm{e}-06 \mathrm{PS}=3.15 \mathrm{e}-06 \mathrm{NRD}=0.425 \mathrm{NRS}=0.425$ mX2420_X156_M1 17 X2420_10 VDD1 VDD1 MODP $L=3.5 \mathrm{e}-07 \quad \mathrm{~W}=2 \mathrm{e}-06 \quad \mathrm{AD}=2.15 \mathrm{e}-12$ $+\mathrm{AS}=2.15 \mathrm{e}-12 \mathrm{PD}=4.15 \mathrm{e}-06 \mathrm{PS}=4.15 \mathrm{e}-06 \mathrm{NRD}=0.2125 \mathrm{NRS}=0.2125$ mX2420_X169_M0 VSS X2420_10 X2420_X169_5 VSS MODN L=3.5e-07 W=1e-06 $+\mathrm{AD}=5.75 \mathrm{e}-13 \mathrm{AS}=1.075 \mathrm{e}-12 \quad \mathrm{PD}=1.15 \mathrm{e}-06 \quad \mathrm{PS}=3.15 \mathrm{e}-06 \quad \mathrm{NRD}=0.425 \mathrm{NRS}=0.425$ mX2420_X169_M1 X2420_X169_7 X2420_18 VSS VSS MODN L=3.5e-07 W=1e-06 $+\mathrm{AD}=3.25 \mathrm{e}-13 \quad \mathrm{AS}=5.75 \mathrm{e}-13 \quad \mathrm{PD}=6.5 \mathrm{e}-07 \quad \mathrm{PS}=1.15 \mathrm{e}-06 \quad \mathrm{NRD}=0.425 \mathrm{NRS}=0.425$ mX2420_X169_M2 X2420_X169_6 X2420_X169_5 X2420_X169_7 VSS MODN L=3.5e-07 $+\quad W=1 \mathrm{e}-06 \quad A D=1.075 \mathrm{e}-12 \quad A S=3.25 \mathrm{e}-13 \quad P D=3.15 \mathrm{e}-06 \quad P S=6.5 \mathrm{e}-07 \quad \mathrm{NRD}=0.425$ $\mathrm{NRS}=0.425$

mX2420_X169_M3 X2420_X169_8 X2420_18 VSS VSS MODN L=3.5e-07 W=1e-06 $+\mathrm{AD}=3.25 \mathrm{e}-13 \mathrm{AS}=1.075 \mathrm{e}-12 \quad \mathrm{PD}=6.5 \mathrm{e}-07 \quad \mathrm{PS}=3.15 \mathrm{e}-06 \mathrm{NRD}=0.425 \mathrm{NRS}=0.425$ mX2420_X169_M4 X2420_10 X2420_X169_6 X2420_X169_8 vSS MODN L=3.5e-07 W=1e06

$+A D=1.075 \mathrm{e}-12 \quad A S=3.25 \mathrm{e}-13 \quad \mathrm{PD}=3.15 \mathrm{e}-06 \quad \mathrm{PS}=6.5 \mathrm{e}-07 \quad \mathrm{NRD}=0.425 \quad \mathrm{NRS}=0.425$ mX2420_X169_M5 X2420_X169_9 X2420_10 VDD1 VDD1 MODP L=3.5e-07 W=1e-06 $+A D=3.25 \mathrm{e}-13 \quad A S=1.075 \mathrm{e}-12 \quad P D=6.5 \mathrm{e}-07 \quad P S=3.15 \mathrm{e}-06 \quad \mathrm{NRD}=0.425 \quad \mathrm{NRS}=0.425$ mX2420_X169_M6 X2420_X169_5 X2420_18 X2420_X169_9 VDD1 MODP L=3.5e-07 W=1e06

$+A D=1.075 \mathrm{e}-12 \quad A S=3.25 \mathrm{e}-13 \quad \mathrm{PD}=3.15 \mathrm{e}-06 \mathrm{PS}=6.5 \mathrm{e}-07 \quad \mathrm{NRD}=0.425 \mathrm{NRS}=0.425$ $m \times 2420 \_X 169+M 7$ VDD1 X2420_18 X2420_X169_6 VDD1 MODP $L=3.5 \mathrm{e}-07 \mathrm{~W}=1 \mathrm{e}-06$ $+A D=5.95 \mathrm{e}-13 \quad \mathrm{AS}=1.075 \mathrm{e}-12 \quad \mathrm{PD}=1.12 \mathrm{e}-06 \quad \mathrm{PS}=3.15 \mathrm{e}-06 \quad \mathrm{NRD}=0.425 \mathrm{NRS}=0.425$ $m \times 2420 \_X 169 \_M 8 \times 2420 \_10 \times 2420 \_X 169 \_6$ VDD1 VDD1 MODP $L=3.5 \mathrm{e}-07 \mathrm{~W}=1.5 \mathrm{e}-06$ $+\quad \mathrm{AD}=8.625 \mathrm{e}-13 \quad \mathrm{AS}=8.925 \mathrm{e}-13 \quad \mathrm{PD}=1.15 \mathrm{e}-06 \quad \mathrm{PS}=1.68 \mathrm{e}-06 \quad \mathrm{NRD}=0.283333$ $\mathrm{NRS}=0.283333$

mX2420_X169_M9 VDD1 X2420_X169_6 X2420_10 VDD1 MODP L=3.5e-07 W=1.5e-06 $+\quad A D=1.6125 \mathrm{e}-12 \quad A S=8.625 \mathrm{e}-13 \quad \mathrm{PD}=3.65 \mathrm{e}-06 \quad \mathrm{PS}=1.15 \mathrm{e}-06 \quad \mathrm{NRD}=0.283333$ $\mathrm{NRS}=0.283333$

$m \times 2420 \_x 184$ M0 VSS $\times 2420 \_19 \times 2420 \times 184 \_5$ vSS MODN L=3.5e-07 W=1e-06 $+A D=5.75 \mathrm{e}-13 \quad \mathrm{AS}=1.075 \mathrm{e}-12 \quad \mathrm{PD}=1.15 \mathrm{e}-06 \mathrm{PS}=3.15 \mathrm{e}-06 \mathrm{NRD}=0.425 \mathrm{NRS}=0.425$ $\mathrm{mX2420 \_ X184 \_ M1}$ X2420_X184_7 X2420_11 vSS VSS MODN L=3.5e-07 $w=1 \mathrm{e}-06$ $+\mathrm{AD}=3.25 \mathrm{e}-13 \mathrm{AS}=5.75 \mathrm{e}-13 \quad \mathrm{PD}=6.5 \mathrm{e}-07 \quad \mathrm{PS}=1.15 \mathrm{e}-06 \mathrm{NRD}=0.425 \mathrm{NRS}=0.425$ $\mathrm{m} \times 2420 \_X 184 \_M 2 \times 2420 \_\times 184 \_6 \times 2420 \_\times 184+5 \times 2420 \_\times 184 \_7$ VSS MODN L $=3.5 \mathrm{e}-07$ $+\quad W=1 \mathrm{e}-06 \quad A D=1.075 \mathrm{e}-12 \quad A S=3.25 \mathrm{e}-13 \quad P D=3.15 \mathrm{e}-06 \quad P S=6.5 \mathrm{e}-07 \quad \mathrm{NRD}=0.425$ $\mathrm{NRS}=0.425$

$m \times 2420 \times 184$ M3 $\times 2420 \times 1848 \times 242011$ VSS VSS MODN L=3.5e-07 W=1e-06 $+\mathrm{AD}=3.25 \mathrm{e}-13 \mathrm{AS}=1.075 \mathrm{e}-1 \overline{2} \quad \mathrm{PD}=6.5 \mathrm{e}-07 \quad \mathrm{PS}=3.15 \mathrm{e}-06 \quad \mathrm{NRD}=0.425 \mathrm{NRS}=0.425$ mX2420_X184_M4 X2420_19 X2420_X184_6 X2420_X184_8 VSS MODN L=3.5e-07 W=1e06

$+A D=1.075 \mathrm{e}-12 \quad A S=3.25 \mathrm{e}-13 \quad \mathrm{PD}=3.15 \mathrm{e}-06 \mathrm{PS}=6.5 \mathrm{e}-07 \quad \mathrm{NRD}=0.425 \mathrm{NRS}=0.425$ $\mathrm{m} \times 2420 \times 184 \mathrm{M} 5 \times 2420 \times 1849 \times 242019$ VDD1 VDD1 MODP $\mathrm{L}=3.5 \mathrm{e}-07 \mathrm{~W}=1 \mathrm{e}-06$ $+\mathrm{AD}=3.25 \mathrm{e}-13 \mathrm{AS}=1.075 \mathrm{e}-12 \mathrm{PD}=6.5 \mathrm{e}-07 \mathrm{PS}=3.15 \mathrm{e}-06 \mathrm{NRD}=0.425 \mathrm{NRS}=0.425$ mX2420_X184_M6 X2420_X184_5 X2420_11 X2420_X184_9 VDD1 MODP L=3.5e-07 W=1e06

$+\mathrm{AD}=1.075 \mathrm{e}-12 \mathrm{AS}=3.25 \mathrm{e}-13 \mathrm{PD}=3.15 \mathrm{e}-06 \mathrm{PS}=6.5 \mathrm{e}-07 \quad \mathrm{NRD}=0.425 \mathrm{NRS}=0.425$ $m \times 2420 \_X 184 \_M 7$ VDD1 X2420_11 X2420_X184_6 VDD1 MODP L=3.5e-07 $\mathrm{W}=1 \mathrm{e}-06$ $+\mathrm{AD}=5.95 \mathrm{e}-13 \mathrm{AS}=1.075 \mathrm{e}-12 \quad \mathrm{PD}=1.12 \mathrm{e}-06 \mathrm{PS}=3.15 \mathrm{e}-06 \mathrm{NRD}=0.425 \mathrm{NRS}=0.425$ mX2420_X184_M8 X2420_19 X2420_X184_6 VDD1 VDD1 MODP L=3.5e-07 W=1.5e-06 $+\quad \mathrm{AD}=8.625 \mathrm{e}-13 \quad \mathrm{AS}=8.925 \mathrm{e}-13 \quad \mathrm{PD}=1.15 \mathrm{e}-06 \quad \mathrm{PS}=1.68 \mathrm{e}-06 \quad \mathrm{NRD}=0.283333$ $\mathrm{NRS}=0.283333$

mX2420_X184_M9 VDD1 X2420_X184_6 X2420_19 VDD1 MODP L=3.5e-07 $W=1.5 \mathrm{e}-06$ $+\quad A D=1.6125 \mathrm{e}-12 \quad A S=8.625 \mathrm{e}-13 \quad P D=3.65 \mathrm{e}-06 \quad P S=1.15 \mathrm{e}-06 \quad \mathrm{NRD}=0.283333$ NRS $=0.283333$

mX2913_M0 X2913_MC X2913_7 VSS VSS MODN L=3.5e-07 W=1e-06 AD=1.075e-12 $+\mathrm{AS}=1.075 \mathrm{e}-12 \mathrm{PD}=3.15 \mathrm{e}-06 \mathrm{PS}=3.15 \mathrm{e}-06 \mathrm{NRD}=0.425 \mathrm{NRS}=0.425$

mX2913_M1 X2913_22 X2913_Q3 X2913_7 VSS MODN $L=3.5 e-07 \quad W=2 e-06 \quad A D=4.5 e-13$ $+\mathrm{AS}=1.7 \mathrm{e}-12 \mathrm{PD}=4.5 \mathrm{e}-07 \mathrm{PS}=3.7 \mathrm{e}-0 \overline{6} \mathrm{NRD}=0.2125 \mathrm{NRS}=0.2125$ $m \times 2913 \_M 2 \times 2913 \_2312 \times 2913 \_22$ VSS MODN $L=3.5 e-07 \quad W=2 e-06 \quad A D=4.5 e-13$ $+\mathrm{AS}=4.5 \mathrm{e}-13 \mathrm{PD}=4.5 \mathrm{e}-07 \mathrm{PS}=4.5 \mathrm{e}-07 \mathrm{NRD}=0.2125 \mathrm{NRS}=0.2125$ $m \times 2913 \_M 3 \times 2913 \_24 \times 2913 \_Q 2 \times 2913 \_23$ VSS MODN $L=3.5 e-07 \quad w=2 e-06 \quad A D=4.5 e-13$ $+\mathrm{AS}=4.5 \mathrm{e}-13 \mathrm{PD}=4.5 \mathrm{e}-07 \mathrm{PS}=4.5 \mathrm{e}-0 \overline{7} \mathrm{NRD}=0.2125 \mathrm{NRS}=0.2125$ mX2913_M4 X2913_25 X2913_Q1 X2913_24 VSS MODN L=3.5e-07 $W=2 e-06 \quad A D=4.5 e-13$ $+\mathrm{AS}=4.5 \mathrm{e}-13 \mathrm{PD}=4.5 \mathrm{e}-07 \mathrm{PS}=4.5 \mathrm{e}-0 \overline{7} \mathrm{NRD}=0.2125 \mathrm{NRS}=0.2125$ $m \times 2913 \_M 5$ VSS SM X2913_25 VSS MODN L=3.5e-07 $\mathrm{W}=2 \mathrm{e}-06 \quad \mathrm{AD}=1.7 \mathrm{e}-12 \quad \mathrm{AS}=4.5 \mathrm{e}-13$ $+\mathrm{PD}=3.7 \mathrm{e}-06 \mathrm{PS}=4.5 \mathrm{e}-0 \overline{7} \mathrm{NRD}=0.2125 \mathrm{NRS}=0.2125$ mX2913_M6 OUTS3 X2913_S3B VSS VSS MODN L=3.5e-07 $\mathrm{W}=1 \mathrm{e}-06$ AD $=1.075 \mathrm{e}-12$ $+\mathrm{AS}=1.075 \mathrm{e}-12 \mathrm{PD}=3.15 \mathrm{e}-06 \mathrm{PS}=3.15 \mathrm{e}-06 \mathrm{NRD}=0.425 \mathrm{NRS}=0.425$ 
mX2913_M7 VDD3 X2913_D3 X2913_Q3 VDD3 MODP L=3.5e-07 W=2e-06 AD=2.15e-12 $+\mathrm{AS}=2.15 \mathrm{e}-12 \mathrm{PD}=4.15 \mathrm{e}-06 \mathrm{PS}=4.15 \mathrm{e}-06 \mathrm{NRD}=0.2125 \mathrm{NRS}=0.2125$ mX2913_M8 VDD3 X2913_D4 X2913_26 VDD3 MODP $L=3.5 e-07 \quad W=1 e-06 \quad A D=5.875 e-13$ $+\mathrm{AS}=1.075 \mathrm{e}-12 \mathrm{PD}=1.175 \mathrm{e}-06 \mathrm{PS}=3.15 \mathrm{e}-06 \mathrm{NRD}=0.425 \mathrm{NRS}=0.425$ mX2913_M9 X2913_MC X2913_7 VDD3 VDD3 MODP L=3.5e-07 W=3e-06 AD=3.225e-12 $+\mathrm{AS}=3.225 \mathrm{e}-12 \mathrm{PD}=5.15 \mathrm{e}-06 \mathrm{PS}=5.15 \mathrm{e}-06 \mathrm{NRD}=0.141667 \mathrm{NRS}=0.141667$ $m \times 2913 \_M 10 \times 2913 \_28 \times 2913 \_Q 3$ VDD3 VDD3 MODP $L=3.5 e-07 \quad W=1 e-06 \quad A D=3.125 e-13$ $+\mathrm{AS}=5.875 \mathrm{e}-13 \mathrm{PD}=6.25 \mathrm{e}-0 \overline{\mathrm{Q}} \mathrm{PS}=1.175 \mathrm{e}-06 \mathrm{NRD}=0.425 \mathrm{NRS}=0.425$ $\mathrm{m} \times 2913 \_\mathrm{M} 11 \times 2913 \_27 \times 2913 \_26 \times 2913 \_28$ VDD3 MODP $L=3.5 \mathrm{e}-07 \mathrm{~W}=1 \mathrm{e}-06 \mathrm{AD}=1.05 \mathrm{e}-$ 12

$+\mathrm{AS}=3.125 \mathrm{e}-13 \mathrm{PD}=3.1 \mathrm{e}-06 \mathrm{PS}=6.25 \mathrm{e}-07 \mathrm{NRD}=0.425 \mathrm{NRS}=0.425$ mX2913_M12 X2913_33 X2913_31 X2913_D3 VDD3 MODP L=3.5e-07 W=1e-06 $A D=2.875 e-13$

$+\mathrm{AS}=9.5 \mathrm{e}-13 \mathrm{PD}=5.75 \mathrm{e}-07 \mathrm{PS}=2.9 \mathrm{e}-06 \mathrm{NRD}=0.425 \mathrm{NRS}=0.425$ mX2913_M13 X2913_S1A X2913_MC VDD3 VDD3 MODP L=3.5e-07 W=2.5e-06 AD=1.5e-12 $+\mathrm{AS}=2.6875 \mathrm{e}-12 \mathrm{PD}=1.2 \mathrm{e}-06 \mathrm{PS}=4.65 \mathrm{e}-06 \mathrm{NRD}=0.17 \mathrm{NRS}=0.17$ mX2913_M14 VDD3 X2913_Q2 X2913_33 VDD3 MODP $L=3.5 e-07 \quad W=1 e-06$ AD $=1.05 e-12$ $+\mathrm{AS}=2.875 \mathrm{e}-13 \mathrm{PD}=3.1 \mathrm{e}-06 \mathrm{PS}=5.75 \mathrm{e}-07 \mathrm{NRD}=0.425 \mathrm{NRS}=0.425$ $\mathrm{m} \times 2913 \_M 15 \times 2913 \_29 \times 2913 \_Q 3$ VDD3 VDD3 MODP $\mathrm{L}=3.5 \mathrm{e}-07 \mathrm{~W}=1 \mathrm{e}-06$ AD $=2.875 \mathrm{e}-13$ $+\mathrm{AS}=1.05 \mathrm{e}-12 \mathrm{PD}=5.75 \mathrm{e}-07 \mathrm{PS}=3.1 \mathrm{e}-06 \mathrm{NRD}=0.425 \mathrm{NRS}=0.425$ mX2913_M16 VDD3 OUTS3 X2913_S1A VDD3 MODP L=3.5e-07 W=2.5e-06 AD=2.5625e-12 $+\mathrm{AS}=1.5 \mathrm{e}-12 \mathrm{PD}=4.55 \mathrm{e}-06 \mathrm{PS}=1.2 \mathrm{e}-06 \mathrm{NRD}=0.17 \mathrm{NRS}=0.17$ mX2913_M17 X2913_D4 X2913_27 X2913_29 VDD3 MODP L=3.5e-07 W=1e-06 AD=9.5e13

$+\mathrm{AS}=2.875 \mathrm{e}-13 \mathrm{PD}=2.9 \mathrm{e}-06 \mathrm{PS}=5.75 \mathrm{e}-07 \mathrm{NRD}=0.425 \mathrm{NRS}=0.425$ mX2913_M18 X2913_32 X2913_30 X2913_31 VDD3 MODP L=3.5e-07 W=1e-06 $\mathrm{AD}=3.125 \mathrm{e}-13$

$+\mathrm{AS}=1.05 \mathrm{e}-12 \mathrm{PD}=6.25 \mathrm{e}-07 \mathrm{PS}=3.1 \mathrm{e}-06 \mathrm{NRD}=0.425 \mathrm{NRS}=0.425$ $\mathrm{m} \times 2913$ M19 VDD3 X2913 02 X2913 32 VDD3 MODP $\mathrm{L}=3.5 \mathrm{e}-07 \mathrm{~W}=1 \mathrm{e}-06 \quad \mathrm{AD}=5.875 \mathrm{e}-13$ $+\mathrm{AS}=3.125 \mathrm{e}-13 \mathrm{PD}=1.175 \mathrm{e}-06 \mathrm{PS}=6.25 \mathrm{e}-07 \mathrm{NRD}=0.425 \mathrm{NRS}=0.425$ $m \times 2913$ M20 X2913 S2A X2913 S1A VDD3 VDD3 MODP L=3.5e-07 $W=1.7 e-06$ $+\mathrm{AD}=1.8275 \mathrm{e}-12 \mathrm{AS}=1.8275 \mathrm{e}-12 \mathrm{PD}=3.85 \mathrm{e}-06 \mathrm{PS}=3.85 \mathrm{e}-06 \mathrm{NRD}=0.25 \mathrm{NRS}=0.25$ $\mathrm{mX2913}$ 2M21 X2913_30 X2913_D3 VDD3 VDD3 MODP $\mathrm{L}=3.5 \mathrm{e}-07 \mathrm{~W}=1 \mathrm{e}-06$ AD $=1.075 \mathrm{e}-12$ $+\mathrm{AS}=5.875 \mathrm{e}-13 \mathrm{PD}=3.15 \mathrm{e}-06 \mathrm{PS}=1.175 \mathrm{e}-06 \mathrm{NRD}=0.425 \mathrm{NRS}=0.425$ $m \times 2913 \_M 2212$ X2913_D4 VDD3 VDD3 MODP $L=3.5 e-07$ W=2e-06 AD=2.15e-12 $+\mathrm{AS}=2.15 \mathrm{e}-12 \mathrm{PD}=4.15 \mathrm{e}-06 \mathrm{PS}=4.15 \mathrm{e}-06 \mathrm{NRD}=0.2125 \mathrm{NRS}=0.2125$ mX2913_M23 X2913_S3A CL3 VDD3 VDD3 MODP L=3.5e-07 W=1.4e-06 AD=1.505e-12 $+\mathrm{AS}=1.505 \mathrm{e}-12 \mathrm{PD}=3.55 \mathrm{e}-06 \mathrm{PS}=3.55 \mathrm{e}-06 \mathrm{NRD}=0.303571 \mathrm{NRS}=0.303571$ mX2913_M24 VDD3 X2913_Q2 X2913_7 VDD3 MODP L=3.5e-07 W=1e-06 AD=8.5e-13 $+\mathrm{AS}=8.5 \mathrm{e}-13 \mathrm{PD}=2.7 \mathrm{e}-06 \mathrm{PS}=2.7 \mathrm{e}-06 \mathrm{NRD}=0.425 \mathrm{NRS}=0.425$ mX2913_M25 X2913_S1B X2913_S3A VDD3 VDD3 MODP L=3.5e-07 W=2.5e-06 AD=1.5e12

$+\mathrm{AS}=2.6875 \mathrm{e}-12 \mathrm{PD}=1.2 \mathrm{e}-06 \mathrm{PS}=4.65 \mathrm{e}-06 \mathrm{NRD}=0.17 \mathrm{NRS}=0.17$ $\mathrm{m} \times 2913 \_M 26$ VDD3 X2913_S3B X2913_S1B VDD3 MODP $\mathrm{L}=3.5 \mathrm{e}-07 \mathrm{~W}=2.5 \mathrm{e}-06$ $+\mathrm{AD}=2.5625 \mathrm{e}-12 \mathrm{AS}=1.5 \mathrm{e}-12 \mathrm{PD}=4.55 \mathrm{e}-06 \mathrm{PS}=1.2 \mathrm{e}-06 \quad \mathrm{NRD}=0.17 \mathrm{NRS}=0.17$ $\mathrm{m} \times 2913 \_M 27$ VDD3 X2913_D2 X2913_34 VDD3 MODP $L=3.5 \mathrm{e}-07 \mathrm{~W}=1 \mathrm{e}-06 \quad \mathrm{AD}=5.875 \mathrm{e}-13$ $+\mathrm{AS}=1.075 \mathrm{e}-12 \mathrm{PD}=1.175 \mathrm{e}-06 \mathrm{PS}=3.15 \mathrm{e}-06 \mathrm{NRD}=0.425 \mathrm{NRS}=0.425$ $m \times 2913 \_M 28$ VDD3 X2913_D1 X2913_Q1 VDD3 MODP $L=3.5 \mathrm{e}-07 \mathrm{~W}=2 \mathrm{e}-06$ AD $=2.15 \mathrm{e}-12$ $+\mathrm{AS}=2.15 \mathrm{e}-12 \mathrm{PD}=4.15 \mathrm{e}-06 \mathrm{PS}=4.15 \mathrm{e}-06 \mathrm{NRD}=0.2125 \mathrm{NRS}=0.2125$ $m \times 2913 \_M 29 \times 2913 \_S 2 B \times 2913 \_S 1 B$ VDD3 VDD3 MODP L $=3.5$ e-07 $W=1.7 e-06$ $+A D=1.8275 \mathrm{e}-12 \quad \mathrm{AS}=1.8275 \mathrm{e}-12 \mathrm{PD}=3.85 \mathrm{e}-06 \mathrm{PS}=3.85 \mathrm{e}-06 \mathrm{NRD}=0.25 \quad \mathrm{NRS}=0.25$ $\mathrm{m} \times 2913 \_M 30 \times 2913 \_36 \times 2913 \_Q 1$ VDD3 VDD3 MODP $\mathrm{L}=3.5 \mathrm{e}-07 \mathrm{~W}=1 \mathrm{e}-06 \quad \mathrm{AD}=3.125 \mathrm{e}-13$ $+\mathrm{AS}=5.875 \mathrm{e}-13 \mathrm{PD}=6.25 \mathrm{e}-0 \overline{\mathrm{Q}} \mathrm{PS}=1.175 \mathrm{e}-06 \mathrm{NRD}=0.425 \mathrm{NRS}=0.425$ $m \times 2913 \_$M31 X2913_35 X2913_34 X2913_36 VDD3 MODP L $=3.5 \mathrm{e}-07 \mathrm{~W}=1 \mathrm{e}-06 \mathrm{AD}=1.05 \mathrm{e}-$ 12

$+\mathrm{AS}=3.125 \mathrm{e}-13 \mathrm{PD}=3.1 \mathrm{e}-06 \mathrm{PS}=6.25 \mathrm{e}-07 \mathrm{NRD}=0.425 \mathrm{NRS}=0.425$ mX2913_M32 X2913_41 X2913_39 X2913_D1 VDD3 MODP L=3.5e-07 W=1e-06 $\mathrm{AD}=2.8 \overline{7} 5 \mathrm{e}-13$

$+\mathrm{AS}=9.5 \mathrm{e}-13 \mathrm{PD}=5.75 \mathrm{e}-07 \mathrm{PS}=2.9 \mathrm{e}-06 \mathrm{NRD}=0.425 \mathrm{NRS}=0.425$ $\mathrm{m} \times 2913 \_M 33 \times 2913$ S3B CL3 VDD3 VDD3 MODP $L=3.5 \mathrm{e}-07 \mathrm{~W}=1.4 \mathrm{e}-06$ AD $=1.505 \mathrm{e}-12$ $+\mathrm{AS}=1.505 \mathrm{e}-12 \mathrm{PD}=3.55 \mathrm{e}-06 \mathrm{PS}=3.55 \mathrm{e}-06 \mathrm{NRD}=0.303571 \mathrm{NRS}=0.303571$ $m \times 2913 \_M 34$ VDD3 OUTS3 X2913_41 VDD3 MODP $L=3.5 \mathrm{e}-07 \mathrm{~W}=1 \mathrm{e}-06$ AD $=1.05 \mathrm{e}-12$ $+\mathrm{AS}=2.875 \mathrm{e}-13 \mathrm{PD}=3.1 \mathrm{e}-06 \mathrm{PS}=5.75 \mathrm{e}-07 \mathrm{NRD}=0.425 \mathrm{NRS}=0.425$ $m \times 2913 \_M 35 \times 2913 \_37 \times 2913 \_Q 1$ VDD3 VDD3 MODP $L=3.5 e-07 \quad W=1 e-06$ AD $=2.875 e-13$ $+\mathrm{AS}=1.05 \mathrm{e}-12 \mathrm{PD}=5.75 \mathrm{e}-07 \mathrm{PS}=3.1 \mathrm{e}-06 \mathrm{NRD}=0.425 \mathrm{NRS}=0.425$ mX2913_M36 X2913_D2 X2913_35 X2913_37 VDD3 MODP L=3.5e-07 W=1e-06 AD=9.5e13

$+\mathrm{AS}=2.875 \mathrm{e}-13 \mathrm{PD}=2.9 \mathrm{e}-06 \mathrm{PS}=5.75 \mathrm{e}-07 \mathrm{NRD}=0.425 \mathrm{NRS}=0.425$ $\mathrm{m} \times 2913 \_$M37 X2913_40 X2913_38 X2913_39 VDD3 MODP L=3.5e-07 W=1e-06 $A D=3.125 \mathrm{e}-13$ 
$+\mathrm{AS}=1.05 \mathrm{e}-12 \mathrm{PD}=6.25 \mathrm{e}-07 \mathrm{PS}=3.1 \mathrm{e}-06 \mathrm{NRD}=0.425 \mathrm{NRS}=0.425$

mX2913_M38 VDD3 OUTS3 X2913_40 VDD3 MODP L=3.5e-07 W=1e-06 AD=5.875e-13 $+\mathrm{AS}=3.125 \mathrm{e}-13 \mathrm{PD}=1.175 \mathrm{e}-06 \mathrm{PS}=6.25 \mathrm{e}-07 \mathrm{NRD}=0.425 \mathrm{NRS}=0.425$

$\mathrm{m} \times 2913 \_M 39$ OUTS3 X2913_S3B VDD3 VDD3 MODP $\mathrm{L}=3.5 \mathrm{e}-07 \mathrm{~W}=2 \mathrm{e}-06 \quad \mathrm{AD}=2.15 \mathrm{e}-12$ $+\mathrm{AS}=2.15 \mathrm{e}-12 \mathrm{PD}=4.15 \mathrm{e}-06 \mathrm{PS}=4.15 \mathrm{e}-06 \mathrm{NRD}=0.2125 \mathrm{NRS}=0.2125$ mX2913_M40 X2913_Q2 X2913_D2 VDD3 VDD3 MODP L=3.5e-07 W=2e-06 AD=2.15e-12 $+\mathrm{AS}=2.15 \mathrm{e}-12 \mathrm{PD}=4.15 \mathrm{e}-06 \mathrm{PS}=4.15 \mathrm{e}-06 \mathrm{NRD}=0.2125 \mathrm{NRS}=0.2125$ mX2913_M41 X2913_38 X2913_D1 VDD3 VDD3 MODP L=3.5e-07 W=1e-06 AD=1.075e-12 $+\mathrm{AS}=5.875 \mathrm{e}-13 \mathrm{PD}=3.15 \mathrm{e}-06 \mathrm{PS}=1.175 \mathrm{e}-06 \mathrm{NRD}=0.425 \mathrm{NRS}=0.425$ mX2913_X44_M0 X2913_Q3 X2913_D3 VSS VSS MODN L=3.5e-07 W=3e-06 AD=3.225e-12 $+\mathrm{AS}=3.225 \mathrm{e}-12 \mathrm{PD}=5.15 \mathrm{e}-06 \mathrm{PS}=5.15 \mathrm{e}-06 \mathrm{NRD}=0.141667 \mathrm{NRS}=0.141667$ mX2913_X45_M0 X2913_X45_7 X2913_D4 X2913_26 VSS MODN L=3.5e-07 W=1e-06 $+\mathrm{AD}=5.875 \mathrm{e}-13 \mathrm{AS}=1.075 \mathrm{e}-12 \mathrm{PD}=1.175 \mathrm{e}-06 \mathrm{PS}=3.15 \mathrm{e}-06 \mathrm{NRD}=0.425 \mathrm{NRS}=0.425$ mX2913_X45_M1 VSS X2913_Q3 X2913_X45_7 VSS MODN L=3.5e-07 W=1e-06 AD=1e-12 $+\mathrm{AS}=5.875 \mathrm{e}-13 \mathrm{PD}=3 \mathrm{e}-06 \mathrm{PS}=1.175 \mathrm{e}-06 \mathrm{NRD}=0.425 \mathrm{NRS}=0.425$ mX2913_X45_M2 VSS X2913_Q3 X2913_27 VSS MODN L=3.5e-07 W=1e-06 AD=6.1e-13 $+\mathrm{AS}=1.175 \mathrm{e}-12 \mathrm{PD}=1.12 \mathrm{e}-06 \mathrm{PS}=3.35 \mathrm{e}-06 \mathrm{NRD}=0.425 \mathrm{NRS}=0.425$ mX2913_X45_M3 X2913_D4 X2913_27 VSS VSS MODN L=3.5e-07 W=1.5e-06 $\mathrm{AD}=7.6875 \mathrm{e}-13$

$+\mathrm{AS}=9.15 \mathrm{e}-13 \mathrm{PD}=1.025 \mathrm{e}-06 \mathrm{PS}=1.68 \mathrm{e}-06 \mathrm{NRD}=0.283333 \mathrm{NRS}=0.283333$ mX2913_X45_M4 VSS X2913_27 X2913_D4 VSS MODN L=3.5e-07 W=1.5e-06 AD=1.425e12

$+\mathrm{AS}=7.6875 \mathrm{e}-13 \mathrm{PD}=3.4 \mathrm{e}-06 \mathrm{PS}=1.025 \mathrm{e}-06 \mathrm{NRD}=0.283333 \mathrm{NRS}=0.283333$ $\mathrm{m} \times 2913 \_X 54 \_M 0 \times 2913 \_\times 54 \_7 \times 2913 \_D 3 \times 2913 \_30$ VSS MODN L=3.5e-07 W=1e-06 $+\mathrm{AD}=5.875 \mathrm{e}-13 \mathrm{AS}=1.075 \mathrm{e}-12 \mathrm{PD}=1.175 \mathrm{e}-06 \mathrm{PS}=3.15 \mathrm{e}-06 \mathrm{NRD}=0.425 \mathrm{NRS}=0.425$ $m \times 2913 \_\times 54 \_M 1$ VSS X2913_Q2 X2913_X54_7 VSS MODN L=3.5e-07 W=1e-06 AD =1e-12 $+\mathrm{AS}=5.875 \mathrm{e}-13 \mathrm{PD}=3 \mathrm{e}-06 \mathrm{PS}=1.175 \mathrm{e}-06 \mathrm{NRD}=0.425 \mathrm{NRS}=0.425$ $m \times 2913 \_\times 54 \_M 2$ VSS X2913_Q2 X2913_31 VSS MODN L=3.5e-07 W=1e-06 AD=6.1e-13 $+\mathrm{AS}=1.175 \mathrm{e}-12 \mathrm{PD}=1.12 \mathrm{e}-06 \mathrm{PS}=3.35 \mathrm{e}-06 \mathrm{NRD}=0.425 \mathrm{NRS}=0.425$ $\mathrm{m} \times 2913 \_\times 54 \_M 3 \times 2913 \_D 3 \times 2913 \_31$ VSS VSS MODN L=3.5e-07 W=1.5e-06 $A D=7.6875 \mathrm{e}-13$

$+\mathrm{AS}=9.15 \mathrm{e}-13 \mathrm{PD}=1.025 \mathrm{e}-06 \mathrm{PS}=1.68 \mathrm{e}-06 \mathrm{NRD}=0.283333 \mathrm{NRS}=0.283333$ mX2913_X54_M4 VSS X2913_31 X2913_D3 VSS MODN L=3.5e-07 W=1.5e-06 AD=1.425e12

$+\mathrm{AS}=7.6875 \mathrm{e}-13 \mathrm{PD}=3.4 \mathrm{e}-06 \mathrm{PS}=1.025 \mathrm{e}-06 \mathrm{NRD}=0.283333 \mathrm{NRS}=0.283333$ $m \times 2913 \_\times 56 \_M 0$ X2913_S1A CL3 VSS VSS MODN L=8e-07 $W=1 e-06 \quad A D=1.1 e-12$ $\mathrm{AS}=1.1 \mathrm{e}-12$

$+\mathrm{PD}=3.2 \mathrm{e}-06 \mathrm{PS}=3.2 \mathrm{e}-06 \mathrm{NRD}=0.425 \mathrm{NRS}=0.425$

mX2913_X56_M1 VSS CL3 X2913_S2A VSS MODN L=3.5e-07 W=1.55e-06 AD=9.04846e13

$+\mathrm{AS}=1.74375 \mathrm{e}-12 \mathrm{PD}=1.38684 \mathrm{e}-06 \mathrm{PS}=3.8 \mathrm{e}-06 \quad \mathrm{NRD}=0.274194 \mathrm{NRS}=0.274194$

$m \times 2913 \_\times 56 \_M 2 \times 2913 \_S 3 A$ X2913_S2A VSS VSS MODN L $=3.5 e-07 \quad W=1.3 e-06$

$+\mathrm{AD}=7.475 \mathrm{e}-13 \mathrm{AS}=7.58904 \mathrm{e}-13 \mathrm{PD}=1.15 \mathrm{e}-06 \mathrm{PS}=1.16316 \mathrm{e}-06 \mathrm{NRD}=0.326923$

$+\mathrm{NRS}=0.326923$

mX2913_X56_M3 VSS X2913_S2A X2913_S3A VSS MODN L=3.5e-07 W=1.3e-06

$+\quad A D=1.5925 \mathrm{e}-12 \quad A S=7.475 \mathrm{e}-13 \quad P D=3.75 \mathrm{e}-06 \quad P S=1.15 \mathrm{e}-06 \quad \mathrm{NRD}=0.326923$

$\mathrm{NRS}=0.326923$

mX2913_X62_M0 $12 \times 2913$ D4 VSS VSS MODN L=3.5e-07 $W=3 e-06 \quad A D=3.225 e-12$

$+\mathrm{AS}=3.225 \mathrm{e}-12 \mathrm{PD}=5.15 \mathrm{e}-06 \mathrm{PS}=5.15 \mathrm{e}-06 \mathrm{NRD}=0.141667 \mathrm{NRS}=0.141667$

mX2913_X95_M0 X2913_S1B CL3 VSS VSS MODN L=8e-07 W=1e-06 AD=1.1e-12 $\mathrm{AS}=1.1 \mathrm{e}-12$

$+\mathrm{PD}=3.2 \mathrm{e}-06 \mathrm{PS}=3.2 \mathrm{e}-06 \mathrm{NRD}=0.425 \mathrm{NRS}=0.425$

mX2913_X95_M1 VSS CL3 X2913_S2B VSS MODN L=3.5e-07 W=1.55e-06 AD=9.04846e13

$+\mathrm{AS}=1.74375 \mathrm{e}-12 \mathrm{PD}=1.38684 \mathrm{e}-06 \mathrm{PS}=3.8 \mathrm{e}-06 \mathrm{NRD}=0.274194 \mathrm{NRS}=0.274194$

mX2913_X95_M2 X2913_S3B X2913_S2B VSS VSS MODN L=3.5e-07 W=1.3e-06

$+A D=7.475 \mathrm{e}-13$ AS $=7.58904 \mathrm{e}-13 \quad P D=1.15 \mathrm{e}-06 \quad P S=1.16316 \mathrm{e}-06 \quad \mathrm{NRD}=0.326923$

$+\mathrm{NRS}=0.326923$

mX2913_X95_M3 VSS X2913_S2B X2913_S3B VSS MODN L=3.5e-07 W=1.3e-06

$+\quad A D=1.5925 \mathrm{e}-12 \quad A S=7.475 \mathrm{e}-13 \quad P D=3.75 \mathrm{e}-06 \quad P S=1.15 \mathrm{e}-06 \quad N R D=0.326923$ NRS $=0.326923$

mX2913_X119_M0 X2913_X119_7 X2913_D2 X2913_34 VSS MODN L=3.5e-07 W=1e-06

$+\mathrm{AD}=5.875 \mathrm{e}-13 \mathrm{AS}=1.075 \mathrm{e}-12 \mathrm{PD}=1.175 \mathrm{e}-06 \mathrm{PS}=3.15 \mathrm{e}-06 \mathrm{NRD}=0.425 \mathrm{NRS}=0.425$

mX2913_X119_M1 VSS X2913_Q1 X2913_X119_7 VSS MODN L=3.5e-07 W=1e-06 AD=1e12

$+\mathrm{AS}=5.875 \mathrm{e}-13 \mathrm{PD}=3 \mathrm{e}-06 \mathrm{PS}=1.175 \mathrm{e}-06 \mathrm{NRD}=0.425 \mathrm{NRS}=0.425$

$m \times 2913 \_X 119 \_M 2$ VSS X2913_Q1 X2913_35 VSS MODN L=3.5e-07 $W=1 e-06 \quad A D=6.1 e-13$

$+\mathrm{AS}=1.175 \mathrm{e}-12 \mathrm{PD}=1.12 \mathrm{e}-06 \mathrm{PS}=3.35 \mathrm{e}-06 \mathrm{NRD}=0.425 \mathrm{NRS}=0.425$

mX2913_X119_M3 X2913_D2 X2913_35 VSS VSS MODN L=3.5e-07 W=1.5e-06 
$+\mathrm{AD}=7.6875 \mathrm{e}-13 \quad \mathrm{AS}=9.15 \mathrm{e}-13 \quad \mathrm{PD}=1.025 \mathrm{e}-06 \quad \mathrm{PS}=1.68 \mathrm{e}-06 \quad \mathrm{NRD}=0.283333$
$\mathrm{NRS}=0.283333$ mX2913_X119_M4 VSS X2913_35 X2913_D2 VSS MODN L=3.5e-07 W=1.5e-06 $\mathrm{AD}=1.4 \overline{2} 5 \mathrm{e}-1 \overline{2}$ $+\mathrm{AS}=7.6875 \mathrm{e}-13 \mathrm{PD}=3.4 \mathrm{e}-06 \mathrm{PS}=1.025 \mathrm{e}-06 \mathrm{NRD}=0.283333 \mathrm{NRS}=0.283333$ mX2913_X120_M0 X2913_Q1 X2913_D1 VSS VSS MODN L=3.5e-07 W=3e-06 AD=3.225e12

$+\mathrm{AS}=3.225 \mathrm{e}-12 \mathrm{PD}=5.15 \mathrm{e}-06 \mathrm{PS}=5.15 \mathrm{e}-06 \mathrm{NRD}=0.141667 \mathrm{NRS}=0.141667$ mX2913_X130_M0 X2913_X130_7 X2913_D1 X2913_38 VSS MODN L=3.5e-07 W=1e-06 $+\mathrm{AD}=5.875 \mathrm{e}-13 \mathrm{AS}=1.075 \mathrm{e}-\overline{1} 2 \mathrm{PD}=1.175 \mathrm{e}-06 \mathrm{PS}=3.15 \mathrm{e}-06 \mathrm{NRD}=0.425 \mathrm{NRS}=0.425$ mX2913_X130_M1 VSS OUTS3 X2913_X130_7 VSS MODN L=3.5e-07 W=1e-06 AD=1e-12 $+\mathrm{AS}=5.875 \mathrm{e}-13 \mathrm{PD}=3 \mathrm{e}-06 \mathrm{PS}=1.175 \mathrm{e}-0 \overline{6} \mathrm{NRD}=0.425 \mathrm{NRS}=0.425$ mX2913_X130_M2 VSS OUTS3 X2913_39 VSS MODN L=3.5e-07 $W=1 e-06$ AD $=6.1 e-13$ $+\mathrm{AS}=1.175 \mathrm{e}-12 \mathrm{PD}=1.12 \mathrm{e}-06 \mathrm{PS}=3.35 \mathrm{e}-06 \mathrm{NRD}=0.425 \mathrm{NRS}=0.425$ mX2913_X130_M3 X2913_D1 X2913_39 VSS VSS MODN L=3.5e-07 W=1.5e-06 $+\quad A D=7.6875 \mathrm{e}-13 \quad \mathrm{AS}=9.15 \mathrm{e}-13 \quad \mathrm{PD}=1.025 \mathrm{e}-06 \quad \mathrm{PS}=1.68 \mathrm{e}-06 \quad \mathrm{NRD}=0.283333$ $\mathrm{NRS}=0.283333$

mX2913_X130_M4 VSS X2913_39 X2913_D1 VSS MODN L=3.5e-07 W=1.5e-06 $\mathrm{AD}=1.425 \mathrm{e}-1 \overline{2}$

$+\mathrm{AS}=7.6875 \mathrm{e}-13 \mathrm{PD}=3.4 \mathrm{e}-06 \mathrm{PS}=1.025 \mathrm{e}-06 \mathrm{NRD}=0.283333 \mathrm{NRS}=0.283333$ mX2913_X139_M0 X2913_Q2 X2913_D2 VSS VSS MODN L=3.5e-07 W=3e-06 AD=3.225e12

$+\mathrm{AS}=3.225 \mathrm{e}-12 \mathrm{PD}=5.15 \mathrm{e}-06 \mathrm{PS}=5.15 \mathrm{e}-06 \mathrm{NRD}=0.141667 \mathrm{NRS}=0.141667$ $m \times 3798 \_M 0 \times 3798 \_412$ VSS VSS MODN L=3.5e-07 $\mathrm{W}=2 \mathrm{e}-06 \quad A D=2.15 \mathrm{e}-12 \quad A S=2.15 \mathrm{e}-12$ $+\mathrm{PD}=4.15 \mathrm{e}-06 \mathrm{PS}=4.15 \mathrm{e}-06 \mathrm{NRD}=0.2125 \mathrm{NRS}=0.2125$

mX3798_M1 X3798_5 X3798_4 VSS VSS MODN L=3.5e-07 $W=6 e-06 \quad A D=6.45 e-12$

$+\mathrm{AS}=6.45 \mathrm{e}-12 \mathrm{PD}=8.15 \mathrm{e}-06 \mathrm{PS}=8.15 \mathrm{e}-06 \mathrm{NRD}=0.0708333 \mathrm{NRS}=0.0708333$

$m \times 3798 \_M 2 \times 3798 \_6 \times 3798 \_5$ VSS VSS MODN L=3.5e-07 $W=1.5 \mathrm{e}-05$ AD $=1.475 \mathrm{e}-11$

$+\mathrm{AS}=1.65 \mathrm{e}-11 \mathrm{PD}=1.25 \mathrm{e}-05 \mathrm{PS}=1.72 \mathrm{e}-05 \mathrm{NRD}=0.0283333 \mathrm{NRS}=0.0283333$

$m \times 3798 \_M 3$ VSS X3798_5 x3798_6 VSS MODN L=3.5e-07 W=3e-06 AD =3.15e-12

$+\mathrm{AS}=2.95 \mathrm{e}-12 \mathrm{PD}=5.1 \mathrm{e}-06 \mathrm{PS}=2.5 \mathrm{e}-06 \mathrm{NRD}=0.141667 \mathrm{NRS}=0.141667$

$m \times 3798 \_M 4$ OUT3 X3798_6 VSS VSS MODN $L=3.5 \mathrm{e}-07 \mathrm{~W}=1.5 \mathrm{e}-05 \quad \mathrm{AD}=8.25 \mathrm{e}-12$

$+\mathrm{AS}=1.65 \mathrm{e}-11 \mathrm{PD}=1.1 \mathrm{e}-06 \mathrm{PS}=1.72 \mathrm{e}-05 \mathrm{NRD}=0.0283333 \mathrm{NRS}=0.0283333$

mX3798_M5 VSS X3798_6 OUT3 VSS MODN L=3.5e-07 W=1.5e-05 AD=1.125e-11

$+\mathrm{AS}=8.25 \mathrm{e}-12 \mathrm{PD}=1.5 \mathrm{e}-06 \mathrm{PS}=1.1 \mathrm{e}-06 \mathrm{NRD}=0.0283333 \mathrm{NRS}=0.0283333$

mX3798_M6 OUT3 X3798_6 VSS VSS MODN L=3.5e-07 $W=1.5 \mathrm{e}-05 \quad A D=1.29375 \mathrm{e}-11$

$+\mathrm{AS}=1.125 \mathrm{e}-11 \mathrm{PD}=5.75 \mathrm{e}-06 \mathrm{PS}=1.5 \mathrm{e}-06 \mathrm{NRD}=0.0283333 \mathrm{NRS}=0.0283333$

$m \times 3798 \_M 7$ VSS $\times 3798 \_6$ OUT3 VSS MODN L $=3.5 \mathrm{e}-07 \mathrm{~W}=9 \mathrm{e}-06 \mathrm{AD}=9.45 \mathrm{e}-12$

$+\mathrm{AS}=7.7625 \mathrm{e}-12 \mathrm{PD}=1.11 \mathrm{e}-05 \mathrm{PS}=3.45 \mathrm{e}-06 \mathrm{NRD}=0.0472222 \mathrm{NRS}=0.0472222$

$m \times 3798 \_M 8 \times 3798 \_412$ VDDB VDDB MODP $L=3.5 \mathrm{e}-07 \quad \mathrm{~W}=4 \mathrm{e}-06 \quad \mathrm{AD}=4.4 \mathrm{e}-12 \quad \mathrm{AS}=4.2 \mathrm{e}-12$

$+\mathrm{PD}=6.2 \mathrm{e}-06 \mathrm{PS}=6.1 \mathrm{e}-06 \mathrm{NRD}=0.10625 \mathrm{NRS}=0.10625$

$m \times 3798 \_M 9 \times 3798 \_5 \times 3798 \_4$ VDDB VDDB MODP $\mathrm{L}=3.5 \mathrm{e}-07 \quad \mathrm{~W}=1.2 \mathrm{e}-05 \quad \mathrm{AD}=1.32 \mathrm{e}-11$

$+\mathrm{AS}=1.32 \mathrm{e}-11 \mathrm{PD}=1.42 \mathrm{e}-05 \mathrm{PS}=1.42 \mathrm{e}-05 \mathrm{NRD}=0.0354167$ NRS $=0.0354167$

$m \times 3798 \_M 10 \times 3798 \_6 \times 3798 \_5$ VDDB VDDB MODP $L=3.5 \mathrm{e}-07 \quad \mathrm{~W}=1.5 \mathrm{e}-05 \quad \mathrm{AD}=8.25 \mathrm{e}-12$

$+\mathrm{AS}=1.65 \mathrm{e}-11 \mathrm{PD}=1.1 \mathrm{e}-06 \mathrm{PS}=1.72 \mathrm{e}-05 \mathrm{NRD}=0.0283333 \mathrm{NRS}=0.0283333$

$m \times 3798 \_M 11$ VDDB X3798_5 X3798_6 VDDB MODP $L=3.5 \mathrm{e}-07 \quad W=1.5 \mathrm{e}-05 \quad A D=1.35 \mathrm{e}-11$

$+\mathrm{AS}=8.25 \mathrm{e}-12 \mathrm{PD}=8.57143 \mathrm{e}-06 \mathrm{PS}=1.1 \mathrm{e}-06 \mathrm{NRD}=0.0283333 \mathrm{NRS}=0.0283333$

$\mathrm{m} \times 3798 \_M 12 \times 3798 \_6 \times 3798 \_5$ VDDB VDDB MODP $L=3.5 \mathrm{e}-07 \mathrm{~W}=6 \mathrm{e}-06 \quad \mathrm{AD}=6.3 \mathrm{e}-12$

$+\mathrm{AS}=5.4 \mathrm{e}-12 \mathrm{PD}=8.1 \mathrm{e}-06 \mathrm{PS}=3.42857 \mathrm{e}-06 \mathrm{NRD}=0.0708333 \mathrm{NRS}=0.0708333$

$m \times 3798 \_M 13$ OUT3 X3798_6 VDDB VDDB MODP $L=3.5 \mathrm{e}-07 \quad W=1.5 \mathrm{e}-05 \quad A D=8.25 \mathrm{e}-12$

$+\mathrm{AS}=1.65 \mathrm{e}-11 \mathrm{PD}=1.1 \mathrm{e}-06 \mathrm{PS}=1.72 \mathrm{e}-05 \mathrm{NRD}=0.0283333 \mathrm{NRS}=0.0283333$

$m \times 3798 \_M 14$ VDDB X3798_6 OUT3 VDDB MODP $L=3.5 \mathrm{e}-07 \quad w=1.5 \mathrm{e}-05$ AD $=8.25 \mathrm{e}-12$

$+\mathrm{AS}=8.25 \mathrm{e}-12 \mathrm{PD}=1.1 \mathrm{e}-06 \mathrm{PS}=1.1 \mathrm{e}-06 \mathrm{NRD}=0.0283333 \mathrm{NRS}=0.0283333$

$\mathrm{m} \times 3798 \_$M15 OUT3 X3798_6 VDDB VDDB MODP $\mathrm{L}=3.5 \mathrm{e}-07 \mathrm{~W}=1.5 \mathrm{e}-05$ AD $=8.25 \mathrm{e}-12$

$+\mathrm{AS}=8.25 \mathrm{e}-12 \mathrm{PD}=1.1 \mathrm{e}-06 \mathrm{PS}=1.1 \mathrm{e}-06 \mathrm{NRD}=0.0283333 \mathrm{NRS}=0.0283333$

$\mathrm{m} \times 3798 \_$M16 VDDB X3798_6 OUT3 VDDB MODP $\mathrm{L}=3.5 \mathrm{e}-07 \mathrm{~W}=1.5 \mathrm{e}-05 \quad \mathrm{AD}=8.25 \mathrm{e}-12$

$+\mathrm{AS}=8.25 \mathrm{e}-12 \mathrm{PD}=1.1 \mathrm{e}-06 \mathrm{PS}=1.1 \mathrm{e}-06 \mathrm{NRD}=0.0283333 \mathrm{NRS}=0.0283333$

mX3798_M17 OUT3 X3798_6 VDDB VDDB MODP $L=3.5 \mathrm{e}-07 \quad W=1.5 \mathrm{e}-05 \quad A D=1.125 \mathrm{e}-11$

$+\mathrm{AS}=8.25 \mathrm{e}-12 \mathrm{PD}=1.5 \mathrm{e}-06 \mathrm{PS}=1.1 \mathrm{e}-06 \mathrm{NRD}=0.0283333 \mathrm{NRS}=0.0283333$

$m \times 3798 \_M 18$ VDDB X3798_6 OUT3 VDDB MODP L $=3.5 \mathrm{e}-07 \mathrm{~W}=1.5 \mathrm{e}-05$ AD $=1.2 \mathrm{e}-11$

$+\mathrm{AS}=1.125 \mathrm{e}-11 \mathrm{PD}=1.6 \mathrm{e}-06 \mathrm{PS}=1.5 \mathrm{e}-06 \mathrm{NRD}=0.0283333 \mathrm{NRS}=0.0283333$

mX3798_M19 OUT3 X3798_6 VDDB VDDB MODP $L=3.5 \mathrm{e}-07 \quad \mathrm{~W}=1.5 \mathrm{e}-05 \quad \mathrm{AD}=1.45 \mathrm{e}-11$

$+A S=1.2 \mathrm{e}-11 \mathrm{PD}=1.26667 \mathrm{e}-05 \mathrm{PS}=1.6 \mathrm{e}-06 \mathrm{NRD}=0.0283333 \mathrm{NRS}=0.0283333$

$m \times 3798 \_M 20$ VDDB X3798_6 OUT3 VDDB MODP $L=3.5 \mathrm{e}-07 \quad W=3 \mathrm{e}-06 \quad \mathrm{AD}=3.15 \mathrm{e}-12$

$+\mathrm{AS}=2.9 \mathrm{e}-12 \mathrm{PD}=5.1 \mathrm{e}-06 \mathrm{PS}=2.53333 \mathrm{e}-06 \mathrm{NRD}=0.141667$ NRS $=0.141667$

$m \times 3803$ M0 X3803_4 17 VSS VSS MODN L=3.5e-07 $\mathrm{W}=2 \mathrm{e}-06 \quad \mathrm{AD}=2.15 \mathrm{e}-12 \quad \mathrm{AS}=2.15 \mathrm{e}-12$

$+\mathrm{PD}=4.15 \mathrm{e}-06 \mathrm{PS}=4.15 \mathrm{e}-06 \mathrm{NRD}=0.2125 \mathrm{NRS}=0.2125$

mX3803_M1 X3803_5 X3803_4 VSS VSS MODN L=3.5e-07 $w=6 e-06 \quad A D=6.45 e-12$

$+\mathrm{AS}=6.45 \mathrm{e}-12 \mathrm{PD}=8.15 \mathrm{e}-06 \mathrm{PS}=8.15 \mathrm{e}-06 \mathrm{NRD}=0.0708333 \mathrm{NRS}=0.0708333$

$m \times 3803 \_M 2 \times 3803 \_6 \times 3803 \_5$ VSS VSS MODN L=3.5e-07 $W=1.5 \mathrm{e}-05$ AD $=1.475 \mathrm{e}-11$ 
$+\mathrm{AS}=1.65 \mathrm{e}-11 \mathrm{PD}=1.25 \mathrm{e}-05 \mathrm{PS}=1.72 \mathrm{e}-05 \mathrm{NRD}=0.0283333 \mathrm{NRS}=0.0283333$

$\mathrm{mX3803 \_ M3}$ VSS X3803_5 X3803_6 VSS MODN L=3.5e-07 W=3e-06 AD=3.15e-12 $+\mathrm{AS}=2.95 \mathrm{e}-12 \mathrm{PD}=5.1 \mathrm{e}-06 \mathrm{PS}=2.5 \mathrm{e}-06 \mathrm{NRD}=0.141667 \mathrm{NRS}=0.141667$

mX3803_M4 OUT1 X3803_6 VSS VSS MODN L=3.5e-07 W=1.5e-05 AD=8.25e-12 $+\mathrm{AS}=1.65 \mathrm{e}-11 \mathrm{PD}=1.1 \mathrm{e}-06 \mathrm{PS}=1.72 \mathrm{e}-05 \mathrm{NRD}=0.0283333 \mathrm{NRS}=0.0283333$

mX3803_M5 VSS X3803_6 OUT1 VSS MODN L=3.5e-07 $W=1.5 \mathrm{e}-05$ AD $=1.125 \mathrm{e}-11$ $+\mathrm{AS}=8.25 \mathrm{e}-12 \mathrm{PD}=1 . \overline{\mathrm{e}}-06 \mathrm{PS}=1.1 \mathrm{e}-06 \mathrm{NRD}=0.0283333 \mathrm{NRS}=0.0283333$ mX3803_M6 OUT1 X3803_6 VSS VSS MODN $L=3.5 \mathrm{e}-07 \quad \mathrm{~W}=1.5 \mathrm{e}-05 \quad \mathrm{AD}=1.29375 \mathrm{e}-11$ $+\mathrm{AS}=1.125 \mathrm{e}-11 \mathrm{PD}=5.75 \mathrm{e}-06 \mathrm{PS}=1.5 \mathrm{e}-06 \mathrm{NRD}=0.0283333 \mathrm{NRS}=0.0283333$ mX3803_M7 VSS X3803_6 OUT1 VSS MODN L=3.5e-07 W=9e-06 AD=9.45e-12 $+\mathrm{AS}=7.7625 \mathrm{e}-12 \mathrm{PD}=1.11 \mathrm{e}-05 \mathrm{PS}=3.45 \mathrm{e}-06 \mathrm{NRD}=0.0472222 \mathrm{NRS}=0.0472222$ $\mathrm{m} \times 3803 \_\mathrm{M} 8$ X3803_4 17 VDDB VDDB MODP $\mathrm{L}=3.5 \mathrm{e}-07 \mathrm{~W}=4 \mathrm{e}-06 \quad \mathrm{AD}=4.4 \mathrm{e}-12 \quad \mathrm{AS}=4.2 \mathrm{e}-12$ $+\mathrm{PD}=6.2 \mathrm{e}-06 \mathrm{PS}=6.1 \mathrm{e}-06 \mathrm{NRD}=0.10625 \mathrm{NRS}=0.10625$ $\mathrm{mX3803 \_ M9} \times 3803 \_5 \times 3803 \_4$ VDDB VDDB MODP $\mathrm{L}=3.5 \mathrm{e}-07 \mathrm{~W}=1.2 \mathrm{e}-05$ AD $=1.32 \mathrm{e}-11$ $+\mathrm{AS}=1.32 \mathrm{e}-11 \mathrm{PD}=1.42 \mathrm{e}-05 \mathrm{PS}=1.42 \mathrm{e}-05 \mathrm{NRD}=0.0354167 \mathrm{NRS}=0.0354167$ $\mathrm{m} \times 3803 \_M 10 \times 3803 \_6 \times 3803 \_5$ VDDB VDDB MODP L=3.5e-07 W=1.5e-05 AD=8.25e-12 $+\mathrm{AS}=1.65 \mathrm{e}-11 \mathrm{PD}=1.1 \mathrm{e}-06 \mathrm{PS}=1.72 \mathrm{e}-05 \mathrm{NRD}=0.0283333 \mathrm{NRS}=0.0283333$ $\mathrm{m} \times 3803 \_M 11$ VDDB X3803_5 X3803_6 VDDB MODP $L=3.5 \mathrm{e}-07 \mathrm{~W}=1.5 \mathrm{e}-05 \quad \mathrm{AD}=1.35 \mathrm{e}-11$ $+\mathrm{AS}=8.25 \mathrm{e}-12 \mathrm{PD}=8.57143 \mathrm{e}-06 \mathrm{PS}=1.1 \mathrm{e}-06 \mathrm{NRD}=0.0283333 \mathrm{NRS}=0.0283333$ $\mathrm{m} \times 3803 \_M 12 \times 3803 \_6 \times 3803 \_5$ VDDB VDDB MODP $\mathrm{L}=3.5 \mathrm{e}-07 \mathrm{~W}=6 \mathrm{e}-06$ AD $=6.3 \mathrm{e}-12$ $+\mathrm{AS}=5.4 \mathrm{e}-12 \mathrm{PD}=8.1 \mathrm{e}-06 \mathrm{PS}=3.42857 \mathrm{e}-06 \mathrm{NRD}=0.0708333 \mathrm{NRS}=0.0708333$ $\mathrm{m} \times 3803 \_M 13$ OUT1 X3803_6 VDDB VDDB MODP $\mathrm{L}=3.5 \mathrm{e}-07 \mathrm{~W}=1.5 \mathrm{e}-05 \quad \mathrm{AD}=8.25 \mathrm{e}-12$ $+\mathrm{AS}=1.65 \mathrm{e}-11 \mathrm{PD}=1.1 \mathrm{e}-06 \mathrm{PS}=1.72 \mathrm{e}-05 \mathrm{NRD}=0.0283333 \mathrm{NRS}=0.0283333$ $\mathrm{m} \times 3803 \_$M14 VDDB X3803_6 OUT1 VDDB MODP $\mathrm{L}=3.5 \mathrm{e}-07 \mathrm{~W}=1.5 \mathrm{e}-05 \mathrm{AD}=8.25 \mathrm{e}-12$ $+\mathrm{AS}=8.25 \mathrm{e}-12 \mathrm{PD}=1.1 \mathrm{e}-06 \mathrm{PS}=1.1 \mathrm{e}-06 \mathrm{NRD}=0.0283333 \mathrm{NRS}=0.0283333$ $\mathrm{m} \times 3803 \_M 15$ OUT1 X3803_6 VDDB VDDB MODP $\mathrm{L}=3.5 \mathrm{e}-07 \mathrm{~W}=1.5 \mathrm{e}-05 \quad \mathrm{AD}=8.25 \mathrm{e}-12$ $+\mathrm{AS}=8.25 \mathrm{e}-12 \mathrm{PD}=1.1 \mathrm{e}-06 \mathrm{PS}=1.1 \mathrm{e}-06 \mathrm{NRD}=0.0283333 \mathrm{NRS}=0.0283333$ $\mathrm{m} \times 3803 \_M 16$ VDDB X3803_6 OUT1 VDDB MODP $\mathrm{L}=3.5 \mathrm{e}-07 \mathrm{~W}=1.5 \mathrm{e}-05 \quad \mathrm{AD}=8.25 \mathrm{e}-12$ $+\mathrm{AS}=8.25 \mathrm{e}-12 \mathrm{PD}=1.1 \mathrm{e}-06 \mathrm{PS}=1.1 \mathrm{e}-06 \mathrm{NRD}=0.0283333 \mathrm{NRS}=0.0283333$ $\mathrm{m} \times 3803 \_$M17 OUT1 X3803_6 VDDB VDDB MODP L=3.5e-07 $\mathrm{W}=1.5 \mathrm{e}-05 \quad \mathrm{AD}=1.125 \mathrm{e}-11$ $+\mathrm{AS}=8.25 \mathrm{e}-12 \mathrm{PD}=1.5 \mathrm{e}-06 \mathrm{PS}=1.1 \mathrm{e}-06 \mathrm{NRD}=0.0283333 \mathrm{NRS}=0.0283333$ $\mathrm{m} \times 3803 \_$M18 VDDB X3803_6 OUT1 VDDB MODP L $=3.5 \mathrm{e}-07 \mathrm{~W}=1.5 \mathrm{e}-05$ AD $=1.2 \mathrm{e}-11$ $+\mathrm{AS}=1.125 \mathrm{e}-11 \mathrm{PD}=1.6 \mathrm{e}-06 \mathrm{PS}=1.5 \mathrm{e}-06 \mathrm{NRD}=0.0283333 \mathrm{NRS}=0.0283333$ $m \times 3803 \_M 19$ OUT1 X3803_6 VDDB VDDB MODP $L=3.5 \mathrm{e}-07 \mathrm{~W}=1.5 \mathrm{e}-05 \mathrm{AD}=1.45 \mathrm{e}-11$ $+\mathrm{AS}=1.2 \mathrm{e}-11 \mathrm{PD}=1.26667 \mathrm{e}-05 \mathrm{PS}=1.6 \mathrm{e}-06 \mathrm{NRD}=0.0283333 \mathrm{NRS}=0.0283333$ $m \times 3803 \_M 20$ VDDB X3803_6 OUT1 VDDB MODP $L=3.5 \mathrm{e}-07 \quad W=3 \mathrm{e}-06 \quad \mathrm{AD}=3.15 \mathrm{e}-12$ $+\mathrm{AS}=2.9 \mathrm{e}-12 \mathrm{PD}=5.1 \mathrm{e}-06 \mathrm{PS}=2.53333 \mathrm{e}-06 \mathrm{NRD}=0.141667 \mathrm{NRS}=0.141667$ $\mathrm{m} \times 3804$ M0 X3804_4 18 VSS VSS MODN L=3.5e-07 $\mathrm{W}=2 \mathrm{e}-06 \quad \mathrm{AD}=2.15 \mathrm{e}-12 \quad \mathrm{AS}=2.15 \mathrm{e}-12$ $+\mathrm{PD}=4.15 \mathrm{e}-06 \mathrm{PS}=4.15 \mathrm{e}-06 \mathrm{NRD}=0.2125 \mathrm{NRS}=0.2125$

$\mathrm{m} \times 3804$ M1 X3804_5 X3804_4 VSS VSS MODN L $=3.5 \mathrm{e}-07 \mathrm{~W}=6 \mathrm{e}-06 \mathrm{AD}=6.45 \mathrm{e}-12$ $+\mathrm{AS}=6.45 \mathrm{e}-12 \mathrm{PD}=8.15 \mathrm{e}-06 \mathrm{PS}=8.15 \mathrm{e}-06 \mathrm{NRD}=0.0708333 \mathrm{NRS}=0.0708333$ $\mathrm{m} \times 3804$ 32 X3804_6 X3804_5 VSS VSS MODN L=3.5e-07 $\mathrm{W}=1.5 \mathrm{e}-05 \mathrm{AD}=1.475 \mathrm{e}-11$ $+\mathrm{AS}=1.65 \mathrm{e}-11 \mathrm{PD}=1.25 \mathrm{e}-05 \mathrm{PS}=1.72 \mathrm{e}-05 \mathrm{NRD}=0.0283333 \mathrm{NRS}=0.0283333$ $\mathrm{m} \times 3804$ 33 VSS X3804_5 X3804_6 VSS MODN L=3.5e-07 $\mathrm{W}=3 \mathrm{e}-06$ AD $=3.15 \mathrm{e}-12$ $+\mathrm{AS}=2.95 \mathrm{e}-12 \mathrm{PD}=5.1 \mathrm{e}-06 \mathrm{PS}=2.5 \mathrm{e}-06 \mathrm{NRD}=0.141667 \mathrm{NRS}=0.141667$ $\mathrm{m} \times 3804$ 34 OUT2 X3804_6 VSS VSS MODN $\mathrm{L}=3.5 \mathrm{e}-07 \mathrm{~W}=1.5 \mathrm{e}-05 \mathrm{AD}=8.25 \mathrm{e}-12$ $+\mathrm{AS}=1.65 \mathrm{e}-11 \mathrm{PD}=1.1 \mathrm{e}-06 \mathrm{PS}=1.72 \mathrm{e}-05 \mathrm{NRD}=0.0283333 \mathrm{NRS}=0.0283333$ $\mathrm{m} \times 3804$ 35 VSS X3804_6 OUT2 VSS MODN L=3.5e-07 $W=1.5 \mathrm{e}-05$ AD $=1.125 \mathrm{e}-11$ $+\mathrm{AS}=8.25 \mathrm{e}-12 \mathrm{PD}=1 . \overline{\mathrm{e}}-06 \mathrm{PS}=1.1 \mathrm{e}-06 \mathrm{NRD}=0.0283333 \mathrm{NRS}=0.0283333$ $m \times 3804 \_M 6$ OUT2 X3804_6 VSS VSS MODN $L=3.5 \mathrm{e}-07 \quad W=1.5 \mathrm{e}-05 \quad A D=1.29375 \mathrm{e}-11$ $+\mathrm{AS}=1.125 \mathrm{e}-11 \mathrm{PD}=5 . \overline{7} 5 \mathrm{e}-06 \mathrm{PS}=1.5 \mathrm{e}-06 \mathrm{NRD}=0.0283333 \mathrm{NRS}=0.0283333$ $\mathrm{m} \times 3804 \_M 7$ VSS X3804_6 OUT2 VSS MODN L=3.5e-07 W=9e-06 AD=9.45e-12 $+\mathrm{AS}=7.7625 \mathrm{e}-12 \mathrm{PD}=1.11 \mathrm{e}-05 \mathrm{PS}=3.45 \mathrm{e}-06 \mathrm{NRD}=0.0472222 \mathrm{NRS}=0.0472222$ $\mathrm{m} \times 3804 \_M 8 \times 3804 \_418$ VDDB VDDB MODP $\mathrm{L}=3.5 \mathrm{e}-07 \quad \mathrm{~W}=4 \mathrm{e}-06 \quad \mathrm{AD}=4.4 \mathrm{e}-12 \quad \mathrm{AS}=4.2 \mathrm{e}-12$ $+\mathrm{PD}=6.2 \mathrm{e}-06 \mathrm{PS}=6.1 \mathrm{e}-06 \mathrm{NRD}=0.10625 \mathrm{NRS}=0.10625$ $\mathrm{m} \times 3804 \_M 9 \times 3804 \_5 \times 3804 \_4$ VDDB VDDB MODP $\mathrm{L}=3.5 \mathrm{e}-07 \mathrm{~W}=1.2 \mathrm{e}-05$ AD $=1.32 \mathrm{e}-11$ $+\mathrm{AS}=1.32 \mathrm{e}-11 \mathrm{PD}=1.42 \mathrm{e}-05 \mathrm{PS}=1.42 \mathrm{e}-05 \mathrm{NRD}=0.0354167 \mathrm{NRS}=0.0354167$ mX3804_M10 X3804_6 X3804_5 VDDB VDDB MODP L=3.5e-07 $W=1.5 \mathrm{e}-05 \quad \mathrm{AD}=8.25 \mathrm{e}-12$ $+\mathrm{AS}=1.65 \mathrm{e}-11 \mathrm{PD}=1.1 \mathrm{e}-06 \mathrm{PS}=1.72 \mathrm{e}-05 \mathrm{NRD}=0.0283333 \mathrm{NRS}=0.0283333$ $\mathrm{m} \times 3804$ M11 VDDB X3804_5 X3804_6 VDDB MODP $\mathrm{L}=3.5 \mathrm{e}-07 \quad \mathrm{~W}=1.5 \mathrm{e}-05 \quad \mathrm{AD}=1.35 \mathrm{e}-11$ $+\mathrm{AS}=8.25 \mathrm{e}-12 \mathrm{PD}=8.57 \overline{1} 43 \mathrm{e}-06 \mathrm{PS}=1.1 \mathrm{e}-06 \mathrm{NRD}=0.0283333 \mathrm{NRS}=0.0283333$ $\mathrm{m} \times 3804 \_M 12 \times 3804 \_6 \times 3804 \_5$ VDDB VDDB MODP $\mathrm{L}=3.5 \mathrm{e}-07 \mathrm{~W}=6 \mathrm{e}-06 \quad \mathrm{AD}=6.3 \mathrm{e}-12$ $+\mathrm{AS}=5.4 \mathrm{e}-12 \mathrm{PD}=8.1 \mathrm{e}-06 \mathrm{PS}=3.42857 \mathrm{e}-06 \mathrm{NRD}=0.0708333 \mathrm{NRS}=0.0708333$ $\mathrm{m} \times 3804 \_M 13$ OUT2 X3804_6 VDDB VDDB MODP $\mathrm{L}=3.5 \mathrm{e}-07 \mathrm{~W}=1.5 \mathrm{e}-05 \quad \mathrm{AD}=8.25 \mathrm{e}-12$ $+\mathrm{AS}=1.65 \mathrm{e}-11 \mathrm{PD}=1.1 \mathrm{e}-06 \mathrm{PS}=1.72 \mathrm{e}-05 \mathrm{NRD}=0.0283333 \mathrm{NRS}=0.0283333$ $\mathrm{m} \times 3804 \_M 14$ VDDB X3804_6 OUT2 VDDB MODP $L=3.5 \mathrm{e}-07 \mathrm{~W}=1.5 \mathrm{e}-05 \mathrm{AD}=8.25 \mathrm{e}-12$ $+\mathrm{AS}=8.25 \mathrm{e}-12 \mathrm{PD}=1.1 \mathrm{e}-06 \mathrm{PS}=1.1 \mathrm{e}-06 \mathrm{NRD}=0.0283333 \mathrm{NRS}=0.0283333$ $\mathrm{m} \times 3804 \_M 15$ OUT2 X3804_6 VDDB VDDB MODP L $=3.5 \mathrm{e}-07 \mathrm{~W}=1.5 \mathrm{e}-05$ AD $=8.25 \mathrm{e}-12$ $+\mathrm{AS}=8.25 \mathrm{e}-12 \mathrm{PD}=1.1 \mathrm{e}-06 \mathrm{PS}=1.1 \mathrm{e}-06 \mathrm{NRD}=0.0283333 \mathrm{NRS}=0.0283333$ mX3804_M16 VDDB X3804_6 OUT2 VDDB MODP L $=3.5 \mathrm{e}-07$ W=1.5e-05 AD=8.25e-12 
$+\mathrm{AS}=8.25 \mathrm{e}-12 \mathrm{PD}=1.1 \mathrm{e}-06 \mathrm{PS}=1.1 \mathrm{e}-06 \mathrm{NRD}=0.0283333 \mathrm{NRS}=0.0283333$

$\mathrm{mX3804}$ M17 OUT2 X3804_6 VDDB VDDB MODP $\mathrm{L}=3.5 \mathrm{e}-07 \mathrm{~W}=1.5 \mathrm{e}-05 \quad \mathrm{AD}=1.125 \mathrm{e}-11$ $+\mathrm{AS}=8.25 \mathrm{e}-12 \mathrm{PD}=1.5 \mathrm{e}-06 \mathrm{PS}=1.1 \mathrm{e}-06 \mathrm{NRD}=0.0283333 \mathrm{NRS}=0.0283333$

$m \times 3804 \_M 18$ VDDB X3804_6 OUT2 VDDB MODP L=3.5e-07 $W=1.5 \mathrm{e}-05 \quad A D=1.2 \mathrm{e}-11$ $+\mathrm{AS}=1.125 \mathrm{e}-11 \mathrm{PD}=1.6 \mathrm{e}-06 \mathrm{PS}=1.5 \mathrm{e}-06 \mathrm{NRD}=0.0283333 \mathrm{NRS}=0.0283333$

$\mathrm{m} \times 3804 \_M 19$ OUT2 $\times 3804 \_6$ VDDB VDDB MODP $\mathrm{L}=3.5 \mathrm{e}-07 \mathrm{~W}=1.5 \mathrm{e}-05 \quad \mathrm{AD}=1.45 \mathrm{e}-11$ $+\mathrm{AS}=1.2 \mathrm{e}-11 \mathrm{PD}=1.26667 \mathrm{e}-05 \mathrm{PS}=1.6 \mathrm{e}-06 \mathrm{NRD}=0.0283333 \mathrm{NRS}=0.0283333$ $m \times 3804 \_M 20$ VDDB X3804_6 OUT2 VDDB MODP $L=3.5 \mathrm{e}-07 \mathrm{~W}=3 \mathrm{e}-06 \quad \mathrm{AD}=3.15 \mathrm{e}-12$ $+\mathrm{AS}=2.9 \mathrm{e}-12 \mathrm{PD}=5.1 \mathrm{e}-06 \mathrm{PS}=2.53333 \mathrm{e}-06 \mathrm{NRD}=0.141667 \mathrm{NRS}=0.141667$ C_29 VDD2 $0891.38 \mathrm{f}$

C_58 VDD3 $0 \quad 843.216 \mathrm{f}$ C_91 VDD1 $01.02267 \mathrm{p}$ C_122 SM $0647.322 \mathrm{f}$

C_152 VDDB 0 5.37418p

c_156 OUT1 $0 \quad 399.412 f$

C_160 OUT2 $0 \quad 397.174 \mathrm{f}$

C_164 OUT3 $0 \quad 426.026 \mathrm{f}$

C_172 IN 0 465.86f

C_190 CL2 $0 \quad 29.5534 f$

C_204 $12 \quad 0 \quad 2.26134 \mathrm{f}$

C_212 OUTS1 $01.23085 f$

C_239 CL1 $0112.485 \mathrm{f}$

C_255 CL3 0 92.8516f

C_270 OUTS3 $0 \quad 2.32411 \mathrm{f}$

C_277 $17 \quad 0 \quad 5.77287 f$

C_284 $18 \quad 0 \quad 5.94326 \mathrm{f}$

C_296 OUTS2 $0 \quad 4.45201 f$

C_301 X5_4 $00.536363 \mathrm{f}$

c_306 X5_5 $01.18107 f$

C_311 X5_6 $011.60805 f$

C_316 X58_4 $00.536363 f$

c_321 X58_5 $01.18107 f$

C_326 X58_6 $01.60805 f$

C_331 X59_4 $00.536363 f$

c_336 X59_5 $01.18107 f$

C_341 X59_6 $011.60805 f$

C_350 X1385_7 $00.0778866 \mathrm{f}$

C_357 X1385_8 $00.405138 \mathrm{f}$

c_369 X1385_9 0 2.11468f

C_379 X1385_10 0 1.60013f

C_391 X1385_11 $002.35105 f$

C_398 X1385_12 $00.809932 f$

c_405 X1385_13 $00.289675 f$

C_412 X1385_14 $01.88677 f$

C_422 X1385_15 $001.39046 f$

C_430 X1385_16 $00.916239 f$

c_438 X1385_17 $00.803681 f$

C_444 X1385_18 $00.391567 \mathrm{f}$

C_450 X1385_19 $00.42652 f$

C_461 X1385_20 $03.76665 f$

C_468 X1385_21 0 1.59919f

C_475 X1385_22 $01.99883 f$

C_481 X1385_X112_4 $00.572461 f$

C_487 X1385_X112_5 $000.383034 \mathrm{f}$

C_494 X1385_X193_4 $00.55172 \mathrm{f}$

C_500 X1385_X193_5 $00.394375 f$

C_506 X1385_X212_4 $00.581088 \mathrm{f}$

C_512 X1385_X212_5 $000.394375 f$

C_521 X2420_7 $01.53511 \mathrm{f}$

C_528 X2420_8 $00.248284 \mathrm{f}$

C_543 X2420_9 $01.28124 \mathrm{f}$

C_557 X2420_10 $02.35623 f$

C_575 X2420_11 $002.44761 f$

C_584 X2420_12 $02.48753 \mathrm{f}$

C_599 X2420_13 $02.28881 f$

c_609 X2420_14 $01.0295 f$

C_620 X2420_15 0 1.60542f

C_631 X2420_16 $01.11683 f$

c_642 X2420_17 $00.450309 f$

C_650 X2420_18 $0 \quad 2.10029 f$ 


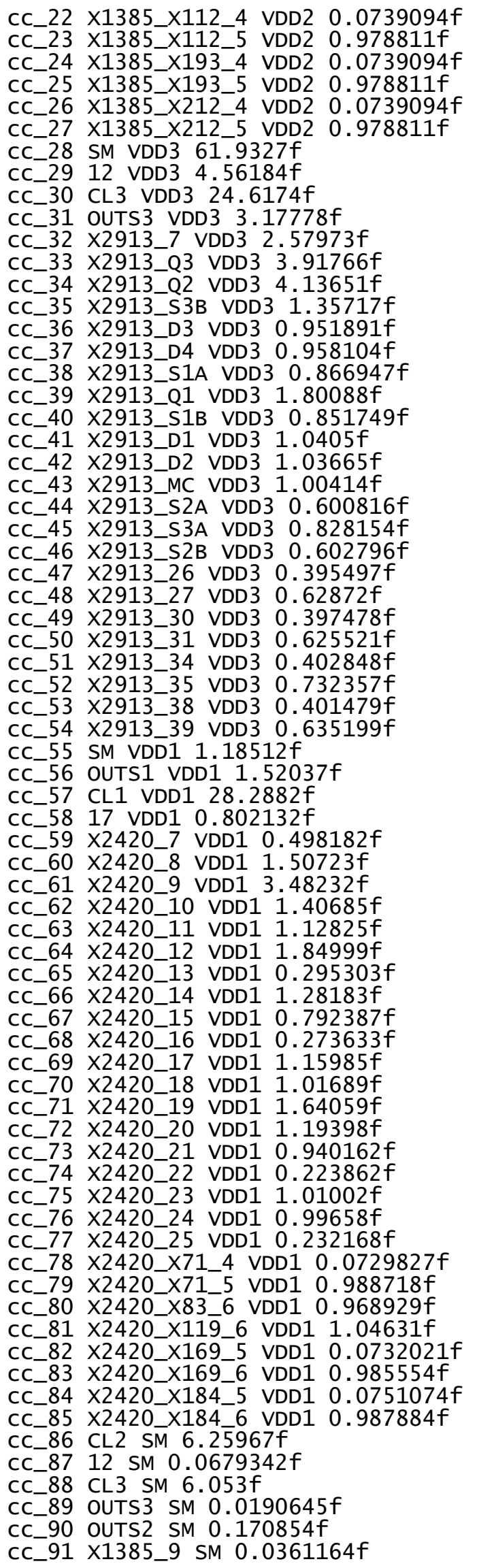




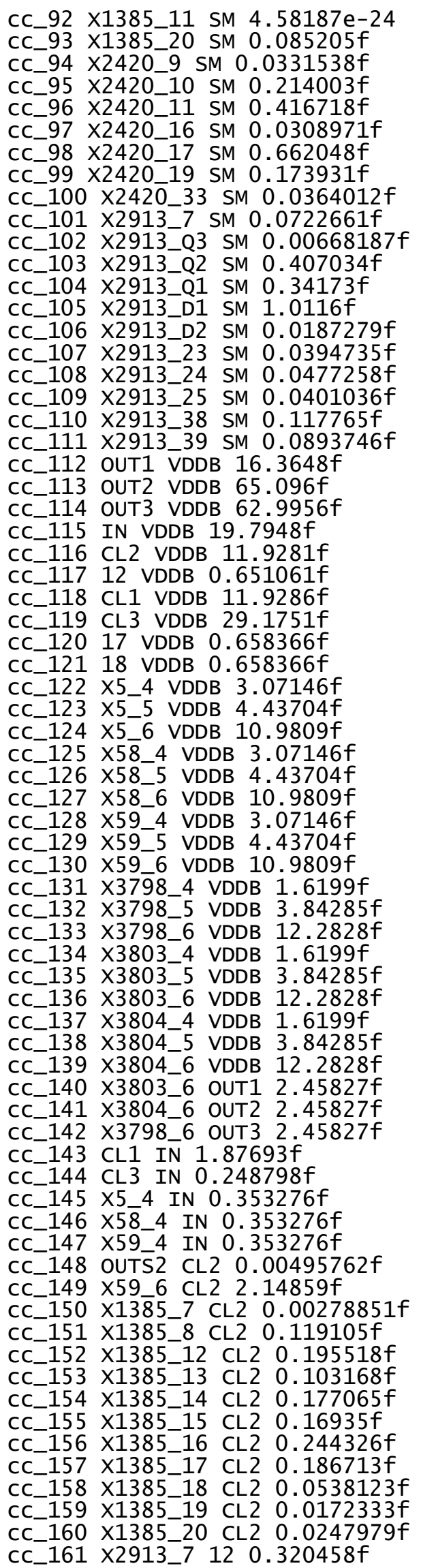




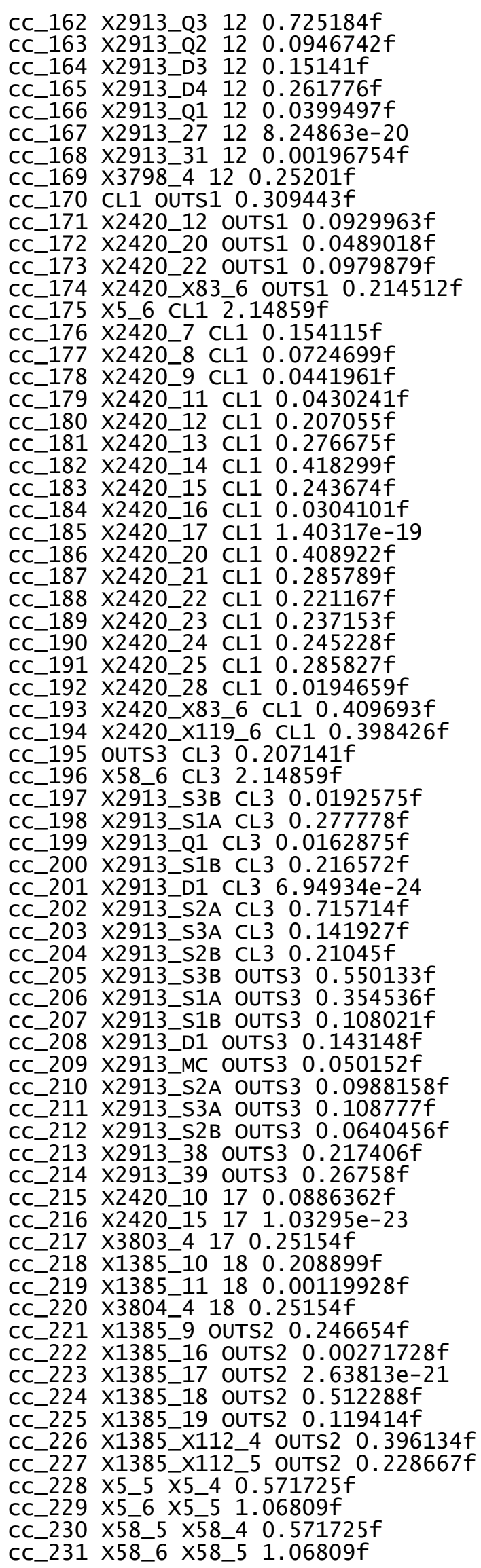




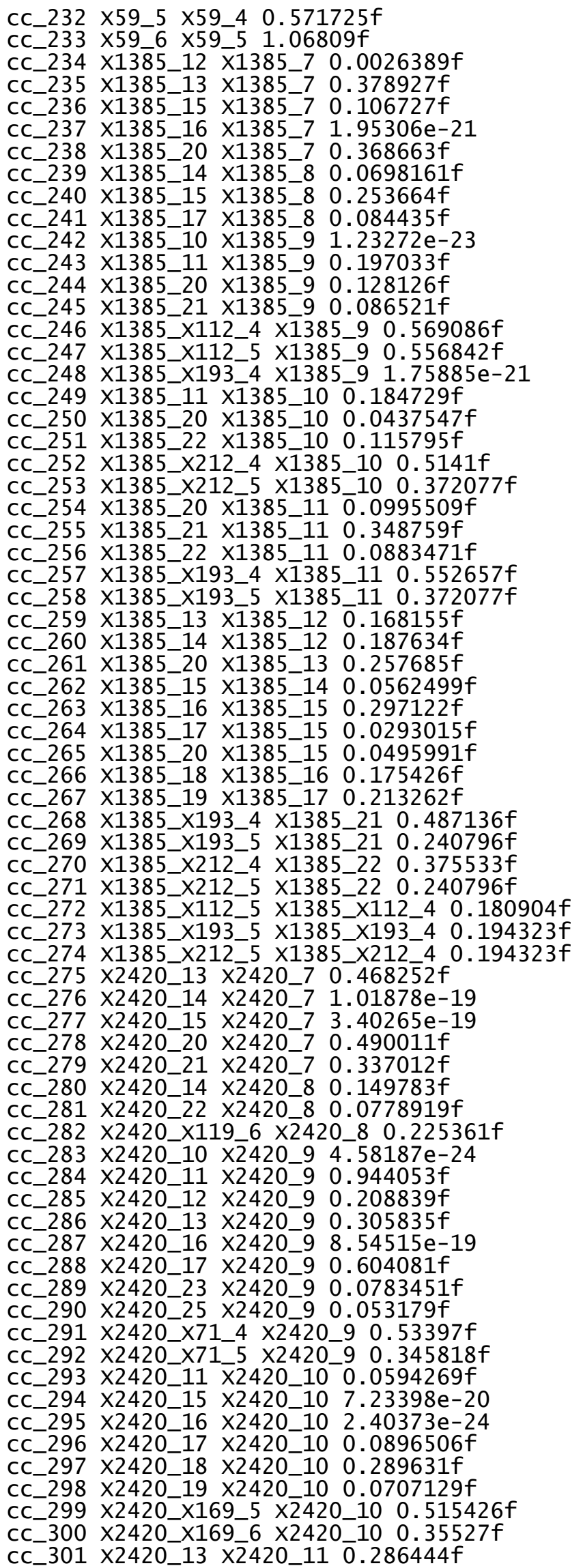




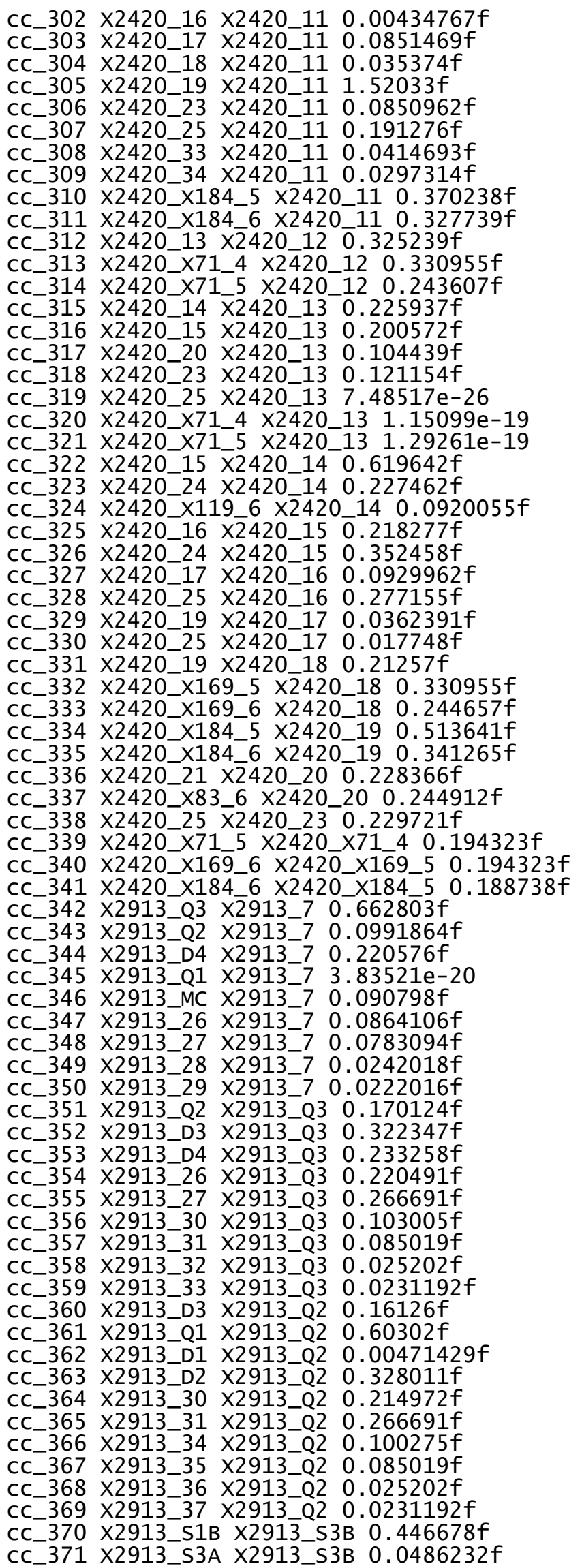




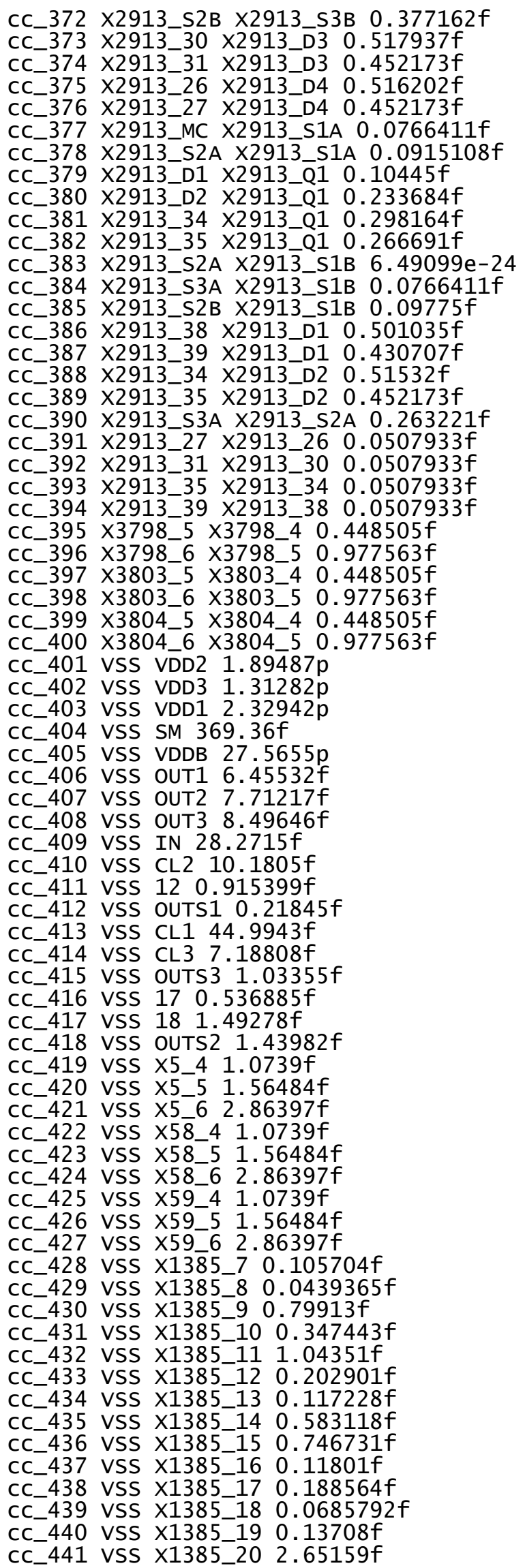




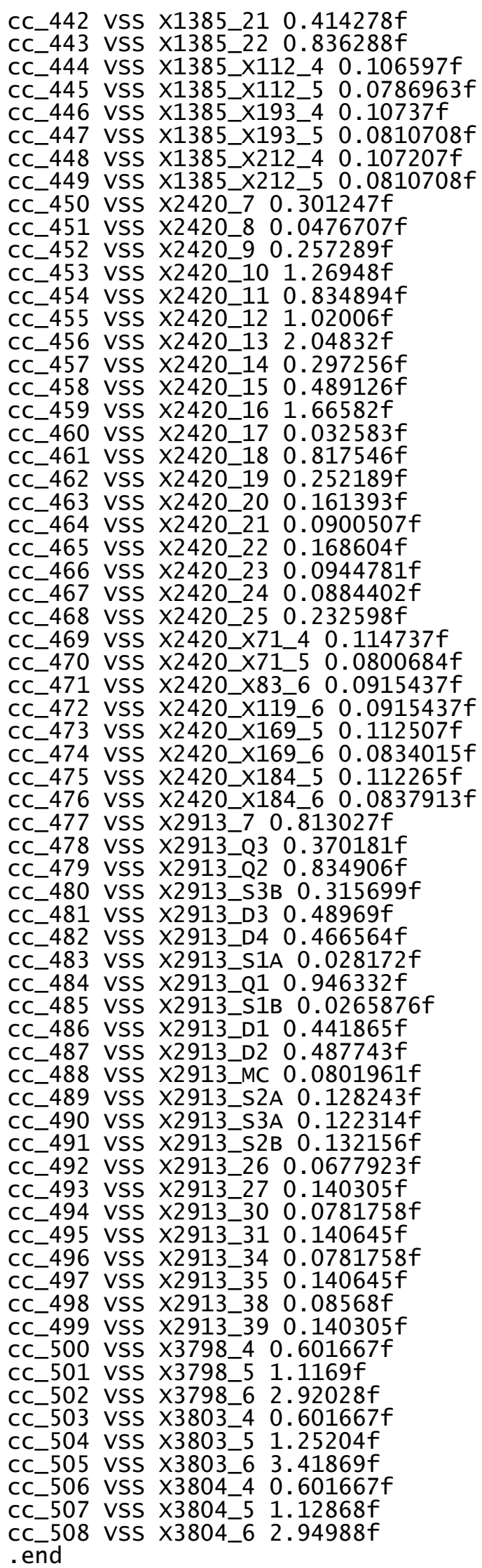

